UNIVERSIDAD POLITÉCNICA DE MADRID

ESCUELA TÉCNICA SUPERIOR DE INGENIEROS AGRONÓMOS

DEPARTAMENTO DE PRODUCCIÓN AGRARIA

\title{
Response of maize and olive to climate change under the semi-arid conditions of southern Spain
}

Tesis doctoral

CLARA GABALDÓN LEAL

Ingeniera Agrónoma 

DEPARTAMENTO DE PRODUCCIÓN AGRARIA

ESCUELA TÉCNICA SUPERIOR DE INGENIEROS AGRÓNOMOS

UNIVERSIDAD POLITÉCNICA DE MADRID

\title{
Response of maize and olive to climate change under the semi-arid conditions of southern Spain
}

\author{
TESIS DOCTORAL \\ Clara Gabaldón Leal \\ Ingeniera Agrónoma
}

DIRECTORES

Dr. Ignacio Lorite Torres. Doctor Ingeniero Agrónomo

Dra. Margarita Ruiz-Ramos. Doctora Ingeniera Agrónoma 



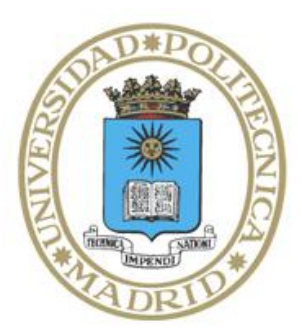

\section{UNIVERSIDAD POLITÉCNICA DE MADRID}

Tribunal nombrado por el Mgfco. y Excmo. Sr. Rector de la Universidad Politécnica de Madrid, el día. de. de 2016.

\section{Presidente:}

Vocal:

Vocal:

Vocal:

Secretario:

Suplente:

Suplente:

Realizado el acto de defensa y lectura de la Tesis el día.... de. de 2016, en la E.T.S.I. Agrónomos.

EL PRESIDENTE

LOS VOCALES 

En primer lugar, quiero agradecer a mis dos directores de Tesis, Dra. Margarita Ruiz-Ramos y Dr. Ignacio Lorite Torres, por darme la oportunidad de realizar este trabajo, por sus enseñanzas, su paciencia y por ayudarme a conseguir que este documento llegue a buen puerto. Gracias también por darme la oportunidad de asistir a congresos que me han abierto puertas y me han dado más seguridad en mi misma.

Al Dr Jon Lizaso por estar siempre disponible para mis preguntas sobre el maíz y los modelos de cultivo. También quiero agradecer a la Dra. Heidi Webber, al Dr. Thomas Gaiser y al Dr. Frank Ewert por acogerme en la Universidad de Bonn, por facilitarme trabajar con ellos, gracias por su valiosa colaboración en parte de esta tesis. A Alfredo, por su ayuda con el Matlab, gracias por tu paciencia. Asimismo quiero agradecer a todos los coautores de los artículos incluidos en esta Tesis y cuyos nombres figuran en la primera página de cada capítulo, muchas gracias por vuestros valiosos comentarios y aportaciones.

Quiero agradecer a todos mis compañeros tanto de la Universidad de Madrid, Alba, Maria S., Maria, Espe, Mirian, Omar, Juan y Javi como del IFAPA de Córdoba, Cristina S., María, Nestor y en especial a mi compañero de despacho Juanmi, y como no a todos mis compañeros de Córdoba por acogerme y apoyarme desde el primer día que llegue. Pedro, Ana, Juanma, Belén, Fran, Pepe, sin vosotros este trabajo hubiera sido mucho más difícil.

A Miguel Zamora, por enseñarme tanto sobre el maíz y el campo, por sacarme siempre una sonrisa bajo los más de 40 grados del julio Cordobés.

A Cris y a Olga porque amigas como vosotras hacen que todo sea más fácil, aunque vivamos lejos os he sentido muy cerca en este proceso, gracias también a vosotras.

A mi familia, gracias a mis padres y a mi hermano por su apoyo incondicional. Gracias a Josu, sin ti esto no hubiera sido posible, gracias por animarme siempre a seguir, por apoyarme incansablemente, esta recta final ha sido mucho más fácil a tu lado. Gracias 



\section{INDEX}

ABBREVIATIONS

CHAPTER 1. STRATEGIES FOR ADAPTING MAIZE TO CLIMATE CHANGE AND EXTREME

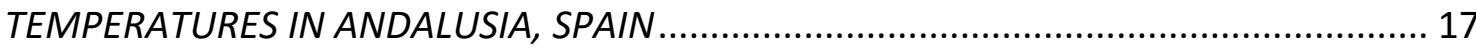

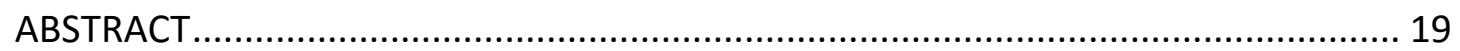

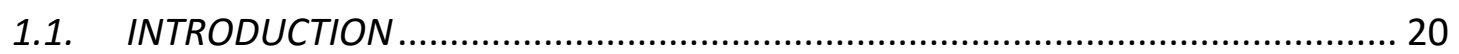

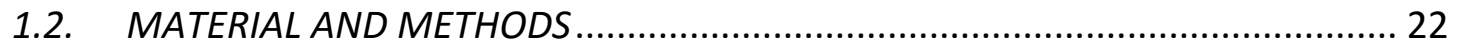

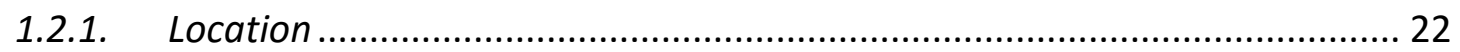

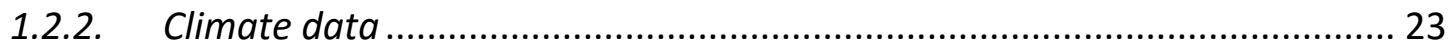

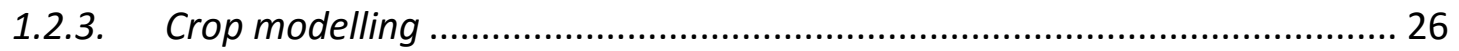

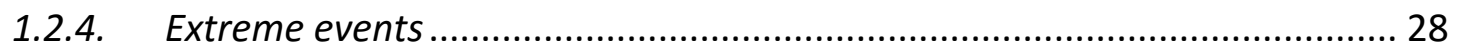

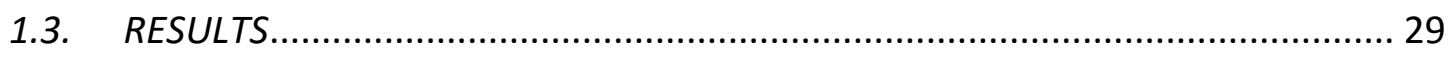

1.3.1. Crop model calibration and validation ........................................................ 29

1.3.2. Evaluation under the present climate ..................................................... 29

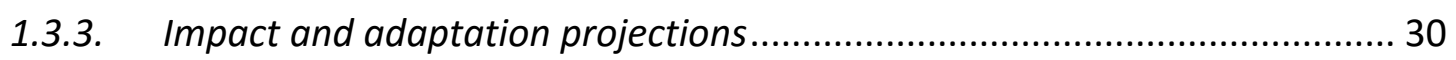

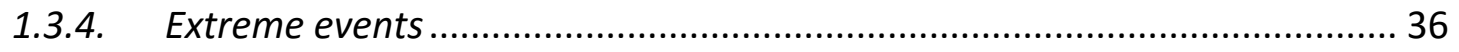

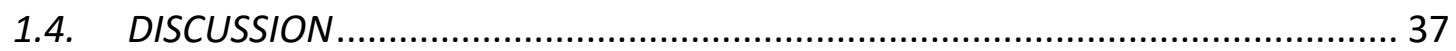

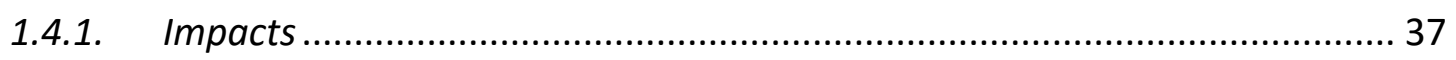

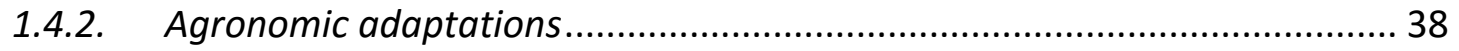

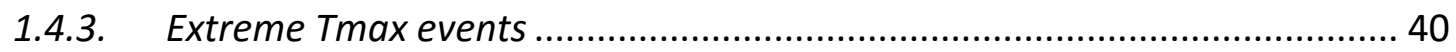

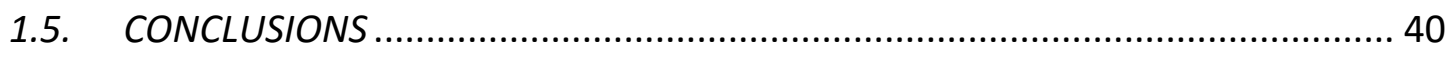

CHAPTER 2. MODELLING THE IMPACT OF HEAT STRESS ON MAIZE YIELD FORMATION43

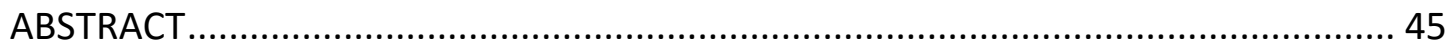

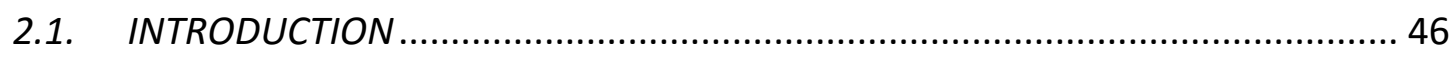




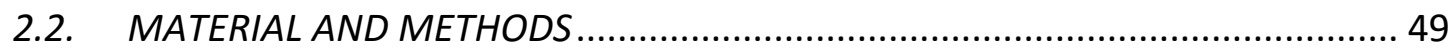

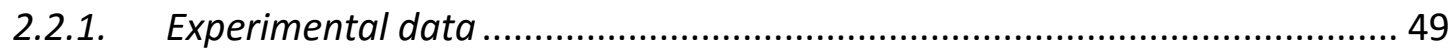

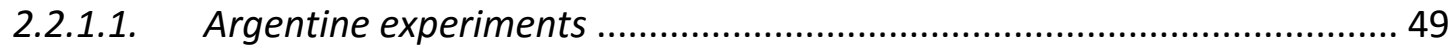

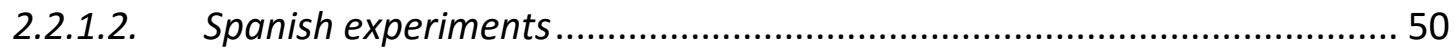

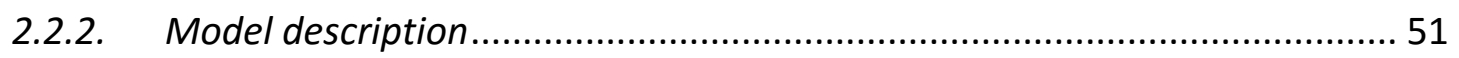

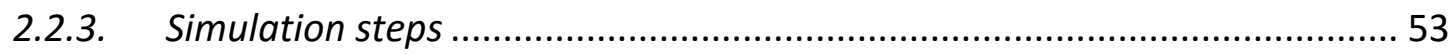

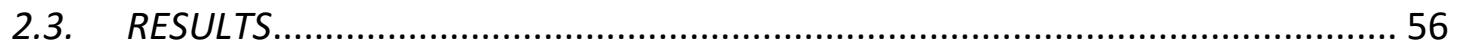

2.3.1. Step1: Determination of yield reduction heat stress factor ......................... 56

2.3.2. Step 2. Model calibration ........................................................................... 56

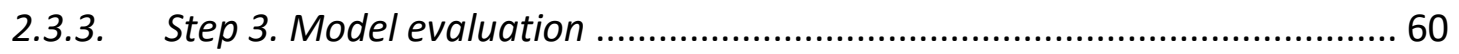

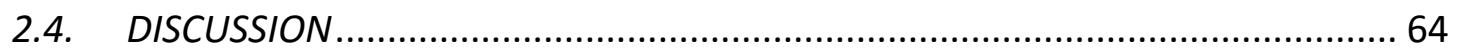

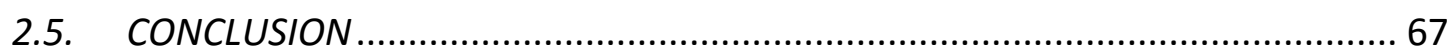

CHAPTER 3. IMPACT OF CHANGES IN MEAN AND EXTREME TEMPERATURES CAUSED BY

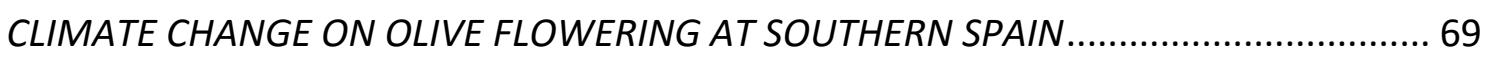

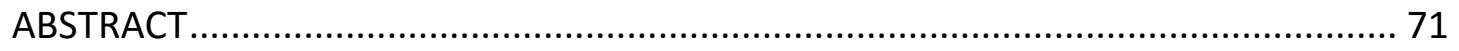

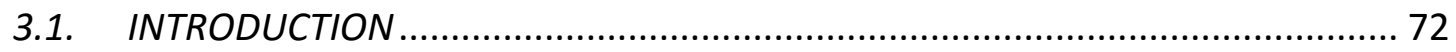

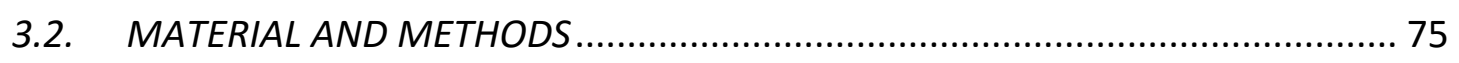

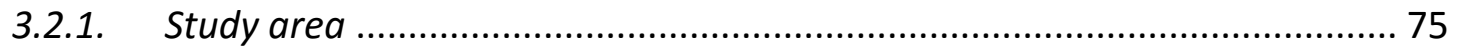

3.2.2. Experimental design and measurements ................................................. 76

3.2.3. Baseline and projected climate for southern Spain ................................... 77

3.2.4. Approaches for flowering date estimation ............................................... 79

3.2.5. Evaluation of olive vulnerability to extreme events ................................. 82

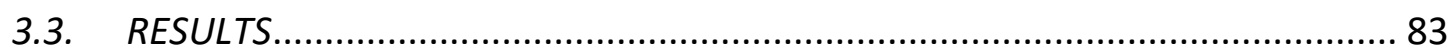

3.3.1. Observed phenological behavior for olive crop under baseline and future

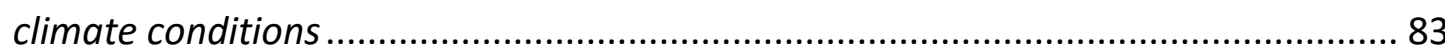

3.3.2. Performance of phenological model parameters under baseline and future

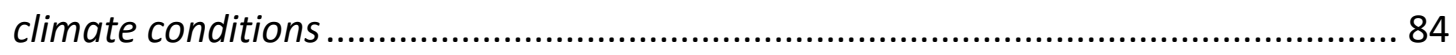

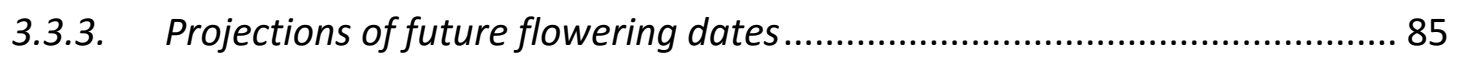

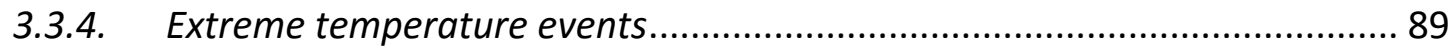

3.3.5. Vulnerability and alternative suitable areas for olive cultivation at southern

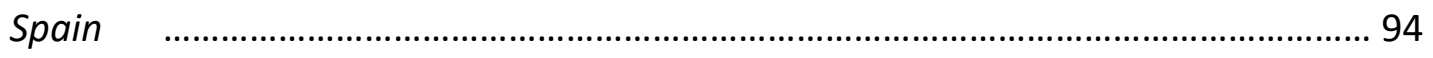

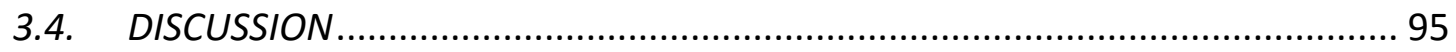




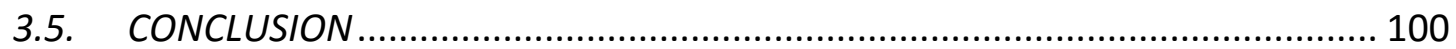

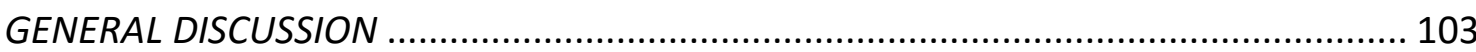

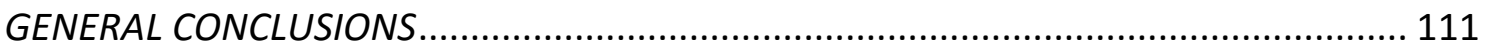

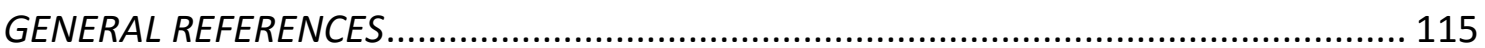

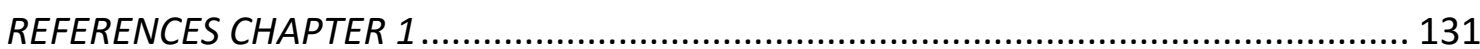

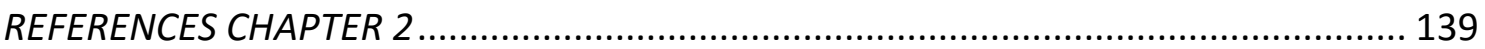

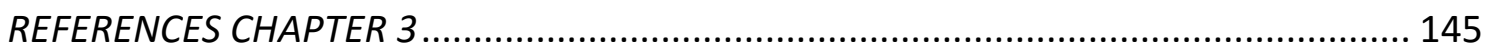

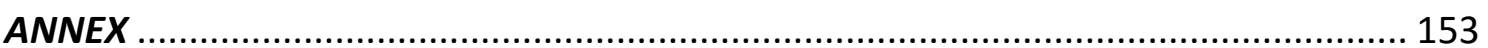





\section{ABBREVIATIONS}

\begin{tabular}{|c|c|}
\hline ADAT & Anthesis date \\
\hline ADPS & Adaptation selected \\
\hline AEMET & Spanish meteorological agency \\
\hline$A_{n}$ & Argentine experiment $n$ \\
\hline $\mathrm{AOC}$ & Atlantic ocean coast \\
\hline B & Baseline period \\
\hline C & Control plots \\
\hline CV & Coefficient of variation \\
\hline DAS & Days after sowing \\
\hline DJF & Winter (December, January, February) \\
\hline DOY & Day of the year \\
\hline DSSAT & Decision Support System for Agrotechnology Transfer \\
\hline DTmax & Mean increment of maximum temperatures \\
\hline DTmin & Mean increment of minimum temperatures \\
\hline EDO & End of dormancy \\
\hline ENS-EOBS & $\begin{array}{l}12 \text { RCMs from the ENSEMBLES project with a bias correction in } \\
\text { temperature and precipitation with respect to the E-OBS gridded } \\
\text { observational dataset }\end{array}$ \\
\hline ENS-Spain02 & $\begin{array}{l}12 \text { RCMs from the ENSEMBLES project with a bias correction in } \\
\text { temperature and precipitation with respect to the Spain } 02 \text { gridded } \\
\text { observational dataset }\end{array}$ \\
\hline E-OBS & Gridded observational dataset (Haylock et al. 2008) \\
\hline EPP & Effective pollination period \\
\hline $\mathrm{ET}_{\mathrm{c}}$ & Crop evapotranspiration \\
\hline FAO & Food and Agriculture Organization \\
\hline fdmgn & Simulated attainable yield normalized by the maximum value \\
\hline FF & Far Future \\
\hline fHS & Fractional stress intensity index \\
\hline Fobs-Forg & Difference between flowering dates observed and estimated \\
\hline FRTDM & Fraction of aboveground biomass to be translocated to seeds \\
\hline G2 & Maximum possible number of kernels per plant \\
\hline G3 & $\begin{array}{l}\text { Kernel filling rate during the linear grain-filling stage and under optimum } \\
\text { conditions }\end{array}$ \\
\hline GCM & Global climate model \\
\hline GDD & Growing degree days \\
\hline GDP & Gross domestic product \\
\hline $\mathrm{GH}$ & Greenhouse \\
\hline
\end{tabular}




\begin{tabular}{|c|c|}
\hline $\mathrm{GS}_{\mathrm{n}}$ & Growing stage $n$ \\
\hline GV & Guadalquivir Valley \\
\hline $\mathrm{H}$ & Heated plots \\
\hline hs1d & Heat stress events of one day above threshold \\
\hline hs3d & Heat stress events of three consecutive days above threshold \\
\hline HSF & Heat stress during flowering \\
\hline IP & Iberian Peninsula \\
\hline IPCC & Intergovernmental Panel on Climate Change \\
\hline IRR & Irrigation requirements \\
\hline IWP & Irrigation water productivity \\
\hline JJA & Summer (June, July, August) \\
\hline LAD & Leaf area duration \\
\hline LAI & Leaf area index \\
\hline MAM & Spring (May, April, May) \\
\hline MBE & Mean bias error \\
\hline MDAT & Maturity date \\
\hline $\mathrm{N}$ & North \\
\hline NE & Northeast \\
\hline NF & Near future \\
\hline NW & Northwest \\
\hline $\mathrm{O}_{\mathrm{i}}$ & Observed value \\
\hline OU & Outdoors \\
\hline $\mathrm{p}$ & Dimensionless penalty constant \\
\hline P1 & Thermal time from seedling emergence to the end of the juvenile phase \\
\hline P2 & $\begin{array}{l}\text { Extent to which development (expressed as days) is delayed for each hour } \\
\text { increase in photoperiod above the longest photoperiod at which } \\
\text { development proceeds at a maximum rate }\end{array}$ \\
\hline P5 & Thermal time from silking to physiological maturity \\
\hline PAR & Photosynthetically active radiation \\
\hline PARi & Intercepted PAR \\
\hline PHINT & Phylochron interval \\
\hline PostS & Post-silking treatment \\
\hline Precip & Precipitation \\
\hline Pres & Pre-silking treatment \\
\hline RAEA & Red Andaluza de Experimentación Agraria \\
\hline $\mathrm{RCM}$ & Regional climate model \\
\hline $\mathrm{RCP}$ & Representative concentration pathways \\
\hline RedHS & Heat stress reduction factor \\
\hline RGRLAI & Maximum relative increase in $\mathrm{LAI}$ \\
\hline RIA & Agroclimatic Information Network of Andalusia \\
\hline
\end{tabular}




\begin{tabular}{|c|c|}
\hline RMSE & Root mean square error \\
\hline RTMCO & Correction factor for RUE \\
\hline RUE & Radiation use efficiency \\
\hline$S_{i}$ & Simulated value \\
\hline$S$ & South \\
\hline SE & Southeast \\
\hline $\begin{array}{l}\text { SIMPLACE } \\
<\text { Lintul5,HS,TC> }\end{array}$ & Combined model SIMPLACE<Lintul5, DRUNIR, CanopyT, HeatStressHourly> \\
\hline SLA & Specific leaf area \\
\hline$S_{n}$ & Spanish experiment $n$ \\
\hline SON & Autumn (September, October, November) \\
\hline Spain02 & Gridded observational dataset (Herrera et al., 2012) \\
\hline SRAD & Solar radiation \\
\hline SRES & Special Report on Emission Scenarios \\
\hline $\mathrm{T}_{\text {air }}$ & Air temperature \\
\hline $\mathrm{T}_{\text {air_ear }}$ & Air temperature at ear level \\
\hline $\mathrm{T}_{\text {air_tas }}$ & Air temperature at tassel level \\
\hline $\mathrm{T}_{\mathrm{b}}$ & Base temperature \\
\hline $\mathrm{T}_{\text {can }}$ & Canopy temperature \\
\hline $\mathrm{T}_{\text {can,lower }}$ & $\mathrm{T}_{\text {can }}$ lower limit \\
\hline$T_{\text {can, upper }}$ & $\mathrm{T}_{\text {can }}$ upper limit \\
\hline $\mathrm{T}_{\text {crit }}$ & Critical temperature \\
\hline Tday & Daytime \\
\hline Th & Hourly temperature \\
\hline Tlim & Limit temperature for chilling accumulation \\
\hline Tmax & Maximum temperature \\
\hline Tmean & Mean temperature \\
\hline Tmin & Minimum temperature \\
\hline To & Optimal temperature \\
\hline TSUM1 & Thermal time from emergence to anthesis \\
\hline TSUM2 & Thermal time from anthesis to maturity \\
\hline TT & Thermal time \\
\hline $\mathrm{TT}_{\mathrm{hs}}$ & Hourly stress thermal time \\
\hline TTorg & Thermal time (from De Melo-Abreu et al., 2004) \\
\hline TU & Total chilling units \\
\hline TUE & Transpiration use efficiency \\
\hline TUmax & Maximum value chilling units \\
\hline TUmean & Mean value chilling units \\
\hline TUmin & Minimum value chilling units \\
\hline
\end{tabular}




$\begin{array}{ll}\text { TUorg } & \text { Chilling units (from De Melo-Abreu et al., 2004) } \\ \text { TWP } & \text { Total water productivity } \\ \text { Tx } & \text { Breakpoint temperature } \\ Y & \text { Maize grain yield } \\ Y_{n} & \text { Normalized } Y\end{array}$




\section{SUMMARY}

Global climate projections indicate an increase in atmospheric $\mathrm{CO}_{2}$ concentration causing for Mediterranean regions an increase in both mean and maximum temperatures, an average decrease in precipitation and an increase in the temporal and spatial variability of extreme events related with rainfall, such as droughts. All these changes in many areas within Andalusia region (southern Spain) would have a direct impact on the agriculture, a critical sector with great social and economic importance.

This Thesis is a further step in the knowledge of the impact assessment that climate projections may have on agriculture in the region. To achieve this purpose, two ensembles of regional climate models (ENS-EOBS and ENS-Spain02) with a bias correction in temperature and precipitation were used in order to reduce the uncertainty linked to the use of climate models. Crop development, growth and yield under these climate conditions were simulated using crop models previously sitespecific calibrated and validated. The assessment of these impacts aims to be useful for decision-making, allowing exploring the potential of adaptation measures to maintain or even increase the yield under future climate conditions.

In this Thesis the impacts of climate change on two crops of great importance in Mediterranean regions were evaluated. On the one hand, the maize crop, a reference irrigated crop under semi-arid conditions, which was analyzed in the first two chapters of the Thesis. On the other hand, the olive, crop extensively cultivated in Andalusia, the main olive oil producer region in the World, that was analyzed in Chapter 3.

Chapter 1 describes the impacts and adaptation to climate change for maize cultivated in five locations of Andalusia. For this purpose experimental data obtained from irrigated maize (FAO-700 cycle) under not limiting conditions of water and nutrients were considered. With these data CERES-Maize model under the DSSAT platform was calibrated and validated. For the consideration of climate data several sources were used; for the observed climate, data from the Agro-climatic Information 
Network of Andalusia (RIA) was used and for the simulated climate, data from an ensemble of twelve regional models (ENS-EOBS) with a bias correction in temperature and precipitation over the original European project ENSEMBLES was used.

The results for the end of the $21^{\text {st }}$ century project a reduction in the maize crop cycle length causing a decrease in the duration of the grain filling period and then, a decrease in yield maize and irrigation requirements. In addition, the stomatal closure caused by the increase in $\mathrm{CO}_{2}$ concentration, could lead to an increase in the water use efficiency. To reduce the negative impacts on maize crop, in this Thesis some adaptation measures were evaluated. Thus, some proposed adaptations were to advance the sowing date 30 days earlier than current and to change the maize cultivar seeking to increase the grain filling period and its efficiency. These adaptations offset the yield losses and even in some cases, the projected yield was increased. The impacts and the adaptation strategies effect were also evaluated from the point of view of the incidence of extreme temperature events at flowering, showing an increase in the number of extreme events as well as in the production damage at the end of the $21^{\text {st }}$ century. The proposed adaptation strategies previously described resulted in an overall reduction of crop damage by extreme maximum temperatures at all locations with the exception of specific locations such as Granada, where losses were limited to $8 \%$.

With this precedent, the Chapter 2 deals with the modelling of heat stress events on maize yield. A heat stress response function was developed and evaluated into the modeling framework SIMPLACE, within the Lintul5 crop model and the canopy temperature model (CanopyT). For this task, experimental data from Pergamino (Argentina) considering a maize temperate hybrid, and from Lleida (Spain), with a maize cultivar FAO-700 cycle, were used. In both experiments the maize plants were subjected to high temperature conditions around flowering by placing polyethylene tents. Argentine data were used to obtain a yield reduction factor in relation with thermal time under a critical temperature of $34^{\circ} \mathrm{C}$ during the flowering period. On the other hand, the Spanish data were divided into two sets, one of them under control 
conditions to calibrate the model, and the other set to validate it using the reduction factor obtained from the Argentina data. The model evaluated consider canopy temperature $\left(T_{\text {can }}\right)$ or air temperature $\left(T_{\text {air }}\right)$ for the simulation of impact of heat events on maize yield, obtaining better model performance using $T_{c a n}$ when the critical temperature was set to $34{ }^{\circ} \mathrm{C}$. However, when critical temperature for $T_{\text {air }}$ was increased to $39{ }^{\circ} \mathrm{C}$, the results were similar for both temperatures (canopy and air) indicating that for irrigated and high radiation conditions the air temperature could be used as input in the model without the need to simulate the canopy temperature.

The Chapter 3 evaluates the impacts of climate change on olive flowering for current and future climate conditions at southern Spain. For this purpose an experiment located at Cordoba from $1^{\text {st }}$ October 2013 to the end of May 2014 was set to evaluate ten olive genotypes under two different climate conditions, one outdoors $(\mathrm{OU})$ and the other inside of a greenhouse $(\mathrm{GH})$. The aim of the experiments carried out in $\mathrm{GH}$ was to identify the impacts of the increase in temperatures on olive phenology, reproducing the mean increment of maximum and minimum temperatures (DTmax, DTmin) projected at the end of the $21^{\text {st }}$ century. To quantify these increases, data from an ensemble of twelve regional climate models (ENS-Spain02), with a bias correction in temperature and precipitation from the original climate models of the ENSEMBLES European project were used. Once the foreseen climate conditions were reproduced in $\mathrm{GH}$, olive flowering dates were evaluated under both climate conditions using previous flowering models, obtaining good results under OU conditions, but not for $\mathrm{GH}$. Based on these results, a new model was proposed and evaluated taken into account on one hand the chilling hour accumulation and on the other hand obtaining the flowering dates achieved after heating accumulation. Once the new model was developed, flowering dates were evaluated for the whole region of Andalusia, obtaining a mean advance in the flowering date of 17 days for all the genotypes for the climate conditions foreseen at the end of the $21^{\text {st }}$ century. A spatial analysis of the results was carried out, identifying the highest advance in flowering date in the mountainous area of Jaen and Granada provinces and the lowest in the Atlantic Ocean Coast area. Finally, a spatial analysis evaluating the vulnerable and suitable areas for 
olive cultivation in Andalusia at the end of the $21^{\text {st }}$ century was held. Thus, several areas were vulnerable due to high temperatures in flowering (North and Northeast regions) or to lack of chilling hour accumulation in winter (Atlantic Ocean and the Southeast coast). Equally, potential new areas for olive cultivation were detected as the southern area of Andalusia. 


\section{RESUMEN}

Las proyecciones climáticas globales indican un aumento en la concentración de $\mathrm{CO}_{2}$ atmosférico que, para las regiones mediterráneas, implican un aumento tanto en las temperaturas medias como en las máximas, una disminución promedio de las precipitaciones y un aumento de la variabilidad temporal y espacial de los fenómenos extremos relacionados tanto con la lluvia como con las sequías. Todos estos cambios tendrían un impacto directo en la agricultura de muchas áreas de la región de Andalucía (sur de España), sector crítico de gran importancia social y económica.

Esta tesis es un paso más en el conocimiento de la evaluación de impactos que las proyecciones climáticas pueden tener sobre la agricultura en la región. Para lograr este propósito, se han utilizado dos conjuntos de modelos climáticos regionales (ENSEOBS y ENS-Spain02) con una corrección del sesgo de la temperatura y la precipitación con el fin de reducir la incertidumbre relacionada con el uso de modelos climáticos. El desarrollo del cultivo, crecimiento y rendimiento en estas condiciones climáticas se han simulado utilizando modelos de cultivos previamente calibrados y validados localmente. La evaluación de estos impactos pretende ser útil para la toma de decisiones, lo que permite explorar el potencial de las medidas de adaptación para mantener o incluso aumentar el rendimiento bajo condiciones climáticas futuras.

En esta Tesis han evaluado los efectos del cambio climático en dos cultivos de gran importancia en las regiones mediterráneas. Por un lado, el maíz, un cultivo en regadío de referencia en condiciones semiáridas, analizado en los dos primeros capítulos de la tesis. Por otro lado, el olivo, ampliamente cultivado en Andalucía, siendo la principal región productora de aceite de oliva a nivel mundial; este cultivo se analiza en el Capítulo 3.

El Capítulo 1 se describe los impactos y adaptaciones al cambio climático para el maíz cultivado en cinco localizaciones de Andalucía. Para este fin se han utilizado datos experimentales obtenidos a partir de maíz en regadío (ciclo FAO-700) bajo condiciones no limitantes de agua y nutrientes. Con estos datos el modelo CERES-Maize bajo la 
plataforma DSSAT se ha calibrado y validado. Los datos climáticos considerados en este estudio proceden de varias fuentes; para el clima observado, se han utilizado los datos de la Red de Información Agro-climáticas de Andalucía (RIA), y para el clima simulado, los datos de un conjunto de doce modelos regionales (ENS-EOBS) con una corrección del sesgo en la temperatura y la precipitación sobre los modelos originales del proyecto Europeo ENSEMBLES.

Los resultados obtenidos para el final del siglo XXI proyectan una reducción en la longitud del ciclo del maíz causando una disminución en la duración del periodo de llenado de grano y, por tanto, una disminución del rendimiento del maíz y de las necesidades de riego. Además, el cierre estomático causado por el aumento de la concentración de $\mathrm{CO}_{2}$, podría conducir a un aumento en la eficiencia del uso del agua. Para reducir los impactos negativos sobre el cultivo de maíz, en esta Tesis se evalúan algunas medidas de adaptación. De este modo, algunas adaptaciones propuestas son el adelanto de la fecha de siembra 30 días antes de la fecha actual y el cambio de la variedad de maíz buscando aumentar la eficiencia y período de llenado del grano.. Estas adaptaciones compensan las pérdidas de rendimiento e incluso en algunos casos, las proyecciones indican un aumento del rendimiento. Los impactos y el efecto estrategias de adaptación también se han evaluado desde el punto de vista de la incidencia de eventos extremos de temperatura en la floración, mostrando un aumento en el número de eventos extremos, así como en el daño en la producción a finales del siglo XXI. Las estrategias de adaptación propuestas descritas anteriormente dieron lugar a una reducción en los daños por temperaturas máximas extremas en todos los lugares, con la excepción de zonas específicas, como Granada, donde las pérdidas se limitan al $8 \%$.

Una vez identificado el problema en el Capítulo 1, una vía de solución se plantea en el Capítulo 2, que trata la modelización de eventos de estrés térmico en el rendimiento del maíz. Una función de respuesta al estrés térmico fue desarrollado y evaluado en el marco de modelado SIMPLACE, dentro del modelo de cultivo Lintul5 y de un modelo de temperatura de la cubierta (CanopyT). Para este cometido se han utilizado datos experimentales de Pergamino (Argentina) considerando un híbrido templado maíz, y de Lleida (España), con un ciclo de cultivo de maíz FAO-700. En ambos 
experimentos las plantas de maíz fueron sometidas a condiciones de alta temperatura alrededor de la floración mediante la colocación de tiendas de polietileno. Los datos de Argentina se han utilizado para obtener un factor de reducción de rendimiento en relación con el tiempo térmico durante el periodo de floración considerando una temperatura crítica de $34{ }^{\circ} \mathrm{C}$. Por otra parte, los datos de España se dividieron en dos grupos, uno de ellos en condiciones de control para calibrar el modelo, y el otro conjunto para validarlo usando el factor de reducción obtenido a partir de los datos de Argentina. El modelo evaluado considera la temperatura de cubierta $\left(T_{\text {can }}\right)$ o la temperatura del aire $\left(\mathrm{T}_{\text {air }}\right)$ para la simulación del impacto de los eventos de calor sobre el rendimiento del maíz, obteniendo un mejor resultado utilizando $T_{\text {can }}$ cuando la temperatura crítica se fijó en $34^{\circ} \mathrm{C}$. Sin embargo, cuando la temperatura crítica para $\mathrm{T}_{\text {air }}$ se aumentó a $39^{\circ} \mathrm{C}$, los resultados fueron similares para ambas temperaturas (cubierta y aire) que indican que para las condiciones de riego y alta radiación la temperatura del aire se podría utilizar como dato de entrada en el modelo sin necesidad de simular la temperatura de la cubierta.

El Capítulo 3 evalúa los impactos del cambio climático en la floración del olivo para las condiciones climáticas actuales y futuras en el sur de España. Para este propósito se ha llevado a cabo un experimento en la localidad de Córdoba desde el 1 de Octubre 2013 hasta finales de Mayo 2014 en el que se han evaluado diez genotipos de olivo en dos condiciones climáticas diferentes, uno en el exterior (OU) y el otro en el interior de un invernadero (GH). El objetivo de los experimentos llevados a cabo en GH fue identificar los impactos del aumento de las temperaturas en la fenología del olivo, reproduciendo el incremento medio de las temperaturas máximas y mínimas (DTmax, DTmin) proyectados al final del siglo XXI. Para cuantificar estos aumentos, se han utilizado los datos de un conjunto de doce modelos climáticos regionales (ENS-Spain02), con una corrección en el sesgo de la temperatura y la precipitación de los modelos climáticos sobre los originales del proyecto Europeo ENSEMBLES. Una vez que las condiciones climáticas previstas fueron reproducidas en $\mathrm{GH}$, las fechas de floración del olivo han sido evaluadas bajo las dos condiciones climáticas usando modelos de floración anteriores, obteniendo buenos resultados en condiciones $\mathrm{OU}$, pero no para $\mathrm{GH}$. Basándose en estos resultados, se ha propuesto y evaluado un nuevo modelo 
teniendo cuenta por un lado la acumulación frío y por otra parte el cálculo de las fechas de floración después de un periodo de acumulación por calor. Una vez desarrollado el nuevo modelo, se han evaluado las fechas de floración para toda la región de Andalucía, obteniendo un adelanto medio en la fecha de floración de 17 días para todos los genotipos bajo las condiciones climatológicas previstas al final del siglo XXI. Finalmente se realizó un análisis espacial de los resultados, identificando el mayor adelanto en la fecha de floración en las zonas montañosas de las provincias de Jaén y Granada y la menor en la costa del océano Atlántico. Igualmente, se ha realizado un análisis espacial evaluando las áreas vulnerables y adecuadas para el cultivo del olivo en Andalucía a finales del siglo XXI. De este modo, varias zonas muestran vulnerables a las altas temperaturas en floración (regiones Norte y Nordeste) o por falta de acumulación de frío en invierno (costa del Océano Atlántico y la costa sureste). Igualmente, se han identificado nuevas áreas potenciales para el cultivo del olivo como la zona sur de Andalucía. 


\section{INTRODUCTION}

Agriculture is one of the most important social and economic activity at global scale, and directly dependent on the climate and edaphic conditions, making this activity high vulnerable to climate change effects (Olesen and Bindi, 2002; Easterling et al., 2007; Tubiello and Fischer, 2007). This Thesis has been developed in Andalusia, located in the South of Spain, and is focused on the impact of climate change in two representative crops of the region: maize (Zea mays) and olive (Olea europaea). Maize is a summer crop that is the world's most widely grown cereal in terms of grain production, although wheat and rice are the most important for direct human consumption and cultivated area (Steduto et al., 2012). Maize crop is cultivated in a wide range of climate and soil conditions, and can be considered as a reference herbaceous irrigated crop of the Andalusian cropping systems. In Andalusia, maize is irrigated and accounted for a mean cultivated area of around 34.000 ha and $11.000 \mathrm{~kg} \mathrm{ha}^{-1}$ production for the period 20102013 (RAEA, 2015). Olive is a traditional Mediterranean crop, being Spain the first olive oil producer in the world with around $40 \%$ of the total production (FAOSTAT, 2016). The southern Spanish region of Andalusia represents the first national olive oil producer with $80 \%$ of the national production (1.1M tons; CAPDR, 2016a, covering 1.4 Mha which around $33 \%$ correspond to irrigated olives (MAGRAMA, 2015). Olive is recognized by its social role as this crop generates a high rate of employment per surface unit and currently provides around $32 \%$ of total agriculture employees in Andalusia region (CAPDR, 2008).

According to the World Meteorological Organization (WMO), climate change refers to a statistically significant variation in either the mean state of the climate or in its variability, persisting for an extended period (typically decades or longer). Furthermore, the United Nations Framework Convention on Climate Change (UNFCCC) provides another definition, where the "climate change refers to a change of climate that is attributed directly or indirectly to human activity that alters the composition of the global atmosphere and that is in addition to natural climate variability observed over comparable time periods". Therefore, both definitions are different, as the anthropic attribution of the change is not part of the WMO definition. 
Historical observational atmospheric data until date show a significant increase in the greenhouse gases concentration (Fig I.1). This trend is projected to continue, causing an increase in global temperature at the end of the $21^{\text {st }}$ century (Intergovernmental Panel on Climate Change, IPCC, 2014). The changes in mean precipitation will not be uniform: an increase is projected in the high latitudes, mid-latitudes wet regions and equatorial Pacific while in many mid latitude as southern Europe and subtropical dry regions precipitation will likely decrease (IPCC, 2014).

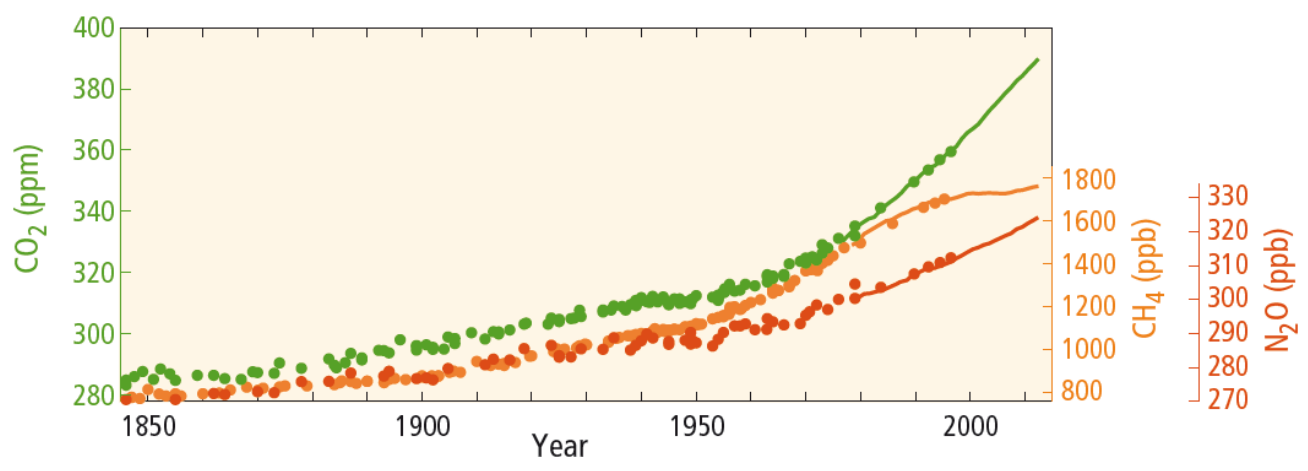

Figure I.1. Past atmospheric concentrations of the greenhouse gases carbon dioxide (CO2, green), methane ( $\mathrm{CH} 4$, orange) and nitrous oxide (N2O, red) determined from ice core data (dots) and from direct atmospheric measurements (lines). Concentration units are parts per million (ppm) or parts per billion (ppb) (source: IPCC, 2014)

In order to simulate the foreseen changes in the climate conditions and based on the current information, the generation of climate projections implies a successive decision steps. One of these steps is the selection of emission scenarios, for instance among the SRES scenarios (Special Report on Emission Scenarios, Nakićenović et al., 2000), which describe the driving forces of future emissions. SRES scenarios follow four storylines grouped into four scenario families: A1, A2, B1 and B2. Group A1 describes a world in development with rapid economic growth and a reduction of regional differences. This group is disaggregated in three scenarios according to the base of the technological development: fossil fuels (A1F), non-fossil (A1T) or balanced (A1B). Scenario A2 describes a very heterogeneous world, determined by self-reliance and preservation of local identities, while the B1 describes a convergent world population that reaches a maximum and then decreases. Finally the B2 scenario describes a world with an increased concern for environmental and social sustainability compared to the A2 scenario. Until recently, climate projections have been given only using these 
emission scenarios; however, there are currently a new generation of proposed scenarios, the Representative Concentration Pathways (RCPs; Moss et al., 2010), taking into account also the system resilience and mitigation and adaptation strategies. These RCPs have been considered in the last IPCC report (IPCC, 2014).

Simulated climate under climate scenarios is produced by Global Climate Models (GCMs). These models cover the entire globe with a resolution ranging from $150 \times 150$ $\mathrm{km}$ to $300 \times 300 \mathrm{~km}$ and describe the climate behavior by integrating different oceanatmospheric dynamics with mathematical equations to generate climate projections. There are two main downscaling techniques for the generation of climate projections at regional level providing climate information on a scale compatible with the regional and local impact studies, the dynamic and the statistical methods. The dynamic downscaling approach reduces the scale of the GCM outputs through the Regional Climate Model (RCM) maintaining their boundary conditions; therefore the generated RCM are numerical models run in a limited area nested in a GCM (Castro et al., 2005). The current RCMs provide a resolution between $50 \times 50 \mathrm{~km}$ and $5 \times 5 \mathrm{~km}$. In the other hand, statistical downscaling techniques use transfer functions to represent the observed, historical relationships between large-scale atmospheric variables with those observed locally (Wilby et al., 1998).

This Thesis uses the first approach based on RCMs. RCMs consider the altitudinal variation by including the topographic forcing in the atmospheric variability (Castro et al., 2005), which is essential in the evaluation of climate change impacts on agriculture in heterogeneous regions as Andalusia (Guereña et al., 2001). In spite of the use of RCMs with high spatial resolution, climate projections contain multiple sources of uncertainty such as the selection of emission scenarios, the driver GCM or the inherent uncertainty to the climate model, as the different physical parameterization of models and their resolution (Olesen et al., 2007; Ruiz-Ramos and Mínguez, 2010; Osborne et al., 2013). Furthermore, RCMs simulations may present large biases when compared to observations (Dosio and Paruolo, 2011; Ceglar and Kajfež-Bogataj, 2012) that can limit their application at local and regional scale. For example, several studies indicate that the simulated summer temperature at southern Europe of recent decades is overestimated by RCMs (Christensen et al., 2008; Dosio et al., 2012). Another example is given by Ceglar and Kajfež-Bogataj (2012), who showed that the use of raw simulations 
from RCMs into a crop model produces unrealistic maize yield estimations due to the underestimation of the intensity of daily precipitation. This uncertainty could be reduced with the bias correction of climate projections (Dosio et al., 2012; Ruiz-Ramos et al., 2015). But it is noteworthy that the uncertainties in regional climate projections can be better characterized and reduced when an ensemble of simulations exploring all the relevant uncertainty dimensions is considered (Giorgi et al., 2009). For that reason, in this Thesis an ensemble of climate projections from one of the major projects that has generated regional projections for Europe, ENSEMBLES (www.ensembles-eu.org, Van der Linden and Mitchell 2009), is used. The ENSEMBLES projections were still referred to SRES scenarios and do not consider RCPs.

Most of the climate projections obtained with these climate models foresee a global increase in mean temperature around 1 to $4{ }^{\circ} \mathrm{C}$ considering the range of RCPs emissions scenarios by the end of the $21^{\text {st }}$ century (IPCC, 2014), similar to the increase provided by the previous IPCC report (IPCC, 2007). Temperature projections over Europe (A1B scenario) show increases in the mean annual temperature, this increase being higher in the summer months. Regarding precipitation, increases in northern Europe (up to $16 \%$ ) and decreases in the South (from -4 to $-24 \%$ ) are projected with high uncertainty (Christensen et al., 2007; Bindi and Olesen, 2011) (Fig.I.2). Climate change will also strongly impact on the frequency and intensity of extreme events (Easterling et al., 2000; Sánchez et al., 2004; Beniston et al., 2007), this has been already observed, as in the summer heat wave of 2003 and 2010 (Schär and Jendritzky, 2004; Barriopedro et al., 2011). Extreme maximum temperature events (Meehl and Tebaldi, 2004; Hertig et al., 2010) are projected to become more frequent in the future (Beniston, 2004; Schär and Jendritzky, 2004; Tebaldi et al., 2006; Beniston et al., 2007; van der Velde et al., 2012). 

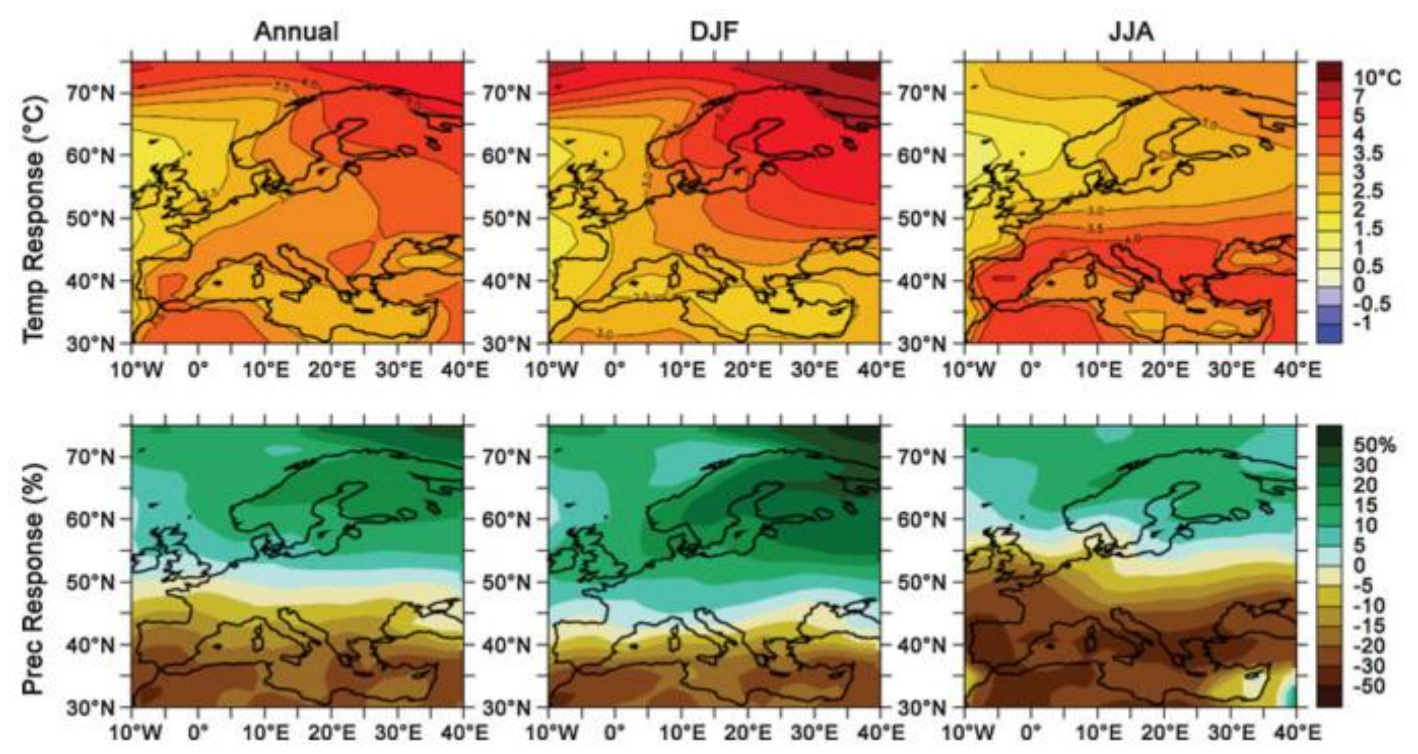

Figure I.2 Temperature and precipitation changes over Europe for the A1B scenario. Top row, Annual mean, DJF and JJA temperature change between 1980 and 1999 and 2080 to 2099, averaged over 21 models. Bottom row, same as top, but for percentage of change in precipitation (from Christensen et al., 2007 and Bindi and Olesen, 2011).

The Mediterranean region is expected to be one of the most affected areas by climate change (Giorgi and Lionello, 2008). In Spain, some temperature projections from GCMs indicate an increase of around $4{ }^{\circ} \mathrm{C}$ during the warmest months considering both A2 and B2 scenarios (Giannakopoulos et al., 2009). These results are in agreement with Gosling et al. (2011) through the Met Office report for Spain, which projects an increase in annual temperature up to around $4{ }^{\circ} \mathrm{C}$ for A1B scenario. Within the CMIP3 multimodel ensemble of GCMs, made up of 21 members, the highest agreement between models was found in the southern Spain when comparing the increase of the mean annual temperature by 2100 with regard to the baseline climate (1960-1990). Also, these authors report projections of rainfall decrease for the Southwest of Spain over 20 $\%$, and between 10 and $20 \%$ over other rest of the country. Van der Linden and Mitchel (2009) in the ENSEMBLES European project (A1B scenario), report projections of increase in temperatures for southern of Spain from $2{ }^{\circ} \mathrm{C}$ in winter months to up to $5{ }^{\circ} \mathrm{C}$ in summer months, with a decrease in precipitation from $15 \%$ in winter months to $30 \%$ in summer months. In general, regional projections for ENSEMBLES project for A1B scenario showed the same trends that those of the former project PRUDENCE for A2, B2 scenarios (Christensen and Christensen, 2007) but the magnitudes of projected changes are larger. 
Future projections of the impact of climate change on crops are usually obtained through crop models combined with climate change scenarios. Crop models simulate crop growth, phenology, development and production once calibrated and validated, using mathematical representations of the main processes involved with different degree of complexity and biophysical understanding. Crop models are commonly classified into empirical or mechanistic (Dent and Blackie, 1979; Connolly, 1998; Thornley and France, 2007). In one hand, empirical models apply functions fitted to data without considering true simulations of the physiological processes involved in growth (Fourcaud et al., 2008). In the other hand, the mechanistic models represent the physiological responses of the crops to environmental variables and management to estimate crop development, growth and yield.

Other way to classify the crop models is attending the way that the model estimates the daily biomass accumulation under potential conditions; for instance the carbon driven group, when the model is based on the carbon assimilation by leaves through the photosynthesis process. Simulated growth processes and phenological development are regulated by temperature, radiation, and atmospheric $\mathrm{CO}_{2}$ concentration and are limited by water availability (Todorovic et al., 2009); within this kind of crop models we can find the WOFOST (Diepen et al., 1989; Boogaard et al., 1998) and CROPGRO (Boote et al., 1998) models. The second group is the radiation driven models, which simulate the biomass through the intercepted radiation using the radiation use efficiency (RUE), as the models used in this Thesis: CERES-Maize (Jones and Kiniry, 1986) and SIMPLACE (Gaiser et al., 2013). Finally, the third group, the water driven models, uses the transpiration use efficiency (TUE) to calculate the biomass as proportional to transpired water, as for instance, AQUACROP model (Raes et al., 2009; Steduto et al., 2012).

Specifically for the crops addressed in this Thesis, maize growth and development have been modeled through different procedures and several approaches have been considered to achieve maize yield assessment. Thus, empirical functions applied to grain yield, as GAEZ model (Fischer et al., 2002) or GLAM (Challinor et al., 2004, 2005); considering daily increment in harvest index, as AQUACROP (Raes et al., 2009; Steduto et al., 2012) or CROPSYST (Stockle et al., 2003; Moriondo et al., 2011); or 
determining grain number, as CERES-Maize (Jones and Kiniry, 1986) or APSIM maize (Carberry et al., 1989).

The olive crop modelling has lower development than the maize one. To evaluate the olive flowering dates, different models have been published based on the pollen density (Galan et al., 2005; Bonofiglio et al., 2008; Oteros et al., 2014) or in phenological observations (Orlandi et al., 2005). There are some models that calculate different processes of the olive productivity, as the photosynthesis, transpiration or water use efficiency (Diaz-Espejo et al., 2002, 2006; Connor and Fereres, 2005). Other models calculate the biomass production based on annual radiation (Villalobos et al. 2006), the functional approach based on the relation between yield and potential evapotranspiration (Viola et al., 2012) or calculates the potential olive oil production based on a three-dimensional model of canopy photosynthesis and respiration and the dynamic distribution of assimilates among organs (Morales et al., 2016). However, there is a need to improve the olive crop models under elevated both temperatures and $\mathrm{CO}_{2}$ concentrations (Moriondo et al., 2015).

To evaluate the impact of climate change on crops is essential to analyze each component that affects crop growth, development and yield. Thus, components as phenology, transpiration efficiency or harvest index play a critical role in the response to crops to climate change. Phenology has been defined as the timing of recurring biological events regarding to biotic (genetic background) and abiotic (environmental and management) forces, and the interrelation among them (Lieth, 1974; Slafer et al., 2009). It is noteworthy that the phenological phases are largely controlled by temperature and day length (Sadras and Calderini, 2009). During the phenological period of flowering, high temperatures affect the number of flowers per plant, limit the pollen release and diminish the pollen viability, flower fertility and therefore the viable seeds (Prasad et al., 2000, 2006; Wheeler et al., 2000; Moriondo et al., 2011; Vuletin Selak et al., 2013). On the other hand, crop growth has been defined as an increase in the size of an individual or organ with time and depends on the capture of resources including $\mathrm{CO}_{2}$, radiation, water, $\mathrm{N}$ and other nutrients (Sugiyama, 1995; Sadras and Calderini, 2009).

Experiments under elevated $\mathrm{CO}_{2}$ concentration have shown that the carbon uptake, growth and above-ground production increase, while specific leaf area and stomatal conductance decrease (Ainsworth and Long, 2005) under these conditions. 
Those changes could benefit plants and especially C3 plants (olive), and both C3 and C4 under water stress conditions, due to the increase in water use efficiency ( $\mathrm{Vu}$ and Allen, 2009; Allen et al., 2011). For herbaceous species, the C3 present more positive effect than C4 species (maize) (Warrick et al., 1986). The trees are more responsive than herbaceous species to elevated $\mathrm{CO}_{2}$ (Ainsworth and Long, 2005). There are few studies dealing with olive trees under $\mathrm{CO}_{2}$ elevated concentrations, but the existing ones have shown a positive response of the photosynthetic rate and a decreased stomatal conductance, leading to greater water use efficiency with no effect on biomass accumulation rate (Sebastiani et al., 2002; Tognetti et al., 2002). Therefore, in addition to the effects of temperature and rainfall it is important to evaluate the effect of the projected $\mathrm{CO}_{2}$ increase.

Maize grain yield is determined by the number of grains and its weight, being largely dependent on the climate conditions during the critical period of flowering (Fischer and Palmer, 1984; Kiniry and Ritchie, 1985; Grant et al., 1989; Lizaso et al., 2007). During this period the grain number is determined (Fischer and Palmer, 1984; Otegui and Bonhomme, 1998). Under high temperatures, the source capacity is reduced; both the photosynthetic rate causing a reduction in the carbohydrates synthesis (Barnabás et al., 2008) and the respiration rate (Wahid et al., 2007) are reduced. When these net assimilation reductions occur during the critical period of flowering a reduction in grain yield was observed (Andrade et al., 1999, 2002). Furthermore, the sink capacity could be reduced under high temperatures due to low pollen viability (Herrero and Johnson, 1980), grain abortion (Rattalino Edreira et al., 2011; Ordóñez et al., 2015) or the synchrony disruption between anthesis and silking (Cicchino et al., 2010); this reduction in sink capacity makes the losses of grain number irreversible. Large-scale observational studies analyzing maize yields and temperature records indicate that large yield losses are associated with even brief periods of high temperature when cropspecific thresholds are surpassed (Schlenker and Roberts, 2009; Gourdji et al., 2013).

Regarding olive trees, pollen concentration studies have shown that the elevated temperatures could generate an advance in the flowering date (Osborne et al., 2000; Galán et al., 2005; Avolio et al., 2008; Orlandi et al., 2010), being this advancement an indicator of the climate warming in the Mediterranean area (Osborne et al., 2000; Moriondo et al., 2013). These higher temperatures and the heat stress events during 
flowering may cause damages such as ovarian abortion (Rallo, 1994), vegetative damage (Mancuso and Azzarello, 2002) and pollen germination damage (Cuevas et al., 1994; Koubouris et al., 2009), with the subsequent decrease in yield. Another important factor to take into account is the projected water shortage. Thus, in spite of the olive drought resistance (Connor and Fereres, 2005), the olive under water stress reduces the photosynthetic rate due to the stomata closure (Fereres, 1984; Angelopoulos et al., 1996). Another effect that can reduce yield appears when water stress during flowering affect the fertilization, as the flowers remain closed (Rapoport et al., 2012). Also, between the period from floral development to fruit development water stress has a direct effect on fruit tissues (Rapoport et al., 2004; Gucci et al., 2009).

Observed phenological trends across Europe (1971-2000) for 542 plant species indicate a mean advance 2.5 days per decade in leafing, flowering and fruiting records (Menzel et al., 2006). Data since 1986 showed an advancement in foliation, flowering and fruit ripening more evident in arboreal species (Olive, vine, Quercus spp.) than in herbaceous ones, showing that the major factor in the earlier foliation, flowering and fruit ripening was the increase in temperature (García-Mozo et al., 2010). In Cordoba, a province located at southern Spain in Andalusia, an increase in mean temperature of 1 ${ }^{\circ} \mathrm{C}$ during March-April-May induced an advance in olive flowering of 7.6 days during the 1982-2007 (Orlandi et al., 2010).

Concerning the crop yield, French maize yields observed over the past 50-years were found to decrease; this decrease has been related with an increase in the number of days with maximum air temperature above $32{ }^{\circ} \mathrm{C}$ (Hawkins et al., 2013). Likewise, a panel analysis for this species in the US determined that yields decreased with cumulative degree days above $29{ }^{\circ} \mathrm{C}$ (Schlenker and Roberts, 2009). Furthermore, Lobell et al., (2011) detected maize yield losses across Sub-Saharan Africa ranging from 1 to 1.7 $\%$ (depending on water availability) per each degree day above $30^{\circ} \mathrm{C}$.

Under climate change conditions, projected phenological trend across Europe implies an advancement of the flowering and maturity dates of spring cereals of 1 to 3 weeks by 2040 (Olesen et al., 2012), partially explained by an advancement of sowing dates. The projected rising temperatures in the spring and summer in the South of the Iberian Peninsula would lead to a shortening of the cereal phenological cycles (Guereña 
et al., 2001), and in the case of the olive trees, a general advance of the crop cycle from 1 to 3 weeks could be expected at the end of the $21^{\text {st }}$ century (Galan et al., 2005).

The projected effects on crop yield in Europe have been studied both at the continental level (Olesen and Bindi, 2002, 2004; Bindi and Olesen, 2011), and at regional level as well. In Mediterranean Europe, yield decreases are expected for spring-sown crops, as maize, sunflower or soybeans (Audsley et al., 2006; Giannakopoulos et al., 2009; Moriondo et al., 2010). For autumn-sown crops as winter and spring wheat, the impact would be more geographically variable, with projections of yield decrease in the most southern areas and of yield increase in the northern areas of the Mediterranean region, as the North of Spain and Portugal (Mínguez et al., 2007; Olesen et al., 2007; Giannakopoulos et al., 2009; Moriondo et al., 2010).

For the Iberian Peninsula, the published studies describe that rising temperatures, changes in rainfall patterns and the interaction of these two changes with increasing in $\mathrm{CO}_{2}$ levels would cause widely varying effects on crops, depending on their location, growing season, management and variety. The decrease in maize biomass and yield due to the increase of future temperatures in the Iberian Peninsula has been projected (Iglesias and Mínguez, 1995; Guereña et al., 2001; Mínguez et al., 2007; Garrido et al., 2011). Yield decrease was projected with high degree of coincidence between climate models for irrigated maize (Ruiz-Ramos and Mínguez, 2010). Rey et al. (2011) project a maize yield decrease for the Iberian Peninsula in the future period (2071-2100) between $8 \%$ to $20-25 \%$ depending of the region. Nevertheless, not all projections are negative; for example in the case of rainfed spring wheat sowing in autumn, a yield increase is projected in some areas of current low production (Mínguez et al, 2007; Olesen et al., 2007; Ruiz-Ramos and Mínguez, 2010). In addition, results to date on yield projections present different uncertainty degrees linked to the studied crop and the water management regime (rainfed or irrigated), being determinant the water availability related to the inter-annual variability of precipitation and its uncertainty (Ruiz-Ramos and Mínguez, 2010). This uncertainty is smaller for southern than for northern regions due to the consistent occurrence of water stress through the 30 year simulations. Regarding the impact on olive oil yield, studies under future climate conditions for Andalusia region have shown that climate change may not be a large 
threat and even suggest a slighly increase in oil yield (Iglesias et al., 2010; Morales et al., 2016) due to the increase of the photosynthesis rate per unit of absorbed PAR.

For some crops and under certain conditions, the benefits of increased $\mathrm{CO}_{2}$ could offset the projected yield decrease under future climate (Long et al., 2006). However other studies have showed that the shortening of the phenological cycle in herbaceous species due to the higher projected temperatures under climate change will not be compensated by the increase in the photosynthetic rate caused by increased $\mathrm{CO}_{2}$ (Boote et al., 2005; Christensen et al., 2007; Ferrise et al., 2011; Garrido et al., 2011).

Additionally to the described impacts, the increase in the frequency and intensity of extreme events (that for the Mediterranean area mainly related with heat stress and drought), together with the projected increase in mean temperature are expected to cause negative impacts on crop yield (Seneviratne et al., 2012; Gourdji et al., 2013; Lobell et al., 2013). For most crops and regions, the intensity, frequency and relative production damage due to heat stress are projected to increase from the baseline to the A1B scenario (Teixeira et al., 2013). In the Iberian Peninsula, the heat extreme events represent a threat to summer-grown but not to winter-grown crops (Ruiz-Ramos et al., 2011). The term "heat stress" on plants under these extreme temperature events has been used to refer to brief episodes of high temperature lying outside of the range typically experienced (Porter and Gawith, 1999; Luo, 2011; Moriondo et al., 2011).

To cope with the impacts of climate change on agriculture, adaptation strategies could be used, depending of the crop, climate scenario or location. Adaptation strategies evaluated could be earlier sowing dates to avoid the warmer periods, longer grain-filling period or decreasing irrigation intervals in order to decrease canopy temperature especially at anthesis day (Giannakopoulos et al., 2009; Moriondo et al, 2010; Moradi et al., 2013; Trnka et al., 2014). These adaptations singly or in combination have substantial potential to offset negative climate change impacts (Howden et al., 2007). In the olive trees case the adaptation strategies are designed to reduce the air temperature, using cover crops and soil management practices to modify the albedo (Davin et al. 2014), or the consideration of supplementary irrigation to reduce the olive canopy temperature (Doughty et al., 2011; Andrade et al., 2012).

A recently approach developed by FAO (Food and Agriculture Organization of the United Nations), the Climate-smart agriculture (CSA) (http://www.fao.org/climate- 
smart-agriculture/en/) includes these adaptation strategies that could reduce or even increase the actual and projected yield under climate change conditions. The CSA approach looks forward to transform and reorient the agricultural systems, supporting the development and ensuring the food security under a changing climate.

In spite of the previous studies, important knowledge gaps remain for both maize and olive crops in key process as flowering under water and heat stress conditions. The only way to determine accurate functions defining these processes that fill this knowledge gap is the development of field experimentation that could lead to an uncertainty reduction based on the correct calibration and validation of the crop models under local conditions, as well as under forced climate conditions. This aspect is partially addressed also in this Thesis. 


\section{OBJECTIVES}

The general objective of this Thesis is to evaluate the impacts of climate change and extreme events on maize and olive crops under the semi-arid conditions of Andalusia, located at southern Spain, and to propose adaptation strategies. For this purpose, the impact of climate change on phenology, water requirements and yield as well as key aspects of model improvement for both crops, are undertaken. Finally, an evaluation of adaptation strategies to limit the impact of climate change on these crops in the Mediterranean region will be proposed.

For this purpose, the specific objectives are:

- To evaluate different adaptation strategies for irrigated maize in five locations of Andalusia under future climate conditions, considering maximum temperature events during flowering, by using CERES-Maize crop model calibrated and validated with local experimental data.

- To develop, parameterize and evaluate the performance of a canopy heat stress method to account for the negative impacts of extreme high temperatures on maize grain yield at field scale.

- To evaluate olive flowering at southern Spain at the end of $21^{\text {st }}$ century by developing a phenological model based on experimental data obtained under current and forced climate conditions, assessing the vulnerable and suitable areas within Andalusia for olive cultivation considering chilling requirements and heat stress during flowering. 


\section{THESIS STRUCTURE}

The present Thesis is structured as described in the Figure I.3. In this scheme the three chapters are related. Firstly we evaluate the impact and adaptation strategies on two reference crops, for one side, Maize and for the other side Olive. The usefulness of the current tools has been evaluated, assessing the impact and adaptation in maize and considering the extreme events on flowering, using a method external to the crop model. For the olive some of the current olive flowering methods were evaluated. Once evaluated the current tools, some points to improve as the heat or water stress and the phenology dates estimation have been addressed: The Chapter 2 proposes a model improvement to capture the effect of heat stress during flowering on maize, and in the Chapter 3 a model to estimate the flowering date under current and forced climate conditions was proposed and evaluated.

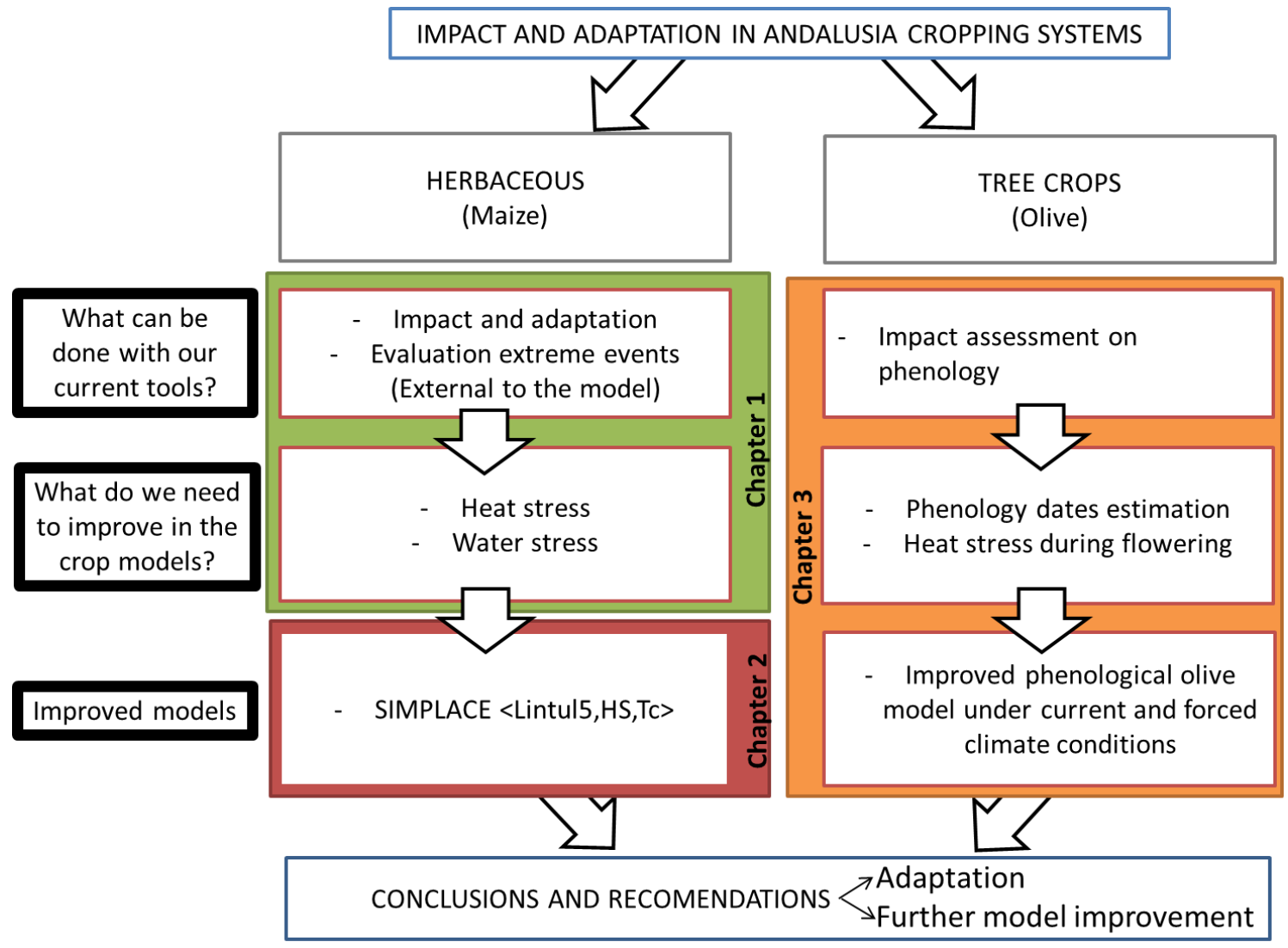

Figure I.3 Schematic representation of the Thesis structure. 


\section{CHAPTER 1. STRATEGIES FOR ADAPTING MAIZE TO CLIMATE CHANGE AND EXTREME TEMPERATURES IN ANDALUSIA, SPAIN}

Published in: Gabaldón-Leal, C., Lorite, I. J., Mínguez, M. I., Lizaso, J. I., Dosio, A., Sanchez, E., Ruiz-Ramos, M., 2015. Strategies for adapting maize to climate change and extreme temperatures in Andalusia, Spain. Climate Research, 65, 159. 
CHAPTER 1. Strategies for adapting maize to climate change and extreme temperatures in Andalusia, Spain

\section{ABSTRACT}

Climate projections indicate that rising temperatures will affect summer crops in the southern Iberian Peninsula. The aim of this study was to obtain projections of the impacts of rising temperatures, and of higher frequency of extreme events on irrigated maize, and to evaluate some adaptation strategies. The study was conducted at several locations in Andalusia using the CERES Maize crop model, previously calibrated/validated with local experimental datasets. The simulated climate consisted of projections from regional climate models from the ENSEMBLES project; these were corrected for daily temperature and precipitation with regard to the E-OBS observational dataset. These bias-corrected projections were used with the CERESMaize model to generate future impacts. Crop model results showed a decrease in maize yield by the end of the $21^{\text {st }}$ century from 6 to $20 \%$, a decrease of up to $25 \%$ in irrigation water requirements, and an increase in irrigation water productivity of up to $22 \%$, due to earlier maturity dates and stomatal closure caused by $\mathrm{CO}_{2}$ increase. When adaptation strategies combining earlier sowing dates and cultivar changes were considered, impacts were compensated, and maize yield increased up to $14 \%$, compared with the baseline period (1981-2010), with similar reductions in crop irrigation water requirements. Effects of extreme maximum temperatures rose to $40 \%$ at the end of the $21^{\text {st }}$ century, compared with the baseline. Adaptation resulted in an overall reduction in extreme Tmax damages in all locations, with the exception of Granada, where losses were limited to $8 \%$. 
CHAPTER 1. Strategies for adapting maize to climate change and extreme temperatures in Andalusia, Spain

\subsection{INTRODUCTION}

The effects of climate change on agriculture in Europe have been studied at both continental (Olesen and Bindi, 2002; Bindi and Olesen, 2011; Christensen et al., 2012) and regional scales, focusing on e.g. the Mediterranean basin or the Iberian Peninsula (IP) (Mínguez et al., 2007; Ruiz-Ramos and Mínguez, 2010; Garrido et al., 2011). The projected increase in temperature, the changes in the pattern of rainfall, and their interactions with increasing $\mathrm{CO}_{2}$ concentrations would cause variable effects on harvests depending on location, growing season, crop, and variety. For example, projections for southern Spain show a higher rise of spring and summer temperatures, compared with other seasons and regions of IP (Christensen and Christensen, 2007; López de la Franca et al., 2013). This should cause a shortening of the phenological cycle that would offset the enhanced photosynthetic rates under increased $\mathrm{CO}_{2}$. The final result of these counteracting effects would be a decrease in yield and biomass for irrigated summer crops in southern Spain (Guereña et al., 2001; Mínguez et al., 2007; Giannakopoulos et al., 2009; Garrido et al., 2011).

Most impact assessment studies in agriculture use crop models in combination with climate scenarios (Meza et al., 2008; Moriondo et al., 2010; Vučetić 2011). The climate scenarios are usually provided by general climate models (GCMs) downscaled by either statistical (Wilby et al., 1998) or dynamical (Castro et al., 2005) techniques, or by a combination of both (Førland et al., 2011). Dynamical downscaling is done by using regional climate models (RCMs) that generate projections (Giorgi et al., 2001) at a compatible resolution with the assessment of regional and local impacts. RCMs are especially useful in regions of complex orography, as is the case for IP (Guereña et al., 2001).

Climate projections contain multiple sources of uncertainty, such as selection of emission scenarios and model-dependent uncertainty, e.g. parameterization and resolution (Olesen et al., 2007; Ruiz-Ramos and Mínguez, 2010; Osborne et al., 2013). RCM simulations may present large biases when compared to observations (Dosio and Paruolo, 2011; Ceglar and Kajfež- Bogataj, 2012), which can limit their application for local/regional assessment. For that reason, the current methodology includes the use of 
CHAPTER 1. Strategies for adapting maize to climate change and extreme temperatures in Andalusia, Spain

ensembles of climate projections (Christensen et al., 2009; Semenov and Stratonovitch 2010), and evaluation using local climate data.

Climate change will strongly increase the frequency and intensity of extreme events (Easterling et al., 2000; Sánchez et al., 2004; Beniston et al., 2007), similar to the case of extreme maximum temperature (Tmax) events (Beniston 2004; Meehl and Tebaldi, 2004; Schär and Jendritzky, 2004; Tebaldi et al., 2006; Beniston et al., 2007; Hertig et al., 2010). These episodes have a direct influence on crops and therefore should be considered in a comprehensive impact assessment (García-López et al., 2014). For example, Tmax events have been reported as the most hazardous events for maize under irrigated conditions in Andalusia, since high temperatures during flowering and grain-filling are expected to result in lower grain yield (Herrero and Johnson, 1980; RuizRamos et al., 2011).

Although some studies address the adaptation of irrigated crops to climate change (Garrido et al., 2011; Olesen et al., 2011; Moradi et al., 2013), or the effect of extreme events (Ruiz-Ramos et al., 2011), few have evaluated adaptations in relation to those extreme events (Travis and Huisenga, 2013; Trnka et al., 2014). In fact, the current ecophysiological crop models do not simulate the whole extent of weather extremes on critical crop phases such as pollination or grain-filling (García-López et al., 2014), in turn introducing an important additional source of uncertainty in the context of climate change impact. Furthermore, crop modeling also incorporates uncertainty, due to both the model mechanisms to describe the processes, which is partially addressed by the use of several crop models, i.e. an ensemble of impact models, and the lack of local calibration (Palosuo et al., 2011; Rötter et al., 2011). For that reason, the crop model has to be calibrated with field data at the relevant spatial scale for the study to improve its application (Boote et al., 2013). Then, for a specific crop in a regional cropping system, as is the case for maize in Andalusia, an ecophysiological crop model with site-specific calibration and validation must be considered.

In Andalusia, agriculture and livestock account for $4.3 \%$ of regional gross domestic product (GDP; MAGRAMA 2015). Irrigated agriculture represents around $64 \%$ of total agricultural income, although only $32 \%$ of the area is irrigated (CAPDR 2011). Maize is a traditional irrigated summer crop in this region, with $81.9 \%$ (32000 ha) of the 
CHAPTER 1. Strategies for adapting maize to climate change and extreme temperatures in Andalusia, Spain

cultivated area located in the Guadalquivir Valley (RAEA 2012). Due to the foreseen increase in temperature and reference evapotranspiration (Espadafor et al., 2011), water requirements for maize could increase in the future in this region (Mínguez et al., 2005) if adaptation strategies are not used.

Considering the importance of irrigated agriculture in Mediterranean environments, the objective of this study is to determine the effect of adaptation strategies for irrigated maize in Andalusia in terms of yield and water requirements. The adaptation strategies proposed are evaluated in relation to the impact of Tmax as one of the most relevant extreme events for irrigated maize in Andalusia

\subsection{MATERIAL AND METHODS}

\subsubsection{Location}

We selected 5 locations (Fig. 1.1) according to field experimental data availability, representing different areas of maize cultivation in Andalusia: 2 in Seville province (Alcalá del Río and Lora del Río), 2 in Córdoba province (Palma del Río and Córdoba), and 1 in Granada. The Seville and Córdoba locations are in the Guadalquivir River basin, ranging from 11 to $117 \mathrm{~m}$ above sea level. Granada has a greater altitude (630 m), and is close to the Sierra Nevada Mountains. The climate is Mediterranean type, with dry summers, at all locations, according to the Köppen classification (Essenwanger 2001). For the locations along the Guadalquivir basin, annual mean precipitation is ca. $600 \mathrm{~mm}$, concentrated mainly from autumn to spring; annual mean temperature is ca. $18^{\circ} \mathrm{C}$, with a Tmax during the maize-growing season (March-August) of ca. $30{ }^{\circ} \mathrm{C}$ (Table 1.1). Conditions are drier and cooler in Granada, with a Tmax during the growing season (March-August) around $28^{\circ} \mathrm{C}$ (Table 1.1). 
CHAPTER 1. Strategies for adapting maize to climate change and extreme temperatures in Andalusia, Spain

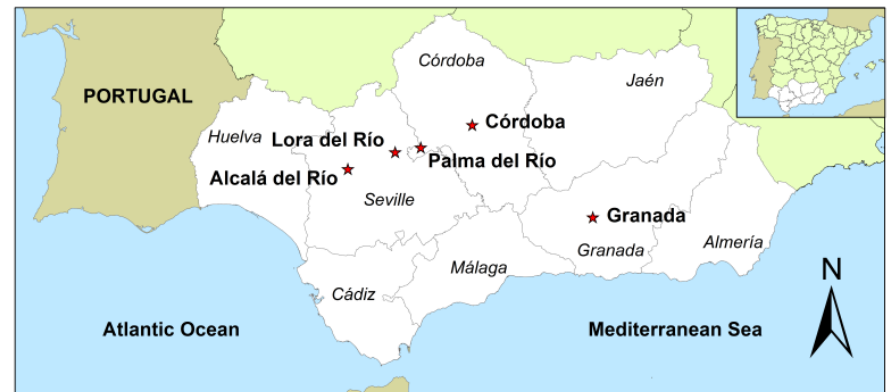

Figure 1.1. Study locations, corresponding to sites with maize field experiments

Table 1.1. Location, soil type (Soil Survey Staff 1999), annual mean temperature (Tmean) and accumulated precipitation (Precip) from the nearest weather stations from each location, years with experimental data from Red Andaluza de Experimentación Agraria (RAEA), and mean observed sowing date for the 5 sites. All locations have a Mediterranean climate according to Essenwanger's (2001) classification

\begin{tabular}{|c|c|c|c|c|c|c|}
\hline Location & Coordinates & Soil type & $\begin{array}{c}\text { Tmean } \\
\left({ }^{\circ} \mathrm{C}\right)\end{array}$ & $\begin{array}{l}\text { Precip } \\
\text { (mm) }\end{array}$ & $\begin{array}{c}\text { RAEA } \\
\text { Data Years }\end{array}$ & $\begin{array}{l}\text { Sowing } \\
\text { date }\end{array}$ \\
\hline Alcalá del Río & $\begin{array}{l}37.51 \mathrm{~N} \\
5.96 \mathrm{~W}\end{array}$ & Xerofluvent & 18.3 & 597 & $\begin{array}{l}2003,2005 \\
2006,2007\end{array}$ & 17-march \\
\hline Lora del Río & $\begin{array}{l}37.64 \mathrm{~N} \\
5.52 \mathrm{~W}\end{array}$ & Xerofluvent & 18.2 & 663 & 2003 & 20-march \\
\hline Palma del Río & $\begin{array}{l}37.7 \mathrm{~N} \\
5.28 \mathrm{~W}\end{array}$ & Xerofluvent & 18.2 & 634 & 2003,2007 & 21-march \\
\hline Córdoba & $\begin{array}{l}37.86 \mathrm{~N} \\
4.79 \mathrm{~W}\end{array}$ & Xerofluvent & 17.9 & 661 & $\begin{array}{l}2005,2006,2007 \\
2008,2009,2011\end{array}$ & 21-march \\
\hline Granada & $\begin{array}{l}37.17 \mathrm{~N} \\
3.63 \mathrm{~W}\end{array}$ & Xerorthent & 15 & 385 & $\begin{array}{l}2005,2006,2007 \\
2008,2009,2010\end{array}$ & 23-april \\
\hline
\end{tabular}

\subsubsection{Climate data}

Daily observed and simulated climate data of Tmax and Tmin, solar radiation, and precipitation were used. For observed climate, climate data from the Agroclimatic Information Network of Andalusia (Red de Información Agroclimática de Andalucia, RIA in Spanish; Gavilán et al., 2006) from 2001- 2010 were used (www. juntadeandalucia.es/agriculturaypesca/ifapa/ria).

For simulated climate, data from a subset of 12 RCMs from the ENSEMBLES project (www.ensembles-eu.org) at $25 \mathrm{~km}$ horizontal resolution with a bias correction in temperature and precipitation (Dosio and Paruolo, 2011; Dosio et al., 2012) were used. 
CHAPTER 1. Strategies for adapting maize to climate change and extreme temperatures in Andalusia, Spain

The correction was done with respect to the E-OBS gridded observational database (Haylock et al., 2008). The bias-corrected ensemble is hereafter named ENS-EOBS. Before using the simulated database as input for the crop model, it was tested for Tmax, Tmin, and seasonal rainfall (March-August; Table 1.2) against observed weather station data (from RIA). The bias correction could not be done for solar radiation (SRAD), because E-OBS does not include radiation data. The SRAD bias was small, and it ranged between $0 \mathrm{MJ} \mathrm{m}^{-2} \mathrm{~d}^{-1}$ (at Córdoba in spring) and $-1.8 \mathrm{MJ} \mathrm{m}^{-2} \mathrm{~d}^{-1}$ (at Palma del Río in July). The consequences of SRAD bias on simulated yield were evaluated, and resulted in a mean error of maximum yield change, averaged over locations, of $4.3 \%$ (results not shown). 
Table 1.2. Climate data during maize growing cycle: monthly maximum (Tmax) and minimum (Tmin) temperatures and accumulated precipitation for Agroclimatic Information Network of Andalusia (RIA) station data (2001-2010), and difference between mean values from these data and those from the ensemble mean (12 regional climate models) from the bias-corrected ensemble ENS-EOBS, for the baseline period 1981-2010

\begin{tabular}{|c|c|c|c|c|c|c|c|c|c|c|c|c|c|c|c|c|c|c|c|}
\hline & & \multicolumn{6}{|c|}{$\operatorname{Tmax}\left({ }^{\circ} \mathrm{C}\right)$} & \multicolumn{6}{|c|}{$\operatorname{Tmin}\left({ }^{\circ} \mathrm{C}\right)$} & \multicolumn{6}{|c|}{ Precipitation (mm month ${ }^{-1}$ ) } \\
\hline & & March & April & May & June & July & August & March & April & May & June & July & August & March & April & May & June & July & August \\
\hline \multirow{2}{*}{$\begin{array}{l}\text { Alcalá } \\
\text { del Río }\end{array}$} & RIA & 20.7 & 23.4 & 27.1 & 32.4 & 35.4 & 35.2 & 8.3 & 10.2 & 12.8 & 16.5 & 17.6 & 17.9 & 62 & 59 & 31 & 5 & 0 & 7 \\
\hline & ENS-EOBS & -0.2 & -0.4 & 0.0 & -0.6 & 0.3 & 0.4 & 0.1 & 0.1 & 0.4 & 0.3 & 1.6 & 1.4 & -14 & -15 & -6 & 6 & 2 & -3 \\
\hline \multirow{2}{*}{$\begin{array}{c}\text { Lora del } \\
\text { Río }\end{array}$} & RIA & 20.6 & 23.6 & 27.5 & 33.3 & 36.3 & 36.0 & 7.8 & 9.6 & 12.4 & 16.5 & 17.8 & 18.3 & 66 & 63 & 43 & 4 & 1 & 2 \\
\hline & ENS-EOBS & -0.4 & -0.8 & -0.4 & -1.3 & -0.4 & -0.1 & 0.2 & 0.4 & 0.7 & 0.3 & 1.4 & 1.1 & -15 & -17 & -17 & 7 & 2 & 1 \\
\hline \multirow{2}{*}{$\begin{array}{l}\text { Palma } \\
\text { del Río }\end{array}$} & RIA & 20.0 & 23.1 & 27.2 & 33.2 & 36.3 & 36.0 & 8.0 & 10.0 & 12.9 & 17.0 & 18.8 & 19.1 & 70 & 56 & 49 & 7 & 0 & 5 \\
\hline & ENS-EOBS & 0.0 & -0.3 & -0.1 & -1.2 & -0.3 & -0.1 & -0.3 & -0.2 & 0.0 & -0.3 & 0.4 & 0.2 & -18 & -8 & -23 & 4 & 3 & -3 \\
\hline \multirow{2}{*}{ Córdoba } & RIA & 19.7 & 22.5 & 26.6 & 32.8 & 36.4 & 36.1 & 7.5 & 9.3 & 12.1 & 16.6 & 18.5 & 19.2 & 89 & 58 & 40 & 10 & 3 & 6 \\
\hline & ENS-EOBS & 0.1 & 0.1 & 0.4 & -0.8 & -0.2 & -0.1 & -0.2 & 0.1 & 0.5 & -0.1 & 0.6 & 0.1 & -39 & -11 & -13 & -1 & 1 & -3 \\
\hline \multirow{2}{*}{ Granada } & RIA & 18.5 & 21.0 & 25.3 & 32.2 & 35.4 & 34.8 & 4.7 & 6.5 & 9.7 & 14.3 & 16.1 & 16.1 & 50 & 38 & 31 & 4 & 0 & 3 \\
\hline & ENS-EOBS & -1.4 & -1.3 & -1.0 & -2.3 & -0.9 & -0.6 & 1.1 & 1.4 & 1.6 & 1.1 & 2.4 & 2.6 & 0 & 5 & 2 & 17 & 10 & 4 \\
\hline
\end{tabular}




\subsubsection{Crop modelling}

We used the CERES-Maize crop model (Jones and Kiniry, 1986) in the DSSAT v. 4.5 platform (Decision Support System for Agrotechnology Transfer; Jones et al., 2003; Hoogenboom et al., 2010). This is an ecophysiological model which simulates crop growth and development, and can be used with climate projections and elevated $\mathrm{CO}_{2}$ conditions. The CERES-Maize model uses radiation use efficiency (RUE) to calculate biomass from intercepted photosynthetically active radiation (PAR) by the crop canopy. Photoassimilate partitioning and remobilization to grains determine the crop yield. Duration of phenophases, e.g. days from emergence to end of the juvenile phase, or grain-filling duration, are estimated by growing degree days (GDD; $\left.{ }^{\circ} \mathrm{Cd}\right)$, which is the accumulated exposure to average daily temperature above a threshold $\left(8{ }^{\circ} \mathrm{C}\right)$ below which there is no development, and a maximum of $34{ }^{\circ} \mathrm{C}$ above which the rate of development remains constant. Phenophase duration, in days, correlates to average temperature, except for the duration of flower induction, which is controlled by day length (Kiniry 1991). $\mathrm{CO}_{2}$ enrichment affects dry matter production and transpiration. Potential growth rate is affected by a multiplicative coefficient, increasing the daily dry matter production at optimum temperature, water, and nitrogen supply (Kimball 1983; Cure and Acock, 1986). This coefficient is 1.17 for C3 crops and 1.05 for C4 crops when $\left[\mathrm{CO}_{2}\right]$ is $550 \mathrm{mg} \mathrm{l}^{-1}$. Also, transpiration rate is affected by stomatal resistance, which increases with $\mathrm{CO}_{2}$ concentration (Hoogenboom et al., 1995).

Model inputs include 6 cultivar-specific parameters, daily meteorological variables (maximum and minimum temperatures, solar radiation, precipitation, wind run, and relative humidity), soil features (depth, texture by layers, water holding capacity), and crop management (sowing date, population density, fertilization, and irrigation, among others). Cultivar parameters, controlling phenology, growth, and grain yield, have to be set during the calibration process.

Soil and crop experimental data for crop model calibration and validation were taken from the Andalusia Network of Agricultural Trials (Red Andaluza de Experimentación Agraria, or RAEA; www.juntadeandalucia.es/agriculturaypesca/ifapa/web/ifapa/productos/transferencia). 
The data corresponded to field experiments with the HELEN cultivar (FAO 700), from 2003 to 2011 (Table 1.1). Omitted years were due to insufficient weather data or agronomic causes not simulated by the crop model, such as pests and diseases preventing adequate crop growth. Sowing dates were in March for sites in the Guadalquivir basin, and in April for Granada (Table 1.1). Target population densities of 10 plants $\mathrm{m}^{-2}$ were sown in rows $0.75 \mathrm{~m}$ apart, and arranged in a randomized block design. Fertilizer and irrigation management was always set to avoid nutrient and water limitations.

Crop measurements included sowing, emergence, silking, and harvest dates, plant population at emergence, grain weight, and yield. Maturity dates were estimated from Iglesias and Mínguez (1995). The experiments used for calibration were from Granada (years 2005, 2006, and 2007), while the other locations were used for validation, as were some years from Granada (2008, 2009, and 2010). Calibration and validation were evaluated in terms of root mean square error (RMSE) and mean bias error (MBE) between observed and simulated data:

$$
\begin{aligned}
& R M S E=\sqrt{\frac{\sum_{i}^{n}\left(S_{i}-O_{i}\right)^{2}}{n}} \\
& M B E=n^{-1} \sum_{i=1}^{N}\left(S_{i}-O_{i}\right)
\end{aligned}
$$

where $\mathrm{S}$ and $\mathrm{O}$ are the simulated and observed data, and $\mathrm{n}$ is the number of observations.

Once the crop model was calibrated and validated, impact assessment in terms of crop yield and water requirements were calculated for the near future (2021-2050) and far future (2071-2100) in comparison to the baseline period (1981-2010), hereafter called NF, FF, and B, respectively. Then a set of autonomous adaptation strategies (i.e. farmers' adaptations; Garrido et al., 2011) were tested to avoid or reduce the negative biophysical impacts found. Adaptations were compared to un-adapted baseline and future projections in terms of crop yield and water requirements. The adaptations included earlier sowing dates, up to $60 \mathrm{~d}$ in advance, at $15 \mathrm{~d}$ intervals, and cultivar changes through the modification of cultivar phenology. This latter was implemented 
through the change of the CERES cultivar coefficients controlling the duration of grainfilling (P5) and the grain-filling growth rate (G3). The P5 coefficient was changed, seeking a longer but feasible grain-filling from 800 to $850 \mathrm{GDD}$, while the grain-filling rate was increased by modifying the $\mathrm{G} 3$ coefficient from 8 to $9 \mathrm{mg} \mathrm{d}^{-1}$; the objective was to test changes within the scope of current breeding research. These adaptations were simulated individually and in combination.

Water requirements were evaluated in terms of crop evapotranspiration $\left(\mathrm{ET}_{c}\right.$; $\mathrm{mm}$ ) estimated by the CERES-Maize crop model. Equally, this model was used for the determination of irrigation requirements (IRR; $\mathrm{mm}$ ), and water use efficiency in terms of water productivity (TWP; $\mathrm{kg} \mathrm{m}^{-3}$ ) and irrigation water productivity (IWP; $\mathrm{kg} \mathrm{m}^{-3}$ ).

\subsubsection{Extreme events}

Impacts of extreme Tmax events on maize were quantified by the method of Teixeira et al., (2013). Briefly, this approach considers (1) critical and limiting temperatures, which are the thresholds above which yield damage increases until a limit when total production fails; these limits are set to 35 and $45{ }^{\circ} \mathrm{C}$, respectively; (2) calculation of the stress intensity index (fHS, fractional) based on the Tmax during the sensitive period to temperature ( $30 \mathrm{~d}$ centered in the mid-point of the reproductive phase); it represents the intensity and number of stress events that may affect the crop during flowering; the mentioned period is considered as the only one sensitive to heat stress; and (3) the production damage index, calculated from the simulated attainable yield normalized by the maximum value for each period and location $\left(\mathrm{fdmg}_{\mathrm{n}}\right)$; this index quantifies the impact on yield.

Similar to previous modifications (Hawkins et al., 2013), two changes to the method were made: (1) the use of daily Tmax during $30 \mathrm{~d}$ after silking instead of the daytime Tday, given that current cultivars are adapted to the high temperature regime of the study area; and (2) the use of potential yield data from the CERES-Maize simulations instead of attainable yield, as simulations without nitrogen and water stresses were considered.

Both fHS and $\mathrm{fdmg}_{\mathrm{n}}$ were calculated and evaluated for the 5 locations (Fig. 1.1) and for the 3 periods (B, NF, and $\mathrm{FF}$ ), with and without adaptation strategies. 


\subsection{RESULTS}

\subsubsection{Crop model calibration and validation}

The combination of cultivar-specific coefficients that present agronomic coherence and the lowest RMSE and MBE between observed and simulated silking dates and yield data for the HELEN cultivar was determined (Table 1.3). RMSE for the silking date simulation (expressed in days after sowing, DAS) was 3.1 and $5.6 \mathrm{~d}$ for calibration and validation, respectively, with MBE values equal to -1 and $3 d$, respectively. RMSE errors for yield assessment were 344 and $1457 \mathrm{~kg} \mathrm{ha}^{-1}$ for calibration and validation, respectively, and MBE errors were -138 and $224 \mathrm{~kg} \mathrm{ha}^{-1}$, respectively.

Table 1.3. Cultivar-specific parameters calibrated in the CERES-Maize crop model for the HELEN cultivar (FAO 700) using measured data from Red Andaluza de Experimentación Agraria (RAEA) experiments. P1: thermal time from seedling emergence to the end of the juvenile phase (expressed in degree days above a base temperature of $8^{\circ} \mathrm{C}$ ) during which the plant does not response to changes in photoperiod; P2: extent to which development (expressed as days) is delayed for each hour increase in photoperiod above the longest photoperiod at which development proceeds at a maximum rate (which is considered to be $12.5 \mathrm{~h}$ ); P5: thermal time from silking to physiological maturity (expressed in degree days above a base temperature of $8^{\circ} \mathrm{C}$ ); G2: maximum possible number of kernels per plant; G3: kernel filling rate during the linear grain-filling stage and under optimum conditions ( $\mathrm{mg} \mathrm{d}^{-1}$ ); PHINT: phylochron interval, the interval in thermal time (degree days, ${ }^{\circ} \mathrm{Cd}$ ) between successive leaf tip appearances

\begin{tabular}{c|c|c|c|c|c} 
P1 & P2 & P5 & G2 & G3 & PHINT \\
\hline 245 & 0 & 800 & 1100 & 8 & 45
\end{tabular}

\subsubsection{Evaluation under the present climate}

The ENS-EOBS ensemble mean of climate variables for the grain-filling period (June-August) showed small biases related to measured data by RIA (Table 1.2); all locations showed a small bias or no difference with respect to the RIA dataset for monthly Tmax, Tmin (except for Granada), and precipitation (Table 1.2). Precipitation biases were not considered important in this study because crops were well irrigated.

The evaluation of ENS-EOBS was extended to its performance on impact assessment comparing yield simulations done by CERES-Maize with RIA and ENS-EOBS 
climate datasets for the baseline period (Table 1.4). The yield difference ranged from $-6.1 \%$ (for Granada) to 0.6 \% (for Palma del Rio; Table 1.4). Both simulated time series showed similar interannual variability (coefficient of variation, $\mathrm{CV}_{\text {time }}$ ), with the greatest difference in Granada (Table 1.4).

Table 1.4. Simulated yield run with observed Agroclimatic Information Network of Andalusia (RIA) data (2001-2010), and interannual variability (coefficient of variation, CVtime). Difference (\% of yield) regarding RIA-derived simulations and those conducted with the bias-corrected ensemble ENS-EOBS for the baseline period (1981-2010), and CVtime for these simulations

Climate data used in the crop simulations

\begin{tabular}{cccccc}
\hline \multirow{2}{*}{ Location } & \multicolumn{2}{c}{ RIA } & & \multicolumn{2}{c}{ ENS-EOBS (\%) vs RIA } \\
\cline { 2 - 3 } \cline { 5 - 6 } & $\begin{array}{c}\text { Yield } \\
\left(\mathrm{kg} \mathrm{ha}^{-1)}\right.\end{array}$ & $\mathrm{CV}_{\text {time }}$ & & $\begin{array}{c}\text { Yield difference } \\
(\%)\end{array}$ & $\mathrm{CV}_{\text {time }}$ \\
\hline Alcalá del Río & 16177 & $8.7 \%$ & & 1.9 & $7.3 \%$ \\
$\begin{array}{c}\text { Lora del Río } \\
\text { Palma del }\end{array}$ & 16055 & $10.8 \%$ & & 1.1 & $7.7 \%$ \\
Río & 16094 & $10.8 \%$ & & 0.6 & $7.4 \%$ \\
Córdoba & 15961 & $7.5 \%$ & & 1.0 & $7.7 \%$ \\
Granada & 16966 & $4.5 \%$ & & -6.1 & $8.6 \%$ \\
\hline
\end{tabular}

\subsubsection{Impact and adaptation projections}

Simulated phenological dates for Palma del Río (representative of Guadalquivir locations) and Granada are shown in Fig. 1.2 for B, NF, and FF periods. As GDD accumulated faster in future climate, both silking (anthesis date, ADAT) and maturity (MDAT) dates occurred earlier compared to the baseline simulations when sowing date was not changed, leading to a shorter grain-filling duration (MDAT - ADAT), especially in the FF period (ca. $17 \mathrm{~d}$ for the Guadalquivir locations and $20 \mathrm{~d}$ for Granada).

The simulated yield impact for irrigated maize, considering an optimal irrigation schedule for the ENS-EOBS ensemble mean, is shown in Table 1.5 for the B, NF, and FF periods and for the 5 locations. The results show a decrease in maize yield, greater in FF, when yield decrease was ca. 6-7\% at Guadalquivir locations and ca. $20 \%$ in Granada. However, these effects when compared to the B period were only statistically significant in Córdoba and Granada (Table 1.5). 
CHAPTER 1. Strategies for adapting maize to climate change and extreme temperatures in Andalusia, Spain

Interannual variability ( $\mathrm{CV}_{\text {time }}$ in $\%$ for the $30 \mathrm{yr}$ period) in the future (NF and $\mathrm{FF}$ ) was ca. $8 \%$ for all Guadalquivir locations, similar to that of the baseline simulations (Table 1.5). Granada showed a higher increase in variability, especially in the FF (ca. 15 $\%)$. The spread or uncertainty related to the differences among the $12 \mathrm{RCM}$ projections that form ENS-EOBS was measured by the coefficient of variation among them $\left(\mathrm{CV}_{\text {ensemble, }} \%\right)$. This spread was similar for all locations ( $\mathrm{CV}_{\text {ensemble: }}$ 7-8 \%), decreasing slightly in the FF, except for Granada, where it increased up to ca. $12 \%$ (Table 1.5).

These results show that recovering the baseline yields, particularly in Granada, requires adaptation measures. The first adaptation proposed consisted of earlier sowing dates (Fig. 1.3a,b).
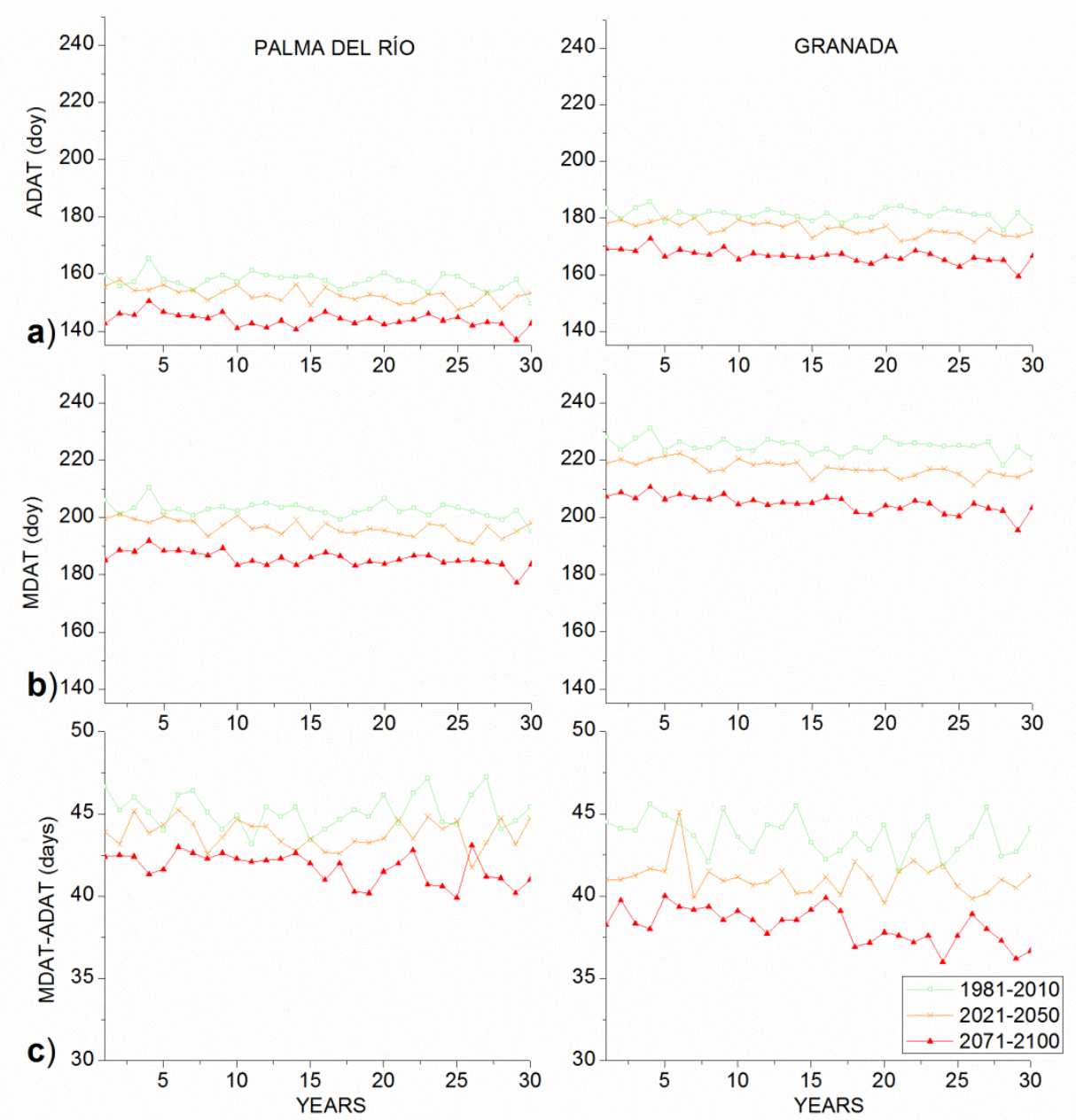

Figure 1.2. Simulated phenology for the baseline period (1981-2010), near future (2021-2050), and far future (2071-2100): (a) anthesis date (ADAT), (b) maturity date (MDAT), and (c) grain-filling duration (MDAT - ADAT). DOY: day of the year 
Table 1.5. Simulated yield obtained with the bias-corrected ensemble ENS-EOBS for the baseline period (1981-2010), near future (2021-2050), and far future (2071-2100). Difference (\% of yield) between future and baseline periods is indicated in brackets. a,b Significant differences $(p<0.05)$. Interannual variability is expressed as coefficient of variation from year to year $\left(C_{\text {time }}\right)$; spread of the ENS-EOBSderived ensemble of impacts is expressed as coefficient of variation among the 12 projections $\left(\mathrm{CV}_{\text {ensemble }}\right)$

\begin{tabular}{|c|c|c|c|c|c|c|c|c|c|}
\hline \multirow[b]{2}{*}{ Location } & \multicolumn{3}{|c|}{$1981-2010$} & \multicolumn{3}{|c|}{$2021-2050$} & \multicolumn{3}{|c|}{$2071-2100$} \\
\hline & $\begin{array}{l}\text { Yield } \\
\left(\mathrm{kg} \mathrm{ha}^{-1}\right)\end{array}$ & $\begin{array}{c}\mathrm{CV}_{\text {time }} \\
(\%)\end{array}$ & $\begin{array}{c}\mathrm{CV}_{\text {ensemble }} \\
(\%)\end{array}$ & $\begin{array}{l}\text { Yield } \\
\left(\mathrm{kg} \mathrm{ha}^{-1}\right)\end{array}$ & $\begin{array}{c}\mathrm{CV}_{\text {time }} \\
(\%)\end{array}$ & $\begin{array}{c}\mathrm{CV}_{\text {ensemble }} \\
(\%)\end{array}$ & $\begin{array}{c}\text { Yield } \\
\left(\mathrm{kg} \mathrm{ha}^{-1}\right)\end{array}$ & $\begin{array}{c}\mathrm{CV}_{\text {time }} \\
(\%)\end{array}$ & $\begin{array}{c}\mathrm{CV}_{\text {ensemble }} \\
(\%)\end{array}$ \\
\hline $\begin{array}{l}\text { Alcalá } \\
\text { del Río }\end{array}$ & $16491^{a}$ & 7.3 & 6.9 & $\begin{array}{l}16272^{a} \\
(-1.3 \%)\end{array}$ & 7.9 & 7.4 & $\begin{array}{l}15410^{\mathrm{a}} \\
(-6.5 \%)\end{array}$ & 8.0 & 6.9 \\
\hline $\begin{array}{c}\text { Lora del } \\
\text { Río }\end{array}$ & $16238^{\mathrm{a}}$ & 7.7 & 7.0 & $\begin{array}{l}16016^{a} \\
(-1.3 \%)\end{array}$ & 7.9 & 7.0 & $\begin{array}{l}15127^{a} \\
(-6.8 \%)\end{array}$ & 8.1 & 7.2 \\
\hline $\begin{array}{l}\text { Palma } \\
\text { del Río }\end{array}$ & $16194^{\mathrm{a}}$ & 7.4 & 6.9 & $\begin{array}{l}16012^{a} \\
(-1.1 \%)\end{array}$ & 7.7 & 6.4 & $\begin{array}{l}15126^{a} \\
(-6.5 \%)\end{array}$ & 8.1 & 7.0 \\
\hline Córdoba & $16118^{a}$ & 7.7 & 6.6 & $\begin{array}{l}15885^{a b} \\
(-1.4 \%)\end{array}$ & 7.7 & 6.3 & $\begin{array}{l}15006^{b} \\
(-6.8 \%)\end{array}$ & 8.5 & 6.9 \\
\hline Granada & $15924^{a}$ & 8.6 & 6.2 & $\begin{array}{l}15061^{\mathrm{a}} \\
(-5.3 \%)\end{array}$ & 9.2 & 4.4 & $\begin{array}{c}12665^{b} \\
(-20.6 \%)\end{array}$ & 15.0 & 12.3 \\
\hline
\end{tabular}

Analyzing Fig. 1.3a, sowing dates $30 \mathrm{~d}$ earlier allowed for recovering the baseline yield in NF, although the option that minimized the impact was sowing $45 \mathrm{~d}$ earlier for all locations in FF (Fig. 1.3b). Results indicate a different behavior for Granada than for the rest of the locations. In Granada, even with earlier sowing dates, future yield was 9 to 11 $\%$ lower than that for the B period, while in the other locations, yield was consistently around $3 \%$ lower than for the B period.

The second adaptation proposed in this study was the modification of the cultivar, adapting the grain-filling duration (P5 in Table 1.3) and grain- filling rate (G3 in Table 1.3) (Fig. 1.3c). For the NF period, modifying grain-filling duration was enough to recover the baseline yield (results not shown). However, for the FF period, baseline yields were recovered for all locations except for Granada, which still had lower yields than in the B period. Similar behavior was found when grain-filling rate was increased. The combination of both changes in the cultivar exceeded the B yields by up to $10 \%$ at all locations except Granada, where the yield remained ca. $10 \%$ lower than that of the B simulations. 


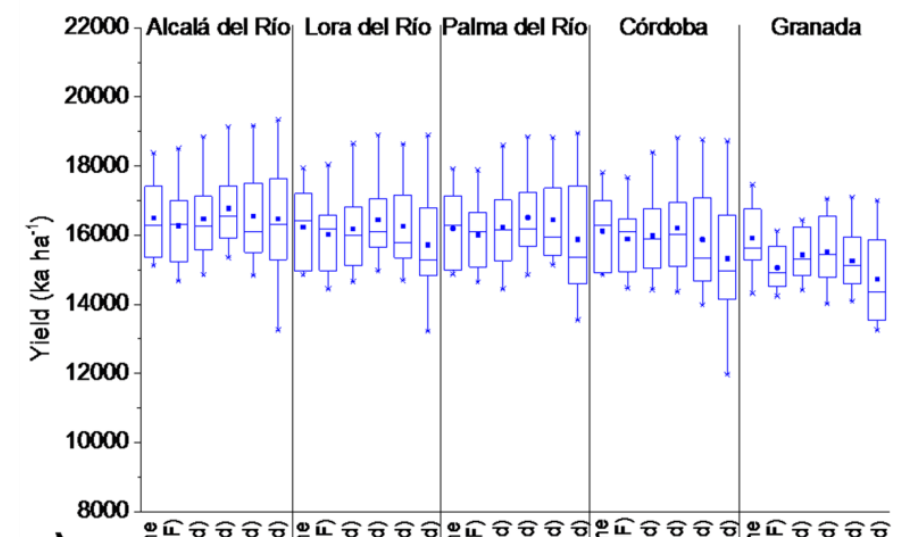

a)
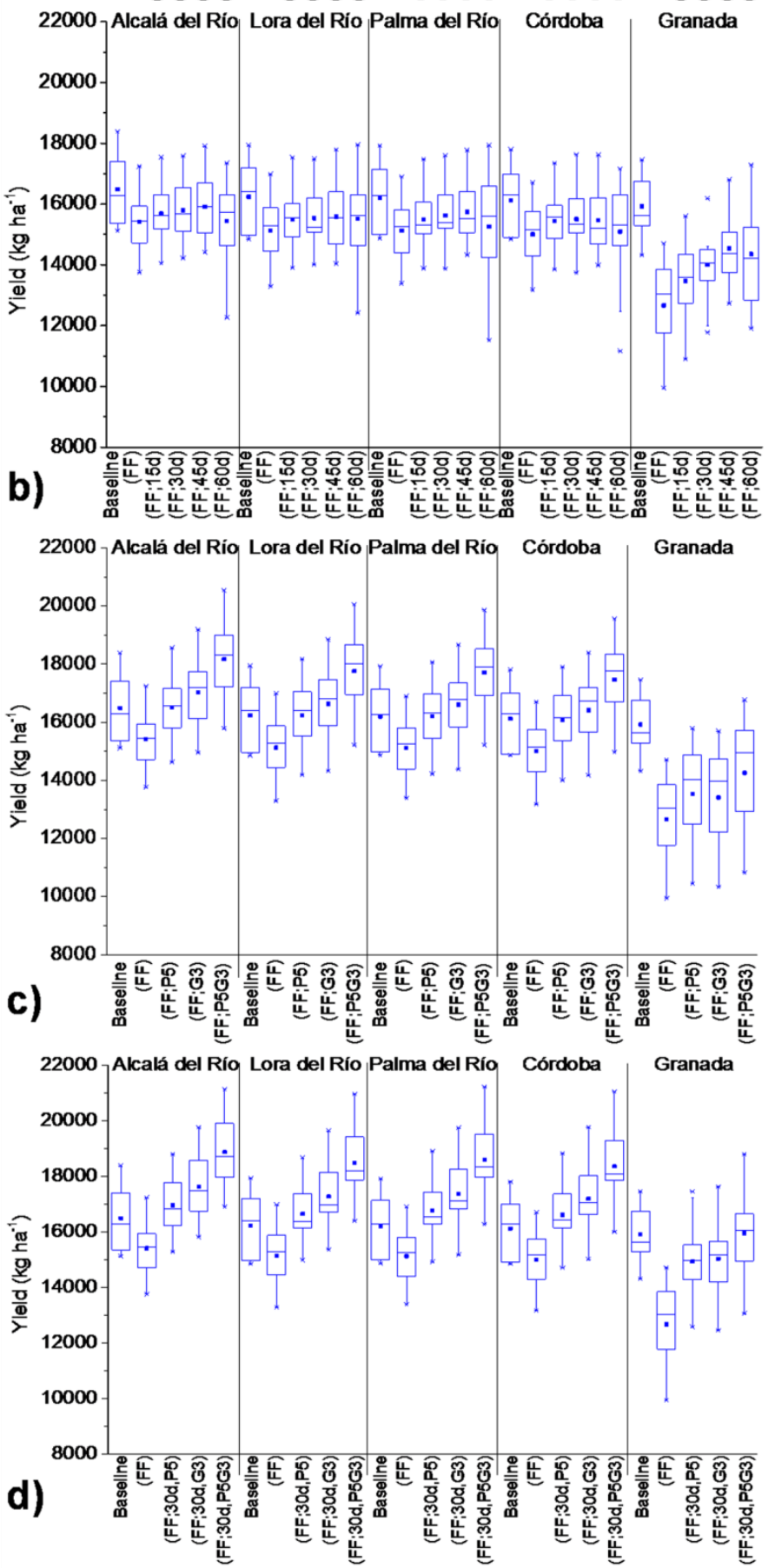

Figure 1.3. Projections of crop yield, impacts, and adaptations for the 12 regional climate model (RCM) projections of the bias-corrected ensemble ENS-EOBS at each location. The $y$-axis shows the simulated yield; $x$-axis specifies the simulation: yield for 1981-2010 (baseline), yield without adaptation for 2051-2071 or near future (NF), for 2071-2100 or far future (FF), and adaptations for NF (NF; adaptation) and FF (FF; adaptation). Adaptations are as follows: (a) sowing date advanced 15, 30,45 , and $60 \mathrm{~d}$ in the NF; (b) sowing date advanced $15,30,45$, and $60 \mathrm{~d}$ in the FF; (c) increase in the CERES cultivar coefficients for duration of grain-filling (P5) and grain-filling rate (G3), and increase in both P5 and G3, in the FF; (d) combination of sowing $30 \mathrm{~d}$ earlier and increased P5, sowing $30 \mathrm{~d}$ earlier and increased G3, and sowing $\mathbf{3 0} \mathrm{d}$ earlier and increased P5 and G3, in the FF. Boxplots show the distribution of the 12 RCM-derived results: box: 2nd and 3rd quartiles; line in the middle: median; point in the middle: mean; whiskers: maximum and minimum 
The advance in sowing dates and the changes in crop phenology were combined in several ways, to improve Granada's result, and to explore the potential of these combinations for the Guadalquivir locations (Fig. 1.3d for FF). When the sowing date was advanced by $30 \mathrm{~d}$ and the cultivar-specific coefficients were set to P5 $=850$ GDD and G3 $=9 \mathrm{mg} \mathrm{d}^{-1}$, the B yields were recovered at Granada (0.2\% of change). The same phenology, but with a sowing date $45 \mathrm{~d}$ earlier, showed an even higher yield for Granada (4.5\% of change). However, the $30 \mathrm{~d}$ option was the adaptation selected (hereafter called ADPS), valid for all locations to minimize disruption of the current cropping system, as large shifts in sowing dates may imply changes in crop rotations.

An average reduction of $\mathrm{ET}_{\mathrm{c}}$ of 10 and $25 \%$ was found for the $\mathrm{NF}$ and $\mathrm{FF}$, respectively (Table 1.6). The baseline $\mathrm{ET}_{\mathrm{c}}$ values were lower for Granada than for the Guadalquivir locations. IRR ranged from $668 \mathrm{~mm}$ for Granada to $726 \mathrm{~mm}$ for the Guadalquivir Valley. As a consequence of the $\mathrm{ET}_{\mathrm{c}}$ reductions, IRR showed decreases of around $9 \%$ in all locations for the NF period, which were slightly higher for the Guadalquivir locations (ca. $25 \%$ ) compared to Granada (ca. 16\%) by the end of the $21^{\text {st }}$ century. These reductions in $\mathrm{ET}_{\mathrm{c}}$ and IRR values were accompanied by an increase in water productivity (Table 1.6); both TWP and IWP were higher for all locations in NF and FF compared with baseline values.

In the ADPS simulations for Guadalquivir locations, $\mathrm{ET}_{\mathrm{c}}$ values increased around $3.5 \%$ compared with the results obtained without adaptation strategies. This increase was around $9.5 \%$ for Granada. The IRR results showed limited changes for the Guadalquivir locations (0.4 and $-1.1 \%$ ) and an increase for Granada (7 and $6 \%$ ) for NF and FF periods, respectively, compared with the same period 
Table 1.6 Mean values of crop cycle duration, maturity date (MDAT), total season evapotranspiration $\left(E T_{c}\right)$, total irrigation requirements (IRR), water productivity (TWP), and irrigation water productivity (IWP), with the 12 regional climate models of the bias-corrected ensemble ENS-EOBS, for the baseline period (1981-2010), near future (2021-2050), and far future (2071-2100), with (ADPS) and without ('Impact') adaptation. ADPS: Adaptation selected (sowing date $30 \mathrm{~d}$ earlier, P5 = $850 \mathrm{GDD}$ and G3 = $9 \mathrm{mg}$ $\left.d^{-1}\right)$,), DOY: day of the year

\begin{tabular}{|c|c|c|c|c|c|c|}
\hline \multirow[t]{2}{*}{ Location } & \multirow[t]{2}{*}{ Result } & $1981-2010$ & \multicolumn{2}{|c|}{ 2021-2050 } & \multicolumn{2}{|c|}{$2071-2100$} \\
\hline & & Baseline & Impact & ADPS & Impact & ADPS \\
\hline \multirow{6}{*}{$\begin{array}{c}\text { Alcala del } \\
\text { Río }\end{array}$} & Crop cycle (d) & 138 & 132 & 154 & 121 & 143 \\
\hline & MDAT (DOY) & 200 & 194 & 187 & 183 & 175 \\
\hline & $\mathrm{ET}_{\mathrm{C}}(\mathrm{mm})$ & 722 & 650 & 673 & 543 & 555 \\
\hline & IRR (mm) & 729 & 659 & 658 & 554 & 543 \\
\hline & TWP $\left(\mathrm{kg} \mathrm{m}^{-3}\right)$ & 3.1 & 3.5 & 4.2 & 4.1 & 4.9 \\
\hline & IWP $\left(\mathrm{kg} \mathrm{m}^{-3}\right)$ & 2.3 & 2.5 & 3.1 & 2.8 & 3.5 \\
\hline \multirow{6}{*}{ Lora del Río } & Crop cycle (d) & 137 & 131 & 153 & 120 & 141 \\
\hline & MDAT (DOY) & 202 & 196 & 189 & 185 & 177 \\
\hline & $\mathrm{ET}_{\mathrm{C}}(\mathrm{mm})$ & 705 & 635 & 665 & 532 & 550 \\
\hline & $\mathrm{IRR}(\mathrm{mm})$ & 699 & 631 & 633 & 531 & 527 \\
\hline & TWP $\left(\mathrm{kg} \mathrm{m}^{-3}\right)$ & 3.1 & 3.5 & 4.1 & 4.0 & 4.8 \\
\hline & $\operatorname{IWP}\left(\mathrm{kg} \mathrm{m}^{-3}\right)$ & 2.3 & 2.6 & 3.1 & 2.9 & 3.5 \\
\hline \multirow{6}{*}{$\begin{array}{l}\text { Palma del } \\
\text { Río }\end{array}$} & Crop cycle (d) & 137 & 130 & 154 & 121 & 143 \\
\hline & MDAT (DOY) & 203 & 196 & 190 & 186 & 179 \\
\hline & $\mathrm{ET}_{\mathrm{C}}(\mathrm{mm})$ & 730 & 658 & 682 & 555 & 566 \\
\hline & IRR (mm) & 768 & 697 & 697 & 592 & 580 \\
\hline & TWP $\left(\mathrm{kg} \mathrm{m}^{-3}\right)$ & 3.1 & 3.5 & 4.2 & 4.0 & 4.9 \\
\hline & IWP $\left(\mathrm{kg} \mathrm{m}^{-3}\right)$ & 2.1 & 2.3 & 2.9 & 2.6 & 3.2 \\
\hline \multirow{6}{*}{ Córdoba } & Crop cycle (d) & 138 & 131 & 154 & 121 & 143 \\
\hline & MDAT (DOY) & 204 & 197 & 191 & 187 & 180 \\
\hline & $\mathrm{ET}_{\mathrm{C}}(\mathrm{mm})$ & 713 & 643 & 673 & 539 & 562 \\
\hline & $\mathrm{IRR}(\mathrm{mm})$ & 710 & 645 & 653 & 542 & 544 \\
\hline & TWP $\left(\mathrm{kg} \mathrm{m}^{-3}\right)$ & 3.1 & 3.5 & 4.1 & 4.0 & 4.8 \\
\hline & $\operatorname{IWP}\left(\mathrm{kg} \mathrm{m}^{-3}\right)$ & 2.3 & 2.5 & 3.0 & 2.8 & 3.4 \\
\hline \multirow{6}{*}{ Granada } & Crop cycle (d) & 126 & 119 & 142 & 108 & 129 \\
\hline & MDAT (DOY) & 225 & 217 & 211 & 205 & 198 \\
\hline & $\mathrm{ET}_{\mathrm{C}}(\mathrm{mm})$ & 688 & 623 & 684 & 525 & 575 \\
\hline & IRR (mm) & 668 & 608 & 649 & 527 & 560 \\
\hline & TWP $\left(\mathrm{kg} \mathrm{m}^{-3}\right)$ & 3.2 & 3.4 & 3.9 & 3.4 & 4.1 \\
\hline & IWP $\left(\mathrm{kg} \mathrm{m}^{-3}\right)$ & 2.4 & 2.5 & 2.8 & 2.5 & 2.9 \\
\hline
\end{tabular}




\subsubsection{Extreme events}

The fHS parameter increased for all locations and for both NF and FF periods (Fig. 1.4). The increase for the future periods compared with the B period was lower in the Guadalquivir Valley locations than for Granada. The implementation of ADPS in NF resulted in a slight decrease of $\mathrm{fHS}$ in the Guadalquivir locations, and in a minor increase in FF. In Granada, the compensation was lower, increasing in both NF and FF compared with the B period.

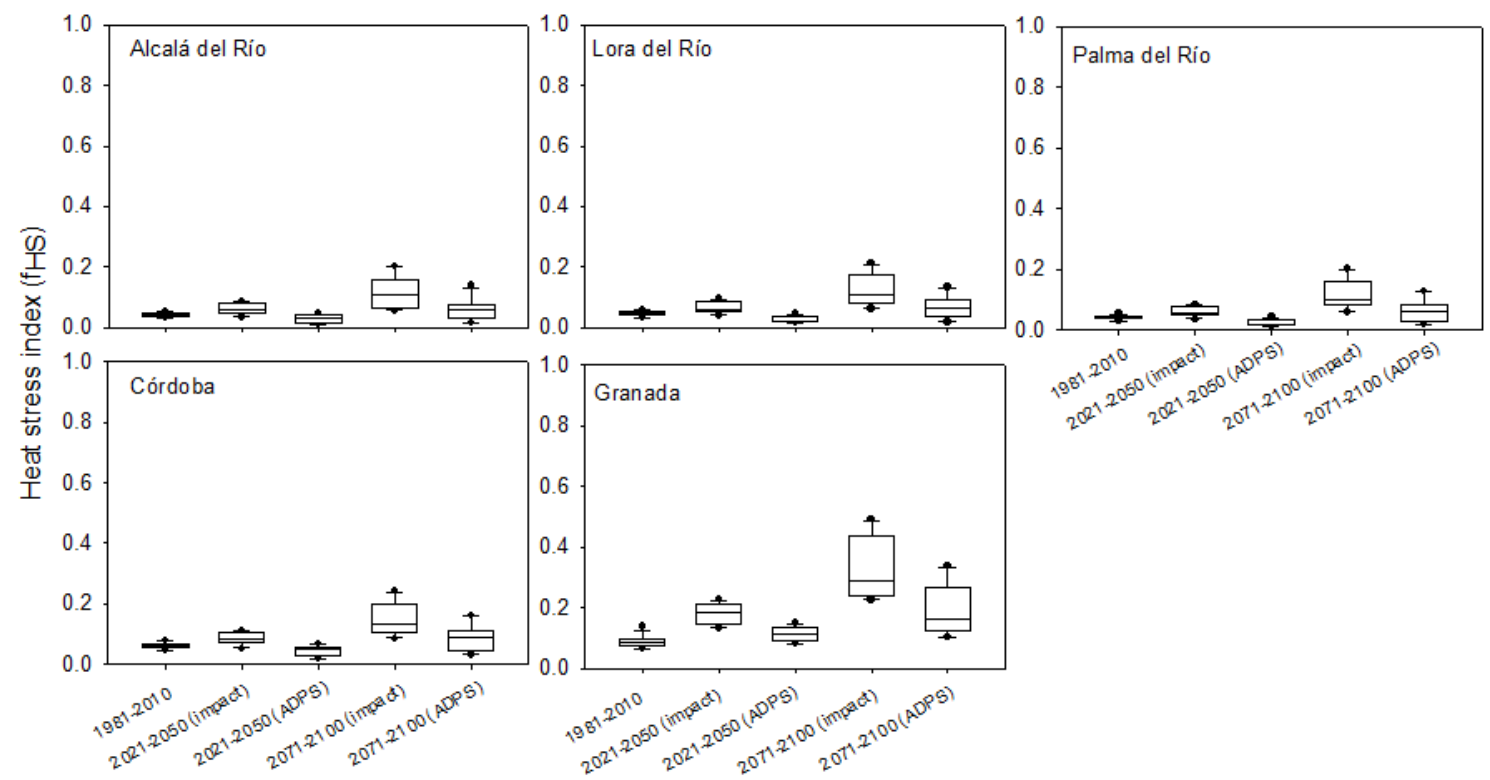

Figure 1.4 Heat stress index (fHS) for the baseline period (1981-2010), for the near future (2021-2050) without adaptation ('impact') and with the adaptation selected (ADPS, sowing date $30 \mathrm{~d}$ earlier, P5 = $850 \mathrm{GDD}$ and G3 $=9 \mathrm{mg} \mathrm{d}^{-1}$ ), and for the far future (2071-2100) without adaptation ('impact') and with the ADPS, for all locations (top to bottom: Alcalá del Río, Lora del Río, Palma del Río, Córdoba, Granada). Lower part of the box: first quartile; line in the middle: second quartile or median; upper part of the box: third quartile; point in the middle: mean; vertical lines (whiskers): maximum and minimum

The $\mathrm{fdmg}_{\mathrm{n}}$ parameter showed an increase in all locations for the future periods (Fig. 1.5), as expected due to the fHS results. This increase was more evident in Granada than in the Guadalquivir locations at the end of the $21^{\text {st }}$ century. This index was also evaluated with the ADPS adaptation for the future periods, compared with the B period without ADPS (Fig. 1.5), showing a decrease in production damage for NF at the Guadalquivir locations equal to $26 \%$, and a slight increase in Granada (5\%). This trend 
continued into the $\mathrm{FF}$, with a decrease in production damage in the Guadalquivir locations of $8 \%$ and an increase in Granada ( $8 \%$ ) compared to B.

The uncertainty of the $\mathrm{fdmg}_{\mathrm{n}}$ projections was evaluated in terms of the ensemble spread: Granada showed the highest ensemble spread for the FF period, with differences between maximum and minimum fdmg $\mathrm{f}_{n}$ values of 0.7 , compared with 0.4 for the Guadalquivir locations. Equally, FF was the period with higher spread among the projections when adaptation was simulated, for all locations (Fig. 1.5).

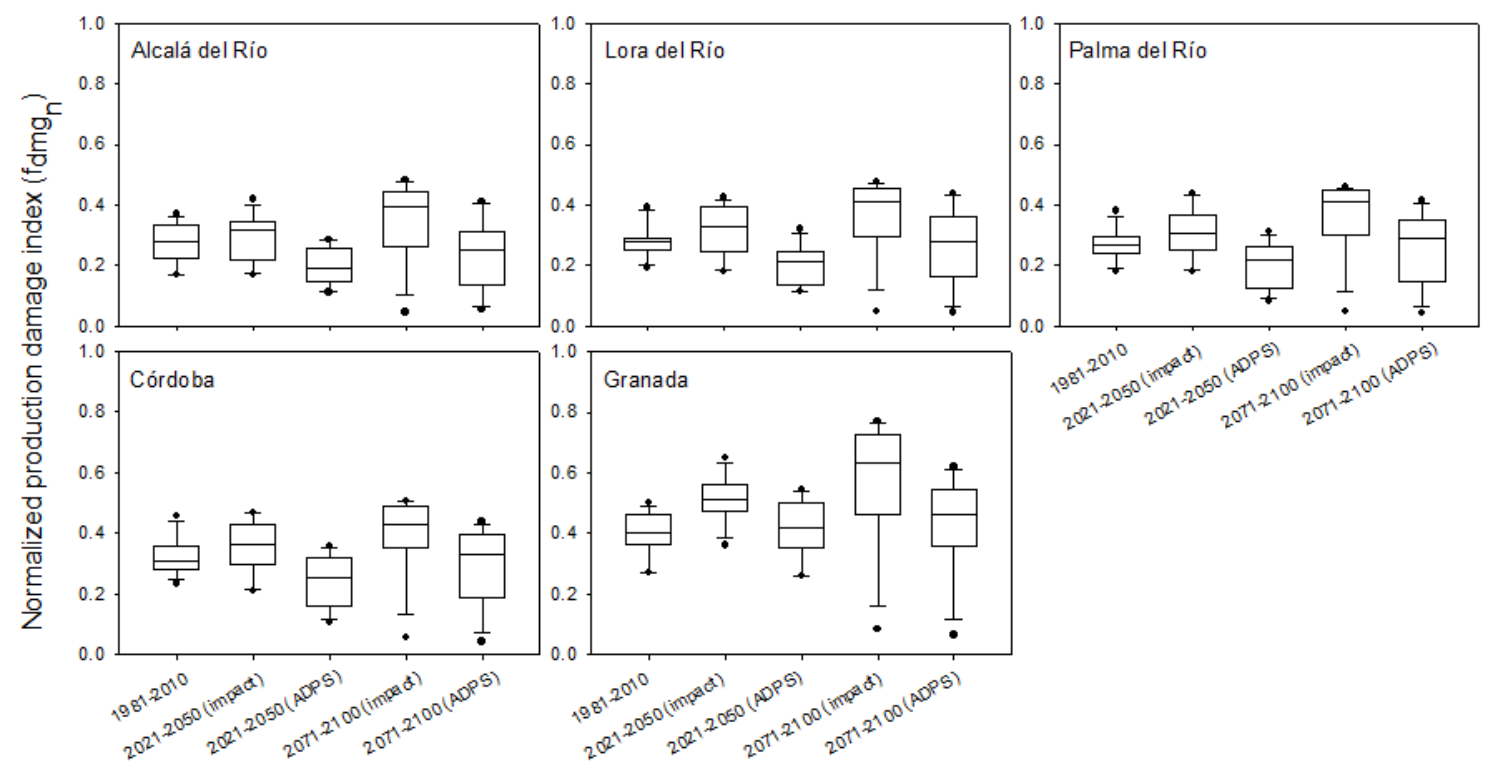

Figure 1.5. Same as for Fig. 1.4, but for normalized production damage index (fdmgn)

\subsection{DISCUSSION}

\subsubsection{Impacts}

The model parameterization and the errors of model calibration and validation were similar to those determined in previous studies (Meza et al., 2008; Vučetić 2011; Angulo et al., 2013; Moradi et al., 2013).

Granada presented different results than the other locations. Granada station is not well represented by the E-OBS grid cell. The complex orography of the Granada area has a lower altitude (633 m), compared to the mean grid altitude of $1034 \mathrm{~m}$ for both $\mathrm{E}$ OBS and ENS-EOBS. This could explain the higher bias in temperatures, which was not 
improved by bias correction. Also, this could explain why yield simulation could not be improved and why there was high uncertainty of crop projections at Granada.

In the Guadalquivir locations, yield decrease in the FF period was moderate and smaller than indicated by previous projections for the Guadalquivir basin (Guereña et al., 2001; Garrido et al., 2011; Rey et al., 2011). However, yield impacts in Granada were in agreement with those previous studies. This response at Granada could be explained because the grain-filling duration projected for the FF period decreased more than at the other locations.

The overall uncertainty of these projections is low compared to other studies (Ruiz-Ramos and Mínguez, 2010). This is a consequence of (1) conducting simulations under an optimum irrigation supply, excluding uncertainty linked to precipitation, which is usually high for the IP (Sánchez and Miguez-Macho, 2010); and (2) the use of the biascorrected ensemble ENS-OBS. Furthermore, the variability of climate conditions in the selected locations adds value to the study and increases the representativeness of the result.

\subsubsection{Agronomic adaptations}

Earlier sowing dates showed positive effects in agreement with previous studies (Tubiello et al., 2000; Moriondo et al., 2011). In Andalusia, the optimum sowing date is determined by matching the crop cycle to a period of temperatures warm enough to not limit maize growth, but cool enough to allow for a long crop cycle, and especially a long grain-filling period. Our results are relevant for adaptation studies, which usually use static sowing dates through the adaptation simulation for simplicity (e.g. Moriondo et al., 2011). A simple rule for computing the sowing date as a function of the year or decade could be more realistic and easy to implement.

Ideotypes taking advantage of the changed conditions with a longer and more efficient grain-filling period would be feasible, and breeders are currently investigating increasing leaf area duration (LAD), stay-green trait (Chen et al., 2013; Ning et al., 2013), and extending the duration of grain-filling (Tollenaar and Lee, 2011). The 2 coefficients affecting the targeted variables were modified within a feasible range, taking as reference their values from previously calibrated cultivars. The simulations confirmed 
that these changes are promising, although in Granada, further adaptations would be needed.

The combination of both strategies confirms that their effects are not additive. The objective of recovering the potential baseline yield in Granada was accomplished with the combined adaptation ADPS. Future farming will exhibit a yield gap (Cassman et al., 2003; van Ittersum et al., 2013) compared to our simulations. The crop model does not simulate some processes, such as pests and diseases that could be enhanced by longer crop cycles, together with elevated temperatures. Also, the current model description of some processes might not be robust enough under future conditions (Prasad et al., 2006). Therefore, the actual yields should be lower than our projections (ca. 36 \%; see MAGRAMA 2013 for current yields).

For crop irrigation requirements (IRR), Mínguez et al., (2005) determined increases in crop water requirements; however, Yano et al., (2007) reported an IRR reduction of $25 \%$ in 2079 for Turkey, and Guereña et al., (2001) showed a reduction of $16 \%$ for maize in Spain in 2050, due to the $\mathrm{CO}_{2}$ concentration increase. In our study, the observed decrease in estimated IRR for future periods without adaptation strategies agrees with these studies, and could be explained by: (1) reduction of the crop cycle duration due to warmer temperatures, avoiding the crop cycle going into the summer; and (2) the $\mathrm{ET}_{\mathrm{c}}$ reduction due to decreased stomatal conductance as an effect of future $\mathrm{CO}_{2}$ concentrations (Cure and Acock, 1986; Ainsworth and Long, 2005).

IRR values under the ADPS simulations were lower for the NF and FF periods than for the B period. This reduction could be due to the earlier maturity dates, avoiding the driest and hottest period for the maize crop.

The increased water productivity (TWP) in the future periods could be related to reduced stomatal conductance (Leakey et al., 2006; Vanuytrecht et al., 2012). When the adaptations were implemented, TWP and IWP increased because yield increased more than crop transpiration and irrigation water requirements, respectively. 


\subsubsection{Extreme Tmax events}

In this study, we considered daily Tmax instead day-time Tday: (1) to take into account that cultivars used in the Mediterranean region could have more heat tolerance than those of colder latitudes; and (2) to test another possible adaptation consisting of developing cultivars with further tolerance to high temperatures.

The increase in projected heat stress index resulted in an increase in production damages at the end of the $21^{\text {st }}$ century, in agreement with previous results (Beniston et al., 2007, Ruiz-Ramos et al., 2011). The adaptation strategies tested here, such as the crop cycle change and the consideration of new cultivars, diminish negative impacts at field, regional, and European levels (Olesen et al., 2011). However, our results emphasize that the adaptations for these events must be local, due to differences in the spatial pattern of extreme events (Teixeira et al., 2013).

\subsection{CONCLUSIONS}

The CERES-Maize crop model was calibrated and validated using experimental data for 5 semi-arid locations, spanning an overall time period of $9 \mathrm{yr}$, obtaining a locally tailored approach for yield and irrigation needs estimation. Analysis of how extreme events can enhance or reduce the impacts, and the effect of adaptation strategies, is essential. The methodological improvement obtained with bias correction increased the quality of the climate data inputs.

A negative impact of climate change on irrigated maize yield was simulated due to (1) the shorter crop cycle, and (2) an increase in the frequency of events generating heat stress. The implementation of adaptation strategies consisting of a combination of earlier sowing dates and cultivars with a more efficient grain-filling period could compensate both effects, and even increase the maize yield in southern Spain. In parallel, irrigation requirements were reduced around $25 \%$ for future periods compared with the baseline period, both with and without adaptation strategies, due to the reduction in $\mathrm{ET}_{\mathrm{c}}$ and higher water use efficiency. 
CHAPTER 1. Strategies for adapting maize to climate change and extreme temperatures in Andalusia, Spain

\section{Acknowledgements}

This work was financially supported by FACCE MACSUR - Modelling European Agriculture with Climate Change for Food Security, a FACCE JPI knowledge hub, by Consejería de Innovación, Ciencia y Empresa Junta de Andalucía (AGR-6126 project), and by MULCLIVAR, from the Spanish Ministerio de Economía y Competitividad (MINECO, CGL2012-38923-C02-02). We are grateful to Alfredo Sanchez for technical support. 


\section{CHAPTER 2. MODELLING THE IMPACT OF HEAT STRESS ON MAIZE YIELD FORMATION}

This Chapter is the result of a stay at University of Bonn from 01/02/2015 to $30 / 03 / 2015$, being Dr. Thomas Gaiser the supervisor of the stay.

Submitted: Gabaldón-Leal, C., Webber, H., Otegui, M., Slafer, G., Gaiser, T., Lorite, I., Ruiz-Ramos, M., and Ewert, F. (Submitted 8 April 2016. Field Crops Research Journal. Under review) 


\section{ABSTRACT}

The frequency and intensity of extreme high temperature events is expected to increase with climate change. Higher temperatures near anthesis have a large and negative effect on maize (Zea mays, L.) grain yield. While crop growth models are commonly used to assess climate change impacts on maize and other crops, it is only recently that they have accounted for such heat stress effects, despite limited field data availability for model evaluation. There is also increasing awareness but limited testing about the importance of canopy temperature as compared to air temperature for heat stress impact simulations. In this study, four independent irrigated field trials with controlled heating imposed with polyethylene tents were used to develop and evaluate a heat stress response function in the crop modeling framework SIMPLACE, in which the Lintul5 crop model was combined with a canopy temperature model. A dataset from Argentina with the temperate hybrid Nidera AX 842 MG (RM 119) were used to develop a yield reduction function based on accumulated hourly stress thermal time above a critical temperature of $34{ }^{\circ} \mathrm{C}$. A second dataset from Spain with a FAO-700 cultivar was used to evaluate the model with daily climate inputs in two sets of simulations. The first was used to calibrate SIMPLACE for conditions with no heat stress, and the second was used to evaluate SIMPLACE under conditions of heat stress using the reduction factor obtained with the Argentine dataset. Both sets of simulations were conducted twice; the heat stress function was alternatively driven with air and simulated canopy temperature. Grain yield simulated under heat stress conditions improved when using canopy temperature instead of air temperature (RMSE equal to 175 and $309 \mathrm{~g} \mathrm{~m}^{-2}$, respectively). For the irrigated and high radiative conditions, raising the critical threshold temperature for heat stress to $39{ }^{\circ} \mathrm{C}$ improved yield simulation using air temperature (RMSE: $221 \mathrm{~g} \mathrm{~m}^{-}$ $\left.{ }^{2}\right)$ without the need to simulate canopy temperature (RMSE: $175 \mathrm{~g} \mathrm{~m}^{-2}$ ). However, this approach of adjusting thresholds is only likely to work in environments where climatic variables and the level of soil water deficit are constant, such as irrigated conditions and are not appropriate for rainfed production conditions.

KEYWORDS: Heat stress; Maize; Zea mays (L); Crop models. 


\subsection{INTRODUCTION}

The frequency of extreme temperature (Alexander et al., 2006; IPCC, 2007; Orlowsky and Seneviratne, 2012) and drought (Alexander et al., 2006) events has increased across many world regions in the past 60 years, and is expected to further increase (Beniston et al., 2007; Seneviratne et al., 2012). Together with higher mean temperatures, these extreme events are expected to cause negative impacts on crop growth (Seneviratne et al., 2012; Gourdji et al., 2013). Large-scale observational studies analyzing maize yield and temperature records indicate that large yield losses are associated with even brief periods of high temperatures when crop-specific high temperature thresholds are surpassed. French maize yields over the past 50-years were found to have decreased as the number of days with maximum air temperature above $32{ }^{\circ} \mathrm{C}$ increased (Hawkins et al., 2013). Likewise, a panel analysis of maize yields in the US, determined that yield decreased with cumulative degree days above $29{ }^{\circ} \mathrm{C}$ (Schlenker and Roberts, 2009). Similarly, Lobell et al. (2011) detected maize yield losses across Sub-Saharan Africa ranging from 1 to $1.7 \%$ (depending on water availability) per each degree day above 30 ${ }^{\circ} \mathrm{C}$.

Maize yield is largely determined during a rather narrow window of time of four to five weeks bracketing silking (Fischer and Palmer, 1984; Otegui and Bonhomme, 1998). It is during this time that crop growth rates strongly determine the number of grains set (Otegui and Bonhomme, 1998), a key determinant of final grain yield (Fischer and Palmer, 1984). This is why this period is referred to as "critical" for maize yield determination with a high sensitivity to abiotic stress (Fischer and Palmer, 1984; Kiniry and Ritchie, 1985; Grant et al., 1989; Lizaso et al., 2007). The mechanisms of yield reduction with high temperatures are associated with reductions in both source and sink capacity. Equally crop development rate, photosynthesis and respiration rates also respond non-linearly to high temperatures (Lobell et al., 2011), but the reducing effects on these processes are reversed when temperatures return to optimal ranges (Rattalino Edreira and Otegui, 2012; Ordóñez et al., 2015). Nevertheless, reductions in net assimilation (photosynthesis plus respiration) that produce a marked decrease in plant growth rate can result in large yield reductions if they occur during the critical period for kernel number determination (Andrade et al., 1999, 2002). The reduction in sink 
capacity can be caused by direct high temperature effects on flowering dynamics, ovary fertilization or grain abortion, with resulting losses in grain number being irreversible (Herrero and Johnson, 1980; Rattalino Edreira et al., 2011; Ordóñez et al., 2015).

Evidence from field trials has demonstrated that when heating was performed during the critical period, reductions in maize yield were very large (Cicchino et al., 2010; Rattalino Edreira and Otegui, 2012; Ordóñez et al., 2015). These reductions were independent of the negative effects of heat on pollen viability (Rattalino Edreira et al., 2011; Ordóñez et al., 2015), and were predominantly driven by reduced ovary fertilization of pollinated spikelets exposed to temperatures above $35{ }^{\circ} \mathrm{C}$ (Dupuis and Dumas, 1990). The reduction in grain number due to kernel abortion was the main effect of high temperatures during flowering in other work (Rattalino Edreira and Otegui, 2013; Ordóñez et al., 2015).

Various studies have identified a threshold optimum temperature of about 30 (Gilmore and Rogers, 1958; Tollenaar et al., 1979) to $35^{\circ} \mathrm{C}$ (Jones and Kiniry, 1986) for maize. In field trials with controlled heating, Cicchino et al. (2010b) determined the critical optimum temperature at flowering in two years as $35.5 \pm 1.3^{\circ} \mathrm{C}$ and $32.2 \pm 1.1{ }^{\circ} \mathrm{C}$ with a temperate hybrid. Porter and Semenov (2005) reported that temperatures above $36{ }^{\circ} \mathrm{C}$ reduced pollen viability in this species. Finally, Sánchez et al. (2014) reported 37.3 and $36{ }^{\circ} \mathrm{C}$ for the flowering and grain filling period, respectively, as the threshold optimum temperature.

Some evidence suggests that the crop canopy temperature better explains yield reductions associated with surpassing high temperature thresholds better than air temperature (Craufurd et al., 2013; Siebert et al., 2014; Webber et al., 2016). The differences between air temperature and the temperature of the canopy surface can differ significantly depending on the irrigation conditions, as the irrigation have a cooling effect on the ambient that could reduce the canopy temperatures (Lobell et al., 2008) by as much as $10^{\circ} \mathrm{C}$ (Kimball et al., 2015) . However under rainfed conditions when soil water is limiting, or when transpiration rates are low due to low vapor pressure deficit, crop canopy temperature can increase above air temperature leading to yield loss from high crop temperatures (Lobell et al., 2015). The difference between air and crop canopy temperature is thought to be critical for heat stress responses as the difference of 1 - 2 
${ }^{\circ} \mathrm{C}$ can lead to large over or underestimation of yield loss from heat stress (Webber et al., 2016). While temperature gradients exist within the vertical plant profile (Rattalino Edreira et al., 2012), it may be sufficient to capture the difference between the canopy surface and air temperature for simulations at the field and larger scales.

Currently, only a few published crop models include the effects of heat stress on maize yield and its physiological determinants, such as GLAM (Challinor et al., 2005, 2004), Aquacrop (Raes et al., 2009; Steduto et al., 2012), a modified Cropsyst (Moriondo et al., 2011) or APSIM maize (Lobell et al., 2015). Additionally, other research groups are currently developing heat stress modules specific for maize such as Lizaso et al. (2016). However, no published studies have evaluated model performance under heat stress using field trials with controlled heating. Consequently, heat stress model development and testing has been limited by a lack of data from field experiments with the application of high temperatures compared to a non-heated control. This applies even more so for modelling the effect of canopy temperature as compared to air temperature. Without such data, correct attribution of heat stress is difficult to distinguish from other growth limiting factors.

This study makes use of two independent datasets collected at Argentina and Spain in which controlled heating was applied to field grown maize crops. These datasets are used to parametrize and evaluate the performance of a canopy heat stress approach to account for the negative effects of extreme high temperatures on maize grain yield. The model performance is evaluated using both air and simulated canopy temperature as inputs to the heat stress module. These functions are included in crop models to be applied at field and larger scales. 


\subsection{MATERIAL AND METHODS}

\subsubsection{Experimental data}

\subsubsection{Argentine experiments}

To develop a relationship with high temperatures, two experimental datasets obtained at Pergamino $\left(33^{\circ} 56^{\prime} \mathrm{S}, 60^{\circ} 34^{\prime} \mathrm{W}\right)$, Argentina, were used. Crops were cultivated under field conditions, but with controlled heat stress. These two experiments were carried out during two growing seasons (Table 2.1), in 2006/2007 (A1) and 2007/2008 (A2). Details of crop husbandry can be found in Cicchino et al. (2010a, 2010b). Briefly, the cultivar used was the temperate hybrid Nidera AX 842 MG, classified as 119 for relative maturity (Peterson et al., 1973). The experiments were fully fertilized and irrigation was supplied to avoid water stress. Crop management ensured minimal weed, pest and disease pressure. Two temperature regimes were applied ( $C$ : control plots; $\mathrm{H}$ : heated plots). The timing of heating was applied was an experimental treatment with two levels: GS1 heating between the appearance of the $11^{\text {th }}$ leaf (V11 of Ritchie and Hanway, 1982) and tasseling and GS2 with heating from tasseling to 15days after silking . In A1, only GS1 has applied, whereas in A2, heating was applied for each of GS1 and GS2. The duration of heating periods in GS1 and GS2 (ca. 15-20 days) was based on dates of VT and silking of control plots. Shoot biomass was estimated based on plants tagged before heating. Yield $(\mathrm{Y})$ and yield components (kernel number per plant and individual kernel weight) were determined by harvesting ears with grains of each tagged plant, oven dried until constant weight and then weighed.

Temperature regime treatments were obtained by placing polyethylene shelters over two consecutive central rows of plots to increase the temperature via the greenhouse effect created by the shelters. In the heated treatments $(H)$, the shelters reached close to the ground surface, except for one side that remained open to approximately $15 \mathrm{~cm}$ above ground level. For the control treatments (C), the South facing side remained open up to $1.4 \mathrm{~m}$ above the soil surface. The purpose of the open shelters in the $\mathrm{C}$ treatment was to avoid differences in solar radiation between treatments. Hourly records of air temperature in $\mathrm{C}$ and $\mathrm{H}$ plots were obtained by means 
of sensors (TC1047, Microchip Technologies, Chandler, AZ) installed at ear height and connected to dataloggers (Temp-Logger, Cavadevices, Buenos Aires, Argentina). Solar radiation, wind speed and relative humidity data were collected from a weather station $500 \mathrm{~m}$ from the experimental site. The Argentine experiments were used for determination of the heat stress reduction factor, but not used for simulations with the canopy heat stress model, as only the air temperature at ear level $\left(T_{\text {air_ear }}\right)$ was recorded in these experiments.

\subsubsection{Spanish experiments}

Datasets from two field experiments with controlled heating were used in the model evaluation. These two experiments were arranged into two studies, S1 and S2, each replicated for two consecutive growing seasons. The first year (2009) was conducted in Menarguens $\left(41^{\circ} 43^{\prime} 48^{\prime \prime} \mathrm{N}, 0^{\circ} 44^{\prime} 24^{\prime \prime} \mathrm{E}\right)$ and the following three years (2010, 2011,2012 ) in Algerri $\left(41^{\circ} 48^{\prime} 36^{\prime \prime} \mathrm{N}, 0^{\circ} 38^{\prime} 24^{\prime \prime} \mathrm{E}\right)$, both in Lleida, Spain (Table 2.1). Study S1 was carried out in 2009 (S1.1) and 2010 (S1.2) and S2 in 2011 (S2.1) and 2012 (S2.2). The cultivar Pioneer 31N28 (FAO-700) was used in S1.1, S1.2 and S2.1. For S2.2, Pioneer 33 Y72 (FAO700) was used. PR33Y72 is similar to PR31N28 in all traits considered. Biomass was estimated by above-ground dry weight through oven drying the samples collected in each plot at maturity. Yield and its components were measured on these same samples. Additional details are reported in Ordoñez et al. (2015). Similar to the Argentine experiments, crop management ensured that there was minimal water, nitrogen or biotic stresses during the cropping season. The temperature regimes for S1 were (i) C: a control with no imposed heating, (ii) S1_Pre: heating imposed from 15 days before silking (Silk-15d) to maturity, and (iii) S1_Post: heating imposed from 15 days after silking $($ Silk $+15 d)$ to maturity. Heating periods were about 76 days in S1. The temperature regimes for S2 were (i) C, as described above, (ii) S2_Pre: heating imposed from 7 days before silking (Silk-7d) to 9 days after silking (Silk+9d), and (iii) S2_Post: heating imposed from 14 days after silking $(S i l k+14 d)$ to 32 days after silking (Silk+32d). Heated treatments were established by means of polyethylene shelters mounted on structures of 3-3.5 m height (leaving the bottom $0.3 \mathrm{~m}$ open). As in the experiments from Agentina, elevated temperatures were obtained due to the greenhouse effect of 
the shelters. Air temperature inside the shelters was measured at tassel ( $\left.T_{\text {air_tas }}\right)$ and ear levels ( $\left.T_{\text {air_ear }}\right)$.

Tabla 2.1 Details of experiments used in the study

\begin{tabular}{|c|c|c|c|c|c|}
\hline Location & Experiment & $\begin{array}{c}\text { Harvest } \\
\text { Year }\end{array}$ & $\begin{array}{l}\text { Heating } \\
\text { treatment } \\
\text { code }\end{array}$ & $\begin{array}{l}\text { Heating } \\
\text { treatment } \\
\text { period }\end{array}$ & $\begin{array}{c}\text { Air temperature } \\
\text { measurement } \\
\text { level }\end{array}$ \\
\hline \multirow{3}{*}{ Argentina } & A1 & 2007 & $\mathrm{~A} 1 \mathrm{GS1}^{\mathrm{a}}$ & V11 to VT & Ear \\
\hline & \multirow[b]{2}{*}{$\mathrm{A} 2$} & 2008 & A2_GS1 & V11 to VT & Ear \\
\hline & & 2008 & A2_GS2 & $\begin{array}{c}\text { VT to } \\
\text { Silk+15d }\end{array}$ & Ear \\
\hline \multirow{8}{*}{ Spain } & \multirow{2}{*}{ S1.1 } & \multirow{2}{*}{2009} & & $\begin{array}{l}\text { Silk-15d to } \\
\text { Mat }\end{array}$ & Ear and tassel \\
\hline & & & S1_PostS & $\begin{array}{c}\text { Silk+15d to } \\
\text { Mat }\end{array}$ & Ear and tassel \\
\hline & \multirow{2}{*}{ S1.2 } & \multirow{2}{*}{2010} & S1_PreS & $\begin{array}{l}\text { Silk-15d to } \\
\text { Mat }\end{array}$ & Ear and tassel \\
\hline & & & S1_PostS & $\begin{array}{c}\text { Silk+15d to } \\
\text { Mat }\end{array}$ & Ear and tassel \\
\hline & \multirow{2}{*}{ S2.1 } & \multirow{2}{*}{2011} & S2_PreS & $\begin{array}{c}\text { Silk-7d to Silk } \\
+9 d\end{array}$ & Ear and tassel \\
\hline & & & S2_PostS & $\begin{array}{l}\text { Silk+14d to } \\
\text { Silk+32 }\end{array}$ & Ear and tassel \\
\hline & \multirow{2}{*}{ S2.2 } & \multirow{2}{*}{2012} & S2_PreS & $\begin{array}{l}\text { Silk-7d to Silk } \\
+9 d\end{array}$ & Ear and tassel \\
\hline & & & S2_PostS & $\begin{array}{l}\text { Silk+14 to } \\
\text { Silk+32d }\end{array}$ & Ear and tassel \\
\hline
\end{tabular}

${ }^{a}$ Abbreviations: d, days; GS, Growing stage; Mat, Maturity; PostS, Post silking heating; PreS, Pre silking heating; Silk, Silking; VT, tasseling.

\subsubsection{Model description}

The maize heat stress model was developed and tested in SIMPLACE (Scientific Impact assessment and Modeling PLatform for Advanced Crop and Ecosystem management) modeling framework (Gaiser et al., 2013) together with the Lintul5 model (Wolf, 2012), the DRUNIR water balance model (Spitters and Schapendonk, 1990; Van Oijen and Leffelaar, 2008) and the CanopyT model (Webber et al., 2016). The combined model is SIMPLACE<Lintul5, DRUNIR, CanopyT, HeatStressHourly>, further referred to as SIMPLACE <Lintul5,HS,TC>. The Lintul5 model is radiation use efficiency (RUE) based, that accounts for water and nutrient limitation. Crop development rates are a function of 24-h mean temperature above a base temperature, variety-specific parameters, and 
photoperiod sensitivity. Two parameters (TSUM1 and TSUM2) account for the thermal time required from emergence to anthesis and anthesis to maturity, respectively. Biomass growth is determined as the product of RUE and the amount of photosynthetically active radiation (PAR) that is intercepted by the crop (PARi). PARi is determined using Beer's Law as a function of the leaf area index (LAI). LAI growth is exponential, early determined by biomass accumulation and a time-varying specific leaf area (SLA). RUE also varies as a function of the crop development stage, and is reduced as a function of water stress. Water stress occurs when the crop transpiration is lower than the rate of potential transpiration. Partitioning of biomass to roots, stems, leaves and grains varies with the crop development stage, with partitioning to roots increasing under water stress. Lintul5 also has a RUE correction factor (RTMCO) that reduces RUE when daily mean temperature rises above $35^{\circ} \mathrm{C}$ throughout the entire growing season.

Consideration of canopy temperature $\left(T_{\text {can }}\right)$ allows accounting for the feedback between crop water status and crop temperature. The CanopyT model calculates hourly $\mathrm{T}_{\text {can }}$ using daily climate data with an energy balance approach correcting for atmospheric stability conditions using the Monin-Obukhov Similarity Theory (Webber et al., 2016). The model makes simplifications about the canopy resistance term to avoid the need to calculate stomatal conductance. It is assumed that the upper (warm) temperature limit $\left(T_{\text {can,upper }}\right)$ for particular weather conditions is reached when the crop does not transpire, as occurs under conditions of high water stress. Likewise, the lower (cool) temperature limit $\left(T_{\text {can,lower }}\right)$ is reached when the crop is transpiring at its maximum potential rate, as occurs under non-water limiting conditions. Actual $\mathrm{T}_{\mathrm{can}}$ is determined by interpolating between these two extremes as a function of crop water stress. This simplification renders it suitable for application in crop models aimed at field, regional and larger scales. The evaluated model approach compared very well to other approaches used to simulate $T_{\text {can }}$ (Webber et al., 2015).

The heat stress module developed here, HeatStressHourly, is based on an approach implemented in the APSIM crop model (Lobell et al., 2015), modified for hourly time steps with the possibility to use either simulated canopy $\left(T_{\text {can }}\right)$ or air temperature $\left(T_{\text {air }}\right)$. Daily minimum and maximum values of $T_{\text {air }}$ are converted to hourly values using a sinusoidal function as in Goudriaan and van Laar (1994) and Nguyen et al. 
(2014). The module developed here reduces yield (Y) as a function of the hourly stress thermal time $\left(\mathrm{TT}_{\mathrm{hs}}\right.$, in ${ }^{\circ} \mathrm{Ch}$ ) (Blumenthal et al., 1991) accumulated above a critical high temperature threshold $\left(T_{\text {crit }}\right)$ during the critical period for kernel number determination (between $300^{\circ} \mathrm{Cd}$ before and $200^{\circ} \mathrm{Cd}$ after silking, ca. 30 days bracketing silking).

\subsubsection{Simulation steps}

Model development and testing consisted of three main steps: (i) heat stress yield reduction factor determination, (ii) crop model calibration, and (iii) model validation (see Fig. 2.1). Broadly speaking, the Argentine experiments were used in Step 1 to establish the yield reduction heat stress factor (RedHS), by comparing the control and heated treatments. The Spanish dataset was used in Steps 2 and 3, for calibration (using the experiments without heat stress) and validation of the combined model SIMPLACE <Lintul5,HS,TC> with the heat stress experiments, respectively. Simulations were conducted twice using two different estimates of hourly temperature $\left(T_{h}\right)$ to calculate hourly stress thermal time ( $T_{\mathrm{hs}}$ ) (Eq. 1); first using hourly $T_{h}=T_{\text {air }}$, and secondly with hourly $T_{h}=T_{\text {can }}$, as input:

$$
T T_{h s, i}=T_{h, i}-T_{c r i t} \quad \text { Eq. [1] }
$$

Step 1: To determine RedHS based with a specified critical temperature threshold; air temperature at ear level ( $\left.T_{\text {ear }}\right)$ was used, as it can be considered the actual temperature experienced by the ear. RedHs was calculated as the reduction in $\mathrm{Y}$ per $\mathrm{TT}_{\mathrm{hs}}$, with $\mathrm{T}_{\text {crit }}=34^{\circ} \mathrm{C}$ as obtained by Cicchino et al. (2010b) with the same set of experiments. Y was normalized (Eq. 2) with the $Y$ obtained in the control treatment at each experiment, considering the $Y$ in the control as the maximum $Y$ that can be achieved in a particular year and site under the given conditions.

$$
Y_{n, i}=\frac{Y_{o i}}{Y_{m i}} \quad \text { Eq. [2] }
$$

Where, $Y_{n, i}$ is normalized $Y, Y_{0, i}$ is the observed $Y$ from the heated treatment and $Y_{m, i}$ is the maximum $Y$ observed in the control experiment, and $i$ representing the experiment.

With $\mathrm{TT}_{\mathrm{hs}, \mathrm{i}}$ and $\mathrm{Y}_{\mathrm{ni}}$ had been calculated, the RedHS was calculated as 


$$
\operatorname{RedHS}=\frac{\sum_{i=1}^{N}\left(\frac{\Delta Y_{\mathrm{n}, \mathrm{i}}}{\Delta T T_{h s, i}}\right)}{N}
$$

Where, $\Delta Y_{n}$ is the difference between the $Y_{n, i}$ for the control (equal to 1) and $Y_{n, i}$ for the heated treatment for each experiment, and $\Delta \mathrm{TT}_{\mathrm{hs}, \mathrm{i}}$ the difference between the hourly stress thermal time for the control treatment and the heated treatment. The index $i$ indicates the experiment/treatment combination (e.g. 1= A1_GS1, 2= A2_GS1 and 3=A2_GS2) and $\mathrm{N}$ the total number of experiment/treatments combinations.

Step 2: SIMPLACE <Lintul5,HS,TC> was calibrated for conditions of no heat stress using the control treatments in the Spanish dataset following the procedure shown in Fig. 2.1. The first step was to calibrate the phenology routine (anthesis and maturity dates) with the parameters TSUM1 and TSUM2. Then the biomass data were used to calibrate RUE, SLA and RGRLAI (maximum relative increase in LAI). In a final step, Y was used to calibrate FRTDM (fraction of aboveground biomass to be translocated to seeds). Final $Y$ was first simulated using the same $T_{\text {crit }}$ for both $T_{\text {can }}$ and $T_{\text {air, }}$, and later increasing the $T_{\text {crit }}$ for $T_{\text {air }}$ based on the difference in temperatures within the maize canopy (Rattalino Edreira et al., 2012).

Step 3: Validation of calibrated SIMPLACE <Lintul5,HS,TC> was performed with the heated treatments from the Spanish datasets, considering the RedHS factor obtained in Step 1 and the crop parameters calibrated in Step 2.

Steps 1 to 3 were conducted with each $T_{\text {air }}$ and $T_{\text {can, }}$ and results compared. Additionally, simulated $T_{\text {can }}$ for the Spanish experiments were compared with observed ear temperature values. 


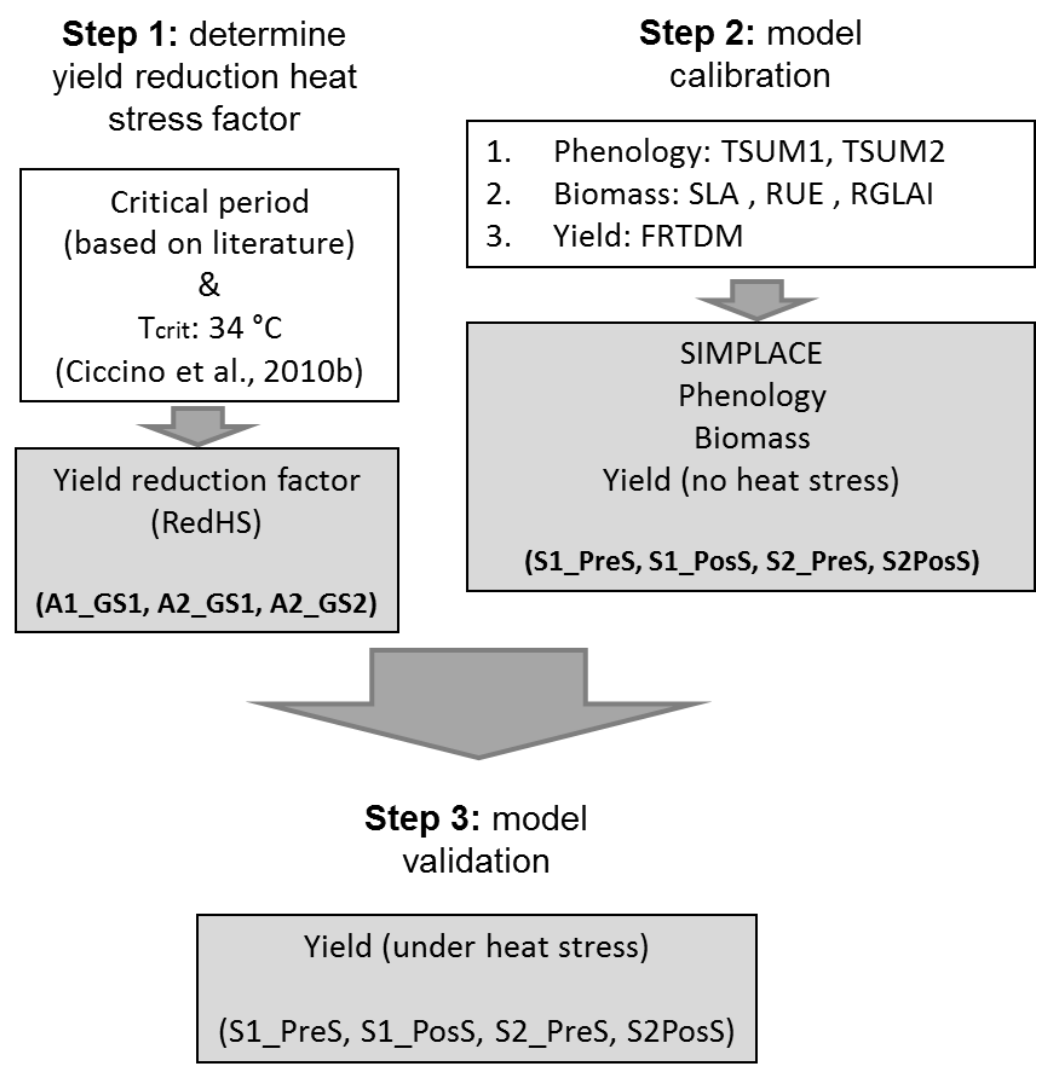

Figure 2.1. Flowchart illustrating heat stress reduction function development and evaluation procedure. The heat stress reduction factor determination (Step 1) is shown on the left, model calibration (Step 2) on the right, and model evaluation (Step 3) in the bottom. The experiment/treatment combinations considered in each step are shown in parentheses of the grey boxes.

To estimate errors in the calibration process, root mean square error (RMSE), and mean bias error (MBE) were determined as:

$$
\begin{array}{r}
R M S E=\sqrt{\frac{\sum_{i=1}^{n}\left(S_{i}-O_{i}\right)^{2}}{n}} \\
M B E=\frac{\sum_{i=1}^{n}\left(S_{i}-O_{i}\right)}{n}
\end{array}
$$

where $S_{i}$ is the simulated value and $O_{i}$ the observed value, and $i$ representing the experiment. 


\subsection{RESULTS}

\subsubsection{Step1: Determination of yield reduction heat stress factor}

$\mathrm{TT}_{\mathrm{hs}, \mathrm{i}}$ calculated with $\mathrm{T}_{\text {ear }}$ from A1_GS and A2_GS experiments (Table 2.1) and $\mathrm{T}_{\text {crit }}$ set at $34{ }^{\circ} \mathrm{C}$ showed a negative relationship with $\mathrm{Y}$ (Table 2.2). The $\mathrm{Y}$ reductions resulting from heating were larger for A2_GS1 than for A1_GS1, with a mean reduction in $\mathrm{Y}$ due to heating of $683 \mathrm{~g} \mathrm{~m}^{-2}$ (59.3\% reduction in $\left.Y_{n}\right)$. Y reduction for A2_GS2 was intermediate between these values. The relative $\mathrm{Y}$ loss per unit $\mathrm{TT}_{\mathrm{hs}}$ between the three experiment/treatment combinations was A1_GS1 > A2_GS2 > A1_GS2. The mean Y decrease per unit $\mathrm{TT}_{\mathrm{hs}}$ during the critical period, i.e. RedHS, was $-0.0025{ }^{\circ} \mathrm{Ch}^{-1}$ (Table 2.2).

Table 2.2. Relationship between hourly stress thermal time $\left(\mathrm{TT}_{\mathrm{hs}}\right)$ based on ear temperature and normalized maize grain yield $\left(Y_{n}\right)$ for the Argentine experiments with a critical threshold temperature of $34{ }^{\circ} \mathrm{C}$. The reduction heat stress factor (RedHS) represents the relationship between Yn and TThs.

\begin{tabular}{cccccc}
\hline & & $\begin{array}{c}\mathrm{TT}_{\mathrm{hs}} \\
\left({ }^{\circ} \mathrm{Ch}\right)\end{array}$ & $\begin{array}{c}\mathrm{Y} \\
\left(\mathrm{g} \mathrm{m}^{-2}\right)\end{array}$ & $\mathrm{Y}_{\mathrm{n}}$ & $\begin{array}{c}\text { RedHS } \\
\left({ }^{\circ} \mathrm{Ch}^{-1}\right)\end{array}$ \\
\hline \multirow{2}{*}{ A1_GS1 } & control & 13.6 & 1015.5 & 1 & -0.0030 \\
& heated & 186.8 & 480.3 & 0.473 & \\
\cline { 2 - 7 } A2_GS1 & control & 194.5 & 1254 & 1 & -0.0019 \\
& heated & 540.4 & 439.7 & 0.351 & \\
\cline { 2 - 7 } A2_GS2 & control & 17.1 & 1161.6 & 1 & -0.0025 \\
\cline { 3 - 6 } Mean & heated & 261.2 & 461.6 & 0.397 & \\
\cline { 2 - 6 } & & & & & -0.0025 \\
\hline
\end{tabular}

\subsubsection{Step 2. Model calibration}

The crop parameters resulting in the lowest values of RMSE and MBE for simulation of the control treatments with SIMPLACE are presented in Table 2.3. The RUE parameter value from emergence to anthesis was $2.7 \mathrm{~g} \mathrm{MJ}^{-1}$, and then decreased linearly from $2.7 \mathrm{~g} \mathrm{MJ}^{-1}$ to $2.5 \mathrm{~g} \mathrm{MJ}^{-1}$ around mid-grain filling, to $1.3 \mathrm{~g} \mathrm{MJ}^{-1}$ at maturity. The other parameters were kept constant throughout the crop cycle. 
Table 2.3. Crop parameters for cultivar FAO-700. TSUM1: thermal time from emergence to anthesis, TSUM2: thermal time from anthesis to maturity, SLA: specific leaf area, RUE: Radiation use efficiency for biomass production, RGRLAI: Maximum Relative increase in LAI and FRTDM: fraction of aboveground biomass to be translocated to seeds.

\begin{tabular}{ccccccc}
\hline & $\begin{array}{c}\text { TSUM1 } \\
\left({ }^{\circ} \mathrm{Cd}\right)\end{array}$ & $\begin{array}{c}\text { TSUM2 } \\
\left({ }^{\circ} \mathrm{Cd}\right)\end{array}$ & $\begin{array}{c}\text { SLA } \\
\left(\mathrm{m}^{2} \mathrm{~g}^{-1}\right),\end{array}$ & $\begin{array}{c}\text { RUE* } \\
\left(\mathrm{g} \mathrm{MJ}^{-1}\right)\end{array}$ & $\begin{array}{c}\text { RGRLAl } \\
\left(\mathrm{m}^{2} \mathrm{~m}^{-2} \mathrm{~d}^{-1}\right)\end{array}$ & FRTDM \\
\hline FAO-700 & 850 & 1100 & 0.014 & $2.7-2.5-1.3$ & 0.014 & 0.01 \\
\hline
\end{tabular}

* Different values corresponding to different crop development stages: $2.7 \mathrm{~g} \mathrm{MJ}^{-1}$ from emergence to anthesis; 2.7 to $2.5 \mathrm{~g} \mathrm{MJ}^{-1}$ from anthesis to mid grain filling; $2.5 \mathrm{~g} \mathrm{MJ}^{-1}$ to $1.3 \mathrm{~g} \mathrm{MJ}^{-1}$ from mid grain filling to maturity

Phenological dates from the Spanish experiments were well simulated with SIMPLACE <Lintul5,HS,TC> using the TSUM1 and TSUM2 parameters (Table 2.4). RMSE results for the anthesis and maturity date calibration were ca. 5 and 3 days, respectively.

Table 2.4. Performance of SIMPLACE <Lintul5,HS,TC> to simulate phenological dates showing simulated (sim) and observed (obs) anthesis and maturity in days after sowing (DAS) for each treatment. The root mean square error (RMSE) and mean bias error (MBE) for each cultivar are shown.

\begin{tabular}{|c|c|c|c|c|c|c|c|c|c|c|}
\hline \multirow[b]{2}{*}{ Cultivar } & \multirow[b]{2}{*}{ Year } & \multicolumn{5}{|c|}{ Anthesis (DAS) } & \multicolumn{4}{|c|}{ Maturity (DAS) } \\
\hline & & Treatment & $\operatorname{sim}$ & obs & RMSE & $\mathrm{MBE}$ & $\operatorname{sim}$ & obs & RMSE & $\mathrm{MBE}$ \\
\hline \multirow{11}{*}{$\begin{array}{l}\text { FAO } \\
700\end{array}$} & 2010 & & 87 & 83 & & & 159 & 161 & & \\
\hline & 2011 & C & 89 & 84 & & & 159 & 155 & & \\
\hline & 2012 & & 102 & 98 & & & 167 & 169 & & \\
\hline & 2009 & S1_PreS & 63 & 71 & & & -- & -- & & \\
\hline & 2009 & S1_PostS & 63 & 70 & & & -- & -- & & \\
\hline & 2010 & S1_PreS & 85 & 85 & 4.7 & 1.0 & -- & -- & 2.8 & 0.00 \\
\hline & 2010 & S1_PostS & 87 & 83 & & & -- & -- & & \\
\hline & 2011 & S2_PreS & 88 & 85 & & & -- & -- & & \\
\hline & 2011 & S2_PostS & 89 & 84 & & & -- & -- & & \\
\hline & 2012 & S2_PreS & 100 & 103 & & & -- & -- & & \\
\hline & 2012 & S2_PostS & 102 & 98 & & & -- & -- & & \\
\hline
\end{tabular}

After phenology calibration, the relationships between $T_{\text {air-tas, }} T_{\text {air-ear, }}$ and simulated $\mathrm{T}_{\mathrm{can}}$ were evaluated using S1_PreS, S1_PostS, S2_PreS and S2_PostS experiments. Simulated $\mathrm{T}_{\text {can }}$ at $14.00 \mathrm{~h}$ from the Spanish experiments was similar to observed daily maximum $T_{\text {air-ear }}$ (Fig.2.2a). During periods with heating, which did not 
entirely correspond with the critical period, the mean difference between simulated $T_{\text {can }}$ and observed $\mathrm{T}_{\text {air-ear }}$ was $0.1^{\circ} \mathrm{C}$. Both $\mathrm{T}_{\text {can }}$ and $\mathrm{T}_{\text {air-ear }}$ were lower than air temperature at tassel height (Fig.2.2b), with a mean difference between $T_{\text {air-ear }}$ and $T_{\text {air-tas }}$ of approximately $8.8^{\circ} \mathrm{C}$.

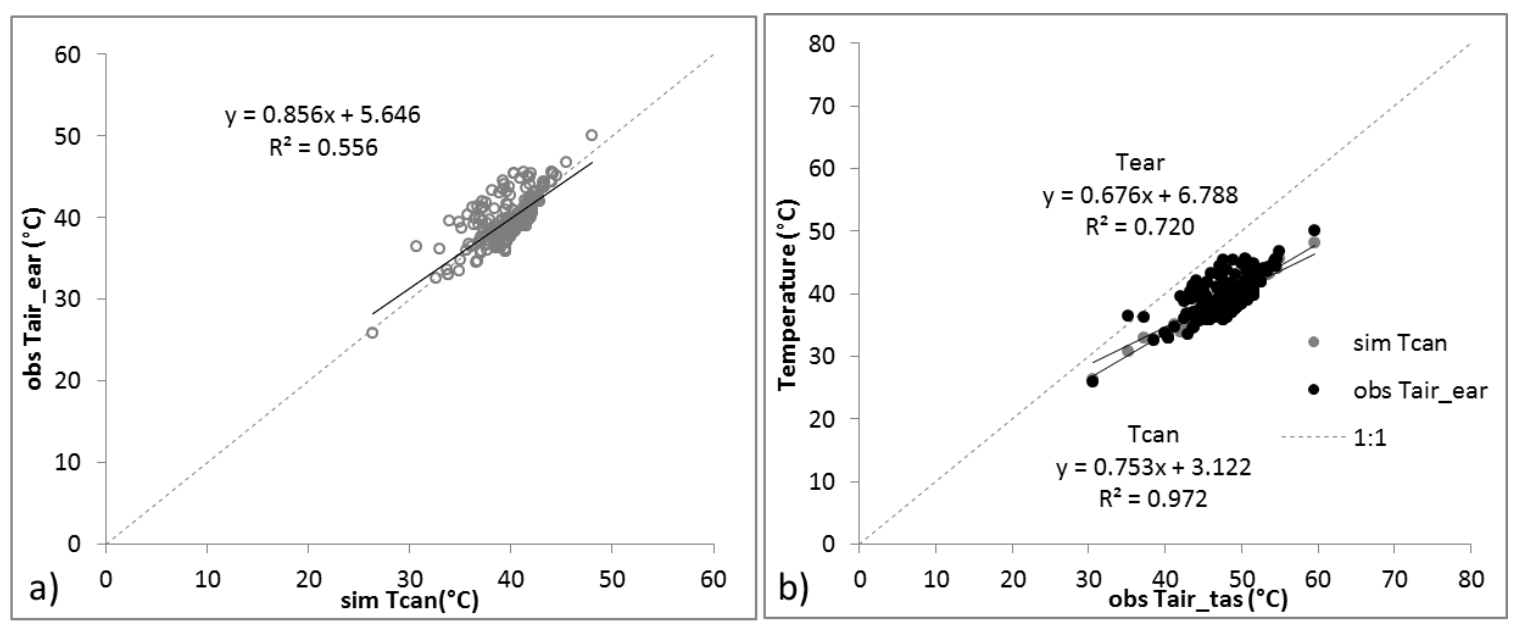

Figure 2.2. Comparison of temperatures: a) Correlation between maximum observed air temperature at ear level (obs $T_{\text {air_ear }}$ ) and simulated canopy temperature $\left(\operatorname{sim} T_{\text {can }}\right.$ ). b) Correlation between maximum observed daily air temperature at tassel height (obs $\mathbf{T}_{\text {air_tas }}$ ) and maximum observed temperature at ear level (obs $\mathrm{T}_{\text {air_ear }}$ ) as well as simulated canopy temperature $\left(\operatorname{sim} \mathrm{T}_{\text {can }}\right)$.

Simulated hourly $\mathrm{T}_{\text {air-tas }}$ for 14:00 $\mathrm{h}$ (from daily measured temperature at tassel height) and simulated $T_{\text {can }}$ at 14:00h were compared for three different periods: (1) the entire growing season, (2) the critical period $\left(-300+200{ }^{\circ} \mathrm{Cd}\right.$ around silking), and (3) the times when temperatures were above $34{ }^{\circ} \mathrm{C}$ within the critical period. Mean differences of around $5{ }^{\circ} \mathrm{C}$ were obtained between simulated $\mathrm{T}_{\text {can }}$ and $\mathrm{T}_{\text {air-tas }}$ for the heated treatments (S1_PreS/PostS and S2_PreS/PostS) during the critical period (Table 2.5). This difference increased to around $5.7{ }^{\circ} \mathrm{C}$ when the temperatures exceeded $34{ }^{\circ} \mathrm{C}$ (Table 2.5). 
Table 2.5. Differences between simulated $14.00 \mathrm{~h} \mathrm{~T}$ air (from daily measured data) and simulated $14.00 \mathrm{~h}$ $\mathrm{T}_{\text {can }}$ with SIMPLACE <Lintul5,HS,Tc> for the entire growing season, the critical period (from -300 to +200 ${ }^{\circ} \mathrm{Cd}$ around silking) and times when $\mathrm{T}_{\text {air }}$ was above $34{ }^{\circ} \mathrm{C}$ in the critical period. Standard deviation is in parenthesis.

\begin{tabular}{|c|c|c|c|c|}
\hline \multirow{2}{*}{ Treatment period } & \multirow{2}{*}{ Year } & \multicolumn{3}{|c|}{ Difference between $\mathrm{T}_{\text {air }}$ and simulated $\mathrm{T}_{\text {can }}$} \\
\hline & & Growing season & Critical period & Critical period with $\mathrm{T}_{\text {air }}>34^{\circ} \mathrm{C}$ \\
\hline & & - & - & 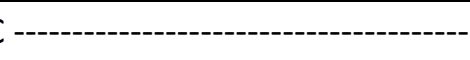 \\
\hline S1_PreS & 2009 & $-5.7(2.6)$ & $-4.5(2.3)$ & $-5.8(2.1)$ \\
\hline S1_PosS & 2009 & $-5.2(2.6)$ & $-3.7(1.6)$ & $-4.3(1.4)$ \\
\hline S1_PreS & 2010 & $-5.6(3.7)$ & $-7.6(2.4)$ & $-8.6(0.7)$ \\
\hline S1_PosS & 2010 & $-4.9(3.6)$ & $-4.1(2.6)$ & $-5.5(1.6)$ \\
\hline S2_PreS & 2011 & $-2.7(2.1)$ & $-5.0(3.3)$ & $-8.2(0.9)$ \\
\hline S2_PosS & 2011 & $-2.8(1.9)$ & $-2.7(1.5)$ & $-5.4(1.9)$ \\
\hline S2_PreS & 2012 & $-2.9(2.1)$ & $-5.2(3.2)$ & $-8.1(1.3)$ \\
\hline S2_PosS & 2012 & $-3.0(2.3)$ & $-2.5(1.2)$ & $-4.0(1.5)$ \\
\hline Mean & & -4.1 & -4.4 & -6.3 \\
\hline
\end{tabular}

After crop parameters calibration (Table 2.3), there was no difference in the model performance for simulating biomass and $Y$ of control treatments with or without use of RedHS with $T_{\text {can }}$. Thus, both models exhibited similar RMSE values for biomass with the critical threshold temperatures of $\mathrm{T}_{\text {crit }}=34{ }^{\circ} \mathrm{C}$ (Table 2.6, Fig. 2.3). However, a larger RMSE was determined when RedHS was used with $\mathrm{T}_{\text {air }}$ as input (394 vs. $373 \mathrm{~g} \mathrm{~m}^{-2}$ for biomass and 260 vs. $234 \mathrm{~g} \mathrm{~m}^{-2}$ for $\mathrm{Y}$ ). Nevertheless, the RMSE for all biomass and $Y$ estimations did not vary when $T_{\text {crit }}$ for $T_{\text {air }}$ was increase to $=39{ }^{\circ} \mathrm{C}$. This increase was due to the best match and the difference in temperature between $T_{\text {air }}$ and $T_{\text {can }}$ obtained during the critical period (Table 2.5).

Table 2.6. Root mean square error (RMSE) and mean bias error (MBE) for calibrations based on measurements performed on control treatments. Values were obtained excluding (no RedHS) or including the heat stress module (RedHS with both $\mathrm{T}_{\text {can }}$ and $\mathrm{T}_{\text {air }}$ ).

\begin{tabular}{ccccccc}
\hline Trait & Error term & no RedHS & With RedHS and $\mathrm{T}_{\text {can }}$ & With RedHS and $\mathrm{T}_{\text {air }}$ \\
\hline \multirow{5}{*}{ Biomass } & & & $\mathrm{T}_{\text {crit }}=34^{\circ} \mathrm{C}$ & $\mathrm{T}_{\text {crit }}=34^{\circ} \mathrm{C}$ & $\mathrm{T}_{\text {crit }}=39^{\circ} \mathrm{C}$ \\
\hline \multirow{5}{*}{ Grain yield } & RMSE & -373 & 373 & 394 & 373 \\
& MBE & -3 & -3 & 110 & -3 \\
\cline { 2 - 7 } & RMSE & 234 & 234 & 260 & 234 \\
& MBE & 25 & 25 & -88 & 25 \\
\hline
\end{tabular}



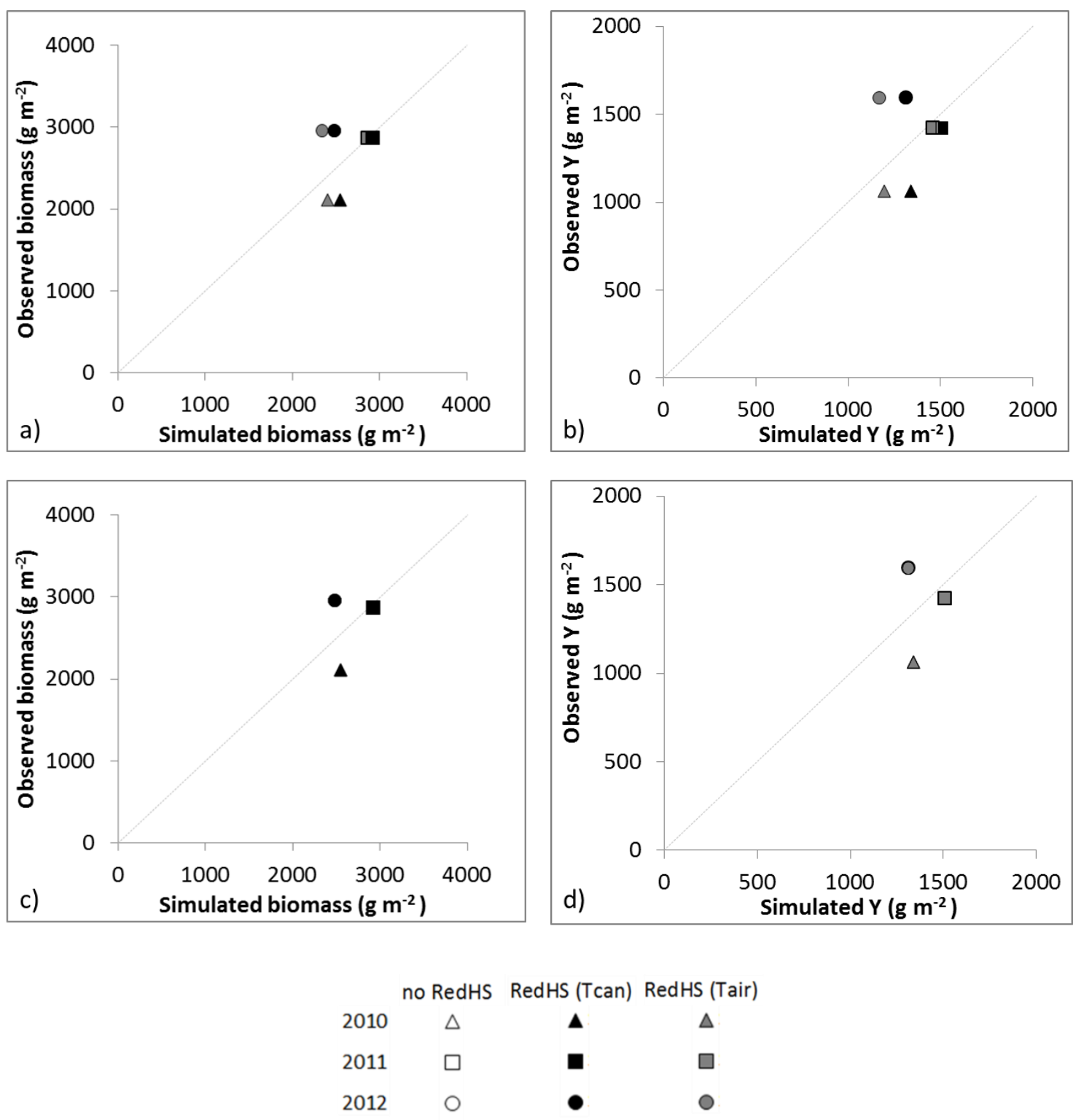

Figure 2.3. Observed and simulated values of above ground biomass and grain yield $(Y)$ for the control treatments using the model (i) without the heat stress module (no RedHS) (a and b), and (ii) with heat stress module (RedHS) including or $\mathrm{T}_{\text {air }}$ (c and d). Upper figures with $\mathrm{T}_{\text {crit }}=34^{\circ} \mathrm{C}$, and lower figures with $T_{\text {crit }}$ for $T_{\text {air }}$ up to $39{ }^{\circ} \mathrm{C}$ and $T_{\text {crit }}$ for $T_{\text {can }}$ equal to $34{ }^{\circ} \mathrm{C}$. The line in each figure represents the 1:1 relationship.

\subsubsection{Step 3. Model evaluation}

The model evaluation with the treatments with heat stress from the Spanish dataset generated an overestimation of crop biomass when the heat stress module was not included in the analysis (no RedHS), with greater error for S_PreS than for S_PostS. This bias was reduced when the heat stress module was added (RMSE declined from 497 
to $416 \mathrm{~g} \mathrm{~m}^{-2}$ ). With the inclusion of the heat stress reduction module, biomass in both treatments (S_PreS and S_PostS) was slightly underestimated. Using the same $T_{\text {crit }}$ (34 ${ }^{\circ} \mathrm{C}$ ) for $T_{\text {air }}$ and $T_{\text {can }}$, the error obtained using $T_{\text {air }}$ as an input was higher than using $T_{\text {can }}$ (RMSE: 557 vs $395 \mathrm{~g} \mathrm{~m}^{-2}$ ); however, when increasing the $\mathrm{T}_{\text {crit }}$ for $\mathrm{T}_{\text {air }}$ up to $39{ }^{\circ} \mathrm{C}$ the error was reduced though still slightly greater than that obtained with $T_{\text {can }}$ using $T_{\text {crit }}=34{ }^{\circ} \mathrm{C}$ (RMSE: 420 vs $395 \mathrm{~g} \mathrm{~m}^{-2}$ ) (Fig. 2.4, Table 2.7).

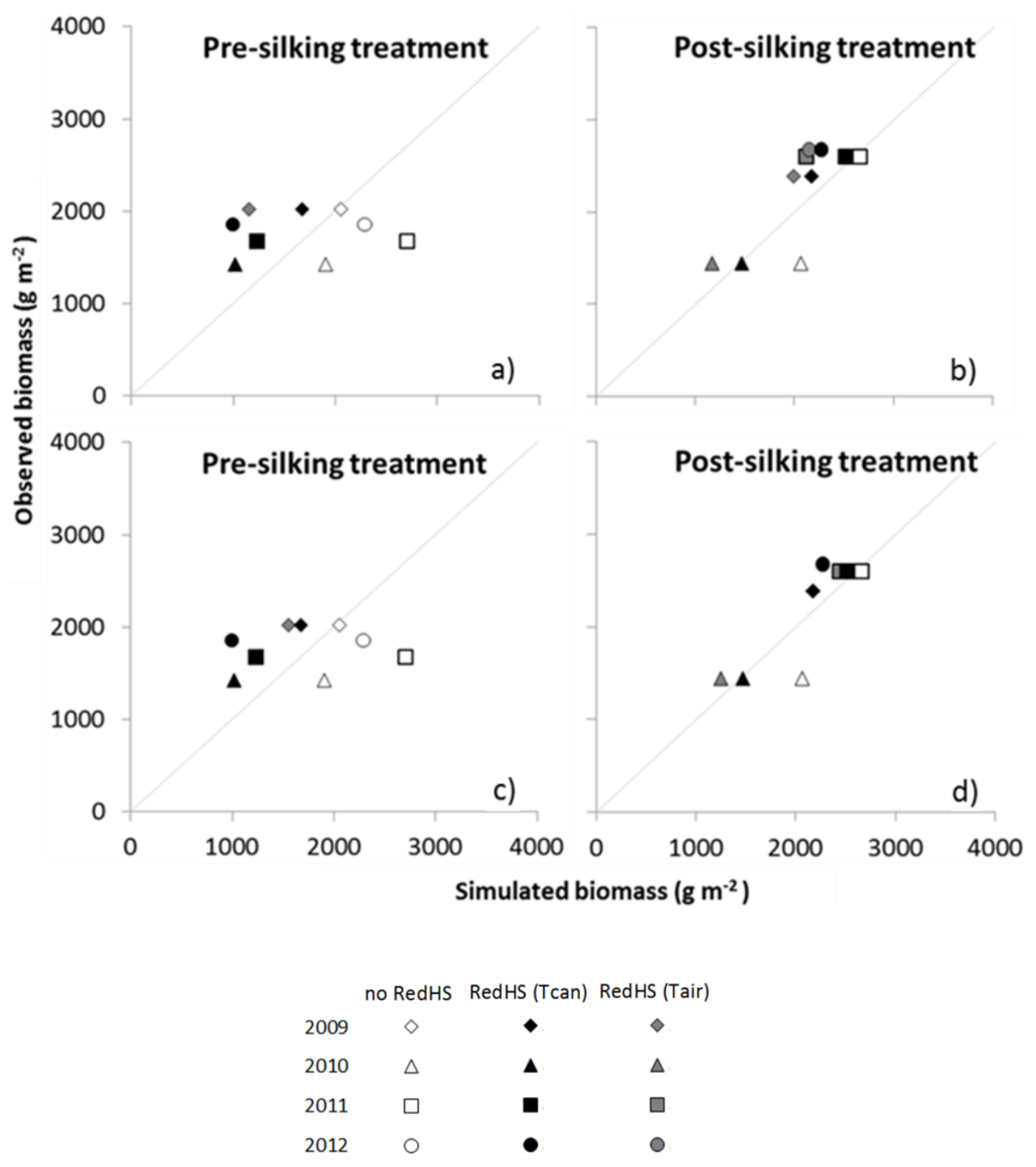

Figure 2.4 Observed and simulated values of Biomass for pre-silking heating), and post-silking heating using the model (i) without the heat stress module (no RedHS) ( $a$ and b) and (ii) with heat stress module (RedHS) including $T_{\text {can }}$ or $T_{\text {air }}$ (c and d). Upper figures with $T_{\text {crit }}$ for $T_{\text {air }}$ and $T_{\text {can }}$ equal to $34{ }^{\circ} \mathrm{C}$, and lower figures with $T_{\text {crit }}$ for $T_{\text {air }}$ up to $39^{\circ} \mathrm{C}$ and $T_{\text {crit }}$ for $T_{\text {can }}$ equal to $34^{\circ} \mathrm{C}$. The line in each figure represents the 1:1 relationship. 
Results for $\mathrm{Y}$ showed a similar trend to those for biomass, with the highest errors reported when the model without the RedHS module was used (Table 2.7). Inclusion of RedHS with $T_{\text {can }}$ as the input temperature reduced errors for both heated periods (S_PreS and S_PostS), with a greater improvement in the S_PostS treatment than in the S_PreS. When $T_{\text {crit }}$ with $T_{\text {air }}$ was increased to $39^{\circ} \mathrm{C}$, the errors were (i) lower compared to the model without RedHS, and (ii) slightly higher than using RedHS with $\mathrm{T}_{\text {can }}$ (Fig. 2.5, Table 2.7).

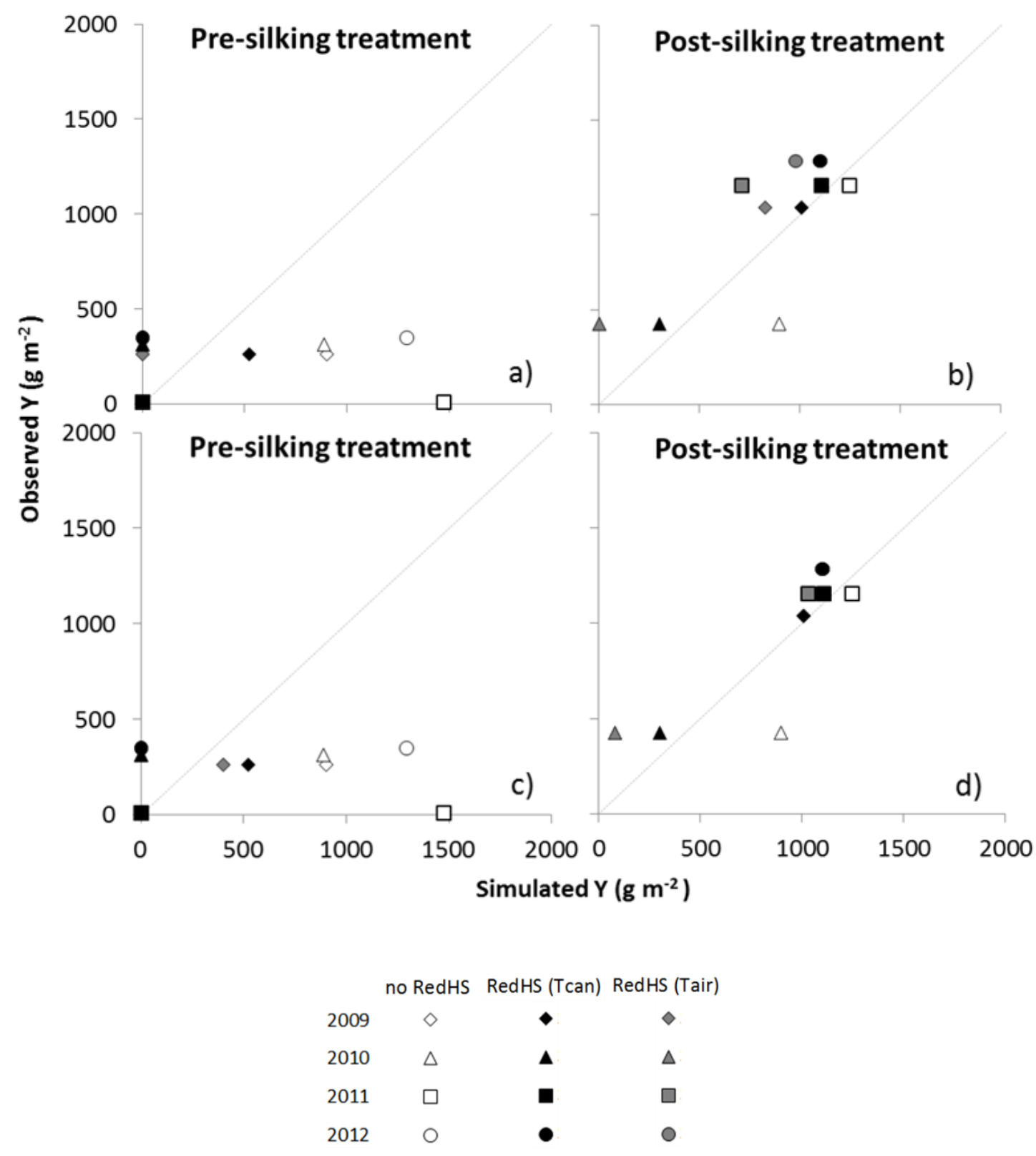

Figure 2.5. Observed and simulated values of grain yield $(Y)$ with pre-silking heating and post-silking heating using the model (i) without the heat stress module (no RedHS) (a and b) and (ii) with heat stress module (RedHS) including $T_{\text {can }}$ or $T_{\text {air }}$ (c and d).. Upper figures with $T_{\text {crit }}$ for $T_{\text {air }}$ and $T_{\text {can }}$ equal to $34^{\circ} \mathrm{C}$, lower figures with $T_{\text {crit }}$ for $T_{\text {air }}$ at $39^{\circ} \mathrm{C}$ and $T_{\text {crit }}$ for $T_{\text {can }}$ equal to $34^{\circ} \mathrm{C}$. 
Table 2.7. Root mean square error (RMSE) of simulated biomass and grain yield for treatments heated during the pre-silking (S_PreS ) or the post-silking (S_PosS) periods, obtained with the model excluding (no RedHS) and including the heat stress module (RedHs). For the latter, results based on canopy $\left(T_{\text {can }}\right)$ or air $\left(T_{\text {air }}\right)$ temperatures are present, considering $T_{\text {crit }}$ for $T_{\text {air }}$ and $T_{\text {can }}$ equal to $34^{\circ} \mathrm{C}$, and $T_{\text {crit }}$ for $T_{\text {air }}$ up to $39{ }^{\circ} \mathrm{C}$ and $\mathrm{T}_{\text {crit }}$ for $\mathrm{T}_{\text {can }}$ equal to $34^{\circ} \mathrm{C}$. Data correspond to the heated treatments.

\begin{tabular}{cccccc}
\hline \multirow{2}{*}{ RMSE } & $\begin{array}{c}\text { Treatment } \\
\text { period }\end{array}$ & no RedHS & RedHS using $\mathrm{T}_{\text {can }}$ & \multicolumn{2}{c}{ RedHS using $\mathrm{T}_{\text {air }}$} \\
& & $-\mathrm{T}_{\text {crit }}=34{ }^{\circ} \mathrm{C}$ & $\mathrm{T}_{\text {crit }}=34{ }^{\circ} \mathrm{C}$ & $\mathrm{T}_{\text {crit }}=39{ }^{\circ} \mathrm{C}$ \\
\hline \multirow{4}{*}{ Biomass } & S_PreS & 606 & 557 & 685 & 579 \\
& S_PosS & 387 & 233 & 428 & 260 \\
& Mean & 497 & 395 & 557 & 420 \\
\hline \multirow{5}{*}{ Grain } & & & & & \\
yield & S_PreS & 917 & 235 & 258 & 235 \\
\hline & S_PosS & 257 & 116 & 361 & 207 \\
\hline & Mean & 587 & 175 & 309 & 221 \\
\hline
\end{tabular}

In addition to the action of RedHS reducing $Y$ on hours when the respective $T_{\text {crit }}$ was exceeded, a reduction factor acting on RUE in response to daily mean temperatures above $35{ }^{\circ} \mathrm{C}$ (RTMCO) may also additionally reduce new biomass production and resultant partitioning to yield due to heat stress. The relationship between these two sources of reduction in $Y$ is shown in Fig. 2.6. Results showed equal reductions due to reductions in RUE (RTMCO) and the action of the RedHS response in most of the experiments. However, for the S_PreS of the years (2010, 2011 and 2012) when the critical and heating periods matched, yield reductions were more relevant (approximately $40 \%$ higher) due to the heat stress (RedHS) than for RTMCO (Fig.2.6).
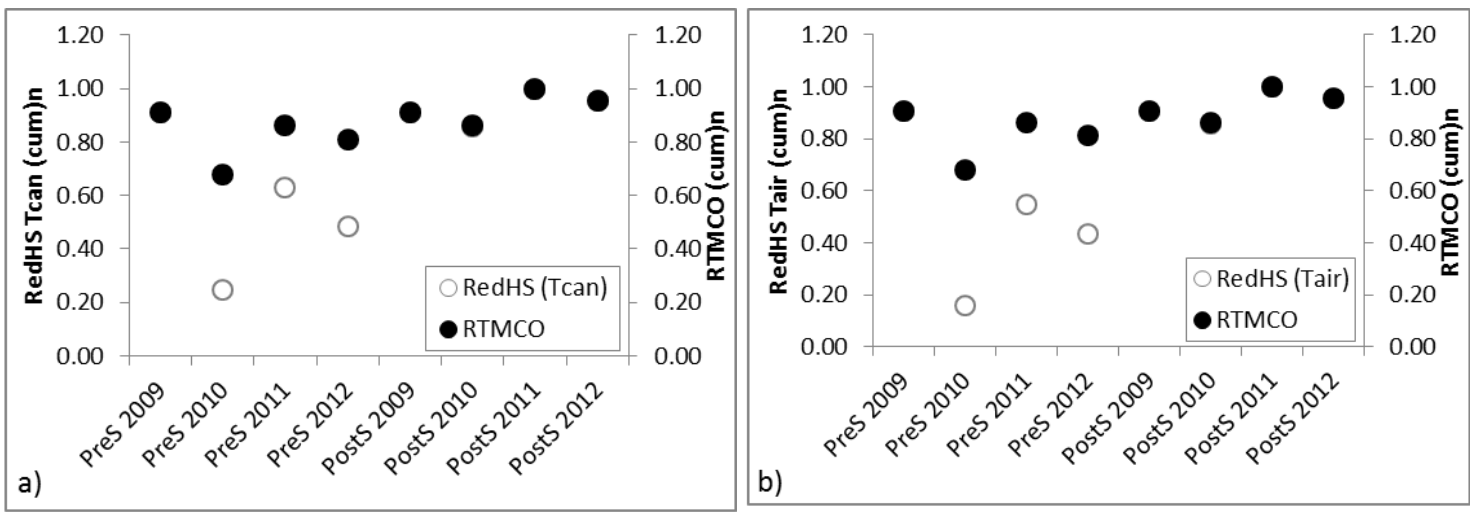

Figure 2.6 Variation of the heat stress reduction factor (RedHS, in normalized units) across heat stress treatments, and its response to the introduction of a correction factor applied to the radiation use efficiency values during critical phase in LINTUL5 (RTMCOn, normalized) for (a) Tcan and (b) Tair. 


\subsection{DISCUSSION}

There is growing consensus that the frequency and magnitude of high temperature events will increase with climate change (Tebaldi et al., 2006; Field et al., 2012) and that these high temperature events will likely lead to increased incidence of heat stress for crops (Schlenker and Roberts, 2009; Lobell et al., 2013; Trnka et al., 2014). It has been emphasized that crop models must be improved to consider the effects of heat stress for both large (Ewert et al., 2015; Rezaei et al., 2015) and local (García-López et al., 2014; Gabaldón et al., 2015) scale assessments of climate change impacts on cropping systems. A challenge for model improvement is often the lack of field experiments with control trials to test model responses, in this case, of imposing high temperatures. A related challenge for simulating heat stress under field conditions and at larger scales is to account for the interaction between water and heat stresses that cannot be accounted for by considering only air temperature (Webber et al., 2016). This is the first study we are aware of in which a heat stress response in a maize crop growth model has been tested with field data from two different datasets from two contrasting world regions, Argentina's Rolling Pampas (isohygrous) and the NE-E Spain (Mediterranean regime).

The goal of the study was to develop and evaluate a model suitable for application in large scale climate change and adaptation impact assessments. The results showed that the model tested in this study (SIMPLACE <Lintul5,HS,TC>) was able to reproduce maize biomass growth and yield of maize grown under high temperature conditions near flowering. The model reduced yield as a function of accumulated stress thermal time during the critical period for $Y$ formation bracketing silking. In the model, the direct heat stress effects on grain was accounted for in a heat stress reduction function, parameterized with the data from Argentina, and validated with the experimental data from Spain. Additionally, RUE is reduced when daily mean temperature is greater than $35{ }^{\circ} \mathrm{C}$. The evaluation showed that the model performs well with a slight underestimation of the effects of heat stress in the Spanish experiments (Fig. 2.4 and 5). However, different cultivars used in the Argentine and Spanish experiments though neither the RedHS factor nor $\mathrm{T}_{\text {crit }}$ were not re-calibrated between experiments. Therefore these parameters may be considered to have general validity for 
long cycle maize varieties and be appropriate for use under climate change conditions, due to the higher temperatures projected at the end of the $21^{\text {st }}$ century.

The heat stress reduction factor using $T_{\text {can }}$ performed better than that using $T_{\text {air }}$ when the critical threshold temperature determined in Cicchino et al. (2010a) was used. This critical threshold is also close to values reported in other studies on the sensitivity of maize yield formation to high temperature (Herrero and Johnson 1980; Dupuis and Dumas, 1990). However, in the conditions of the Spanish validation experiments, evaporative cooling was high due to irrigation combined with high radiation and a high vapor pressure deficit, similar to the conditions of Arizona reported in Kimball et al. (2015). As a result, the crop was consistently several degrees cooler than the ambient air, such that $\mathrm{T}_{\text {crit }}$ used in RedHS with air temperature could be increased to $39{ }^{\circ} \mathrm{C}$ to account for this cooling. In this case, yield simulations had a similar performance as compared to using $\mathrm{T}_{\text {crit }}=34^{\circ} \mathrm{C}$ in RedHS with canopy temperature, with only slightly larger error. Therefore, under irrigated conditions and environmental conditions like those tested in the Spanish conditions (Webber et al., 2016), if estimation of $T_{c a n}$ is not possible, it may be reasonable to increase $T_{\text {crit }}$ when air temperature is used to determine heat stress effects. This approach is not expected to be valid under rainfed conditions when both water availability and the atmospheric demand are more variable. Collectively, using air temperature to simulate heat stress effects, $T_{\text {crit }}$ would need to be increased after rainfall events on clear, dry days, but decreased on hot humid days, or when soil water was limiting. This uncertainty in the response highlights the need to increase the number of field experiments combining heat stress with water availability in order to obtain an accurate approach valid for any climate conditions and crop water status.

The aim of the study was to develop a heat stress response function together with a canopy temperature model for application in regional climate change impact and adaptation assessment studies, rather than to explicitly simulate the detailed mechanism of heat stress. However, a reflection on the main processes causing large yield losses in field trials with controlled heating is compared to processes captured in the model in response to high temperature. Rattalino Edreira et al. (2011, 2012, 2013) indicated that reduction in yield is explained by both a reduction in RUE (-3 to $33 \%$ of 
final biomass) as well as a failure of reproductive processes such as ovary pollination and fertilization together with an increased kernel abortion, all conducive to a reduction in kernel numbers of ca. $60 \%$. We are potentially double counting some of the effects of high temperature with the heat stress reduction function RedHS as it is calculated based on the reduction in yield in the heated treatments as a function of the accumulation of $\mathrm{TT}_{\mathrm{hs}}$ above $\mathrm{T}_{\text {crit }}$ in the experiments from Argentina, in which $\mathrm{Y}$ losses were due to both a failure of reproductive processes and a reduction in RUE. A next step in our model development is to examine how the response of RUE to temperatures greater than $35^{\circ} \mathrm{C}$ correlates with $\mathrm{TT}_{\mathrm{hs}}$ and reduces the RedHS factor in proportion to the amount of heat stress that is already accounted for in RTMCO. However, this relationship between the high temperature dependence of RTMCO and RedHS is expected to vary with the environment depending on the magnitude of diurnal temperature variation.

Another aspect of crop growth and development known to be affected by high temperatures is phenology. Thus, there is evidence to suggest that high temperatures delay flowering (Cicchino et al., 2010a). The error of 5 days in the date of anthesis demonstrates that the model presented here does not contain a response of development rate to extreme high temperatures. This fact should be included in future model improvements in order to obtain an improved yield simulation, as specification of the critical period depends on accurate simulation of the flowering.

Beyond the processes captured in the model, there are two limitations of the study. Firstly, the model was only tested using irrigated trials. Using our canopy temperature model, we hypothesized to be able to account for interaction between crop temperature and levels of soil water stress, though this has not been tested to date for either the canopy temperature model, nor for the heat stress module. Further model testing and experimental datasets are critical for extending the model to these conditions, as many world regions with the largest food security challenges (e.g. SubSaharan Africa) rely on rainfed production, and high temperatures and drought events are likely to coincide. A related limitation is that the trials were conducted under nonnutrient limiting conditions, which are not the case for many rainfed maize systems, particularly in tropical regions. A second limitation is related to the data used for model development and model testing. While these experiments are unique for maize in 
imposing controlled heat stress under field grown conditions, they did present challenges for model testing. The reduction in incident solar radiation due to the polyethylene film was not a severe artefact, but reduced wind speed and increased relative humidity may represent an important bias from many natural conditions. To some extent these variables were measured in the experiments, and reliable estimates generated when required. Ideally for modeling studies, weather stations would be installed for each heat treatment. This raises the more general need for increasing collaboration between modelers and experimentalists - from physiologist to agronomists and engineers. Such collaboration can inform and support model development, as well as support experimental design such that datasets are more fully useful and valid for model improvement. The synergistic relationship extends beyond the sharing of data for model improvement to enabling better science by bringing both sets of knowledge together and systemizing what is known about crop response to climatic factors. This collaboration should be strengthened and facilitated, particularly in joint proposals and experiment planning.

\subsection{CONCLUSION}

Climate change will bring higher temperatures and increased risk of heat stress in cereal crops. Despite crop models being widely used to assess climate change impacts on crops, models have only recently included heat stress responses. This study presented a model to simulate the impacts of high temperatures on maize yield. The model estimated grain yield reductions based on accumulated hourly stress thermal time above a critical threshold temperature in the critical period around flowering. The model was developed and tested with six experiments that used controlled heating conditions in Argentina and Spain. The model performance was better when simulated canopy temperature was used as an input to heat stress function. For satisfactory performance with air temperature, the critical threshold for heat stress was increased from $34{ }^{\circ} \mathrm{C}$, which is a physiologically meaningful threshold, to $39{ }^{\circ} \mathrm{C}$, as the crops were considerably cooler than the air due to ambient cooling caused by irrigation. Increasing the critical temperature is an alternative option to the use of air temperature with the heat stress reduction function in irrigated conditions, but is not expected to be suitable 
under rainfed conditions. This study has reinforced the potential for greater collaboration between modelers and experimentalists.

\section{Acknowledgements}

This study has been financially supported by FACCE MACSUR - Modelling European Agriculture with Climate Change for Food Security, a FACCE JPI knowledge hub, by AGR6126 project funded by the Consejería de Innovación, Ciencia y Empresa (Junta de Andalucía). MO acknowledges funding from the Univ. of Buenos Aires (UBACYT 00493BA). HW, TG and FE contributions were funded by the Federal Ministry of Education and Research (BMBF) through WASCAL (West African Science Service Center on Climate Change and Adapted Land Use). Additionally, FE received supported from the German Science Foundation (project EW 119/5-1) and the FACCE JPI MACSUR project (031A103B) through the German Federal Ministry of Education and Research. 


\section{CHAPTER 3. IMPACT OF CHANGES IN MEAN AND EXTREME TEMPERATURES CAUSED BY CLIMATE CHANGE ON OLIVE FLOWERING AT SOUTHERN SPAIN}

To be submitted: Gabaldón-Leal, C., Ruiz-Ramos, M., de la Rosa, R., León, L., Rodríguez, A., Belaj, A. and Lorite, I.J. (International Journal of Climatology) 


\section{ABSTRACT}

Due to the severe increase in the foreseen temperatures in the future and the great economic and social importance of olive growing for vast agricultural areas in the Mediterranean Basin, accurate climate change impact assessment on olive orchards is required. The aim of this study was to assess the flowering date and the impact of mean and extreme temperature events on olive flowering at southern Spain under baseline and forced climate conditions. For such a purpose, experimental data were obtained from ten olive genotypes: six well-known olive cultivars in the region, one cultivar, 'Chiquitita', obtained from conventional breeding, and three wild olives from Canary Islands. A site-specific model calibration was conducted, obtaining a satisfactory performance with average error for flowering date estimation equal to 2 days for baseline and future climate conditions. The outputs from twelve climate regional models from the ENSEMBLES European project with a bias correction in temperature and precipitation were used. An advance in the olive flowering dates of about 17 days at the end of the $21^{\text {st }}$ century compared with baseline period (1981-2010), and an increase in the frequency of extreme events around flowering were found. A spatial analysis of results allowed determining those areas at southern Spain with higher vulnerability to climate change impact caused by the lack of chilling hours accumulation (areas located at Atlantic Ocean coast and the South-East coast) and by the occurrence of high temperatures during flowering (areas located at North and Northern-East of Andalusia region).

KEYWORDS: olive trees, climate change, southern Spain, ENSEMBLES projections, flowering date 


\subsection{INTRODUCTION}

Olive (Olea europaea L.) has been cultivated in the Iberian Peninsula since second century BC (International Olive Council, 2014). Currently, Spain is the leading world olive oil producer with around $40 \%$ of the global production (FAOSTAT, 2016). The southern Spanish region of Andalusia represents the first national olive oil producer with $80 \%$ of the national production (1.1M tons; CAPDR, 2016a). Olive cultivation in Andalusia plays an important social role as it generates a high rate of employment per surface unit and provides around $32 \%$ of total agriculture employees in the region (CAPDR, 2008). Due to this economic and social importance of olive crop in Andalusia, a detailed analysis of the impacts of climate change on Mediterranean olive orchards at mid- and long-term is required.

Climate projections provided by the last Intergovernmental Panel on Climate Change AR5 (IPCC, 2014) foresee a global increase in mean temperature around $2{ }^{\circ} \mathrm{C}$ by the end of the 21st century. However, the projections of temperature increase are around $4{ }^{\circ} \mathrm{C}$ for Andalusia region during the warmest months (Giorgi and Lionello, 2008; Giannakopoulos et al., 2009). In addition, although high degree of uncertainty due to the difference in model projections has been reported as consequence of the errors for estimating the annual and seasonal variations and across seasons for the region, the climate projections indicate a likely rainfall decrease (CEDEX, 2011) and some authors coincide to forecast an increase in the inter-annual rainfall variability for the Iberian Peninsula (Vicente-Serrano et al., 2011).

Considering the foreseen future climate conditions, some studies have evaluated the impact of climate change on olive yield, projecting a yield decrease at the end of 21st century due to the combined effect of increased mean and extreme temperatures, reduced precipitation (Koubouris et al., 2009; Viola et al., 2013), and increased net irrigation requirements (Rodríguez Díaz et al., 2007; Tanasijevic et al., 2014). However, to understand the impacts of climate change on crop yield is essential the analysis of the effects of such change, especially the temperature and daylength changes, on its phenology (Lieth, 1974; Schwartz, 1999; Sadras and Calderini, 2009). Numerous studies focused specially on temperature have been carried out for a wide range of agricultural species. These studies have demonstrated variations in the phenological phases 
associated to changes in air temperature (Bradley et al., 1999; Schwartz, 1999) and then, warm springs cause advances in the beginning of the growing period (Menzel, 2000; Chmielewski and Rötzer, 2001; Ahas et al., 2002). Similarly, an advancement of the pollen season is strongly correlated with higher temperatures (van Vliet et al., 2002). Furthermore, in the recent past a decrease in the accumulated chilling units for several crop trees around the world has been observed, as for example for olive trees in California over the last 50 years (Baldocchi and Wong, 2008).

For olive, as for many others crops, the flowering is a key phenological stage due to the sensitivity to extreme events related with heat and water stress during this period affecting significantly to the final oil yield (Ayerza and Sibbett., 2001; Rapoport et al., 2012). Traditionally, olive flowering date estimation has been carried out by pollen capturing (Galán et al., 2005; Bonofiglio et al., 2008; Avolio et al., 2012; Orlandi et al., 2013) or by simulation models based on phenological observations (Orlandi et al., 2005a). For flowering date simulation, different approaches have been considered, such as taking in to account both the chilling and heating requirements (Garcia-Mozo et al., 2000; De Melo-Abreu et al., 2004; Galán et al., 2005; Aguilera et al., 2014), or simpler approaches uniquely considering heating requirements with a fixed starting spring date (Orlandi et al., 2010a, 2010b).

Two main procedures have been considered for the estimation of olive chilling requirements. One is based on the methodology described by Richardson et al. (1974) that considers an upper temperature threshold for penalty of chilling accumulation. This threshold for olive varied in a wide range (from 12 to $20.7^{\circ} \mathrm{C}$ ) according to De MeloAbreu et al. (2004), Orlandi et al. (2006) and Aguilera et al. (2014). In the second approach (Aron, 1983) the chilling hours are accumulated without any penalty when temperatures are below a threshold. This threshold for olive ranges from 7 to $7.2{ }^{\circ} \mathrm{C}$ according to De Melo-Abreu et al. (2004) and Galán et al. (2005). Other authors such as Fornaciari et al. (1998) and El Yaacoubi et al. (2014) suggest that olive has not consistent chilling requirements and then, flowering is highly dependent to heat accumulation. For heat accumulation, the most widely used method considers the Growing Degree Days (GDD), in which heat units are accumulated when the mean daily temperature exceeds a threshold. Very different values of this threshold have been reported for olive on several 
studies carried out in the Mediterranean area ranging from 5 to $23^{\circ} \mathrm{C}$, depending of the cultivar and location (De Melo-Abreu et al. 2004, Galán et al. 2005, Orlandi et al. 2005a, 2010a; Aguilera et al. 2014).

Future flowering dates could be estimated through the mentioned phenological models together with future climate projections data provided by Global Climate Models (GCMs) or Regional Climate Models (RCMs). RCMs simulate spatial climate at higher resolution than the GCMs, being their added value more evident in orographically complex areas such as the Iberian Peninsula (Guereña et al., 2001). However, projections from these climate models present biases regarding local observations (Déqué et al., 2007) that increase the uncertainty of the impact projections (Olesen et al., 2007; Carter, 2010; Ruiz-Ramos and Mínguez, 2010). Considering these RCMs changes in the crop phenology have been reported. Thus, a decrease in chilling unit accumulation has been foreseen for a range of tree crops such as olive, peach, vineyard and apple in Spain under future climate conditions (Pérez-López et al., 2012). This reduction could generate lack of fulfilment of the chilling accumulation requirements that could lead to a failed or poor flowering stage (Hartmann and Porlingis, 1957). Additional changes in phenology for olive have been reported, even when chilling requirements are met, detecting an advance of around one week in olive flowering date per $1{ }^{\circ} \mathrm{C}$ of mean temperature increase (Orlandi et al., 2010c; Avolio et al., 2012), which would result in an advance of 2 weeks of the flowering date at the end of $21^{\text {st }}$ century under Southern Spain climate conditions (Galán et al., 2005).

Due to the wide ranges reported in the calibration of key phenological parameters and for some contradictory results related with the chill accumulation requirements previously described, the modelling of the flowering date for olive is affected by a huge uncertainty. The present work aims to mitigate these inaccuracies by generating reduced uncertainty projections of flowering date and of occurrence of extreme events during the flowering stage for olive at southern Spain at the end of $21^{\text {st }}$ century. To achieve this objective, results and conclusions are based on experimental data obtained under baseline and forced climate conditions and on phenological modelling. In addition, a spatial analysis for determining the vulnerability of current olive 
growing areas and for identifying those potential suitable areas for olive cultivation under the future foreseen climate conditions was carried out.

\subsection{MATERIAL AND METHODS}

\subsubsection{Study area}

Andalusia region is located at southern Spain (Fig. 3.1) and presents a wide range of climatic and orographic conditions. Average annual precipitation for the period 19712000 ranged between 200 to more $1500 \mathrm{~mm}$, being the mayor part of Andalusia around $500-750 \mathrm{~mm}$. For the same period, annual mean temperatures ranged between $8-10{ }^{\circ} \mathrm{C}$ in the mountainous area located at Eastern of Andalusia to up to $20^{\circ} \mathrm{C}$ in the South-East Coast, with average mean temperatures around $18{ }^{\circ} \mathrm{C}$ in the Guadalquivir Valley (Agroclimatic Information Network of Andalusia, RIA). Equally, orography varied significantly, from flat areas within the Guadalquivir Valley to mountainous areas, mainly located at the North and East of the region (Supplement Fig A.1).

Olive area in Andalusia covers around 1.4 Mha and is concentrated mainly at the mid- and upper section of the Guadalquivir Valley (Fig. 3.1). In order to evaluate the olive phenology and the occurrence of extreme events under different climate conditions, eight representative locations were selected to summarize the results obtained in the study: Osuna, Antequera, Cordoba, Baena, Martos and Baeza located in the main olive cultivated areas, and Jerez and Seville located outside of them (Fig. 3.1).

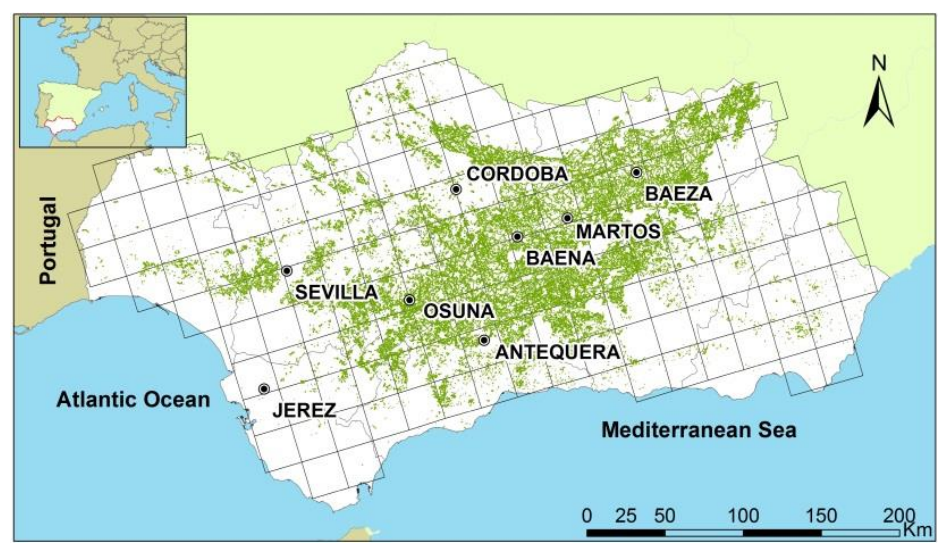

Figure 3.1.Common grid from ENSEMBLES project and ENS-Spain02 dataset over Andalusia including olive cultivated area and some representative locations considered in the study. 


\subsubsection{Experimental design and measurements}

An experimental study for the evaluation and calibration of models for the assessment of olive flowering date described in Section 3.2.4 was conducted in the facilities of IFAPA-Alameda del Obispo, located in Córdoba (Andalusia), southern Spain $\left(37.85^{\circ} \mathrm{N}, 4.8^{\circ} \mathrm{W}\right)$, at an altitude of $110 \mathrm{~m}$ a.s.l. (Fig. 3.1). The area is characterized by a Mediterranean climate with an annual mean temperature of $17.6{ }^{\circ} \mathrm{C}$ and $536 \mathrm{~mm}$ of accumulated rainfall (Spanish Meteorological Agency, AEMET). Ten olive genotypes were considered in the study. Six of them are traditional cultivars originating in southern Spain ('Hojiblanca' and 'Picual'), north-eastern Spain ('Arbequina' and 'Arbosana'), Greece ('Koroneiki') and Italy ('Frantoio'). In addition, a new cultivar ('Chiquitita') obtained by systematic breeding from the cross 'Picual' x 'Arbequina' (Rallo et al., 2008) was also evaluated. The remaining three genotypes ('FV18', 'GM22' and 'GM25') are wild olives that belong to Olea europaea subsp. guanchica and originating at Canary Islands. These wild olive trees are adapted to the subtropical climate of the Islands with annual mean temperatures of $20^{\circ} \mathrm{C}$, and a limited annual oscillation between maximum and minimum temperatures of around $6^{\circ} \mathrm{C}$.

Thirty-two trees per genotype two-years-old and with a mean height of $1.5 \mathrm{~m}$ were grown in five litter pots filled of peat. The trees were split in two groups in separate environments that reproduced baseline and future climate conditions, respectively. One group with 16 trees (four blocks with four repetitions per cultivar) was located outdoors $(\mathrm{OU})$; the other group with 16 trees was maintained inside a greenhouse $(\mathrm{GH})$ under controlled climate conditions from $1^{\text {st }}$ of October 2013 . The $\mathrm{OU}$ experiment represented baseline climate conditions, while the $\mathrm{GH}$ experiment was set to reproduce the projected temperature increase at the end of $21^{\text {st }}$ century. Temperature control in the GH was regulated by a heating and cooling system, windows and a moving thermal blanket. $\mathrm{OU}$ and $\mathrm{GH}$ temperature and humidity were measured and collected every 10 minutes by two data-logger with build-it sensors (Tinitag Ultra 2 TGU-4500) located at $2 \mathrm{~m}$ above the ground (ca. $0.5 \mathrm{~m}$ above the plants). Both OU and GH experiments were irrigated at optimal rate to consider as much as possible uniquely the effect of temperature on phenology. 
The monthly Tmax differences between GH and OU, DTmax (GH-OU), ranged from $3.4^{\circ} \mathrm{C}$ in March to $8.8^{\circ} \mathrm{C}$ in November (Fig. 3.2), while differences in monthly Tmin, DTmin (GH-OU), ranged between $1.7^{\circ} \mathrm{C}$ in December and $3.3{ }^{\circ} \mathrm{C}$ in May. Considering ENS-Spain02 database and comparing far future (FF) and baseline (B) periods, the DTmax (FF-B) ranged from $2.7^{\circ} \mathrm{C}$ in December to $5.6{ }^{\circ} \mathrm{C}$ in May and for DTmin (FF-B) from $2.1^{\circ} \mathrm{C}$ in March to $4.1^{\circ} \mathrm{C}$ in May. For all the months, the difference between DTmax (GH-OU) and DTmax (FF-B) was below $0.5{ }^{\circ} \mathrm{C}$, except for the months May, October and November. Equally, the difference between DTmin (GH-OU) and DTmin (FF-B) was below $0.6{ }^{\circ} \mathrm{C}$ for all the months (Fig 3.2). Daily maximum and minimum temperatures for both experimental conditions are shown in the Fig A.1 (Supplement).

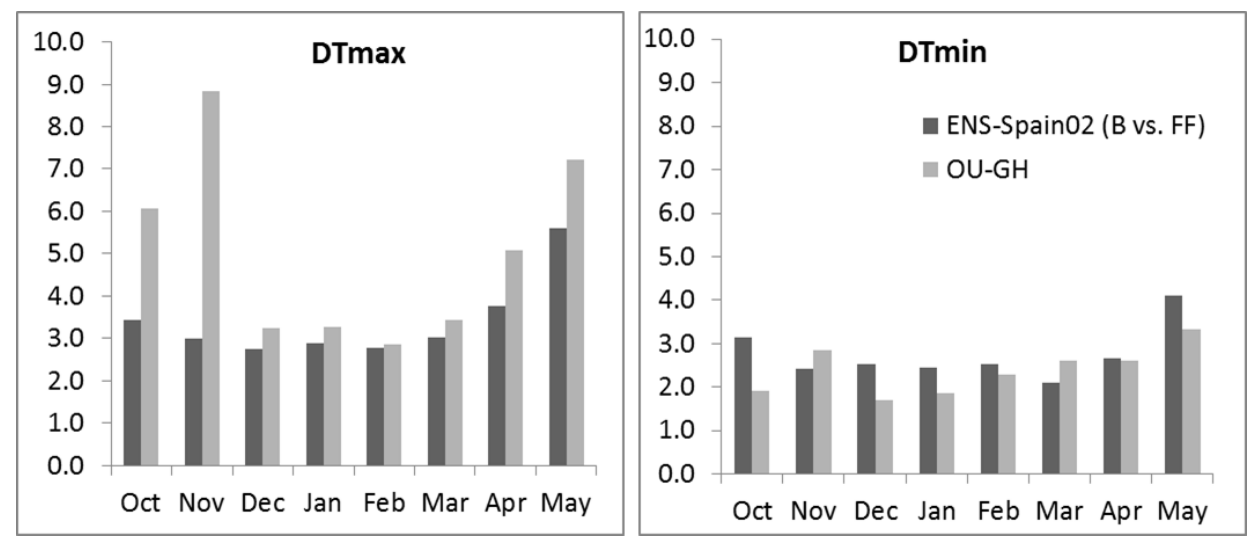

Figure 3.2. Monthly differences for maximum temperature (DTmax) and minimum temperature (DTmin) $\left({ }^{\circ} \mathrm{C}\right)$ obtained with the ENS-Spain02 for the baseline period (1981-2010) and far future (2071-2100) periods, and those obtained between the temperatures outdoors (OU) and inside greenhouse (GH).

The full bloom phase was defined according to De Andrés (1974), and was established as the date when at least $50 \%$ of the flowers were opened, and was identified by visual observation in repeated field visits (Orlandi et al., 2002, 2005a, 2005c; Oteros et al., 2013) carried out during the flowering period.

\subsubsection{Baseline and projected climate for southern Spain}

Simulated daily climate data for Andalusia under baseline and future conditions were obtained from the ENS-Spain02 ensemble of climate models (Ruiz-Ramos et al., 2015), which consist of bias-corrected projections from twelve RCMs from the ENSEMBLES European project (www.ensembles-eu.org) corresponding to the SRES A1B scenario (Nakićenović et al., 2000). For ENS-Spain02, temperature and precipitation bias 
of RCM outputs were corrected following Dosio and Paruolo (2011), using transfer functions with regard to the observational gridded dataset Spain02 (Herrera et al., 2012). Spain02 is developed for continental Spain and the Balearic Islands with 2756 quality-controlled stations, covering the period from 1950 to 2007, with a spatial resolution of $25 \mathrm{~km}$. ENS-Spain2 provided the daily values of minimum (Tmin) and maximum temperature (Tmax) required by the phenological models. Hourly temperature records required for chilling unit accumulation was obtained from the daily maximum and minimum temperatures with the methodology provided by De Wit et al. (1978).

Andalusia region encompasses 145 ENS-Spain02 grid cells (Fig. 3.1). The analyzed periods were 1981-2000 (baseline, B), 2021-2050 (near future, NF) and 2071-2100 (far future, FF). Compared with B period, an increase in mean temperature (Tmean) for Andalusia is projected by the ensemble mean of ENS-Spain02 for both future periods (NF and FF), for all seasons (Fig. 3.3). Thus, compared with B period, for autumn Tmean increased 1.2 and $3{ }^{\circ} \mathrm{C}$, for winter 1.1 and $2.6{ }^{\circ} \mathrm{C}$, for spring 1 and $3.5{ }^{\circ} \mathrm{C}$, and for summer, 1.5 and $4.3^{\circ} \mathrm{C}$ for NF and FF, respectively. 


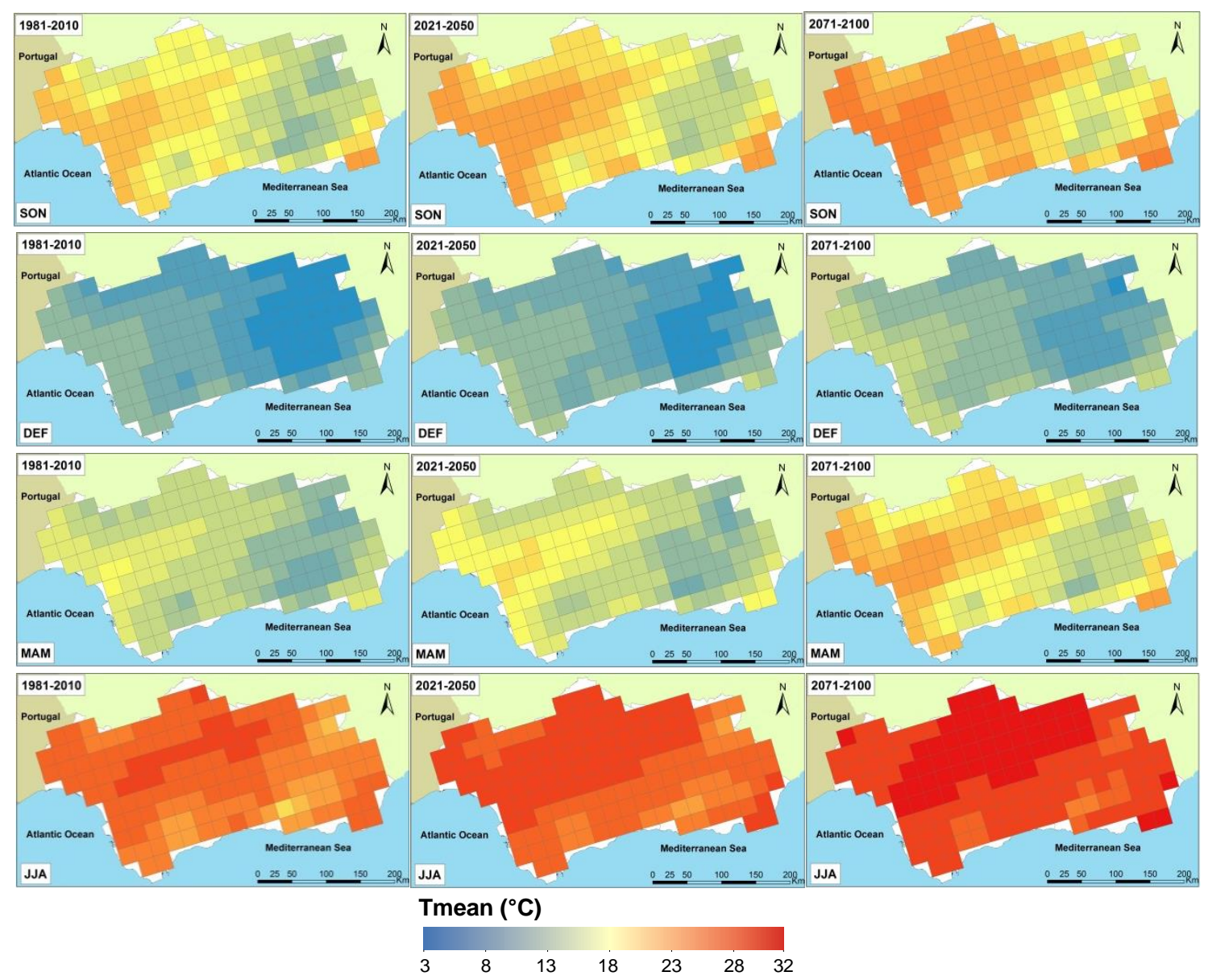

Figure 3.3. ENS-Spain02 ensemble mean for mean temperature (Tmean) projected for autumn (SON), winter (DJF), spring (MAM) and summer (JJA), for the baseline (1981-2010), near future (2021-2050) and far future (2071-2100) periods.

\subsubsection{Approaches for flowering date estimation}

Given the diverse approaches proposed for estimating olive flowering dates, in a first step three methods were considered: 1) taking into account the chilling hours accumulation, calculated depending on the hourly temperature, taking into a account a lower, optimum and breakpoint temperature above which a penalty is applied, followed by a heating accumulation period until flowering, 2 ) the chilling hours were accumulated if the hourly temperature is below a threshold, followed by a heating accumulation period until flowering and 3) only considering a heating accumulation period. The parameters provided by De Melo-Abreu et al. (2004) for each method were considered in the study and are identified hereafter with the subscript "org" as the original values. These three methods were evaluated for the cultivars 'Arbequina', 'Hojiblanca' and 
'Picual', as these were the cultivars from our database in common with De Melo-Abreu et al. (2004) study.

Method 1 considers three specie-parameters for the chilling accumulation: optimal temperature (To), breakpoint temperature $(T x)$ above which a dimensionless penalty constant $(p)$ is applied, and the heating accumulation base temperature (Tb), with original fixed values equal to $7.3^{\circ} \mathrm{C}, 20.7{ }^{\circ} \mathrm{C},-0.56$ and $9.1{ }^{\circ} \mathrm{C}$, respectively (De Melo-Abreu et al., 2004). Specific cultivar-parameters were the requirement of accumulated chilling hours starting on $1^{\text {st }}$ October (TU) and the thermal time (TT) achieved for the flowering date. This method was evaluated for OU and GH conditions by fixing the TU value provided by De Melo-Abreu et al. (2004) (TUorg) and calculating the difference in days between the date when TTorg value was achieved and the observed flowering date (obtaining the observed TT value). Method 2 considers two specie-parameters, the limit temperature for chilling accumulation (Tlim) and the base temperature $(\mathrm{Tb})$ for the thermal time-based period with values equal to $7^{\circ} \mathrm{C}$ and $8.8^{\circ} \mathrm{C}$, respectively (De Melo-Abreu et al., 2004). This method was evaluated with the same procedure than in Method 1. Method 3 does not consider chilling requirements but uniquely one specie-parameter (Tb), equal to $8.5^{\circ} \mathrm{C}$, and one cultivar-parameter, $\mathrm{TT}$. This method was evaluated by calculating the difference in days between the date when TTorg was reached and the observed flowering date (obtaining the observed TT value), similar to Method 1. For this method the starting date for TT computation was established on the $1^{\text {st }}$ February (De Melo-Abreu et al., 2004; Tanasijevic et al., 2014). A sketch of the procedure for determining the errors from each method is shown in the Fig. 3.4. 


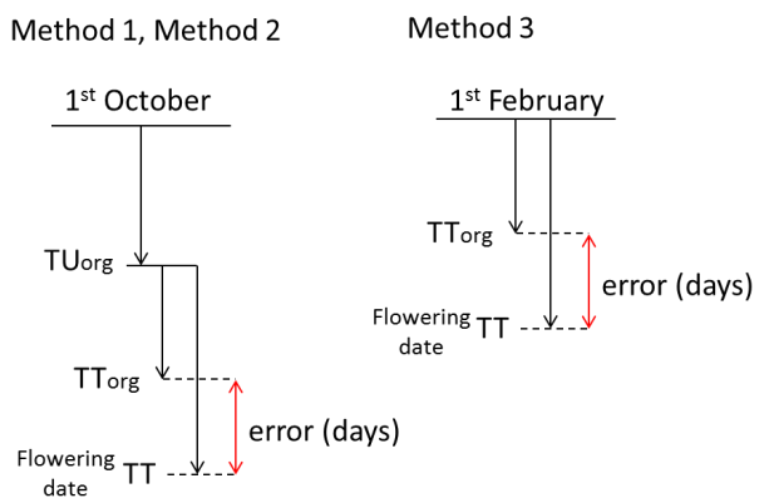

Figure 3.4. Illustrative scheme describing the errors obtained with each method. TUorg: chilling units from the original De Melo Abreu et al. (2004) study; TTorg: thermal time from the original De Melo Abreu et al. (2004) study; TT: thermal time at the observed flowering date.

In a second step, a new approach was developed for estimating the flowering date based on the experimental data obtained from the ten olive genotypes described in Section 3.2.2. and the performance of the previously described methods. The proposed method, hereafter called Method 4, was divided in two independent processes. The first process is based on the existence of chilling requirements to achieve the olive flowering, previously described by Orlandi et al. (2004), Galán et al. (2005) and Aguilera et al. (2014). Due to the lack of experimental data to determine the specific chilling requirements for the cultivars considered in this study, a range of chilling requirements was considered for all the cultivars, following to De Melo-Abreu et al. (2004). Thus, TU values were set to a maximum, a mean and a minimum value: $T U m a x=722 \mathrm{U}$, TUmean= $467 \mathrm{U}$ and TUmin $=302 \mathrm{U}$. Then, dates of the end of dormancy (EDO) were estimated when these TU values were reached. This procedure also allowed measuring the EDO uncertainty by calculating the coefficient of variation (CV, \%) between dates for a same grid cell. This approach also determines whether chilling requirements are met, indicating flowering failure if the requirements are not fulfilled. The second simulated process in Method 4 was the heat accumulation until the flowering date, as the Method 3. The starting date for heat accumulation and the Tb parameter previously considered in Method 3 were evaluated. Three starting dates $\left(1^{\text {st }}\right.$ January, $1^{\text {st }}$ February and $1^{\text {st }}$ March) and twelve Tb values from 5 to $12.5^{\circ} \mathrm{C}$ were tested. The performance of the Method 4 was evaluated by analyzing the simulated flowering date and the GDD reached at flowering under $\mathrm{OU}$ and $\mathrm{GH}$ conditions. 


\subsubsection{Evaluation of olive vulnerability to extreme events}

Flowering dates for the 145 cells comprising Andalusia region were simulated applying the twelve members (RCM outputs) of the ENS-Spain02 ensemble (see Section 3.2.3.) to the phenological method that provided the best performance (see Section 3.2.4), once this was locally calibrated with the experimental data described in Section 3.2.2. Once the flowering date for each cell, genotype and ensemble member of climate was estimated, the vulnerability caused by the occurrence of extreme Tmax events during flowering was assessed considering the effective pollination period (EPP) in order to obtain the sensitive flowering period. In this study EPP was set to 7 days after flowering for all the genotypes, being in the range of previous studies (Arzani and Javady, 2002; Orlandi et al., 2005b; Cuevas et al., 2009). Once EPP period was estimated for each cell, genotype, year and ensemble member, the vulnerability was assessed by calculating for the baseline and projected climate conditions the number of days during EPP with Tmax above a fixed threshold (hs1d) and the number of events with at least three consecutive days during EPP with Tmax above a fixed threshold (hs3d), following Ruiz-Ramos et al. (2011). Three thresholds were selected $\left(30,35\right.$ and $\left.40{ }^{\circ} \mathrm{C}\right)$ to consider highly, medium and low cultivar sensitivity, respectively. These values were chosen according to previous studies of pollen viability under in vitro conditions and high temperature carried out by Fernández-Escobar et al. (1983) and Koubouris et al. (2009).

Finally, the spatial analysis of chilling requirements (using $\mathrm{TU}_{\text {mean }}=467 \mathrm{U}$, as the mean chilling requirements determined in De Melo-Abreu et al. (2004) together with the maps of percentage of years with at least one event with Tmax above $35{ }^{\circ} \mathrm{C}$ during FF period allowed a general characterization of vulnerable and suitable areas for olive cultivation across Andalusia region in the future. 


\subsection{RESULTS}

\subsubsection{Observed phenological behavior for olive crop under baseline and future climate conditions}

Observed mean average flowering date for the ten genotypes considered in the study was $8^{\text {th }}$ May (128 DOY) for OU conditions and $29^{\text {th }}$ April (119 DOY) for GH conditions, indicating an advance of around nine days (from 6 to 14 days depending on genotype) between trees located under OU conditions compared to those located in the $\mathrm{GH}$ experiment (Table 3.1). The average observed range of flowering dates for the analysed olive genotypes under $\mathrm{OU}$ and GH conditions was around 25 days, from 114 to 135 DOY and from 120 to 144 DOY for OU and GH, respectively. 'Arbequina' and 'Koroneiki' cultivars showed the earliest flowering dates for both conditions (120 and 114 DOY, for OU and GH, respectively) although other genotypes as 'Chiquitita', 'Frantoio' and 'Picual' showed similar flowering dates than 'Arbequina' and 'Koroneiki' in GH conditions (Table 3.1). In the opposite case the wild olive genotypes 'GM22' and 'GM25' had the most delayed flowering dates (138 and 130 DOY for OU and GH, respectively, Table 3.1).

Table 3.1. Observed thermal time requirements for flowering (in growing degree days, GDD), and flowering dates (in day of year, DOY) for each genotype using the Method 4 with the optimum parameterisation (starting of heat accumulation on $1^{\text {st }}$ March and $\mathrm{Tb}=5^{\circ} \mathrm{C}$ ) and observed climate data, for both outdoors (OU) and greenhouse (GH) conditions.

\begin{tabular}{cccccc} 
& \multicolumn{3}{c}{ DOY (OU) } & \multicolumn{2}{c}{ DOY (GH) } \\
\cline { 2 - 6 } & GDD & Observed & Simulated & Observed & Simulated \\
\hline Arbequina & 717 & 120 & 123 & 114 & 111 \\
Arbosana & 769 & 126 & 126 & 116 & 114 \\
Chiquitita & 787 & 128 & 127 & 114 & 115 \\
Frantoio & 769 & 126 & 126 & 114 & 114 \\
FV18 & 846 & 128 & 130 & 120 & 118 \\
GM22 & 1140 & 144 & 149 & 134 & 131 \\
GM25 & 1140 & 142 & 149 & 135 & 131 \\
Hojiblanca & 768 & 124 & 126 & 116 & 114 \\
Koroneiki & 717 & 120 & 123 & 114 & 111 \\
Picual & 760 & 125 & 125 & 114 & 114 \\
\hline
\end{tabular}




\subsubsection{Performance of phenological model parameters under}

\section{baseline and future climate conditions}

Considering Method 1 the estimated flowering dates were around 3-6 days earlier than the observed ones under the OU conditions for 'Arbequina', 'Hojiblanca' and 'Picual' and under GH conditions the flowering dates were 19-25 days earlier than observed (Table 3.2). Testing the Method 2, the differences between observed and estimated flowering dates were even larger than with Method 1; the estimated flowering date under OU conditions was 5-9 days earlier than observed, and under GH conditions the differences increased until 28-32 days in advance (Table 3.2). Finally, the differences between observed and estimated flowering dates with Method 3 were smaller, varying between 2-5 days and 13-14 days earlier than observed under OU and GH conditions, respectively (Table 3.2).

For Method 4 the parameterisation that provided the smallest differences between observed and estimated flowering dates under both $\mathrm{OU}$ and $\mathrm{GH}$ conditions was considering the starting date for heat accumulation on $1^{\text {st }}$ of March and $T_{b}=5{ }^{\circ} \mathrm{C}$. This parameterisation provided an average difference of 2 days between observed and estimated flowering dates, which corresponded to average differences of around $3.9 \%$ of the thermal time reached at the flowering date (GDD), for both $\mathrm{OU}$ and GH conditions (Table 3.1). Analyzing the GDD values for each genotype, 'Arbequina' and 'Koroneiki', and 'GM25' showed the lowest and highest GDD values, respectively, and therefore the earliest and latest flowering dates (Table 3.1). The smallest differences between observed and estimated flowering dates were found for 'Picual', for which Model 4 reproduced accurately the observed mean flowering date with differences in GDD between simulated and observed of around $0.4 \%$ for both $\mathrm{OU}$ and $\mathrm{GH}$ conditions. In the opposite case, the highest differences were found for the wild genotype 'GM25' with differences equal to 5.5 days and $7.9 \%$ of GDD (Table 3.1).

As Method 4 was the approach with the lowest errors in the flowering date assessment, this one was selected for calculating future flowering dates, occurrence of extreme temperature events and vulnerability of current and potential olive cultivation areas. 
Table 3.2 Cultivar parameters (total chilling units (TUorg) and thermal time (TTorg), both provided by De Melo Abreu et al. (2004), thermal time observed at flowering (TTobs) and differences between simulated and observed flowering dates (Fobs-Forg) obtained with Method 1, Method 2 and Method 3 for 'Arbequina', 'Hojiblanca' and 'Picual' varieties, under outdoors (OU) and greenhouse (GH) conditions. Negative values mean earlier estimated dates compared with the observed ones.

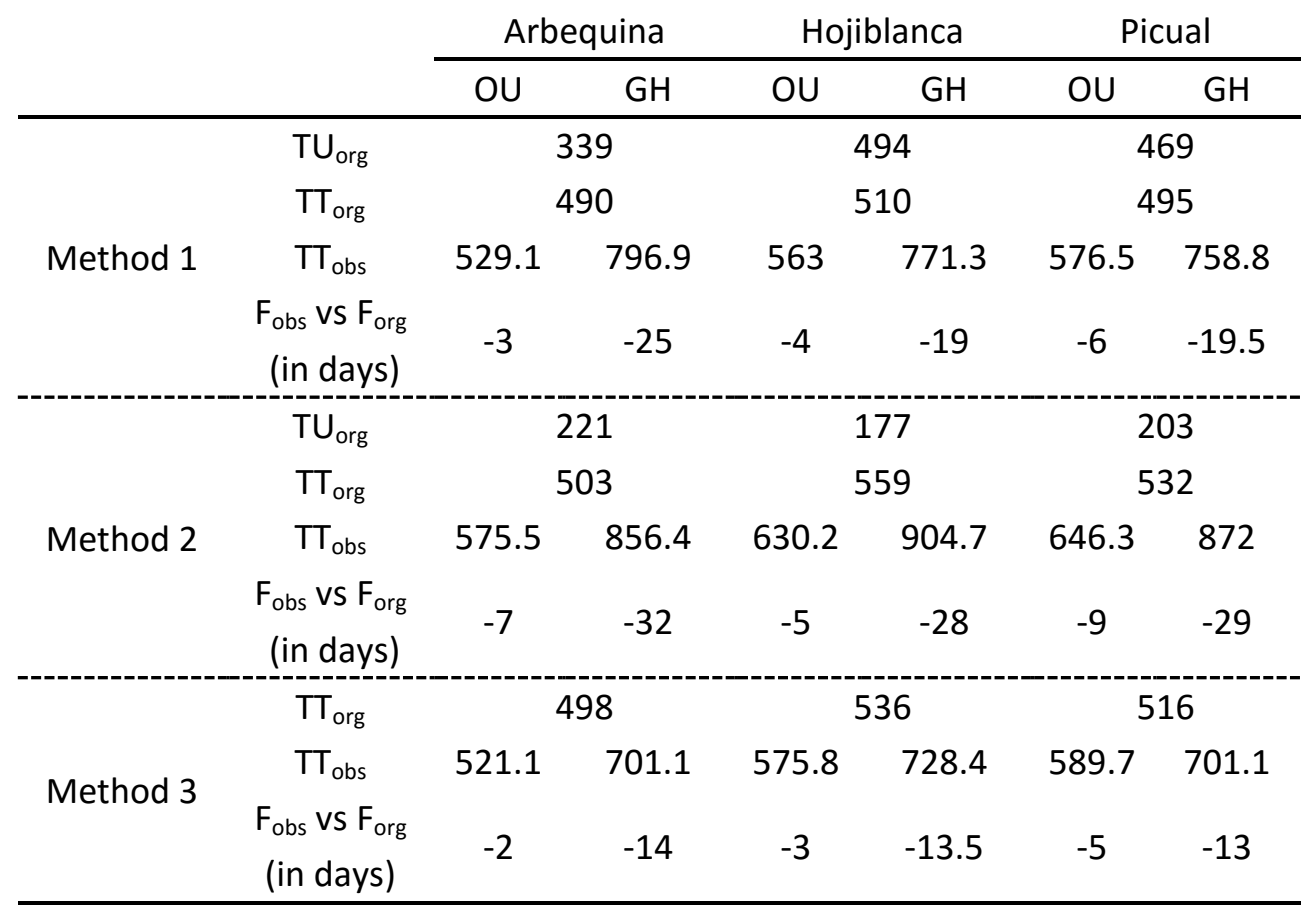

\subsubsection{Projections of future flowering dates}

The twelve ensemble members of ENS-Spain02 were applied to the Method 4 detecting a delay in reaching chilling requirements or end of dormancy (EDO) for both NF and FF periods compared with the B period in the whole region (Fig. 3.5, Supplement Table A.3). Thus, considering $\mathrm{TU}_{\min }(302 \mathrm{U})$, the mean delay in EDO of the ensemble for the 10 previously described genotypes was 9 and 22 days for NF and FF periods regarding B period, respectively. The larger delay was found in the Atlantic Ocean coast area (AOC) with up to 11 and 28 days in Jerez (Fig. 3.5) for the NF and FF periods, respectively. When TU threshold was not reached, flowering failure is generated. This flowering failure across Andalusia region was more frequent in the $A O C$ area, lower section of Guadalquivir Valley (GV) and Southeast coast (SE). For example in Seville (Supplement Table A.3), failure percentage was $0,0.3$ and $10.9 \%$ for B, NF and FF periods, respectively, increasing for Jerez with values equal to $0,1.7$ and $26 \%$, respectively. The uncertainty of EDO dates projections (calculated as the variability in 
the EDO dates obtained from the different climate models and expressed as the coefficient of variation, CV) was very low (values below ca. $2 \%$ for all periods, Supplement Table A.3b). Considering $T U_{\min }(302 \mathrm{U}), \mathrm{TU}_{\text {mean }}(467 \mathrm{U})$ and $\mathrm{TU}_{\max }(722 \mathrm{U})$ the mean delays in the EDO of the ensemble in the region were very similar between them. Thus, delays in EDO dates compared with B period ranged from 8-11 and 20-25 days for NF and FF periods, respectively, limited affected by the TU considered. However for some areas the occurrence of flowering failure varied significantly with TU. Thus, in AOC area the percentage of years with flowering failure for FF period varied from 26 to $87.1 \%$ depending on the TU value (Jerez location; Supplement Table A.3) However for others areas the impact was very limited, no detecting flowering failure regardless of the considered TU value. Finally, uncertainty in EDO values was low (with the highest values for FF period) and very similar between areas (Supplement Table A.3).

Once the chilling requirements are met, simulated flowering date varied depending on the location, cultivar and period considered (Fig. 3.6, Table 3.3). For the B period, 'Arbequina' cultivar had the lowest GDD requirements (Table 3.1) and then showed the earliest flowering date, varying from 127 DOY in locations nearby AOC (Jerez and Seville) to 148 DOY in locations included in the N-NE (North- Northeast) Mountains area (Baeza). For 'Picual' cultivar, with moderate GDD requirements (Table 3.1), the flowering date ranged from 130 DOY for AOC to 151 DOY in N-NW (North-Northwest) area. Finally, 'GM22' wild genotype had the highest GDD requirements (Table 3.1) and then flowering date varied from 155 DOY in AOC to 175 DOY in N-NE area. As summary, considering the whole Andalusia region a similar advance in flowering date was identified for all the genotypes for future periods compared with B period, being the averaged advances equal to 6 and 17 days for the NF and FF periods, respectively.

The uncertainty in the estimation of flowering date for the analysed area evaluating the ENS-Spain02 ensemble results was very low for all the analysed periods. AOC area showed the lowest values (with values around $1.7 \%$ for the FF period for Jerez location), and the highest for N-NE Mountains area (values equal to $2.5 \%$ for the Baeza location for FF period; Table 3.3). 
CHAPTER 3. Impact of changes in temperature and extreme events caused by climate change on olive flowering at southern Spain

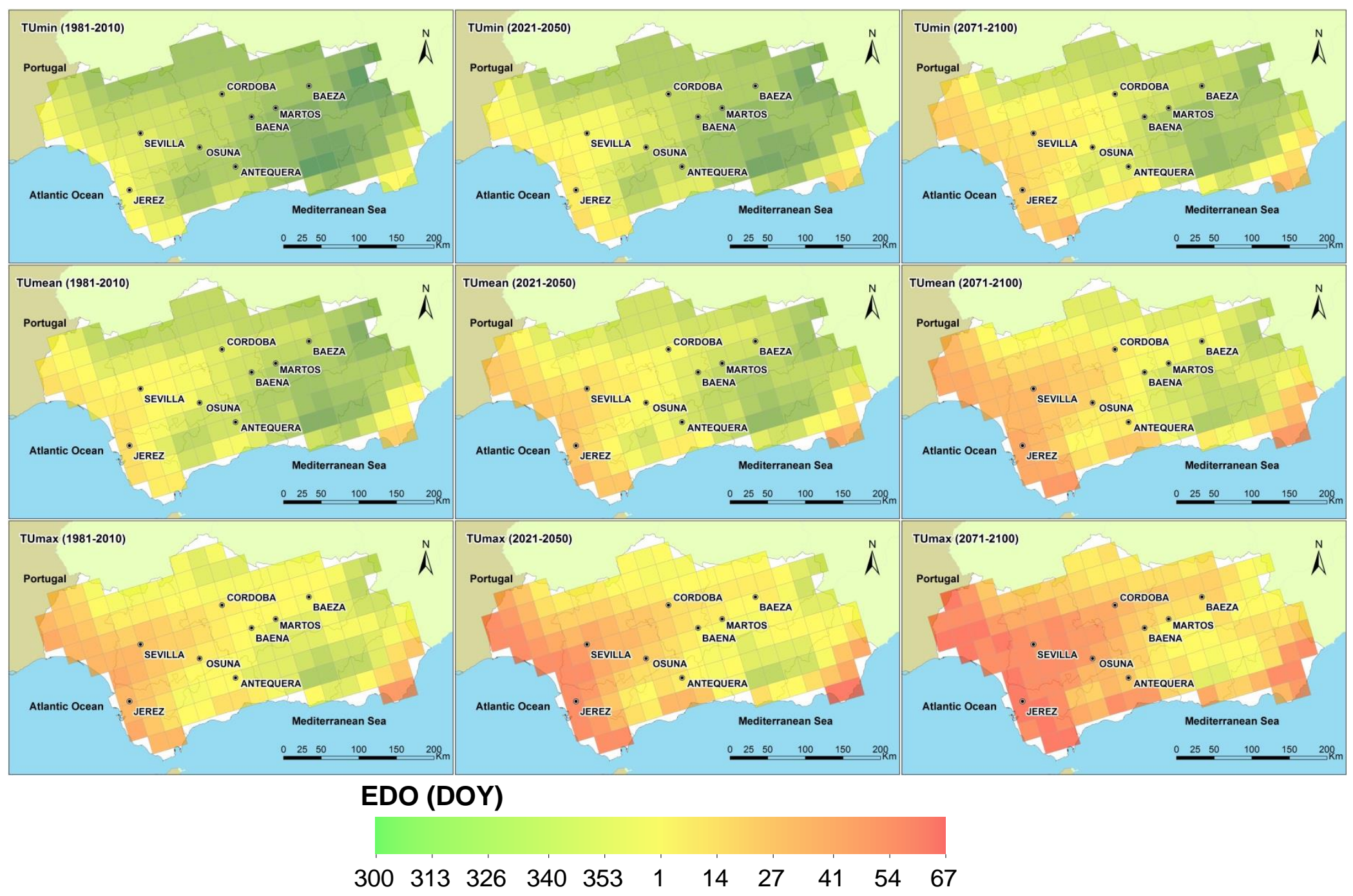

Figure 3.5 End of dormancy (EDO) in day of year (DOY) for the baseline (1981-2010), near future (2021-2050) and far future (2071-2100) periods, calculated with minimum (TUmin (a)), mean (TUmean (b)) and maximum (TUmax (c)) total chilling units value. 
CHAPTER 3. Impact of changes in temperature and extreme events caused by climate change on olive flowering at southern Spain

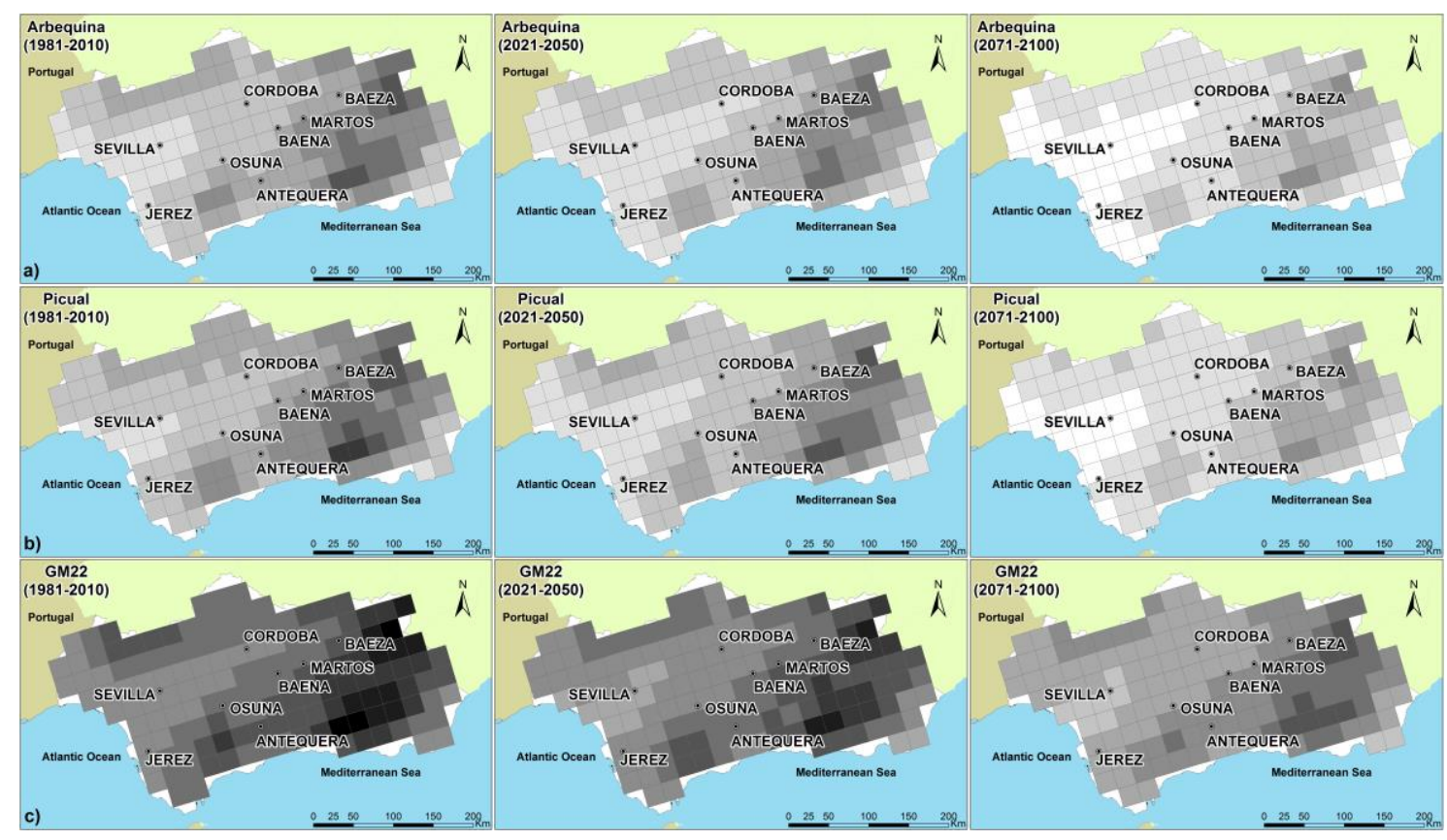

Flowering date (DOY)

$\begin{array}{lllllllllll}110 & 120 & 130 & 140 & 150 & 160 & 170 & 180 & 190 & 200 & 210\end{array}$

Figure 3.6 Simulated flowering date in day of year (DOY) with Method 4 for the baseline (1981-2010), near future (2021-2050) and far future (2071-2100) periods, for the cultivars a) 'Arbequina', b)'Picual' and c) the wild genotype 'GM22' 
Table 3.3. Mean flowering date, for the cultivars 'Arbequina' and 'Picual' and the wild genotype 'GM22' at the selected locations for the baseline (1981-2010), near future (2021-2050) and far future (20712100) periods. The values in parenthesis are the coefficient of variation (CV, \%) of the flowering dates projected by the 12 climate models considered. DOY: day of year.

\begin{tabular}{|c|c|c|c|c|c|c|c|c|c|}
\hline \multirow[b]{2}{*}{ Location } & \multicolumn{3}{|c|}{ Arbequina } & \multicolumn{3}{|c|}{ Picual } & \multicolumn{3}{|c|}{ GM22 } \\
\hline & B & $\mathrm{NF}$ & $\mathrm{FF}$ & B & $\mathrm{NF}$ & $\mathrm{FF}$ & B & $\mathrm{NF}$ & $\mathrm{FF}$ \\
\hline Jerez & $127(0.3)$ & $\begin{array}{c}123 \\
(1.4)\end{array}$ & $\begin{array}{c}116 \\
(1.7)\end{array}$ & $\begin{array}{c}130 \\
(0.3)\end{array}$ & $\begin{array}{c}126 \\
(1.4)\end{array}$ & $\begin{array}{c}119 \\
(1.7)\end{array}$ & $\begin{array}{c}155 \\
(0.4)\end{array}$ & $\begin{array}{c}150 \\
(1.2)\end{array}$ & $\begin{array}{c}141 \\
(1.7)\end{array}$ \\
\hline Seville & $127(0.4)$ & $\begin{array}{c}123 \\
(1.4)\end{array}$ & $\begin{array}{c}116 \\
(1.9)\end{array}$ & $\begin{array}{c}130 \\
(0.4)\end{array}$ & $\begin{array}{c}126 \\
(1.4)\end{array}$ & $\begin{array}{c}118 \\
(1.9)\end{array}$ & $\begin{array}{c}154 \\
(0.5)\end{array}$ & $\begin{array}{c}149 \\
(1.2)\end{array}$ & $\begin{array}{c}139 \\
(1.9)\end{array}$ \\
\hline Osuna & $134(0.4)$ & $\begin{array}{c}129 \\
(1.5)\end{array}$ & $\begin{array}{c}121 \\
(2.0)\end{array}$ & $\begin{array}{c}137 \\
(0.4)\end{array}$ & $\begin{array}{c}132 \\
(1.4)\end{array}$ & $\begin{array}{c}124 \\
(2)\end{array}$ & $\begin{array}{c}161 \\
(0.4)\end{array}$ & $\begin{array}{c}156 \\
(1.2)\end{array}$ & $\begin{array}{c}145 \\
\text { (1.9) }\end{array}$ \\
\hline Antequera & $142(0.6)$ & $\begin{array}{c}137 \\
(1.8)\end{array}$ & $\begin{array}{c}127 \\
(2.3)\end{array}$ & $\begin{array}{c}146 \\
(0.6)\end{array}$ & $\begin{array}{c}140 \\
(1.8)\end{array}$ & $\begin{array}{c}130 \\
(2.3)\end{array}$ & $\begin{array}{c}171 \\
(0.5)\end{array}$ & $\begin{array}{c}165 \\
(1.4)\end{array}$ & $\begin{array}{c}153 \\
(2.3)\end{array}$ \\
\hline Cordoba & $132(0.5)$ & $\begin{array}{c}128 \\
(1.5)\end{array}$ & $\begin{array}{c}119 \\
(2.2)\end{array}$ & $\begin{array}{c}135 \\
(0.5)\end{array}$ & $\begin{array}{c}131 \\
(1.5)\end{array}$ & $\begin{array}{c}122 \\
(2.2)\end{array}$ & $\begin{array}{c}159 \\
(0.5)\end{array}$ & $\begin{array}{c}153 \\
(1.3)\end{array}$ & $\begin{array}{c}143 \\
(2.1)\end{array}$ \\
\hline Baena & $137(0.5)$ & $\begin{array}{c}133 \\
(1.4)\end{array}$ & $\begin{array}{c}124 \\
(2.2)\end{array}$ & $\begin{array}{c}140 \\
(0.5)\end{array}$ & $\begin{array}{c}135 \\
(1.4)\end{array}$ & $\begin{array}{c}127 \\
(2.2)\end{array}$ & $\begin{array}{c}164 \\
(0.4)\end{array}$ & $\begin{array}{c}158 \\
(1.2)\end{array}$ & $\begin{array}{c}147 \\
(2.1)\end{array}$ \\
\hline Martos & $140(0.5)$ & $\begin{array}{c}135 \\
(1.5)\end{array}$ & $\begin{array}{c}126 \\
(2.3)\end{array}$ & $\begin{array}{c}143 \\
(0.5)\end{array}$ & $\begin{array}{c}138 \\
(1.5)\end{array}$ & $\begin{array}{c}129 \\
(2.3)\end{array}$ & $\begin{array}{c}166 \\
(0.4)\end{array}$ & $\begin{array}{c}160 \\
(1.3)\end{array}$ & $\begin{array}{c}149 \\
(2.3)\end{array}$ \\
\hline Baeza & $148(0.6)$ & $\begin{array}{c}143 \\
(1.7)\end{array}$ & $\begin{array}{c}131 \\
(2.6)\end{array}$ & $\begin{array}{c}151 \\
(0.5)\end{array}$ & $\begin{array}{c}145 \\
(1.7)\end{array}$ & $\begin{array}{c}134 \\
(2.5)\end{array}$ & $\begin{array}{c}174 \\
(0.4)\end{array}$ & $\begin{array}{c}167 \\
(1.3)\end{array}$ & $\begin{array}{c}155 \\
(2.5)\end{array}$ \\
\hline
\end{tabular}

\subsubsection{Extreme temperature events}

Once flowering dates were obtained, an analysis of the occurrence of extreme events during this stage was carried out for Arbequina cultivar, the genotype with the lowest GDD requirements for flowering, and GM22, the wild genotype with the highest GDD requirements (Table 3.1).

The results for the whole Andalusia region show an increase in the occurrence of heat extreme events per year for both 1-day and 3-days duration events (see section 3.2.5) (Fig. 3.7 and 3.8). For 'Arbequina' the mean occurrence of at least one hs1d-30 event by year increased around 19 and $38 \%$ for NF and FF periods, respectively, compared with B period (Table 3.4), being in North-North East the areas with the highest occurrence of both hs1d-30 and hs3d-30 events. When a higher threshold temperature 
was considered (hs1d-35 and hs3d-35 events) the occurrence was lower (about the half than for events with temperatures higher than $30^{\circ} \mathrm{C}$ ), showing equally the highest frequencies of occurrence in the North-Eastern area. Finally, for hs1d-40 events the highest occurrence was around $10 \%$ for FF period and was also found in the NorthEastern area, while the occurrence of hs $3 \mathrm{~d}-40$ events was null.

For 'GM22' the occurrence of heat extreme events was higher than for the rest of cultivars and wild olive genotypes (Fig. 3.8, Table 3.4). The mean occurrence of at least one hs $1 \mathrm{~d}-30$ and hs3d-30 events by year increased around 9 and $22 \%$, respectively, for the FF period compared with the B period, with maximum occurrences for hs1d-30 events close to the $100 \%$ in North-North East area (e.g. Baeza location) for the three considered periods (Table 3.4).

Regarding the hs $1 \mathrm{~d}-35$ and hs3d-35 events, the mean number of events and the percentage of years with occurrence was smaller than $30{ }^{\circ} \mathrm{C}$ threshold was considered. The occurrence of at least one of these events (hs1d-35 and hs3d-35) increased in FF period compared with B (around 46 and $83 \%$, for hs $1 \mathrm{~d}-35$ and hs3d-35 respectively) with the maximum occurrences located in North-North East area (Baeza location). Finally, for hs $1 \mathrm{~d}-40$ and hs3d-40 events the occurrence in FF period varied significantly throughout the region, with the highest occurrences projected for FF at the North-East of the region (e.g. for Baeza location 47.7 and $21.1 \%$ for hs $1 d-40$ and hs3d-40 events, respectively), in the upper section of Guadalquivir River. 
CHAPTER 3. Impact of changes in temperature and extreme events caused by climate change on olive flowering at southern Spain

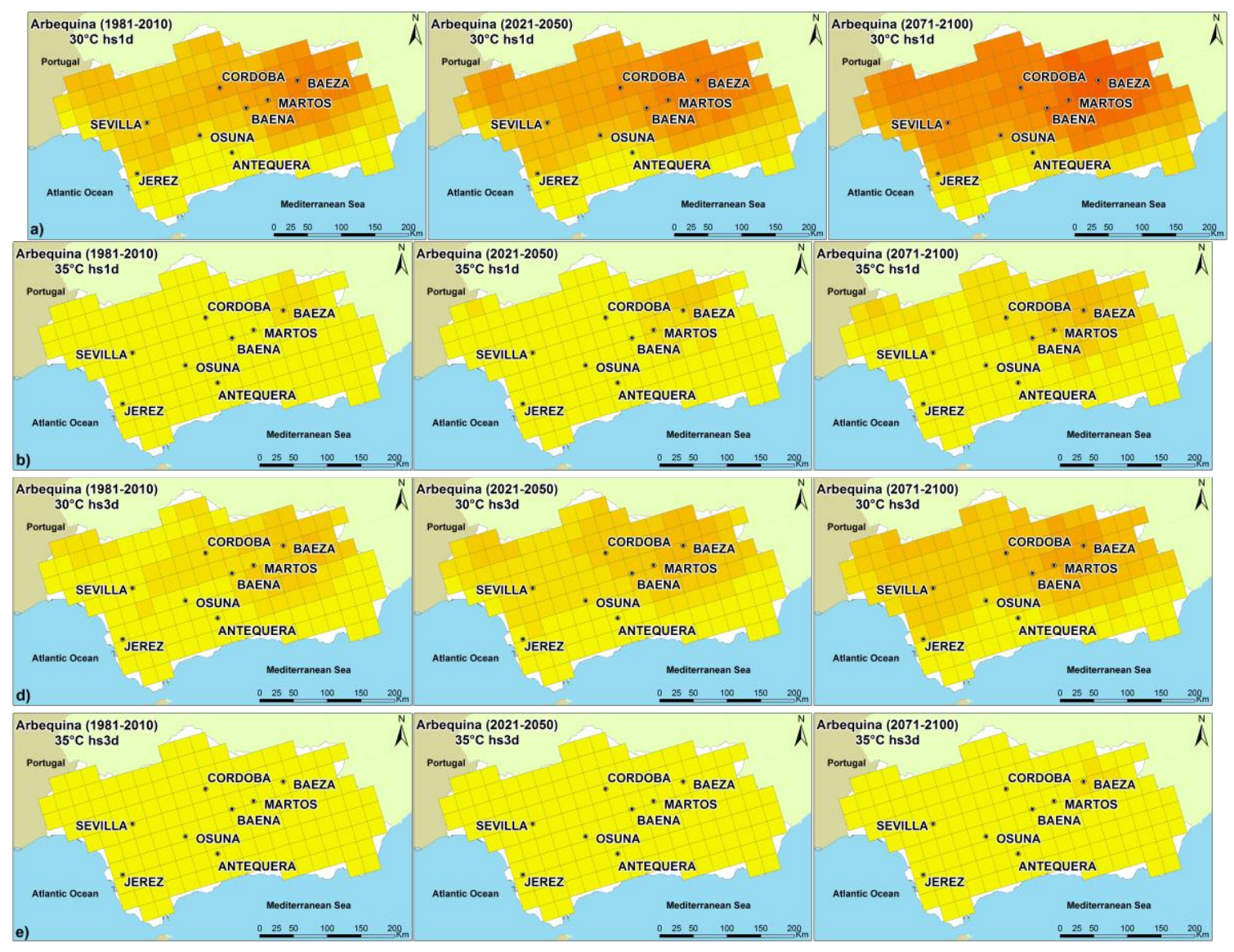

\section{hsxd}

Figure 3.7. Average number of heat extreme events per year during flowering (from the crop point of view) with temperatures above 30 and $35^{\circ} \mathrm{C}$ during at least one day (a, hd1d-30 and $b$, hd1d-35) and during at least three consecutive days (d, hs3d-30 and e, hs3d-35) for Arbequina cultivar (maps for the threshold of $40{ }^{\circ} \mathrm{C}$ are not shown due to the lack of events), for the baseline (1981-2010), near future (2021-2050) and far future (2071-2100) periods 
Table 3.4. Percentage of years with at least one event for one (hs1d) and three consecutive (hs3d) days above 30, 35 or 40 degrees during the flowering phase, for the cultivar 'Arbequina' and the wild genotype 'GM22', for the baseline (B, 1981-2010), near future (NF, 2021-2050) and far future (FF, 2071-2100) periods.

\begin{tabular}{|c|c|c|c|c|c|c|c|c|c|c|c|c|c|c|c|c|c|c|c|}
\hline \multirow[b]{3}{*}{ Location } & \multicolumn{19}{|c|}{ Arbequina } \\
\hline & \multirow[b]{2}{*}{ code } & \multicolumn{3}{|c|}{ hs1d-30 (\%) } & \multicolumn{3}{|c|}{ hs1d-35 (\%) } & \multicolumn{3}{|c|}{ hs1d-40 (\%) } & \multicolumn{3}{|c|}{ hs3d-30 (\%) } & \multicolumn{3}{|c|}{ hs3d-35 (\%) } & \multicolumn{3}{|c|}{ hs3d-40 } \\
\hline & & $\mathrm{B}$ & $\mathrm{NF}$ & $\mathrm{FF}$ & $\mathrm{B}$ & $\mathrm{NF}$ & $\mathrm{FF}$ & $\mathrm{B}$ & NF & $\mathrm{FF}$ & $\mathrm{B}$ & $\mathrm{NF}$ & $\mathrm{FF}$ & $\mathrm{B}$ & $\mathrm{NF}$ & $\mathrm{FF}$ & $\mathrm{B}$ & $\mathrm{NF}$ & $\mathrm{FF}$ \\
\hline Jerez & $A$ & 31.4 & 41.1 & 54.1 & 0.3 & 1.9 & 7.4 & 0.0 & 0.0 & 0.0 & 8.9 & 13.3 & 26.5 & 0.0 & 0.0 & 1.4 & 0.0 & 0.0 & 0.0 \\
\hline Osuna & C & 41.1 & 53.9 & 63.7 & 2.5 & 4.4 & 10.2 & 0.0 & 0.3 & 0.0 & 11.9 & 23.9 & 35.1 & 0.0 & 0.0 & 1.5 & 0.0 & 0.0 & 0.0 \\
\hline Antequera & D & 8.6 & 19.2 & 37.6 & 0.0 & 0.8 & 1.6 & 0.0 & 0.0 & 0.0 & 0.0 & 3.9 & 9.0 & 0.0 & 0.0 & 0.3 & 0.0 & 0.0 & 0.0 \\
\hline Cordoba & $E$ & 61.4 & 70.3 & 78.6 & 8.6 & 16.9 & 27.0 & 0.3 & 0.3 & 1.2 & 28.3 & 41.4 & 47.3 & 0.6 & 3.1 & 9.2 & 0.0 & 0.0 & 0.3 \\
\hline Baeza & $\mathrm{H}$ & 78.9 & 81.9 & 90.5 & 30.6 & 37.5 & 55.8 & 1.9 & 3.9 & 10.3 & 46.4 & 55.3 & 67.4 & 7.5 & 12.5 & 20.7 & 0.0 & 0.3 & 0.9 \\
\hline mean & & 50.3 & 59.7 & 69.4 & 9.1 & 14.9 & 25.0 & 0.3 & 1.0 & 2.3 & 22.9 & 31.8 & 43.4 & 1.8 & 3.8 & 7.8 & 0.0 & 0.2 & 0.2 \\
\hline
\end{tabular}

\begin{tabular}{|c|c|c|c|c|c|c|c|c|c|c|c|c|c|c|c|c|c|c|c|}
\hline \multirow{2}{*}{ Location } & & \multicolumn{18}{|c|}{ GM22 } \\
\hline & & \multicolumn{3}{|c|}{ hs1d-30 (\%) } & \multicolumn{3}{|c|}{ hs1d-35 (\%) } & \multicolumn{3}{|c|}{ hs1d-40 (\%) } & \multicolumn{3}{|c|}{ hs3d-30 (\%) } & \multicolumn{3}{|c|}{ hs3d-35 (\%) } & \multicolumn{3}{|c|}{ hs3d-40 } \\
\hline Jerez & A & 73.6 & 83.9 & 92.6 & 15.6 & 25.3 & 42.8 & 0.0 & 0.6 & 3.0 & 45.0 & 53.6 & 70.8 & 1.7 & 4.2 & 15.5 & 0.0 & 0.0 & 0.3 \\
\hline Osuna & C & 87.2 & 89.7 & 95.3 & 20.6 & 30.6 & 49.6 & 0.3 & 1.1 & 2.7 & 61.1 & 66.9 & 79.7 & 3.6 & 8.1 & 21.4 & 0.0 & 0.0 & 0.3 \\
\hline Antequera & D & 70.0 & 75.0 & 85.4 & 5.6 & 11.7 & 22.0 & 0.0 & 0.0 & 0.3 & 31.1 & 34.7 & 48.9 & 0.8 & 1.1 & 4.9 & 0.0 & 0.0 & 0.0 \\
\hline Cordoba & $E$ & 92.2 & 95.6 & 99.4 & 56.1 & 61.4 & 79.6 & 1.4 & 7.2 & 24.9 & 75.0 & 81.1 & 92.6 & 22.2 & 31.7 & 49.8 & 0.3 & 1.1 & 9.3 \\
\hline Baeza & $\mathrm{H}$ & 98.3 & 98.6 & 99.5 & 78.3 & 84.2 & 90.2 & 18.6 & 26.9 & 47.7 & 89.2 & 89.2 & 95.4 & 46.1 & 55.8 & 64.6 & 4.7 & 8.6 & 21.1 \\
\hline mean & & 88.1 & 90.9 & 96.1 & 44.1 & 50.2 & 64.4 & 5.1 & 8.7 & 19.9 & 66.6 & 70.1 & 81.3 & 20.6 & 25.7 & 37.6 & 0.9 & 2.4 & 7.6 \\
\hline
\end{tabular}




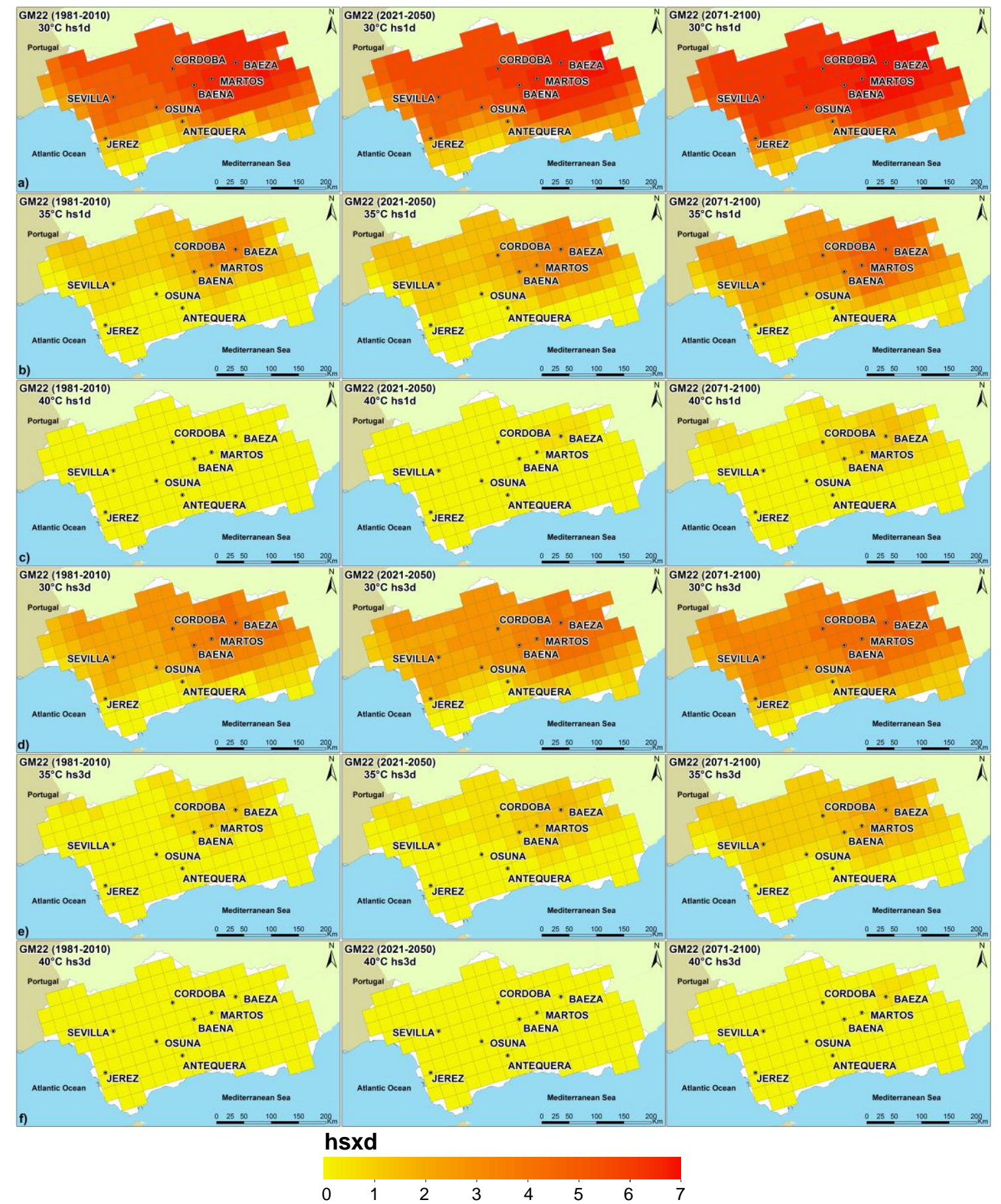

Figure 3.8. Average number of heat extreme events per year during flowering (from the crop point of view) with temperatures above 30,35 and $40{ }^{\circ} \mathrm{C}$ during at least one day (a, hs1d-30, b, hs1d-35 and c, hs1d-40) and during at least three consecutive days (d, hs3d-30, e, hs3d-35 and f, hs3d-40) for 'GM22' wild genotype for the baseline (1981-2010), near future (2021-2050) and far future (2071-2100) periods 


\subsubsection{Vulnerability and alternative suitable areas for olive cultivation at southern Spain}

Combining the maps of percentage of years when the mean threshold of chilling requirements were not achieved and the maps of percentage of years with at least one event of one day with Tmax above $35^{\circ} \mathrm{C}$ during $\mathrm{B}$ and $\mathrm{FF}$ period (Supplement, Fig A.3), a spatial analysis evaluating the flowering threats were defined (Fig. 3.9). Overlapping these threat maps with the current cultivated olive areas in Andalusia, the olive areas with the highest vulnerability to climate change as well as new areas suitable for olive cultivation with the analysed genotypes (Fig. 3.9) arose. Thus, considering 'Arbequina' and 'Picual' cultivars for the future period, the areas $A O C$ and SE (Southeast) were those with the highest vulnerability due to the lack of chilling units. Similarly the areas located at NW (Northwest), North (N) and NE (Northeast) were the most vulnerable to high temperature during flowering for the FF period (Fig. 3.9). These areas are larger and with higher percentage of years with at least one event of one day with Tmax above $35{ }^{\circ} \mathrm{C}$ than for B period (Supplement A.3). In the opposite case, the areas with the lowest vulnerability to extreme events were N-NW (North-Northwest) and the S (South) for 'Arbequina'. The areas with low vulnerability were reduced for 'Picual', being limited to the Southern area. Finally, the wild genotype 'GM22' was the cultivar most vulnerable to high temperatures during flowering for both B and FF periods. However the percentage of years with at least one event of one day with Tmax above $35{ }^{\circ} \mathrm{C}$ was lower in the $\mathrm{B}$ than the FF period (Supplement A.3). The suitable areas were smaller to those determined for the rest of genotypes, being limited to the S-SE (South-Southeast) and S areas (Fig. 3.9).

Using similar methodology, new areas suitable for the olive cultivation at the end of the $21^{\text {st }}$ century was identified. Thus, NW and S would be suitable areas for new plantations for 'Arbequina' and 'Picual' cultivars as heat stress during flowering and the possible lack of chilling units in winter were avoided. Equally, for the wild genotype 'GM22' the suitable area will be very limited to the $S$ area of Andalusia (Fig. 3.9), due to the higher incidence of heat stress events on flowering that the others cultivars. 
It should be noted that these areas were obtained evaluating two processes independently, the lack of chilling hour accumulation and the heat stress during flowering.

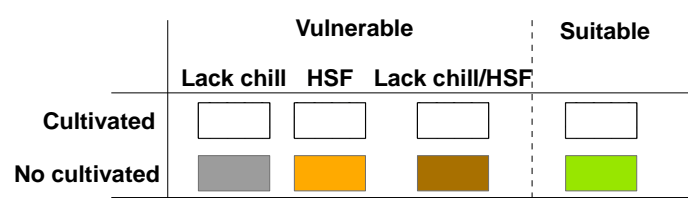

Lack chill: lack of chilling units; HSF: heat stress during flowering

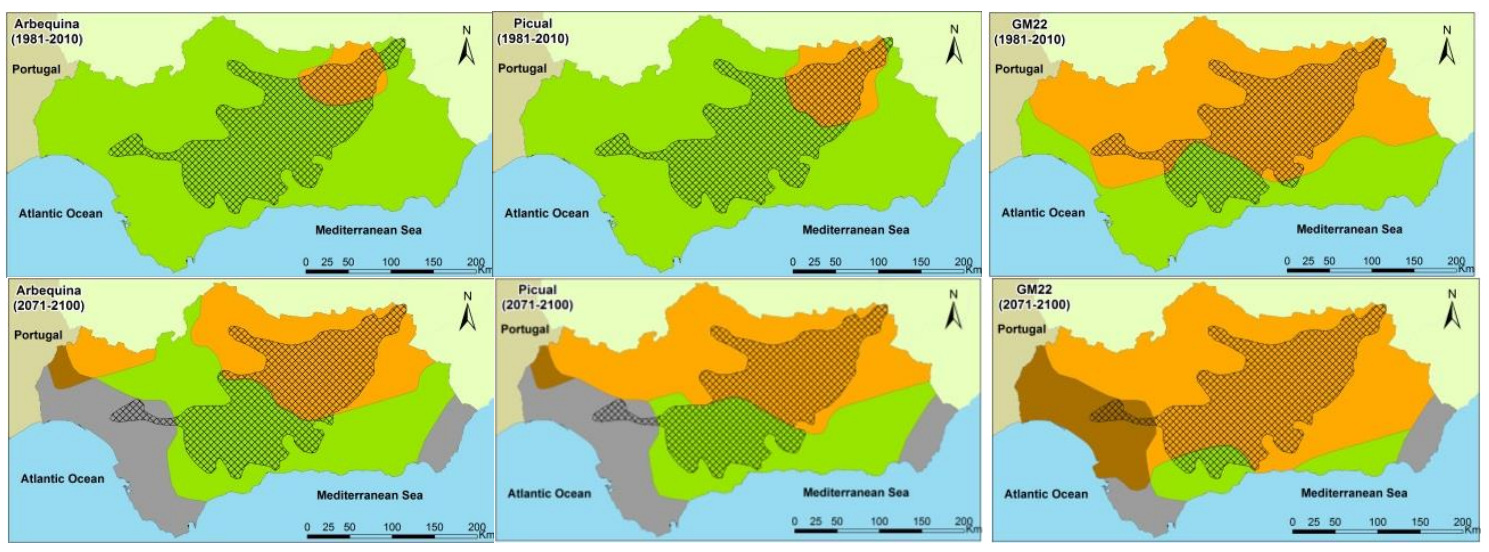

Figure 3.9. Maps of vulnerable and suitable areas for olive cultivation, for the Arbequina, Picual, and GM22, for the baseline (1981-2010) and far future (2071-2100) periods.

\subsection{DISCUSSION}

Previous studies have shown the impact of the projected temperatures at the end of the $21^{\text {st }}$ century on the olive phenology considering simulation models calibrated under baseline climate conditions (Osborne et al., 2000; Galán et al., 2005; Avolio et al., 2012). Under these climate conditions, previous models such as the developed by De Melo-Abreu et al. (2004) were validated using data from outdoors experiments (OU) for 'Arbequina', 'Hojiblanca' and 'Picual' cultivars obtaining limited differences between observed and simulated dates (2-5 days with Method 3) and providing similar flowering dates (118 to 120 DOY) than those obtained in previous studies (115-145 DOY by Fornaciari et al., 2000, 120-160 DOY by Osborne et al., 2000, or 122-134 DOY by De Melo-Abreu et al., 2004). In spite of these consistent results under baseline conditions, a huge variability in the calibration parameters was 
detected. Thus, Tb values reported by De Melo-Abreu et al. (2004), Galán et al. (2005), Orlandi et al. (2005a, 2010a) or Aguilera et al. (2014), ranged from 5 to $23{ }^{\circ} \mathrm{C}$, and the lower and upper temperature thresholds for chilling accumulation requirements described by De Melo Abreu et al. (2004), Orlandi et al. (2006) or Aguilera et al. (2014) ranged from 5.2 to $7.3^{\circ} \mathrm{C}$ and from 12 to $20.7^{\circ} \mathrm{C}$, respectively. This fact indicates the difficulty to develop a general approach for estimating olive flowering date, even under current climate conditions.

The accurate performance of the traditional phenology models when using non-forced climate conditions (De Melo-Abreu et al., 2004) was significantly reduced reproducing experimental data under forced climate, representing future conditions. Thus, the approach that uniquely considered heat accumulation (without chilling requirements) showed the best performance under forced climate conditions but still the large difference between observed and simulated dates (ca. two weeks; Table 3.3) implies that additional studies are required. This result defies our knowledge on the quantity and even on the existence of chilling requirements for olive trees, in agreement with some authors that reported a strong relation between uniquely the flowering date and previous month's temperature (Fornaciari et al., 1998; Galán et al., 2005). Then, to develop alternative approaches for assessing climate change impacts on crop phenology for Mediterranean olive orchards is still required. However the development and local calibration of such models require experimental data under forced climate conditions, which have been almost non-existent up to date.

In order to improve flowering date simulation under baseline and future climate conditions, in this study a new model was developed and tested for ten olive genotypes being locally calibrated using experimental data under baseline (represented by the $\mathrm{OU}$ experiment) and forced (represented by the GH experiment) climate conditions. The new approach provided very accurate results for both OU and GH conditions, with differences between observed and simulated flowering date of around 2 days and 3.9\% for GDD (Table 3.1), with very low associated uncertainty. The simulated flowering dates with the proposed approach for the B period considering all the cultivars except the three wild genotypes ('FV18', 'GM22' and 'GM25') showed a large spatial variability within Andalusia, ranging from 125 DOY for the Atlantic Ocean 
Coast to 184 DOY for the East Mountains area. These values are within the range of the published data by the Unit of Aerobiology at the University of Granada (RAA, 2015), obtained with pollen databases from 1992 to 2007. According to them, the highest concentrations of olive pollen usually occurs during the second week of May (134 DOY) in Almeria and Jaen provinces (Eastern Andalusia), while in the province of Granada (South-Eastern Andalusia) the highest pollen concentration is delayed to the third or fourth week of May (148 DOY) and even spans July (182 DOY) in the mountainous areas. Analyzing flowering date by genotype, also significant variability was found. Thus, the average flowering date in Cordoba for B period ranged from 132 for 'Arbequina' cultivar to 159 for the wild genotype 'GM22', with similar differences in the rest of the region. When the wild olive genotypes were excluded, the differences persisted but they were smaller, and were in agreement with De Melo-Abreu et al. (2004). The proposed model was calibrated under two contrasting climate conditions that encompassed the current and future climate conditions for the whole region of Andalusia, supporting the application of the locally calibrated model to the rest of Andalusia.

In spite of the impossibility to carry out a complete validation process due to the limited number of climate conditions, the similar parameters determined for ou and $\mathrm{GH}$ conditions in the calibration process demonstrated the high quality of the proposed approach (Table 3.1). Equally, the analysis of sensitivity carried out for TU indicated that for obtaining EDO values TU has not a critical importance. However the percentage of years with flowering failure caused by lack of chilling requirements was significantly impacted by the TU value, showing the necessity to promote studies related with the accurate definition of this parameter, and agree with studies carried out by Fornaciari et al. (1998) and Orlandi et al. (2004) that indicated the high uncertainty when olive chilling requirements were estimated.

Advances in the flowering date were foreseen with the proposed approach for the whole Andalusia region under future climate conditions. For FF period and within the current olive cultivated areas in Andalusia, the average advance in flowering date was equal to 17 days compared with the B period. This advance is in agreement to Osborne et al. (2000) and Galán et al. (2005) who indicated advances in flowering date 
for olive of around 15-20 days. These results could be also partially validated taking into account the temperature increase projected for March, April and May at the end of the $21^{\text {st }}$ century (around $2{ }^{\circ} \mathrm{C}$; Fig. 3.3) and the relationship between temperature increase and advance in the flowering date provided by Orlandi et al. (2010c), identifying an advance in flowering date in Cordoba of around 15.2 days.

The use of an ensemble of bias corrected climate projections together with a phenological model calibrated for local varieties has allowed the construction of impact maps to identify vulnerable and potentially suitable areas for olive cultivation in future, as well as to assess the uncertainty of the flowering date estimations. The generation of these maps has been frequent (Ponti et al., 2014; Tanasijevic et al., 2014) although the lack of local calibration, the absence of uncertainty assessment and the reduced number of olive cultivars analysed has limited their applicability.

Thus, this study allowed identifying the most vulnerable and suitable cultivated areas for baseline and future conditions. The spatial analysis of the vulnerable areas by the lack of chilling units (TU) considering high chilling requirements for olive identified the AOC and the SE coast areas are the most susceptible. However, according with the farmers experience and the aggregated reported yields for the AOC area (CAPDR, $2016 b)$, problems associated to the lack of chilling hour requirements have not been found. These results encourage considering low TU values for future impact assessment. In relation with uncertainty, for EDO date projections this was very low ( $\mathrm{CV}$ values below $3 \%$ whenever the period and location), although in this value uniquely uncertainty associated to RCMs under the same emission scenario (SRES-A1B) (Hawkins and Sutton, 2009; Dosio et al., 2012) was considered.

The frequency of occurrence of heat extreme events during olive flowering increased under future climate conditions, identifying the North-Northeast area as the most vulnerable to climate change due to the high temperatures during flowering. Within this area, the percentage of occurrence of at least one event during the sensitive flowering period with temperatures above $35{ }^{\circ} \mathrm{C}$ for 'Arbequina' was around 38 and $56 \%$ during NF and FF periods, respectively. This trend is in agreement with previous studies that shows an increase in the number of extreme temperature events for both global (Tebaldi et al., 2006; Teixeira et al., 2013) and Europe level (Beniston et 
al., 2007). Olive cultivars with later flowering (such as 'GM22' genotype) had a higher exposure to extreme events. Thus, for the same area the frequency of occurrence of at least one heat event during the sensitive period of flowering with temperatures above $35^{\circ} \mathrm{C}$ for 'GM22' was around 84 and $90 \%$ during NF and FF periods, respectively, and therefore a more severe impact of climate change would be foreseen.

As vulnerability related with heat extreme events varied significantly between cultivars and locations, this should be taken into account for an adequate cultivar selection at a specific location avoiding late cultivars in areas with frequent foreseen heat extreme events. The consideration of the extreme events during the simulated flowering period is a recent and useful methodology (Ruiz-Ramos et al., 2011, Eitzinger et al., 2013, Teixeira et al., 2013; Trnka et al., 2014). However, this methodology is affected by uncertainties such as the accurate estimation of the length of the flowering sensitive period for olive that could be reduced due to the effect of high temperatures (Vuletin Selak et al., 2014), or by the unawareness of the impact of heat extreme events during flowering specifically for olive. Thus, contrary to other crops as sunflower (García-Lopez et al. 2014) or maize (Gabaldón-Leal et al., 2015), the available information about these impacts on olive is very limited. To solve this knowledge gap, extensive experimental studies for understanding and quantifying the impacts of these events on olive are still required.

Adaptation strategies for Mediterranean olive orchards to avoid the lack of chilling units for sensitive areas such as AOC area were very limited, and severely affected by the high uncertainty caused by the lack of knowledge for chilling requirements by genotype. Similarly, adaptation strategies to reduce the impact of the foreseen heat stress events in the near future would be the selection of cultivars with early flowering date, the use of cover crops and soil management practices to modify the albedo to reduce air temperature (Davin et al. 2014), or the consideration of supplementary irrigation to reduce the olive canopy temperature (Doughty et al., 2011; Andrade et al., 2012). Equally, new suitable areas for olive cultivation could be extended in the NW and S areas of Andalusia for 'Arbequina' and 'Picual' cultivars.

Finally, the proposed methodology has been designed for olive orchards under the semi-arid conditions of Southern Spain and has only taken into account changes in 
both mean and maximum temperatures, regardless of changes in rainfall and the soil moisture content. The impact of water stress on olive, promoted by the foreseen climate models of Andalusia region, will have similar relevance on olive yield and studies related with this must be promoted.

Although this study has been focused on olive for Southern Spain conditions, the proposed methodology of using greenhouses to reproduce the projected climate could be applicable for other crops and locations. Thus, the described methodology could be replicated to assess the impact of climate change on others Mediterranean crops such as nut or fruit trees.

\subsection{CONCLUSION}

This study has evaluated the olive flowering date for ten olive genotypes (seven traditional cultivars in southern Spain and three olive genotypes from Canary Islands) under baseline and future climate conditions. Validation of previous phenological models for flowering date estimation and the development of a new approach adapted to both baseline and projected climate conditions, were carried out considering experimental data. The study was carried out in Andalusia region, located at Southern Spain and considered an ensemble of climate projections from Regional Climate Models (RCMs) with a bias correction in temperature and precipitation. From these simulations, an advance in the flowering date of around 6 and 17 days for 20212050 and 2071-2100 periods, respectively, compared with 1981-2010 period was projected. The uncertainty associated to these phenological projections coming from climate projections was very low.

The integration of local experimentation, phenological modelling and climate data from an ensemble of climate throughout Andalusia region allowed developing a spatial analysis of the impacts of climate change on olive flowering and its uncertainty. This analysis was based on the estimation of the flowering date, the chilling hour accumulation and the occurrence of heat extreme events during the flowering stage for ten olive genotypes. We concluded in the identification of those areas more 
vulnerable to climate change (such as the Atlantic Ocean Cost and Northern-East areas of Andalusia) and those potential new areas for olive cultivation (such as the NorthWest and South area). Late flowering cultivars (such as wild olive genotypes from Canary Islands) were the most vulnerable ones to high temperatures during flowering.

This study highlights the need to promote experimental studies on crop physiology and phenology under future climate conditions to improve the knowledge about the response of Mediterranean olive orchards to climate change. The described methodology is not exclusive for the olive crop and could be replicated to assess the impact of climate change on others crops and locations.

\section{Acknowledgments}

This study has been financially supported by the project RTA2014-00030-00-00 funded by INIA, FEDER 2014-2020 "Programa Operativo de Crecimiento Inteligente", FACCE MACSUR - Modelling European Agriculture with Climate Change for Food Security, a FACCE JPI knowledge hub, by AGR-6126 project funded by the Consejería de Innovación, Ciencia y Empresa (Junta de Andalucía) and by MULCLIVAR, from the Spanish Ministerio de Economía y Competitividad (MINECO) CGL2012-38923-C02-02.

\section{Appendix. Supplementary data}

Supplementary material related to this article can be found in Annex. 


\section{GENERAL DISCUSSION}

This Thesis has addressed the impacts of climate change on maize and olive crops under semi-arid conditions in Andalusia region. In addition, the incidence of extreme temperature events on flowering, a sensitive phenological period for numerous crops to high temperatures (Koubouris et al., 2009; Gourdji et al., 2013), has been evaluated for both crops. Thus, a model to evaluate the impact of heat stress events during flowering on maize yield has been provided, trying to mitigate the limitations found in current maize grain yield modeling under these conditions (Rezaei et al., 2015). Also for maize, considering modeling tools, possible adaptation strategies were proposed and evaluated in order to minimize the described impacts.

The Thesis is based on the development and use of crop simulation models for the assessment of impacts and adaptation strategies considering the effect of extreme maximum temperatures on the crops. The methodology considers experimental data for local calibration and validation under current and forced climate conditions, being essential this experimentation in order to adjust the model to the future climate regional conditions, with the purpose of generating projections at local and regional scale (Boote et al. 2013). The consideration of experimental data, together with the use of a bias corrected ensemble from regional climate models, has provided future projections with lower uncertainty than previous studies. However further experimental studies are still needed. Thus, in this study uniquely changes in both mean and maximum temperatures has been evaluated, and then changes in rainfall and the soil moisture content have not been considered. The integration of heat and water stress impacts in the crop models will provide a more accurate evaluation of climate change impacts on Mediterranean agriculture.

Future climate projections show an increase in future temperatures, being particularly important for Andalusia region, at southern Spain, with an increase in mean temperature up to $5{ }^{\circ} \mathrm{C}$ in the summer months (Van der Linden and Mitchel, 2009). Furthermore an increase in the frequency and magnitude of heat extreme events is projected worldwide with climate change (Tebaldi et al., 2006; Field et al., 2012), again with a higher increase at southern Spain (Sánchez and Miguez-Macho, 2010). This increase would probably lead to a larger incidence of heat stress for crops 
compared to current conditions (Schlenker and Roberts, 2009; Lobell et al., 2013; Trnka et al., 2014).

Under future climate conditions, advancement in phenological dates was projected for both maize crop and olive trees, due to the higher temperatures projected at the end of $21^{\text {st }}$ century (IPCC, 2014). These results were obtained using crop models calibrated under local conditions, with errors detected in the calibration of the maize crop model similar than those obtained in previous studies (Meza et al., 2008; Vučetić, 2011; Angulo et al., 2013; Moradi et al., 2013). The impacts of future climate conditions using these models showed a shortening in the maize crop cycle, similar to the results observed by Olesen et al. (2012) and Bassu et al. (2014) in cereals, including maize. These changes lead to projections of maize yield decrease for locations along the Guadalquivir River basin, although smaller than the indicated in previous studies (Guereña et al. 2001; Garrido et al. 2011 and Rey et al. 2011). For some locations as Granada, located in the Southern part of Andalusia and nearby Sierra Nevada mountains, the decrease in yield was more severe due to the reduction in crop cycle was higher than for the other locations. Similarly, the impacts of extreme temperature events on maize during flowering were evaluated following Teixeira et al. (2013) for Andalusia region, showing an increase in the heat stress index, causing a higher production damage index at the end of the $21^{\text {st }}$ century.

Another important impact for maize crop in Andalusia is regarding the irrigation requirements (IRR) and the irrigation water productivity (IWP). The results showed a decrease in the estimated IRR for future periods for all the locations. This decrease could be explained by the reduction of the crop cycle duration and the crop evapotranspiration, caused by warmer temperatures and the reduced stomatal conductance as consequence of future $\mathrm{CO}_{2}$ concentrations (Cure and Acock 1986; Ainsworth and Long 2005). The increased IWP in the future periods could be related to the described reduction on stomatal conductance (Leakey et al. 2006; Vanuytrecht et al. 2012).

The projection results for maize yield under future climate conditions were evaluated for five locations, four of them along the Guadalquivir river basin, showing similar results and low uncertainty. This low uncertainty exhibited by the projections is partially as consequence of conducting simulations under an optimum irrigation 
supply, which excludes the uncertainty linked to precipitation. The precipitation uncertainty is usually higher than for other variables (Christensen and Christensen, 2007) due to the spatially and temporally complex structure and its related physical processes, being especially large in the Iberian Peninsula (Sánchez and Miguez-Macho, 2010). However, Granada area showed higher uncertainty than the Guadalquivir locations expressed as the spread of the ensemble members or differences among RCM outputs. In turn, these differences could be enhanced by the complex orography of Granada area. For instance, while mean altitude for the Guadalquivir Valley locations is $100 \mathrm{~m}$ a.s.l, Granada is at $633 \mathrm{~m}$ a.s.I. For this particular location, its actual altitude is lower than the mean grid altitude of $1034 \mathrm{~m}$ considered by both the observational data set E-OBS and the ensemble of corrected RCM projections ENSEOBS; this misrepresentation of altitude would introduce an error and contribute to the accumulated uncertainty.

Impacts on olive trees were studied in relation to the flowering date assessment under current and future climate conditions and the occurrence of extreme events during this critical phenological stage. The new approach provided very accurate results for both current (evaluated by experiments under current actual conditions) and forced conditions (considering experiments placed inside a greenhouse reproducing the future climate conditions), with differences between observed and simulated flowering date of around 2 days and with very low associated uncertainty. The simulated flowering dates projected for the baseline period (1981-2010) showed a significant spatial variability within Andalusia (125-184 DOY). These results are in the range of the published data by the Unit of Aerobiology at the University of Granada (RAA, 2015), that found the highest concentrations of olive pollen during the second week of May in the Eastern areas of Andalusia, and up to July in the mountainous areas.

For flowering date estimation in olive, the fulfillment of chilling requirement (or end of endormancy) has a critical importance (Rallo and Martin, 1991). Analyzing this fulfillment for the whole Andalusia region at the end of the $21^{\text {st }}$ century, the most susceptible areas to lack of chilling requirements accumulation were the Atlantic Ocean and South East Coasts. The results related with the lack of chilling units for olive obtained are in agreement with the yield reports provided by farmers and public 
institutions for the last years in the Atlantic Ocean Coast area, which did not detect problems of lack of chilling hour requirements (CAPDR, 2016b).

For olive trees the impact of extreme temperature events was evaluated using a similar approach than Ruiz-Ramos et al. (2011), considering number of events during flowering period with temperature above different thresholds. The frequency of occurrence of heat extreme events during olive flowering under projected future climate conditions generally increased with very low uncertainty, with the highest frequency in the North-Northeast area of Andalusia. The increasing trend projected was in agreement with previous studies developed by Tebaldi et al. (2006), Beniston et al. (2007), Ruiz-Ramos et al. (2011) and Teixeira et al. (2013). In the study, differences in vulnerability between cultivars and locations were found and should be taken into account for an adequate cultivar selection at a specific location, avoiding late cultivars (such as the wild genotype GM22) in areas with frequent foreseen heat extreme events (such as North-Northern areas of Andalusia).

The general very low uncertainty associated to the olive crop results was due to the fact that the impacts projections were based only in temperature, variable with lower uncertainty than the precipitation, as mention above. Also, in this study the ensemble of climate models used was ENS-Spain02, especially developed for impact assessment (Ruiz-Ramos et al., 2015). In spite of the low uncertainty detected, this one was slightly higher for future periods compared with the baseline due to inherent uncertainty of the climate models and was in agreement to Ferrise et al. (2011) and Hoffmann and Rath (2013).

It should be noted that the uncertainty evaluated was only that caused by differences in the projections provided by the RCMs under the same emission scenario (SRES-A1B) (Hawkins and Sutton, 2009; Dosio et al., 2012). This is one of the largest uncertainty sources in climate change impact assessment as Iglesias et al. (2010) for olive, Hoffmann and Rath (2013) for apple, Ruiz-Ramos and Mínguez (2010) and Asseng et al. (2013) for wheat and maize described. However there are other relevant uncertainty sources not addressed here, as driving GCM, climate scenarios and others decisions related to climate (Déqué et al, 2007). Equally, uncertainty coming from crop models must be considered and it has arisen as an important uncertainty source (Asseng et al., 2015). 
The methodologies used reduce the uncertainty of impact projections improving several uncertainty sources. First, the uncertainty coming from climate model outputs is reduced by the use of regional climate models (RCMs) instead of general climate models (GCMs) providing climate information at the required scale (ca. 5 to $50 \mathrm{~km}$ for RCMs vs. 100 to $200 \mathrm{~km}$ for GCMs) for local and regional assessments, in areas with complex orography as Andalusia (Guereña et al., 2001). Additional steps for reducing the uncertainty were 1 ) the use of an ensemble of RCMs instead of a single one projection, to consider the uncertainty from climate model parameterization (Christensen et al., 2007; Semenov and Stratonovitch 2010), and 2) the use of the bias corrected temperature and precipitation ensemble members. Thus, more specifically, two bias corrected climate datasets from the ENSEMBLES European project were used; one of them based on the observational E-OBS dataset, with 2316 stations covering all Europe (50 of them in Spain) (ENS-EOBS) and the second one, using as observational reference a dataset specifically generated for continental Spain and the Balearic Islands based on 2756 quality-controlled weather stations (Spain02, Herrera et al, 2012). For both climate datasets a bias correction in temperature and precipitation following (Dosio and Paruolo, 2011) and delivered by Ruiz-Ramos et al. (2015) (ENSSpain02) was considered. These improvements resulted in an overall reduction of uncertainty when compared to former studies (Ruiz-Ramos and Mínguez, 2010; RuizRamos et al., 2015).

The adaptation strategies for maize tested, such earlier sowing dates, or cultivar changes with longer and more effective grain filling period have proven to diminish negative impacts at field, regional, and European levels (Olesen et al. 2011). However, our results emphasize that the adaptations for these events must be local, due to differences in the spatial pattern of extreme events (Teixeira et al. 2013) and local cropping system features.

The adaptations proposed for maize to deal with climate change impacts were an earlier sowing date, in agreement with Moriondo et al. (2011), combined with cultivar changes searching for a longer grain filling period (Tollenaar and Lee 2011; Chen et al. 2013; Ning et al. 2013). The combination of both strategies, sowing dates and improved cultivars yielded the best projection results and are feasible from the breeding and management points of view. With this combined adaptation the 
potential yield were recovered in all the locations, and even increased in the Guadalquivir locations.

When impacts and adaptation strategies are evaluated, it is required to consider that actual yield would be lower than the simulated, as the simulations did not include any biotic nor abiotic stresses. Thus, if the effects of extreme maximum temperatures during flowering are considered, in some locations as Granada the yield would still remain around $8 \%$ below current level, even when the adaptation is applied. This aspect stresses the importance of the lack of heat stress consideration by crop models.

When the adaptation strategies were considered irrigation requirements, IRR, were lower for future periods compared with the baseline period. This reduction was due to the earlier maturity dates, avoiding the crop the driest and hottest periods. Equally, with the adaptations implemented, irrigation water productivity also increased because yield increased more than crop transpiration and IRR, which implies that the adaptations are useful not only for increasing or maintaining crop yields, but for saving water and use it efficiently.

Adaptation strategies for Mediterranean olive orchards to reduce the impact of heat stress on olive in the near future are less numerous than for crops as maize, and would be limited to the selection of cultivars with early flowering date (such as Arbequina or Koroneiki), the use of cover crops and soil management practices to modify the albedo to reduce air temperature (Davin et al. 2014), or the consideration of supplementary irrigation to reduce the olive canopy temperature (Doughty et al., 2011; Andrade et al., 2012). An additional adaptation strategy would be the selection of new suitable cultivation areas. Thus, new suitable areas for olive cultivation could be extended in the North-West and South areas of Andalusia region for Arbequina and in the Southern areas for Picual.

After the evaluation of the available crop and phenological models for impact and adaptation strategies assessment, a very significant knowledge gap has been detected for olive crop, contrasting with the available crop models for wheat, maize and other field crops. Thus, key processes such as chilling requirements or heat accumulation must be correctly simulated to make possible a reliable modeling of olive yield formation and therefore, crop yield estimation. Aware of these limitations 
previous approaches have been evaluated and a general approach has developed for estimating olive flowering date. The results obtained showed a good fit with the flowering dates for baseline and future conditions, so the new approach was adequate for generating projections of flowering dates under future climate conditions. However, not only olive crop has limitations in the development of approaches for evaluating key components for identifying the effect of climate change on crops. Thus, crop models must be improved to consider the effects of heat stress for both large (Ewert et al., 2015; Rezaei et al., 2015) and local scales. For that reason the simulation of maize grain yield under heat stress conditions has been evaluated.

A heat stress model has been developed and evaluated in order to simulate maize grain yield under heat stress conditions around silking, obtaining satisfactory performance. Thus, a heat stress reduction factor was obtained using experimental data from Argentine and validated with experimental data from Spain, being appropriate for using under climate change conditions. The model performance was improved when canopy temperature was considered as input for the heat stress function instead of air temperature. To use air temperature as input, the critical threshold must be increased from $34^{\circ} \mathrm{C}$, determined by Cicchino et al. (2010), to $39{ }^{\circ} \mathrm{C}$ as this critical threshold could be several degrees higher under irrigation conditions due to the irrigation cooling effect (Lobell et al., 2008; Kimball et al., 2015). The improvement in crop modeling for maize and olive crops has accomplished and demonstrated the need to promote experimental studies on crop physiology and phenology under forced conditions to increase the knowledge about the response of different Mediterranean crops to climate change. Furthermore, the importance of access to high quality experimental data, to calibrate and validate crop models under local and forced climate conditions has addressed. The collaboration between modellers and experimentalist has been proved to be useful. In addition, the development of specific experimental designs to feed the crop models to evaluate future climate conditions, as heat events or water deficits under different phenological phases for maize, olive or other crops, is recommended.

Several further maize model improvements could be desirable. Among them, to examine the correlation between hourly heat stress and radiation use efficiency under high temperatures. Furthermore the evaluation of the canopy temperature model 
under rainfed conditions could be useful, as uniquely under irrigated conditions has been analyzed. This evaluation under different conditions could improve the model applicability across different climate regions and management options. Regarding the olive model, a complete phenological characterization under different climate conditions, as warmer winters, could be useful to parametrize the chilling requirements and phenological stages. Furthermore an evaluation of the temperature profile along the olive tree could be useful to evaluate the impact of high temperatures during flowering under irrigation or rainfed conditions, as well as evaluating the flowering quality after high temperature exposure during flowering. Finally, the accurate assessment of the impact of water stress during critical phenological stages as flowering could provide a complete approach for determining the impact of climate change on olive crop.

The study is in line with the Climate-smart agriculture (CSA) approach proposed by FAO, as it is focused on the evaluation of the adaptations strategies to cope with the impacts of climate change. In addition, the improvement of crop models for the simulation of crop phenology and yield under heat stress conditions may contribute to further research in the world regions with the largest food security challenges. 


\section{GENERAL CONCLUSIONS}

The present Thesis has confirmed that:

- A reduction of uncertainty of impact and adaptation projections can be achieved by combining 1) bias corrected, reduced uncertainty climate projections, and 2) site-specific calibrated and validated crop models.

- Considering the impacts of extreme events in reducing the crop yield is crucial when assessing adaptations strategies. Crop models needs to be improved to capture these effects.

The present Thesis has concluded that:

- An irrigated maize yield reduction (6-20\%) is projected at the end of the $21^{\text {st }}$ century due to the shorter crop cycle that will cause crop evapotranspiration reduction and an increase in heat stress events frequency.

- Adaptation strategies such as earlier sowing dates and cultivar changes, when they are locally addressed, have the potential to compensate and even increase maize yields in Andalusia.

- The irrigation requirements of maize at the end of the $21^{\text {st }}$ century were reduced around $25 \%$ compared with the baseline period without adaptation strategies due to the reduction in crop evapotranspiration and higher water use efficiency. With the selected adaptation the decrease in the irrigation requirements showed a limited decrease or it was slightly higher in Granada compared to those without adaptation. This was due to the earlier maturity dates, which allowed the crop to avoid the driest and hottest period for the maize crop; however the irrigation requirements were still lower than those of the baseline period.

- Extreme temperature events during flowering may limit the effect of the adaptation measures for maize in some areas of Andalusia (as Granada) due to the later flowering date compared with the others locations studied. 
- SIMPLACE < Lintul5,HS,TC> model performed correctly in simulating grain yield maize reductions based on the accumulated stress thermal time above a critical threshold temperature during the critical period of flowering.

- The SIMPLACE <Lintul5,HS,TC> model performed better when canopy temperature was used as input in the heat stress function.

- When air temperature was considered for the critical threshold for heat stress in SIMPLACE <Lintul5,HS,TC> model, this threshold has to be increased from 34 ${ }^{\circ} \mathrm{C}$ (which is a physiologically meaningful threshold) to $39{ }^{\circ} \mathrm{C}$ (as the maize was considerably cooler than the air due to ambient cooling caused by irrigation).

- Increasing the critical temperature is an alternative option when air temperature is considered in the heat stress reduction function under irrigated conditions, but is not expected to be a suitable approach under rainfed conditions due to the lack of irrigation cooling effect.

- For olive flowering date estimation under climate change conditions a new approach adapted to future climate conditions was proposed and evaluated.

- For the entire Andalusia area, compared with 1981-2010 period, an advance in the flowering date of around 6 and 17 days for 2021-2050 and 2071-2100 periods, respectively, was estimated.

- These estimations for olive crop are robust due to the low associated uncertainty.

- The integration of local experimental data, phenological modelling and climate data from an ensemble of climate models throughout Andalusia allowed developing a spatial analysis of the impacts of climate change on olive flowering.

- Based on the estimation of the flowering date, chilling requirements and the occurrence of extreme events during the flowering stage, identification of vulnerable and potential new areas for olive cultivation was defined. Thus, Atlantic Ocean area and South-East coast were found to be vulnerable due to lack of chilling units in winter and the Northern-East region due to the high 
temperatures during flowering. Olive crop could be potentially extended to new areas as the southern area in the future.

- The described methodology is not exclusive for the olive crop and could be replicated to assess the impact of climate change on others Mediterranean crops such as nuts or fruit trees, requiring previous local calibration based on field experiments. 


\section{GENERAL REFERENCES}

Ainsworth, E.A., Long, S.P., 2005. What have we learned from 15 years of free air CO2 enrichment (FACE)? A meta-analytic review of the response of photosynthesis, canopy properties and plant production to rising CO2. New Phytol. 165, 351372.

Allen, L.H., Kakani, V.G., Vu, J.C. V, Boote, K.J., 2011. Elevated CO2 increases water use efficiency by sustaining photosynthesis of water-limited maize and sorghum. J. Plant Physiol. 168, 1909-1918.

Andrade, J.A., Vega, C., Uhart, S., Cirilo, A., Cantarero, M., Valentinuz, O., 1999. Kernel number determination in maize. Crop Sci. 39, 453-459.

Andrade, F.H., Echarte, L., Rizzalli, R., Della Maggiora, a., Casanovas, M., 2002. Kernel number prediction in maize under nitrogen or water stress. Crop Sci. 42, 11731179.

Andrade, J.A., Santos, F.L., Correia, M., do Paço, T.A., 2012. Effects of Irrigation and Tree Spacing on Soil and Air Temperature Profiles of Olive Orchards. VII Int. Symp. Olive Grow. 1057, 443-450.

Angelopoulos, K., Dichio, B., Xiloyannis, C., 1996. Inhibition of photosynthesis in olive trees (Olea europaea L.) during water stress and rewatering. J. Exp. Bot. 47, 1093-1100.

Angulo, C., Rötter, R., Lock, R., Enders, A., Fronzek, S., Ewert, F., 2013. Implication of crop model calibration strategies for assessing regional impacts of climate change in Europe. Agric. For. Meteorol. 170, 32-46.

Asseng, S., Ewert, F., Rosenzweig, C., Jones, J.W., Hatfield, J.L., Ruane, A.C., Boote, K.J., Thorburn, P.J., Rotter, R.P., Cammarano, D., Brisson, N., Basso, B., Martre, P., Aggarwal, P.K., Angulo, C., Bertuzzi, P., Biernath, C., Challinor, A.J., Doltra, J., Gayler, S., Goldberg, R., Grant, R., Heng, L., Hooker, J., Hunt, L.A., Ingwersen, J., Izaurralde, R.C., Kersebaum, K.C., Mueller, C., Kumar, S.N., Nendel, C., O'Leary, G., Olesen, J.E., Osborne, T.M., Palosuo, T., Priesack, E., Ripoche, D., Semenov, M.A., Shcherbak, I., Steduto, P., Stoeckle, C., Stratonovitch, P., Streck, T., Supit, I., Tao, F., Travasso, M., Waha, K., Wallach, D., White, J.W., Williams, J.R., Wolf, J., 2013. Uncertainty in Simulating Wheat Yields Under Climate Change. Nat. Clim. Chang. 3, 827-832.

Asseng, S., Ewert, F., Martre, P., Rötter, R.P., Lobell, D.B., Cammarano, D., Kimball, B. A., Ottman, M.J., Wall, G.W., White, J.W., Reynolds, M.P., Alderman, P.D., Prasad, P.V. V., Aggarwal, P.K., Anothai, J., Basso, B., Biernath, C., Challinor, A. J., De Sanctis, G., Doltra, J., Fereres, E., Garcia-Vila, M., Gayler, S., Hoogenboom, G., Hunt, L. A., Izaurralde, R.C., Jabloun, M., Jones, C.D., Kersebaum, K.C., Koehler, A.-K., Müller, C., Naresh Kumar, S., Nendel, C., O'Leary, G., Olesen, J.E., 
Palosuo, T., Priesack, E., Eyshi Rezaei, E., Ruane, A. C., Semenov, M. A., Shcherbak, I., Stöckle, C., Stratonovitch, P., Streck, T., Supit, I., Tao, F., Thorburn, P.J., Waha, K., Wang, E., Wallach, D., Wolf, J., Zhao, Z., Zhu, Y., 2015. Rising temperatures reduce global wheat production. Nat. Clim. Chang. 5, 143147.

Audsley, E., Pearn, K.R., Simota, C., Cojocaru, G., Koutsidou, E., Rounsevell, M.D.A., Trnka, M., Alexandrov, V., 2006. What can scenario modelling tell us about future European scale agricultural land use, and what not? Environ. Sci. Policy 9, 148-162.

Avolio, E., Pasqualoni, L., Federico, S., Fornaciari, M., Bonofiglio, T., Orlandi, F., Bellecci, C., Romano, B., 2008. Correlation between large-scale atmospheric fields and the olive pollen season in Central Italy. Int. J. Biometeorol. 52, 787-796.

Barnabás, B., Jäger, K., Fehér, A., 2008. The effect of drought and heat stress on reproductive processes in cereals. Plant, Cell Environ. 31, 11-38.

Barriopedro, D., Fischer, E.M., Luterbacher, J., Trigo, R.M., García-Herrera, R., 2011. The hot summer of 2010: redrawing the temperature record map of Europe. Science (80-. ). 332, 220-224.

Bassu, S., Brisson, N., Durand, J.L., Boote, K., Lizaso, J., Jones, J.W., Rosenzweig, C., Ruane, A.C., Adam, M., Baron, C., Basso, B., Biernath, C., Boogaard, H., Conijn, S., Corbeels, M., Deryng, D., De Sanctis, G., Gayler, S., Grassini, P., Hatfield, J., Hoek, S., Izaurralde, C., Jongschaap, R., Kemanian, A.R., Kersebaum, K.C., Kim, S.H., Kumar, N.S., Makowski, D., Müller, C., Nendel, C., Priesack, E., Pravia, M.V., Sau, F., Shcherbak, I., Tao, F., Teixeira, E., Timlin, D., Waha, K., 2014. How do various maize crop models vary in their responses to climate change factors? Glob. Chang. Biol. 20, 2301-2320.

Beniston, M., 2004. The 2003 heat wave in Europe: A shape of things to come? An analysis based on Swiss climatological data and model simulations. Geophys. Res. Lett. 31.

Beniston, M., Stephenson, D.B., Christensen, O.B., Ferro, C.A.T., Frei, C., Goyette, S., Halsnaes, K., Holt, T., Jylhä, K., Koffi, B., Palutikof, J., Schöll, R., Semmler, T., Woth, K., 2007. Future extreme events in European climate: an exploration of regional climate model projections. Clim. Change 81, 71-95.

Bindi, M., Olesen, J.E., 2011. The responses of agriculture in Europe to climate change. Reg. Environ. Chang. 11, 151-158.

Bonofiglio, T., Orlandi, F., Sgromo, C., Romano, B., Fornaciari, M., 2008. Influence of temperature and rainfall on timing of olive (Olea europaea) flowering in southern Italy. New Zeal. J. Crop Hortic. Sci. 36, 59-69. 
Boogaard, H.L., van Diepen, C.A., Rötter, R.P., Cabrera, J.M.C.A., van Laar, H.H., 1998. WOFOST 7.1. User's Guide for the WOFOST 7.1 Crop Growth Simulation Model and WOFOST Control Center 1.5.52. DLO Winand Staring Centre, Wageningen, p. 142

Boote, K.J., Jones, J.W., Hoogenboom, G., Pickering, N.B., 1998. The CROPGRO model for grain legumes. In: Tsuji, G.Y., et al. (Eds.), Understanding Options for Agricultural Production. Kluwer Academic Publisher, Dordrecht, The Netherlands, pp. 99-128.

Boote, K., Allen, L., Prasad, P.V.V., Baker, J., Gesch, R., Snyder, A., Pan, D., Thomas, J., 2005. Elevated temperature and $\mathrm{CO} 2$ impacts on pollination, reproductive growth, and yield of several globally important crops. J. Agric. Meteorol. 60, 469-474.

Boote, K.J., Jones, J.W., White, J.W., Asseng, S., Lizaso, J.I., 2013. Putting mechanisms into crop production models. Plant, Cell Environ. 36, 1658-1672.

CAPDR, 2008. El Sector del Aceite de Oliva y de la Aceituna de mesa en Andalucía. Consejería de Agriculuta, Pesca y Desarrollo Rural. Junta de Andalucía, Sevilla

CAPDR, 2016a. Observatorio de precios y mercados. Productos industriales. Aceite de oliva. Consejería de Agriculuta, Pesca y Desarrollo Rural. Junta de Andalucía, Sevilla

(http://www.juntadeandalucia.es/agriculturaypesca/observatorio/servlet/Front Controller?action=Subsector $\&$ table $=3940 \& e c=$ subsector $\&$ subsector $=33)$ (verifie d 10/01/2016)

CAPDR, 2016b. Superficies y producciones. Aforos olivar. Consejería de Agriculuta, Pesca y Desarrollo Rural Junta de Andalucía, Sevilla (http://www.juntadeandalucia.es/organismos/agriculturapescaydesarrollorural /servicios/estadisticas/detalle/69843.html)(verified 20/01/2016)

Carberry, P.S., Muchow, R.C., McCown, R.L., 1989. Testing the CERES-Maize simulation model in a semi-arid tropical environment. F. Crop. Res. 20, 297-315.

Castro, C.L., Roger, A., Pielke, S., Leoncini, G., 2005. Dynamical downscaling: Assessment of value retained and added using the Regional Atmospheric Modeling System (RAMS). J. Geophys. Res. 110: D05108.

Ceglar, A., Kajfež-Bogataj, L., 2012. Simulation of maize yield in current and changed climatic conditions: Addressing modelling uncertainties and the importance of bias correction in climate model simulations. Eur. J. Agron. 37, 83-95. 
Challinor, A.J., Wheeler, T.R., Craufurd, P.Q., Slingo, J.M., Grimes, D.I.F., 2004. Design and optimisation of a large-area process-based model for annual crops. Agric. For. Meteorol. 124, 99-120.

Challinor, A.J., Wheeler, T.R., Craufurd, P.Q., Slingo, J.M., 2005. Simulation of the impact of high temperature stress on annual crop yields. Agric. For. Meteorol. 135, 180-189.

Chen, X., Chen, F., Chen, Y., Gao, Q., Yang, X., Yuan, L., Zhang, F., Mi, G., 2013. Modern maize hybrids in Northeast China exhibit increased yield potential and resource use efficiency despite adverse climate change. Glob. Chang. Biol. 19, 923-936.

Christensen, J.H., Christensen, O.B., 2007. A summary of the PRUDENCE model projections of changes in European climate by the end of this century. Clim. Change 81, 7-30.

Christensen, J., Hewitson, B., Busuioc, A., Chen, A., Gao, X., Held, I., Jones, R., Kolli, R., Kwon, W.-T., Laprise, R., Magaña Rueda, V., Mearns, L., Menéndez, C., Räisänen, J., Rinke, A., Sarr, A., Whetton, P., 2007. Climate change 2007: The Physical Science Basis. Contribution of working group I to the fourth assessment report of the intergovernmental panel on climate change. Cambridge University Press, Cambridge, United Kingdom and New York, NY, USA.

Christensen, J.H., Boberg, F., Christensen, O.B., Lucas-Picher, P., 2008. On the need for bias correction of regional climate change projections of temperature and precipitation. Geophys. Res. Lett. 35, L20709

Cicchino, M., Edreira, J.I.R., Uribelarrea, M., Otegui, M.E., 2010. Heat Stress in FieldGrown Maize: Response of Physiological Determinants of Grain Yield. Crop Sci. 50, 1438-1448.

Connolly, R.D., 1998. Modelling effects of soil structure on the water balance of soilcrop systems: a review. Soil Tillage Res. 48, 1-19.

Connor, D.J., Fereres, E., 2005. The physiology of adaptation and yield expression in olive. Hortic. Rev. (Am. Soc. Hortic. Sci). 31, 155-229.

Cuevas, J., Rallo, L., Rapoport, H.F., 1994. Crop load effects on floral quality in olive. Sci. Hortic. (Amsterdam). 59, 123-130.

Cure, J.D., Acock, B., 1986. Crop responses to carbon dioxide doubling: a literature survey. Agric. For. Meteorol. 38, 127-145.

Davin, E.L., Seneviratne, S.I., Ciais, P., Olioso, A., Wang, T., 2014. Preferential cooling of hot extremes from cropland albedo management. Proc. Natl. Acad. Sci. U. S. A. 111, 9757-9761. 
Déqué, M., Rowell, D.P., Lüthi, D., Giorgi, F., Christensen, J.H., Rockel, B., Jacob, D., Kjellström, E., de Castro, M., van den Hurk, B., 2007. An intercomparison of regional climate simulations for Europe: assessing uncertainties in model projections. Clim. Change 81, 53-70.

Dent, J.B., Blackie, M.J., 1979. Systems Simulation in Agriculture. Applied Science Publ., Barking, Essex, UK.

Diaz-Espejo, A., Hafidi, B., Fernandez, J.E., Palomo, M.J., 2002. Transpiration and photosynthesis of the olive tree: a model approach. In: Vitagliano, C., Martelli, G.P. (Eds.), Proc 4th IS Olive Grow 586, 457-460.

Díaz-Espejo, A., Walcroft, A.S., Fernández, J.E., Hafridi, B., Palomo, M.J., Girón, I.F., 2006. Modeling photosynthesis in olive leaves under drought conditions. Tree Physiol. 26, 1445-1456.

Diepen, C.V., Wolf, J., Keulen, H.V., Rappoldt, C., 1989. WOFOST: a simulation model of crop production. Soil use Manag. 5, 16-24.

Dosio, A., Paruolo, P., 2011. Bias correction of the ENSEMBLES high-resolution climate change projections for use by impact models: Evaluation on the present climate. J. Geophys. Res. 116: D16106.

Dosio, A., Paruolo, P., Rojas, R., 2012. Bias correction of the ENSEMBLES high resolution climate change projections for use by impact models : analysis of the climate changes signal. J. Geophys. Res. 117: D17110.

Doughty, C.E., Field, C.B., McMillan, A.M.S., 2011. Can crop albedo be increased through the modification of leaf trichomes, and could this cool regional climate? Clim. Change 104, 379-387.

Easterling, D.R., Meehl, G.A., Parmesan, C., Changnon, S.A., Karl, T.R., Mearns, L.O., 2000. Climate extremes: observations, modeling, and impacts. Science. 289, 2068-2074.

Easterling, W., Aggarwal, P., Batima, P., Brander, K., Erda, L., Howden, M., Kirilenko, A., Morton, J., Soussana, J.F., Schmidhuber, J., Tubiello, F., 2007. Food, fibre and forest products. In: Parry, M.L., Canziani, O.F., Palutikof, J.P., van der Linden, P.J., Hanson,C.E. (Eds.), Climate Change 2007:Impacts, Adaptation and Vulnerability. Contribution of Working Group II to the Fourth Assessment Report of the Intergovernmental Panel on Climate Change. Cambridge University Press, Cambridge, UK, pp. 273-313.

Ewert, F., Rötter, R.P., Bindi, M., Webber, H., Trnka, M., Kersebaum, K.C., Olesen, J.E., van Ittersum, M.K., Janssen, S., Rivington, M., Semenov, M.A., Wallach, D., Porter, J.R., Stewart, D., Verhagen, J., Gaiser, T., Palosuo, T., Tao, F., Nendel, C., Roggero, P.P., Bartošová, L., Asseng, S., 2015. Crop modelling for integrated assessment of risk to food production from climate change. Environ. Model. Softw. 72, 287-303. 
FAOSTAT, 2016. Statistical Databases. Agriculture Data Collection (Primary Crops). FAO Food and Agriculture Organization of the United Nations, Rome (http://faostat.fao.org/).

Fereres, E., 1984. Variability in Adaptive-Mechanisms to Water Deficits in Annual and Perennial Crop Plants. Bull. La Soc. Bot. Fr. Bot. 131, 17-32.

Ferrise, R., Moriondo, M., Bindi, M., 2011. Probabilistic assessments of climate change impacts on durum wheat in the Mediterranean region. Nat. Hazards Earth Syst. Sci. 11, 1293-1302.

Field C, Barros V, Stocker T, Qin D and others (eds) 2012 Managing the risks of extreme events and disasters to advance climate change adaptation. A special report of working groups I and II of the intergovernmental panel on climate change. Cambridge University Press, Cambridge

Fischer, G., van Velthuizen, H., Shah, M., Nachtergaele, F.O., 2002. Global agroecological assessment for agriculture in the 21st century: methodology and results. In: Research Report RR-02-02. International Institute for Applied Systems Analysis (IIASA), Laxenburg.

Fischer, K.S., Palmer, A.F.E., 1984. Tropical maize. In: Goldsworthy, P.R., Fisher, N.M. (Eds.), The Physiology of Tropical Field Crops. John Wiley and Sons, Chichester, England, pp. 213-248.

Fourcaud, T., Zhang, X., Stokes, A., Lambers, H., Körner, C., 2008. Plant growth modelling and applications: The increasing importance of plant architecture in growth models. Ann. Bot. 101, 1053-1063.

Gaiser, T., Perkons, U., Martin, P., Kautz, T., Uteau-Puschmann, D., Ewert, F., Enders, A., Krauss, G., 2013. Modeling biopore effects on root growth and biomass production on soils with pronounced sub-soil clay accumulation. Ecol. Modell. 256, 6-15.

Galán, C., García-Mozo, H., Vázquez, L., Ruiz, L., Díaz de la Guardia, C., Trigo, M.M., 2005. Heat requirement for the onset of the Olea europaea L. pollen season in several sites in Andalusia and the effect of the expected future climate change. Int. J. Biometeorol. 49, 184-188.

García-Mozo, H., Mestre, A., Galán, C., 2010. Phenological trends in southern Spain: A response to climate change. Agric. For. Meteorol. 150, 575-580.

Garrido, A., Rey, D., Ruiz-Ramos, M., Mínguez, M.I., 2011. Climate change and crop adaptation in Spain: consistency of regional climate models. Clim. Res. 49, 211277. 
Giannakopoulos, C., Le Sager, P., Bindi, M., Moriondo, M., Kostopoulou, E., Goodess, C.M., 2009. Climatic changes and associated impacts in the Mediterranean resulting from a $2{ }^{\circ} \mathrm{C}$ global warming. Glob. Planet. Change $68,209-224$.

Giorgi, F., Lionello, P., 2008. Climate change projections for the Mediterranean region. Glob. Planet. Change 63, 90-104.

Giorgi, F., Jones, C., Asrar, G.R., 2009. Addressing climate information needs at the regional level: the CORDEX framework. World Meteorol. Organ. Bull. 58, 175183.

Gosling SN, Dunn R, Carrol F, Christidis N, Fullwood J, de Gusmao D, Golding N, Good L, Hall T, Kendon L. 2011. Climate: observations, projections and impacts. UK Met Office. Nottingham ePrints: Nottingham,UK.

Gourdji, S.M., Sibley, A.M., Lobell, D.B., 2013. Global crop exposure to critical high temperatures in the reproductive period: historical trends and future projections. Environ. Res. Lett. 8, 024041.

Grant, R.F., Jackson, B.S., Kiniry, J.R., Arkin, G.F., 1989. Water deficit timing effects on yield components in maize. Agron. J. 81, 61-65.

Gucci, R., Lodolini, E.M., Rapoport, H.F., 2009. Water deficit-induced changes in mesocarp cellular processes and the relationship between mesocarp and endocarp during olive fruit development. Tree Physiol. 29, 1-11.

Guereña, A., Ruiz-Ramos, M., Díaz-Ambrona, C.H., Conde, J.R., Mínguez, M.I., 2001. Assessment of Climate Change and Agriculture in Spain Using Climate Models. Agron. J. 93, 237-249.

Hawkins, E., Sutton, R., 2009. The potential to narrow uncertainty in regional climate predictions. Bull. Am. Meteorol. Soc. 90, 1095-1107.

Hawkins, E., Fricker, T.E., Challinor, A.J., Ferro, C.A.T., Ho, C.K., Osborne, T.M., 2013. Increasing influence of heat stress on French maize yields from the 1960s to the 2030s. Glob. Chang. Biol. 19, 937-947.

Herrera, S., Gutiérrez, J.M., Ancell, R., Pons, M.R., Frías, M.D., Fernández, J., 2012. Development and analysis of a 50-year high-resolution daily gridded precipitation dataset over Spain (Spain02). Int. J. Climatol. 32, 74-85.

Herrero, M.P., Johnson, R., 1980. High Temperature Stress and Pollen Viability of Maize. Crop Sci. 20, 796-800.

Hertig, E., Seubert, S., Jacobeit, J., 2010. Temperature extremes in the Mediterranean area: trends in the past and assessments for the future. Nat. Hazards Earth Syst. Sci. 10, 2039-2050. 
Hoffmann, H., Rath, T., 2013. Future bloom and blossom frost risk for Malus domestica considering climate model and impact model uncertainties. PLoS One 8, e75033.

Howden, S.M., Soussana, J.-F., Tubiello, F.N., Chhetri, N., Dunlop, M., Meinke, H., 2007. Adapting agriculture to climate change. Proc. Natl. Acad. Sci. 104, 1969119696.

Iglesias, A., Mínguez, M.I., 1995. Prospects for maize production in Spain under climate change. Clim. Chang. Agric. Anal. potential Int. impacts, 259-273.

Iglesias, A., Quiroga, S., Schlickenrieder, J., 2010. Climate change and agricultural adaptation: Assessing management uncertainty for four crop types in Spain. Clim. Res. 44, 83-94.

IPCC 2007 Climate Change 2007: Synthesis Report. Contribution of Working Groups I, II and III to the Fourth Assessment Report of the Intergovernmental Panel on Climate Change [Core Writing Team, Pachauri, R.K. and Reisinger, A. (Eds.)]. IPCC, Geneva, Switzerland, 104 pp.

IPCC, 2014: Climate Change 2014: Synthesis Report. Contribution of Working Groups I, II and III to the Fifth Assessment Report of the Intergovernmental Panel on Climate Change [Core Writing Team, R.K. Pachauri and L.A. Meyer (eds.)]. IPCC, Geneva, Switzerland, $151 \mathrm{pp}$.

Jones, C., Kiniry, J., 1986. CERES-Maize. A simulation model of maize growth and development. Texas A\&M Univ. Press. Coll. Station. TX.

Kimball, B.A., White, J.W., Ottman, M.J., Wall, G.W., Bernacchi, C.J., Morgan, J., Smith, D.P., 2015. Predicting canopy temperatures and infrared heater energy requirements for warming field plots. Agron. J. 107, 129-141.

Kiniry, J.R., Ritchie, J.T., 1985. Shade-sensitive interval of kernel number of maize. Agron. J. 77, 711-715.

Koubouris, G.C., Metzidakis, I.T., Vasilakakis, M.D., 2009. Impact of temperature on olive (Olea europaea L.) pollen performance in relation to relative humidity and genotype. Environ. Exp. Bot. 67, 209-214.

Leakey, A.D.B., Uribelarrea, M., Ainsworth, E. a, Naidu, S.L., Rogers, A., Ort, D.R., Long, S.P., 2006. Photosynthesis, productivity, and yield of maize are not affected by open-air elevation of $\mathrm{CO} 2$ concentration in the absence of drought. Plant Physiol. 140, 779-790.

Lieth, H., 1974. Phenology and Seasonality Modeling, vol.8. Springer-Verlag, BerlinHeidelberg/New York. 
Lizaso, J.I., Fonseca, A. E., Westgate, M.E., 2007. Simulating source-limited and sinklimited kernel set with CERES-Maize. Crop Sci. 47, 2078-2088.

Lobell, D.B., Bonfils, C.J., Kueppers, L.M., Snyder, M.A., 2008. Irrigation cooling effect on temperature and heat index extremes. Geophys. Res. Lett. 35, 1-5.

Lobell, D.B., Bänziger, M., Magorokosho, C., Vivek, B., 2011. Nonlinear heat effects on African maize as evidenced by historical yield trials. Nat. Clim. Chang. 1, 42-45.

Lobell, D.B., Hammer, G.L., McLean, G., Messina, C., Roberts, M.J., Schlenker, W., 2013. The critical role of extreme heat for maize production in the United States. Nat. Clim. Chang. 3, 497-501.

Long, S.P., Ainsworth, E.A., Leakey, A.D.B., Nösberger, J., Ort, D.R., 2006. Food for thought: lower-than-expected crop yield stimulation with rising $\mathrm{CO} 2$ concentrations. Science. 312, 1918-1921.

Luo, Q., 2011. Temperature thresholds and crop production: a review. Clim. Change 109, 583-598.

MAGRAMA. 2015. Anuario de Estadística, 2014. Ministerio de Agricultura, Alimentación y Medio Ambiente

Mancuso, S., Azzarello, E., 2002. Heat tolerance in olive. Adv. Hortic. Sci. 16, 125-130.

Meehl, G.A., Tebaldi, C., 2004. More intense, more frequent, and longer lasting heat waves in the 21st century. Science. 305, 994-997.

Menzel, A., Sparks, T.H., Estrella, N., Koch, E., Aaasa, A., Ahas, R., Alm-Kübler, K., Bissolli, P., Braslavská, O., Briede, A., Chmielewski, F.M., Crepinsek, Z., Curnel, Y., Dahl, A., Defila, C., Donnelly, A., Filella, Y., Jatczak, K., Mage, F., Mestre, A., Nordli, O., Peñuelas, J., Pirinen, P., Remisová, V., Scheifinger, H., Striz, M., Susnik, A., Van Vliet, A.J.H., Wielgolaski, F.E., Zach, S., Zust, A., 2006. European phenological response to climate change matches the warming pattern. Glob. Chang. Biol. 12, 1969-1976.

Meza, F.J., Silva, D., Vigil, H., 2008. Climate change impacts on irrigated maize in Mediterranean climates: Evaluation of double cropping as an emerging adaptation alternative. Agric. Syst. 98, 21-30.

Mínguez, M.I., Ruiz-Ramos, M., Díaz-Ambrona, C.H., Quemada, M., Sau, F., 2007. Firstorder impacts on winter and summer crops assessed with various highresolution climate models in the Iberian Peninsula. Clim. Change 81, 343-355

Moradi, R., Koocheki, A., Nassiri Mahallati, M., Mansoori, H., 2013. Adaptation strategies for maize cultivation under climate change in Iran: irrigation and planting date management. Mitig. Adapt. Strateg. Glob. Chang. 18, 265-284. 
Morales, A., Leffelaar, P.A., Testi, L., Orgaz, F., Villalobos, F.J., 2016. A dynamic model of potential growth of olive (Olea europaea L.) orchards. Eur. J. Agron. 74, 93102.

Moriondo, M., Bindi, M., Kundzewicz, Z.W., Szwed, M., Chorynski, A., Matczak, P., Radziejewski, M., McEvoy, D., Wreford, A., 2010. Impact and adaptation opportunities for European agriculture in response to climatic change and variability. Mitig. Adapt. Strateg. Glob. Chang. 15, 657-679.

Moriondo, M., Giannakopoulos, C., Bindi, M., 2011. Climate change impact assessment: the role of climate extremes in crop yield simulation. Clim. Change 104, 679-701.

Moriondo, M., Trombi, G., Ferrise, R., Brandani, G., Dibari, C., Ammann, C.M., Lippi, M.M., Bindi, M., 2013. Olive trees as bio-indicators of climate evolution in the Mediterranean Basin. Glob. Ecol. Biogeogr. 22, 818-833.

Moriondo, M., Ferrise, R., Trombi, G., Brilli, L., Dibari, C., Bindi, M., 2015. Modelling olive trees and grapevines in a changing climate. Environ. Model. Softw. 72, 387-401.

Moss, R.H., Edmonds, J.A., Hibbard, K.A., Manning, M.R., Rose, S.K., van Vuuren, D.P., Carter, T.R., Emori, S., Kainuma, M., Kram, T., Meehl, G.A., Mitchell, J.F.B., Nakićenović, N., Riahi, K., Smith, S.J., Stouffer, R.J., Thomson, A.M., Weyant, J.P., Wilbanks, T.J., 2010. The next generation of scenarios for climate change research and assessment. Nature 463, 747-756.

Nakićenović, N., Alcamo, J., Davis, G., de Vries, B., Fenhann, J., Gaffin, S., Gregory, K., Grübler, A., Jung, T.Y., Kram, T., La Rovere, E.L., Michaelis, L., Mori, S., Morita, T., Pepper, W., Pitcher, H., Price, L., Riahi, K., Roehrl, A., Rogner, H.-H., Sankovski, A., Schlesinger, M., Shukla, P., Smith, S., Swart, R., van Rooijen, S., Victor, N., Dadi, Z., 2000. IPCC Special Report on Emissions Scenarios. Cambridge University Press, Cambridge, United Kingdom and New York, NY, USA, 599 pp.

Ning, P., Li, S., Yu, P., Zhang, Y., Li, C., 2013. Post-silking accumulation and partitioning of dry matter, nitrogen, phosphorus and potassium in maize varieties differing in leaf longevity. F. Crop. Res. 144, 19-27.

Olesen, J.E., Bindi, M., 2002. Consequences of climate change for European agricultural productivity, land use and policy. Eur. J. Agron. 16, 239-262.

Olesen, J.E., Bindi, M., 2004. Agricultural impacts and adaptations to climate change in Europe. Farm Policy J. 1, 36-46. 
Olesen, J.E., Carter, T.R., Díaz-Ambrona, C.H., Fronzek, S., Heidmann, T., Hickler, T., Holt, T., Mínguez, M.I., Morales, P., Palutikof, J.P., Quemada, M., Ruiz-Ramos, M., Rubaek, G.H., Sau, F., Smith, B., Sykes, M.T., 2007. Uncertainties in projected impacts of climate change on European agriculture and terrestrial ecosystems based on scenarios from regional climate models. Clim. Change 81, 123-143.

Olesen, J.E., Trnka, M., Kersebaum, K.C., Skjelvåg, A. O., Seguin, B., Peltonen-Sainio, P., Rossi, F., Kozyra, J., Micale, F., 2011. Impacts and adaptation of European crop production systems to climate change. Eur. J. Agron. 34, 96-112.

Olesen, J.E., Børgesen, C.D., Elsgaard, L., Palosuo, T., Rötter, R.P., Skjelvåg, A.O., Peltonen-Sainio, P., Börjesson, T., Trnka, M., Ewert, F., Siebert, S., Brisson, N., Eitzinger, J., van Asselt, E.D., Oberforster, M., van der Fels-Klerx, H.J., 2012. Changes in time of sowing, flowering and maturity of cereals in Europe under climate change. Food Addit. Contam. Part A. 29, 1527-1542.

Ordóñez, R.A., Savin, R., Cossani, C.M., Slafer, G.A., 2015. Yield response to heat stress as affected by nitrogen availability in maize. F. Crop. Res. 183, 184-203.

Orlandi, F., Vazquez, L.M., Ruga, L., Bonofiglio, T., Fornaciari, M., Garcia-Mozo, H., Dominguez-Vilches, E., Romano, B., Galan, C., 2005. Bioclimatic requirements for olive flowering in two Mediterranean regions located at the same lalitude (Andalusia, Spain and Sicily, Italy). Ann. Agric. Environ. Med. 12, 47-52.

Orlandi, F., Garcia-Mozo, H., Galán, C., Romano, B., Díaz de la Guardia, C., Ruiz, L., Trigo, M. del M., Dominguez-Vilches, E., Fornaciari, M., 2010. Olive flowering trends in a large Mediterranean area (Italy and Spain). Int. J. Biometeorol. 54, 151-163.

Osborne, C.P., Chuine, I., Viner, D., Woodward, F.I., 2000. Olive phenology as a sensitive indicator of future climatic warming in the Mediterranean. Plant, Cell Environ. 23, 701-710.

Osborne, T., Rose, G., Wheeler, T., 2013. Variation in the global-scale impacts of climate change on crop productivity due to climate model uncertainty and adaptation. Agric. For. Meteorol. 170, 183-194.

Otegui, M.E., Bonhomme, R., 1998. Grain yield components in maize. F. Crop. Res. 56, 247-256.

Oteros, J., Orlandi, F., Garcia-Mozo, H., Aguilera, F., Ben Dhiab, A., Bonofiglio, T., Abichou, M., Ruiz-Valenzuela, L., del Trigo, M., de la Guardia, C., DominguezVilches, E., Msallem, M., Fornaciari, M., Galan, C., 2014. Better prediction of Mediterranean olive production using pollen-based models. Agron. Sustain. Dev. 34, 685-694. 
Porter, J.R., Gawith, M., 1999. Temperatures and the growth and development of wheat: a review. Eur. J. Agron. 10, 23-36.

Prasad, P.V.V., Craufurd, P.Q., Summerfield, R.J., Wheeler, T.R., 2000. Effects of short episode of heat stress on flower production and fruit-set of groundnut (Arachis hypogaea L.). J. Exp. Bot. 51, 777-784.

Prasad, P.V. V, Boote, K.J., Allen, L.H., 2006. Adverse high temperature effects on pollen viability, seed-set, seed yield and harvest index of grain-sorghum [Sorghum bicolor (L.) Moench] are more severe at elevated carbon dioxide due to higher tissue temperatures. Agric. For. Meteorol. 139, 237-251.

RAA (Red Andaluza de Aerobiología), 2015. http://www.ugr.es/ aerobio/. (verified 26/10/2015)

RAEA (Red Andaluza de Experimentación Agraria), 2015. Variedades comerciales de maíz. RAEA, Junta Andalucía, Seville

Raes, D., P. Steduto, T.C. Hsiao, Fereres, E., 2009. AquaCrop-The FAO Crop Model to Simulate Yield Response to Water: II. Main Algorithms and Software Description. Agron. J. 101, 438-447.

Rallo L 1994. Evaluacion agronomica y obtencion de nuevas variedades de olivo. Olivicultura. 62, 17-28

Rallo, L., Martin, G. C., 1991. THE ROLE OF CHILLING AND RELEASING OLIVE FLORAL BUDS FROM DORMANCY. HortScience. 26, 751-751.

Rapoport, H.F., Costagli, G., Gucci, R., 2004. The Effect of Water Deficit during Early Fruit Development on Olive Fruit Morphogenesis. J. Am. Soc. Hortic. Sci. 129, 121-127.

Rapoport, H.F., Hammami, S.B.M., Martins, P., Pérez-Priego, O., Orgaz, F., 2012. Influence of water deficits at different times during olive tree inflorescence and flower development. Environ. Exp. Bot. 77, 227-233.

Rattalino Edreira, J.I., Carpici, E.B., Sammarro, D., Otegui, M.E., 2011. Heat stress effects around flowering on kernel set of temperate and tropical maize hybrids. F. Crop. Res. 123, 62-73.

Rey, D., Garrido, A., Mínguez, M.I., Ruiz-Ramos, M., 2011. Impact of climate change on maize's water needs, yields and profitability under various water prices in Spain. Spanish J. Agric. Res. 9, 1047-1058.

Rezaei, E.E., Webber, H., Gaiser, T., Naab, J., Ewert, F., 2015. Heat stress in cereals: Mechanisms and modelling. Eur. J. Agron. 64, 98-113.

Ruiz-Ramos, M., Mínguez, M.I., 2010. Evaluating uncertainty in climate change impacts on crop productivity in the Iberian Peninsula. Clim. Res. 44, 69-82. 
Ruiz-Ramos, M., Sánchez, E., Galllardo, C., Mínguez, M.I., 2011. Impacts of projected maximum temperature extremes for $\mathrm{C} 21$ by an ensemble of regional climate models on cereal cropping systems in the Iberian Peninsula. Nat. Hazards Earth Syst. Sci. 11, 3275-3291.

Ruiz-Ramos, M., Rodríguez, A., Dosio, A., Goodess, C.M., Harpham, C., Mínguez, M.I., Sánchez, E., 2015. Comparing correction methods of RCM outputs for improving crop impact projections in the Iberian Peninsula for 21st century. Clim. Change 134, 283-297.

Sadras, V., Calderini, D., 2009. Crop physiology: applications for genetic improvement and agronomy. Acad. Press.

Sánchez, E., Gallardo, C., Gaertner, M.A., Arribas, A., Castro, M., 2004. Future climate extreme events in the Mediterranean simulated by a regional climate model: a first approach. Glob. Planet. Change 44, 163-180.

Sánchez, E., Miguez-Macho, G., 2010. Regional Climate Projections over the Iberian Peninsula: Climate Change Scenarios Modeling in Past, Present and Future, edited by: Pérez, F. and Boscolo, R., Regional climate change assessment report, ClivarSpain. 69-80.

Schär, C., Jendritzky, G., 2004. Hot news from summer 2003. Nature 432, 559-560.

Schlenker, W., Roberts, M.J., 2009. Nonlinear temperature effects indicate severe damages to U.S. crop yields under climate change. Proc. Natl. Acad. Sci. U. S. A. $106,15594-15598$.

Sebastiani, L., Minnocci, A., Scebba, F., Vitagliano, C., Panicucci, A., Lorenzini, G., 2002. Physiological and Biochemical Reactions of Olive Genotypes during SiteRelevant Ozone Exposure. Acta Hortic. 586, 445-448.

Semenov, M.A., Stratonovitch, P., 2010. Use of multi-model ensembles from global climate models for assessment of climate change impacts. Clim. Res. 41, 1-14.

Seneviratne, S., Nicholls, N., Easterling, D., Goodess, C., Kanae, S., Kossin, J., Luo, Y., Marengo, J., Mclnnes, K., Rahimi, M., 2012. Changes in climate extremes and their impacts on the natural physical environment: an overview of the IPCC SREX report. In: EGU General Assembly Conference Abstracts, p. 12566.

Slafer, G., Kantolic, A., Appendino, M., Miralles, D., Savin, R., 2009. Crop development: genetic control, environmental modulation and relevance for genetic improvement of crop yield. Crop physiology: Applications for genetic improvement and agronomy, 19, pp 277-308.

Steduto, P., Hsiao, T.C., Fereres, E., Raes, D., 2012. Crop yield response to water. Irrigation and Drainage Paper No. 66. FAO, Rome. 
Stockle, C.O., Donatelli, M., Nelson, R., 2003. CropSyst, a cropping systems simulation model. Eur. J. Agron. 18, 289-307.

Sugiyama, S., 1995. The relationship between growth and developement of vegetative shoots in genotypes of tall fescue (F. arundinacea Schreb.). Ann. Bot. 76, 553558.

Tebaldi, C., Hayhoe, K., Arblaster, J.M., Meehl, G.A., 2006. Going to the Extremes. An intercomparison of model-simulated historical and future changes in extreme events. Clim. Change 79, 185-211.

Teixeira, E.I., Fischer, G., van Velthuizen, H., Walter, C., Ewert, F., 2013. Global hotspots of heat stress on agricultural crops due to climate change. Agric. For. Meteorol. 170, 206-215.

Thornley, J.H., France, J., 2007. Mathematical models in agriculture: quantitative methods for the plant, animal and ecological sciences. Cabi.

Todorovic, M., Albrizio, R., Zivotic, L., Saab, M.-T.A., Stöckle, C., Steduto, P., 2009. Assessment of AquaCrop, CropSyst, and WOFOST Models in the Simulation of Sunflower Growth under Different Water Regimes. Agron. J. 101, 509-521.

Tognetti, R., Sebastiani, L., Minnocci, A., Raschi, A., 2002. Foliar Responses of Olive Trees (Olea Europaea L.) under Field Exposure to Elevated CO 2 Concentration. IV Int. Symp. Olive Grow. 586, 449-452.

Tollenaar, M., Lee, E.A., 2011. 2. Strategies for Enhancing Grain Yield in Maize. Plant Breed. Rev. 34, 37-82.

Trnka, M., Rötter, R.P., Ruiz-Ramos, M., Kersebaum, K.C., Olesen, J.E., Žalud, Z., Semenov, M.A., 2014. Adverse weather conditions for European wheat production will become more frequent with climate change. Nat. Clim. Chang. 4, 637-643.

Tubiello, F.N., Fischer, G., 2007. Reducing climate change impacts on agriculture: Global and regional effects of mitigation, 2000-2080. Technol. Forecast. Soc. Change 74, 1030-1056.

Van der Linden, P., Mitchell, J.F.B. (eds.) 2009. ENSEMBLES: Climate Change and its Impacts: Summary of research and results fromthe ENSEMBLES project. MetOfficeHadley Centre, FitzRoy Road, Exeter EX1 3 PB, UK. 160

van der Velde, M., Tubiello, F.N., Vrieling, A., Bouraoui, F., 2012. Impacts of extreme weather on wheat and maize in France: evaluating regional crop simulations against observed data. Clim. Change 113, 751-765. 
Vanuytrecht, E., Raes, D., Willems, P., Geerts, S., 2012. Quantifying field-scale effects of elevated carbon dioxide concentration on crops. Clim. Res. 54, 35-47.

Villalobos, F.J., Testi, L., Hidalgo, J., Pastor, M., Orgaz, F., 2006. Modelling potential growth and yield of olive (Olea europaea L.) canopies. Eur. J. Hort. Sci 24, 296303.

Viola, F., Noto, L.V., Cannarozzo, M., La Loggia, G., Porporato, A., 2012. Olive yield as a function of soil moisture dynamics. Ecohydrology 5, 99-107.

Vu, J.C., Allen, L.H., 2009. Growth at elevated CO2 delays the adverse effects of drought stress on leaf photosynthesis of the C4 sugarcane. J. Plant Physiol. 166, 107-116.

Vučetić, V., 2011. Modelling of maize production in Croatia: present and future climate. J. Agric. Sci. 149, 145-157.

Vuletin Selak, G., Perica, S., Goreta Ban, S., Poljak, M., 2013. The effect of temperature and genotype on pollen performance in olive (Olea europaea L.). Sci. Hortic. (Amsterdam). 156, 38-46.

Wahid, A., Gelani, S., Ashraf, M., Foolad, M.R., 2007. Heat tolerance in plants: An overview. Environ. Exp. Bot. 61, 199-223.

Warrick, R.A., Gifford, R.M., Parry, M.L. 1986 CO2, climatic change and agriculture. In Scope 29: The Greenhouse Effect, Climatic Change and Ecosystems (eds. B. Bolin, B.R. Doos, J. Jager and R.A. Warrick), pp. 393-473. John Wiley and Sons, Chichester

Wheeler, T.R., Craufurd, P.Q., Ellis, R.H., Porter, J.R., Prasad, P.V.V., 2000. Temperature variability and the yield of annual crops. Agric. Ecosyst. Environ. 82, 159-167.

Wilby, R.L., Wigley, T.M.L., Conway, D., Jones, P.D., Hewitson, B.C., Main, J., Wilks, D.S., 1998. Statistical downscaling of general circulation model output: A comparison of methods. Water Resour. Res. 34, 2995-3008. 


\section{REFERENCES CHAPTER 1}

Ainsworth, E.A., Long, S.P., 2005. What have we learned from 15 years of free air CO2 enrichment (FACE)? A meta-analytic review of the response of photosynthesis, canopy properties and plant production to rising CO2. New Phytol. 165, 351372.

Angulo, C., Rötter, R., Lock, R., Enders, A., Fronzek, S., Ewert, F., 2013. Implication of crop model calibration strategies for assessing regional impacts of climate change in Europe. Agric. For. Meteorol. 170, 32-46.

Beniston, M., 2004. The 2003 heat wave in Europe: A shape of things to come? An analysis based on Swiss climatological data and model simulations. Geophys. Res. Lett. 31: L02202.

Beniston, M., Stephenson, D.B., Christensen, O.B., Ferro, C.A.T., Frei, C., Goyette, S., Halsnaes, K., Holt, T., Jylhä, K., Koffi, B., Palutikof, J., Schöll, R., Semmler, T., Woth, K., 2007. Future extreme events in European climate: an exploration of regional climate model projections. Clim. Change 81, 71-95.

Bindi, M., Olesen, J.E., 2011. The responses of agriculture in Europe to climate change. Reg. Environ. Chang. 11, 151-158.

Boote, K.J., Jones, J.W., White, J.W., Asseng, S., Lizaso, J.I., 2013. Putting mechanisms into crop production models. Plant, Cell Environ. 36, 1658-1672

CAPDR, 2011. Agenda del regadío andaluz. Horizonte 2015. Consejería de Agriculuta, Pesca y Desarrollo Rural. Junta Andalucía, Seville (in Spanish)

Cassman, K.G., Dobermann, A., Walters, D.T., Yang, H., 2003. Meeting Cereal Demand While Protecting Natural Resources and Improving Environmental Quality. Annu. Rev. Environ. Resour. 28, 315-358.

Castro, C.L., Roger, A., Pielke, S., Leoncini, G., 2005. Dynamical downscaling: Assessment of value retained and added using the Regional Atmospheric Modeling System (RAMS). J. Geophys. Res. 110: D05108.

Ceglar, A., Kajfež-Bogataj, L., 2012. Simulation of maize yield in current and changed climatic conditions: Addressing modelling uncertainties and the importance of bias correction in climate model simulations. Eur. J. Agron. 37, 83-95.

Chen, X., Chen, F., Chen, Y., Gao, Q., Yang, X., Yuan, L., Zhang, F., Mi, G., 2013. Modern maize hybrids in Northeast China exhibit increased yield potential and resource use efficiency despite adverse climate change. Glob. Chang. Biol. 19, 923-936. 
Christensen, J.H., Christensen, O.B., 2007. A summary of the PRUDENCE model projections of changes in European climate by the end of this century. Clim. Change 81, 7-30.

Christensen, J.H., Rummukainen, M., Lenderink, G., 2009. Formulation of very-highresolution regional climate model ensembles for Europe ENSEMBLES: Climate Change and its Impacts: Summary of Research and Results from the ENSEMBLES Project. ed P van der Linden J F B Mitchell (Exeter, UK Met Off. Hadley Centre) 47-58.

Christensen, O.B., Goodess, C.M., Ciscar, J.C., 2012. Methodological framework of the PESETA project on the impacts of climate change in Europe. Clim. Change 112, $7-28$.

Cure, J.D., Acock, B., 1986. Crop responses to carbon dioxide doubling: a literature survey. Agric. For. Meteorol. 38, 127-145.

Dosio, A., Paruolo, P., 2011. Bias correction of the ENSEMBLES high-resolution climate change projections for use by impact models: Evaluation on the present climate. J. Geophys. Res. 116, D16106.

Dosio, A., Paruolo, P., Rojas, R., 2012. Bias correction of the ENSEMBLES high resolution climate change projections for use by impact models : analysis of the climate changes signal. J. Geophys. Res. 117, D17110.

Easterling, D.R., Meehl, G.A., Parmesan, C., Changnon, S.A., Karl, T.R., Mearns, L.O., 2000. Climate extremes: observations, modeling, and impacts. Science. 289, 2068-2074.

Espadafor, M., Lorite, I.J., Gavilán, P., Berengena, J., 2011. An analysis of the tendency of reference evapotranspiration estimates and other climate variables during the last 45 years in Southern Spain. Agric. Water Manag. 98, 1045-1061.

Essenwanger, O.M., 2001. General Climatology 1C: Classification of Climates. Amsterdam Elsevier Sci.

Førland, E.J., Benestad, R., Hanssen-Bauer, I., Haugen, J.E., Skaugen, T.E., 2011. Temperature and Precipitation Development at Svalbard 1900-2100. Adv. Meteorol. 2011, 893790.

García-López, J., Lorite, I.J., García-Ruiz, R., Domínguez, J., 2014. Evaluation of three simulation approaches for assessing yield of rainfed sunflower in a Mediterranean environment for climate change impact modelling. Clim. Change $124,147-162$. 
Garrido, A., Rey, D., Ruiz-Ramos, M., Mínguez, M.I., 2011. Climate change and crop adaptation in Spain: consistency of regional climate models. Clim. Res. 49, 211277.

Gavilán, P., Lorite, I.J., Tornero, S., Berengena, J., 2006. Regional calibration of Hargreaves equation for estimating reference ET in a semiarid environment. Agric. Water Manag. 81, 257-281.

Giannakopoulos, C., Le Sager, P., Bindi, M., Moriondo, M., Kostopoulou, E., Goodess, C.M., 2009. Climatic changes and associated impacts in the Mediterranean resulting from a $2{ }^{\circ} \mathrm{C}$ global warming. Glob. Planet. Change 68, 209-224.

Giorgi, F., Christensen, J., Hulme, M., von Storch, H., Whetton, P., Jones, R., Mearns, L., Fu, C., Arritt, R., Bates, B., Benestad, R., Boer, G., Buishand, A., Castro, M., Chen, D., Cramer, W., Crane, R., Crossly, J., Dehn, M., Dethloff, K., Dippner, J., Emori, S., Francisco, R., Fyfe, J., Gerstengarbe, F., Gutowski, W., Gyalistras, D., Hanssen-Bauer, I., Hantel, M., Hassell, D., Heimann, D., Jack, C., Jacobeit, J., Kato, H., Katz, R., Kauker, F., Knutson, T. , Lal, M., Landsea, C., Laprise, R., Leung, L., Lynch, A., May, W., McGregor, J., Miller, N., Murphy, J., Ribalaygua, J., Rinke, A., Rummukainen, M., Semazzi, F., Walsh, K., Werner, P., Widmann, M., Wilby, R., Wild, M. and Xue, Y. 2001: Regional climate information: evaluations and projections. In: Houghton JT, Ding Y, Griggs DJ, Noguer M and others (eds) Climate change 2001: the scientific basis. Contribution of Working Group I to the Third Assessment Report of the Intergovernmental Panel on Climate Change. Cambridge University Press Cambridge, p 583-638

Guereña, A., Ruiz-Ramos, M., Díaz-Ambrona, C.H., Conde, J.R., Mínguez, M.I., 2001. Assessment of Climate Change and Agriculture in Spain Using Climate Models. Agron. J. 93, 237-249.

Hawkins, E., Osborne, T.M., Ho, C.K., Challinor, A.J., 2013. Calibration and bias correction of climate projections for crop modelling: An idealised case study over Europe. Agric. For. Meteorol. 170, 19-31.

Haylock, M.R., Hofstra, N., Tank, A.M.G.K., Klok, E.J., Jones, P.D., New, M., 2008. A European daily high-resolution gridded data set of surface temperature and precipitation for 1950-2006. J. Geophys. Res. 113, D20119.

Herrero, M.P., Johnson, R.., 1980. High Temperature Stress and Pollen Viability of Maize. Crop Sci. 20, 796-800.

Hertig, E., Seubert, S., Jacobeit, J., 2010. Temperature extremes in the Mediterranean area: trends in the past and assessments for the future. Nat. Hazards Earth Syst. Sci. 10, 2039-2050.

Hoogenboom, G., Tsuji, G., Pickering, N., Curry, R., Jones, J., Singh, U., Godwin, D., 1995 Decision support system to study climate change impacts on crop production. 
In: Rosenzweig C, Allen LH Jr, Harper LA, Hollinger SE, Jones JW (eds) Climate change and agriculture: analysis of potential international impacts. Spec Publ 59. American Society of Agronomy, Madison, WI, p 51-75

Hoogenboom, G., Jones, J.W., Porter, C.H., Wilkens, P.W., Boote, K.J., Hunt, L.A., Tsuji, G.Y., 2010. Decision Support System for Agrotechnology Transfer (DSSAT) version 4.5. University of Hawaii, Honolulu

Iglesias, A., Mínguez, M.I., 1995. Perspectives for maize production in Spain under climate change. In: Rosenzweig C, Allen LH Jr, Harper LA, Hollinger SE, Jones JW (eds) Climate change and agriculture: analysis of potential international impacts. Spec Publ 59. American Society of Agronomy, Madison, WI, p 259-273

Jones, C., Kiniry, J., 1986. CERES-Maize. A simulation model of maize growth and development. Texas A\&M Univ. Press. Coll. Station. TX.

Jones, J.W., Hoogenboom, G., Porter, C.H., Boote, K.J., Batchelor, W.D., Hunt, L.A., Wilkens, P.W., Singh, U., Gijsman, A.J., Ritchie, J.T., 2003. The DSSAT cropping system model. Eur. J. Agron. 18, 235-265.

Kimball, B.A., 1983. Carbon dioxide and agricultural yield: an assemblage and analysis of 430 prior observations. Agron. J. 75, 779-788.

Kiniry, J.R., 1991. Maize phasic development.In: Hanks J, Ritchie JT (eds), in: Modeling Plant and Soil Systems. American Society of Agronomy, Crop Science Society of America, Soil Science Society of America. pp. 55-70.

Leakey, A.D.B., Uribelarrea, M., Ainsworth, E. a, Naidu, S.L., Rogers, A., Ort, D.R., Long, S.P., 2006. Photosynthesis, productivity, and yield of maize are not affected by open-air elevation of $\mathrm{CO} 2$ concentration in the absence of drought. Plant Physiol. 140, 779-790.

López de la Franca, N., Sánchez, E., Domínguez, M., 2013. Changes in the onset and length of seasons from an ensemble of regional climate models over Spain for future climate conditions. Theor. Appl. Climatol. 114, 635-642.

MAGRAMA (Ministerio de Agricultura, Alimentación y Medio Ambiente), 2013. Anuario de estadística, 2012. MAGRAMA, Madrid

MAGRAMA (Ministerio de Agricultura, Alimentación y Medio Ambiente), 2015. Análisis y prospectiva en medio ambiente, agricultura, pesca, alimentación y desarrollo rural. Dossier Autonómico Comunidad Autónoma Andalucía. MAGRAMA, Madrid. www.magrama. gob.es/es/ ministerio/servicios/analisis-y-prospectiva/ Dossier_Andalucia_tcm7-183042.pdf (accessed 19 Mar 2015)

Meehl, G.A., Tebaldi, C., 2004. More intense, more frequent, and longer lasting heat waves in the 21st century. Science. 305, 994-997. 
Meza, F.J., Silva, D., Vigil, H., 2008. Climate change impacts on irrigated maize in Mediterranean climates: Evaluation of double cropping as an emerging adaptation alternative. Agric. Syst. 98, 21-30.

Mínguez, I., Ruiz, A., Estrada, A., 2005. Impacts on the agrarian sector. A preliminary general assessment of the impacts in Spain due to the effects of climate change. Ministerio de Medio Ambiente, Spain.

Mínguez, M.I., Ruiz-Ramos, M., Díaz-Ambrona, C.H., Quemada, M., Sau, F., 2007. Firstorder impacts on winter and summer crops assessed with various highresolution climate models in the Iberian Peninsula. Clim. Change 81, 343-355.

Moradi, R., Koocheki, A., Nassiri Mahallati, M., Mansoori, H., 2013. Adaptation strategies for maize cultivation under climate change in Iran: irrigation and planting date management. Mitig. Adapt. Strateg. Glob. Chang. 18, 265-284.

Moriondo, M., Bindi, M., Kundzewicz, Z.W., Szwed, M., Chorynski, A., Matczak, P., Radziejewski, M., McEvoy, D., Wreford, A., 2010. Impact and adaptation opportunities for European agriculture in response to climatic change and variability. Mitig. Adapt. Strateg. Glob. Chang. 15, 657-679.

Moriondo, M., Giannakopoulos, C., Bindi, M., 2011. Climate change impact assessment: the role of climate extremes in crop yield simulation. Clim. Change 104, 679-701.

Ning, P., Li, S., Yu, P., Zhang, Y., Li, C., 2013. Post-silking accumulation and partitioning of dry matter, nitrogen, phosphorus and potassium in maize varieties differing in leaf longevity. F. Crop. Res. 144, 19-27.

Olesen, J.E., Carter, T.R., Díaz-Ambrona, C.H., Fronzek, S., Heidmann, T., Hickler, T., Holt, T., Mínguez, M.I., Morales, P., Palutikof, J.P., Quemada, M., Ruiz-Ramos, M., Rubaek, G.H., Sau, F., Smith, B., Sykes, M.T., 2007. Uncertainties in projected impacts of climate change on European agriculture and terrestrial ecosystems based on scenarios from regional climate models. Clim. Change 81, 123-143.

Olesen, J.E., Trnka, M., Kersebaum, K.C., Skjelvåg, A. O., Seguin, B., Peltonen-Sainio, P., Rossi, F., Kozyra, J., Micale, F., 2011. Impacts and adaptation of European crop production systems to climate change. Eur. J. Agron. 34, 96-112.

Osborne, T., Rose, G., Wheeler, T., 2013. Variation in the global-scale impacts of climate change on crop productivity due to climate model uncertainty and adaptation. Agric. For. Meteorol. 170, 183-194.

Palosuo, T., Kersebaum, K.C., Angulo, C., Hlavinka, P., Moriondo, M., Olesen, J.E., Patil, R.H., Ruget, F., Rumbaur, C., Takáč, J., Trnka, M., Bindi, M., Çaldağ, B., Ewert, F., 
Ferrise, R., Mirschel, W., Şaylan, L., Šiška, B., Rötter, R., 2011. Simulation of winter wheat yield and its variability in different climates of Europe: A comparison of eight crop growth models. Eur. J. Agron. 35, 103-114.

Prasad, P.V. V, Boote, K.J., Allen, L.H., 2006. Adverse high temperature effects on pollen viability, seed-set, seed yield and harvest index of grain-sorghum [Sorghum bicolor (L.) Moench] are more severe at elevated carbon dioxide due to higher tissue temperatures. Agric. For. Meteorol. 139, 237-251.

RAEA (Red Andaluza de Experimentación Agraria), 2012. Variedades comerciales de maíz. RAEA, Junta Andalucía, Seville

Rey, D., Garrido, A., Mínguez, M.I., Ruiz-Ramos, M., 2011. Impact of climate change on maize's water needs, yields and profitability under various water prices in Spain. Spanish J. Agric. Res. 9, 1047-1058.

Rötter, R.P., Carter, T.R., Olesen, J.E., Porter, J.R., 2011. Crop-climate models need an overhaul. Nat. Clim. Chang. 1, 175-177.

Ruiz-Ramos, M., Mínguez, M.I., 2010. Evaluating uncertainty in climate change impacts on crop productivity in the Iberian Peninsula. Clim. Res. 44, 69-82.

Ruiz-Ramos, M., Sánchez, E., Galllardo, C., Mínguez, M.I., 2011. Impacts of projected maximum temperature extremes for $\mathrm{C} 21$ by an ensemble of regional climate models on cereal cropping systems in the Iberian Peninsula. Nat. Hazards Earth Syst. Sci. 11, 3275-3291.

Sánchez, E., Miguez-Macho, G., 2010. Regional Climate Projections over the Iberian Peninsula: Climate Change Scenarios Modeling in Past, Present and Future, edited by: Pérez, F. and Boscolo, R., Regional climate change assessment report, ClivarSpain. 69-80.

Sánchez, E., Gallardo, C., Gaertner, M.A., Arribas, A., Castro, M., 2004. Future climate extreme events in the Mediterranean simulated by a regional climate model: a first approach. Glob. Planet. Change 44, 163-180.

Schär, C., Jendritzky, G., 2004. Hot news from summer 2003. Nature 432, 559-560.

Semenov, M.A., Stratonovitch, P., 2010. Use of multi-model ensembles from global climate models for assessment of climate change impacts. Clim. Res. 41, 1-14.

Soil Survey Staff (1999) Soil taxonomy. Agric Handb 436, 2nd edn. Natural Resources Conservation Service, US Department of Agriculture, Washington, DC

Tebaldi, C., Hayhoe, K., Arblaster, J.M., Meehl, G.A., 2006. Going to the Extremes. An intercomparison of model-simulated historical and future changes in extreme events. Clim. Change 79, 185-211. 
Teixeira, E.I., Fischer, G., van Velthuizen, H., Walter, C., Ewert, F., 2013. Global hotspots of heat stress on agricultural crops due to climate change. Agric. For. Meteorol. 170, 206-215.

Tollenaar, M., Lee, E.A., 2011. 2. Strategies for Enhancing Grain Yield in Maize. Plant Breed. Rev. 34, 37-82.

Travis, W.R., Huisenga, M.T., 2013. The effect of rate of change, variability, and extreme events on the pace of adaptation to a changing climate. Clim. Change 121, 209-222.

Trnka, M., Rötter, R.P., Ruiz-Ramos, M., Kersebaum, K.C., Olesen, J.E., Žalud, Z., Semenov, M.A., 2014. Adverse weather conditions for European wheat production will become more frequent with climate change. Nat. Clim. Chang. 4, 637-643.

Tubiello, F.N., Donatelli, M., Rosenzweig, C., Stockle, C.O., 2000. Effects of climate change and elevated $\mathrm{CO} 2$ on cropping systems: model predictions at two Italian locations. Eur. J. Agron. 13, 179-189.

van Ittersum, M.K., Cassman, K.G., Grassini, P., Wolf, J., Tittonell, P., Hochman, Z., 2013. Yield gap analysis with local to global relevance-A review. F. Crop. Res. 143, 4-17.

Vanuytrecht, E., Raes, D., Willems, P., Geerts, S., 2012. Quantifying field-scale effects of elevated carbon dioxide concentration on crops. Clim. Res. 54, 35-47.

Vučetić, V., 2011. Modelling of maize production in Croatia: present and future climate. J. Agric. Sci. 149, 145-157.

Wilby, R.L., Wigley, T.M.L., Conway, D., Jones, P.D., Hewitson, B.C., Main, J., Wilks, D.S., 1998. Statistical downscaling of general circulation model output: A comparison of methods. Water Resour. Res. 34, 2995-3008.

Yano, T., Aydin, M., Haraguchi, T., 2007. Impact of Climate Change on Irrigation Demand and Crop Growth in a Mediterranean Environment of Turkey. Sensors 7, 2297-2315. 


\section{REFERENCES CHAPTER 2}

Alexander, L. V., Zhang, X., Peterson, T.C., Caesar, J., Gleason, B., Klein Tank, A.M.G., Haylock, M., Collins, D., Trewin, B., Rahimzadeh, F., Tagipour, A., Rupa Kumar, K., Revadekar, J., Griffiths, G., Vincent, L., Stephenson, D.B., Burn, J., Aguilar, E., Brunet, M., Taylor, M., New, M., Zhai, P., Rusticucci, M., Vazquez-Aguirre, J.L., 2006. Global observed changes in daily climate extremes of temperature and precipitation. J. Geophys. Res. Atmos. 111, 1-22.

Andrade, F.H., Vega, C., Uhart, S., Cirilo, A., Cantarero, M., Valentinuz, O., 1999. Kernel number determination in maize. Crop Sci. 39, 453-459.

Andrade, F.H., Echarte, L., Rizzalli, R., Della Maggiora, a., Casanovas, M., 2002. Kernel number prediction in maize under nitrogen or water stress. Crop Sci. 42, 11731179.

Beniston, M., Stephenson, D.B., Christensen, O.B., Ferro, C.A.T., Frei, C., Goyette, S., Halsnaes, K., Holt, T., Jylhä, K., Koffi, B., Palutikof, J., Schöll, R., Semmler, T., Woth, K., 2007. Future extreme events in European climate: an exploration of regional climate model projections. Clim. Change 81, 71-95.

Blumenthal, C., Bekes, F., Batey, I., Wrigley, C., Moss, H., Mares, D., Barlow, E., 1991. Interpretation of grain quality results from wheat variety trials with reference to high-temperature stress. Aust. J. Agric. Res. 42, 325-334.

Bolanos, J., Edmeades, G.O., 1996. The importance of the anthesis - silking interval in breeding for drought tolerance in tropical maize. F. Crop. Res. 48, 65-80.

Challinor, A.J., Wheeler, T.R., Craufurd, P.Q., Slingo, J.M., 2005. Simulation of the impact of high temperature stress on annual crop yields. Agric. For. Meteorol. 135, 180-189.

Challinor, A.J., Wheeler, T.R., Craufurd, P.Q., Slingo, J.M., Grimes, D.I.F., 2004. Design and optimisation of a large-area process-based model for annual crops. Agric. For. Meteorol. 124, 99-120.

Cicchino, M., Rattalino Edreira, J.I., Otegui, M.E., 2010a. Heat stress during late vegetative growth of maize: effects on phenology and assessment of optimum temperature. Crop Sci. 50, 1431-1437.

Cicchino, M., Rattalino Edreira, J.I., Uribelarrea, M., Otegui, M.E., 2010b. Heat stress in field-grown maize: response of physiological determinants of grain yield. Crop Sci. 50, 1438-1448.

Dupuis, L., Dumas, C., 1990. Influence of temperature stress on in vitro fertilization and heat shock protein synthesis in maize (Zea mays L.) reproductive systems. Plant Physiol. 94, 665-670. 
Ewert, F., Rötter, R.P., Bindi, M., Webber, H., Trnka, M., Kersebaum, K.C., Olesen, J.E., van Ittersum, M.K., Janssen, S., Rivington, M., Semenov, M.A., Wallach, D., Porter, J.R., Stewart, D., Verhagen, J., Gaiser, T., Palosuo, T., Tao, F., Nendel, C., Roggero, P.P., Bartošová, L., Asseng, S., 2015. Crop modelling for integrated assessment of risk to food production from climate change. Environ. Model. Softw. 72, 287-303.

Field C, Barros V, Stocker T, Qin D and others (eds) 2012 Managing the risks of extreme events and disasters to advance climate change adaptation. A special report of working groups I and II of the intergovernmental panel on climate change. Cambridge University Press, Cambridge

Fischer, K.S., Palmer, A.F.E., 1984. Tropical maize. In: Goldsworthy, P.R., Fisher, N.M. (Eds.), The physiology of tropical field crops. John Wiley \& Sons, Chichester, England, pp. 213-248.

Fonseca, A.E., Lizaso, J.I., Westgate, M.E., Grass, L., Dornbos, Jr, D.L., 2004. Simulating potential kernel production in maize hybrid seed fields. Crop Sci. 44, 16961709.

Gabaldón-Leal, C., Lorite, I., Mínguez, M., Lizaso, J., Dosio, A., Sanchez, E., Ruiz-Ramos, M., 2015. Strategies for adapting maize to climate change and extreme temperatures in Andalusia, Spain. Clim. Res. 65, 159-173.

Gaiser, T., Perkons, U., Martin, P., Kautz, T., Uteau-puschmann, D., Ewert, F., Enders, A., Krauss, G., 2013. Modeling biopore effects on root growth and biomass production on soils with pronounced sub-soil clay accumulation. Ecol. Modell. 256, 6-15.

García-López, J., Lorite, I.J., García-Ruiz, R., Domínguez, J., 2014. Evaluation of three simulation approaches for assessing yield of rainfed sunflower in a Mediterranean environment for climate change impact modelling. Clim. Change $124,147-162$.

Gilmore, E.C., Rogers, J.S., 1958. Heat units as a method of measuring maturity in corn. Agron. J. 50, 611-615.

Goudriaan, J., van Laar, H.H., 1994. Modelling potential crop growth processes: Textbook with Exercises. Kluwer Academic Publishers, Dordrecht, Boston.

Gourdji, S.M., Sibley, A.M., Lobell, D.B., 2013. Global crop exposure to critical high temperatures in the reproductive period: historical trends and future projections. Environ. Res. Lett. 8, 024041.

Grant, R., Jackson, B., Kiniry, J., Arkin, G., 1989. Water deficit timing effects on yield components in maize. Agron. J. 81, 61-65. 
Hawkins, E., Fricker, T.E., Challinor, A.J., Ferro, C.A.T., Ho, C.K., Osborne, T.M., 2013. Increasing influence of heat stress on French maize yields from the 1960s to the 2030s. Glob. Chang. Biol. 19, 937-947.

Herrero, M.P., Johnson, R., 1980. High Temperature stress and pollen viability of maize. Crop Sci. 20, 796-800.

IPCC (Intergovernmental Panel on Climate Change), 2007. Climate Change 2007: Impacts, adaptation and vulnerability. Contribution of working broup II to the fourth assessment report of the intergovernmental panel on climate change. Cambridge University Press, Cambridge, UK.

Jones, C.A., Kiniry, J.R., 1986. CERES-Maize: A simulation model of maize growth and development. Texas A\&M Univ. Press, College Station, TX.

Kimball, B.A., White, J.W., Ottman, M.J., Wall, G.W., Bernacchi, C.J., Morgan, J., Smith, D.P., 2015. Predicting canopy temperatures and infrared heater energy requirements for warming field plots. Agron. J. 107, 129-141.

Kiniry, J.R., Ritchie, J.T., 1985. Shade-sensitive interval of kernel number of maize. Agron. J. 77, 711-715.

Lizaso, J.I., Rodríguez, L., Ruiz-Ramos, M., Gabaldón-Leal, C., Oliveira J.A., Lorite I.J., 2016. Improving CSM-IXIM maize model in DSSAT to simulated the impact of elevated temperatures. International Crop Modelling Symposium iCropM, 1517 March 2016, Berlin, Germany.

Lizaso, J.I., Fonseca, A. E., Westgate, M.E., 2007. Simulating source-limited and sinklimited kernel set with CERES-Maize. Crop Sci. 47, 2078-2088.

Lobell, D.B., Bänziger, M., Magorokosho, C., Vivek, B., 2011. Nonlinear heat effects on African maize as evidenced by historical yield trials. Nat. Clim. Chang. 1, 42-45.

Lobell, D.B., Hammer, G.L., Chenu, K., Zheng, B., Mclean, G., Chapman, S.C., 2015. The shifting influence of drought and heat stress for crops in northeast Australia. Glob. Chang. Biol. 21, 4115-4127.

Lobell, D.B., Hammer, G.L., McLean, G., Messina, C., Roberts, M.J., Schlenker, W., 2013. The critical role of extreme heat for maize production in the United States. Nat. Clim. Chang. 3, 497-501.

Moriondo, M., Giannakopoulos, C., Bindi, M., 2011. Climate change impact assessment: the role of climate extremes in crop yield simulation. Clim. Change 104, 679-701.

Nguyen, D.N., Lee, K.J., Kim, D.I., Anh, N.T., Lee, B.W., 2014. Modeling and validation of high-temperature induced spikelet sterility in rice. F. Crop. Res. 156, 293-302. 
Ordóñez, R.A., Savin, R., Cossani, C.M., Slafer, G.A., 2015. Yield response to heat stress as affected by nitrogen availability in maize. F. Crop. Res. 183, 184-203.

Orlowsky, B., Seneviratne, S.I., 2012. Global changes in extreme events: Regional and seasonal dimension. Clim. Change 110, 669-696.

Otegui, M.E., Bonhomme, R., 1998. Grain yield components in maize. F. Crop. Res. 56, 247-256.

Peterson, R.H., Hicks, D.R., 1973. Minnesota relative maturity rating of corn hybrids. Agron. No. 27. Univ. of Minn. Agric. Ext. Serv., St. Paul.

Porter, J.R., Semenov, M.A., 2005. Crop responses to climatic variation. Philos. Trans. R. Soc. London. Ser. B 360, 2021-2035.

Raes, D., Steduto, P., Hsiao, T.C., Fereres, E., 2009. AquaCrop-The FAO crop model to simulate yield response to water: II. Main algorithms and software description. Agron. J. 101, 438-447.

Rattalino Edreira, J.I., Budakli Carpici, E., Sammarro, D., Otegui, M.E., 2011. Heat stress effects around flowering on kernel set of temperate and tropical maize hybrids. F. Crop. Res. 123, 62-73.

Rattalino Edreira, J.I., Otegui, M.E., 2013. Heat stress in temperate and tropical maize hybrids: A novel approach for assessing sources of kernel loss in field conditions. F. Crop. Res. 142, 58-67.

Rattalino Edreira, J.I., Otegui, M.E., 2012. Heat stress in temperate and tropical maize hybrids: Differences in crop growth, biomass partitioning and reserves use. F. Crop. Res. 130, 87-98.

Rezaei, E.E., Webber, H., Gaiser, T., Naab, J., Ewert, F., 2015. Heat stress in cereals: Mechanisms and modelling. Eur. J. Agron. 64, 98-113.

Ritchie, S.W., Hanway, J.J., 1982. How a corn plant develops. Spec. Rep. 48. lowa State Univ. of Sci. and Technol., Coop. Ext. Serv., Ames, IA

Sánchez, B., Rasmussen, A., Porter, J.R., 2014. Temperatures and the growth and development of maize and rice: a review. Glob. Chang. Biol. 20, 408-17.

Schlenker, W., Roberts, M.J., 2009. Nonlinear temperature effects indicate severe damages to U.S. crop yields under climate change. Proc. Natl. Acad. Sci. U. S. A. $106,15594-15598$.

Seneviratne, S., Nicholls, N., Easterling, D., Goodess, C., Kanae, S., Kossin, J., Luo, Y., Marengo, J., Mclnnes, K., Rahimi, M., 2012. Changes in climate extremes and their impacts on the natural physical environment: An overview of the IPCC SREX report. EGU General Assembly Conference Abstracts, p. 12566. 
Siebert, S., Ewert, F., Rezaei, E.E., Kage, H., Graß, R., 2014. Impact of heat stress on crop yield-on the importance of considering canopy temperature. Environ. Res. Lett. 9, 1-8.

Spitters, C.J.T., Schapendonk, A.H.C.M., 1990. Evaluation of breeding strategies for drought tolerance in potato by means of crop growth simulation. Plant Soil 123, 193-203.

Steduto, P., Hsiao, T.C., Fereres, E., Raes, D., 2012. Crop yield response to water. Irrigation and drainage Paper No. 66. FAO, Rome.

Tebaldi, C., Hayhoe, K., Arblaster, J.M., Meehl, G.A., 2006. Going to the extremes. Clim. Change 79, 185-211.

Tollenaar, M., Daynard, T.B., Hunter, B., 1979. Effect of temperature on rate of leaf appearance and flowering date in maize. Crop Sci. 19, 363-366.

Trnka, M., Rötter, R.P., Ruiz-Ramos, M., Kersebaum, K.C., Olesen, J.E., Žalud, Z., Semenov, M.A., 2014. Adverse weather conditions for European wheat production will become more frequent with climate change. Nat. Clim. Chang. 4, 637-643.

Vega, C.R.C., Andrade, F.H., Sadras, V.O., Uhart, S.A., Valentinuz, O.R., 2001. Seed number as a function of growth. A comparative study in soybean, sunflower, and maize. Crop Sci. 41, 748-754.

Van Oijen, M., Leffelaar, P.A., 2008. Chapter 10(B) LINTUL-2: water limited crop growth. A simple crop growth model for water-limited growing conditions. Crop ecology 2008. Wageningen University, Wageningen.

Webber, H., Ewert, F., Kimball, B.A., Siebert, S., White, J.W., Wall, G.W., Ottman, M.J., Trawally, D.N.A., Gaiser, T., 2016. Simulating canopy temperature for modelling heat stress in cereals. Environ. Model. Softw. 77, 143-155.

Webber, H., Martre, P., Asseng, S., Kimball, B., White, J., Ottman, M., Wall, G.W., De Sanctis, G., Doltra, J., Grant, R., Kassie, B., Maiorano, A., Olesen, J.E., Ripoche, D., Eyshi Rezaei, E., Semenov, M.A., Stratonovitch, P., Ewert, F., 2015. Canopy temperature for simulation of heat stress in irrigated wheat in a semi-arid environment: A multi-model comparison. F. Crop. Res.

Wolf, J., 2012. LINTUL5: Simple generic model for simulation of crop growth under potential, water limited and nitrogen, phosphorus and potassium limited conditions. Plant Prod. Syst. Group, Wageningen Univ. Wageningen. 


\section{REFERENCES CHAPTER 3}

Aguilera, F., Ruiz, L., Fornaciari, M., Romano, B., Galán, C., Oteros, J., Ben Dhiab, A., Msallem, M., Orlandi, F., 2014. Heat accumulation period in the Mediterranean region: phenological response of the olive in different climate areas (Spain, Italy and Tunisia). Int. J. Biometeorol. 58, 867-76.

Ahas, R., Aasa, R., Menzel, a., Fedotova, V.G., Scheifinger, H., 2002. Changes in European spring phenology. Int. J. Climatol. 22, 1727-1738.

Andrade, J.A., Santos, F.L., Correia, M., do Paço, T.A., 2012. Effects of Irrigation and Tree Spacing on Soil and Air Temperature Profiles of Olive Orchards. VII Int. Symp. Olive Grow. 1057, 443-450.

Aron, R., 1983. Availability of chilling temperatures in California. Agric. Meteorol. 28, 351-363.

Arzani, K., Javady, T., 2002. Study of flower biology and pollen tube growth of mature olive tree cv "Zard." Acta Hortic. 586, 545-547.

Avolio, E., Orlandi, F., Bellecci, C., Fornaciari, M., Federico, S., 2012. Assessment of the impact of climate change on the olive flowering in Calabria (southern Italy). Theor. Appl. Climatol. 107, 531-540.

Ayerza, R., Sibbett, G., 2001. Thermal adaptability of olive (Olea europaea L.) to the Arid Chaco of Argentina. Agric. Ecosyst. Environ. 84, 277-285.

Baldocchi, D., Wong, S., 2008. Accumulated winter chill is decreasing in the fruit growing regions of California. Clim. Change 87, 153-166.

Beniston, M., Stephenson, D.B., Christensen, O.B., Ferro, C.A.T., Frei, C., Goyette, S., Halsnaes, K., Holt, T., Jylhä, K., Koffi, B., Palutikof, J., Schöll, R., Semmler, T., Woth, K., 2007. Future extreme events in European climate: an exploration of regional climate model projections. Clim. Change 81, 71-95.

Bonofiglio, T., Orlandi, F., Sgromo, C., Romano, B., Fornaciari, M., 2008. Influence of temperature and rainfall on timing of olive (Olea europaea) flowering in southern Italy. New Zeal. J. Crop Hortic. Sci. 36, 59-69.

Bradley, N.L., Leopold, A C., Ross, J., Huffaker, W., 1999. Phenological changes reflect climate change in Wisconsin. Proc. Natl. Acad. Sci. U. S. A. 96, 9701-4.

CAPDR, 2008. El Sector del Aceite de Oliva y de la Aceituna de mesa en Andalucía. Consejería de Agriculuta, Pesca y Desarrollo Rural. Junta de Andalucía, Sevilla.

CAPDR, 2016a. Observatorio de precios y mercados. Productos industriales. Aceite de oliva. Consejería de Agriculuta, Pesca y Desarrollo Rural Junta de Andalucía, 
Sevilla

(http://www.juntadeandalucia.es/agriculturaypesca/observatorio/servlet/Front Controller ?action $=$ Subsector $\&$ table $=3940 \&$ ec $=$ subsector $\&$ subsector $=33$ )(verifie d 10/01/2016)

CAPDR, 2016b. Superficies y producciones. Aforos olivar. Consejería de Agriculuta, Pesca y Desarrollo Rural Junta de Andalucía, Sevilla (http://www.juntadeandalucia.es/organismos/agriculturapescaydesarrollorural /servicios/estadisticas/detalle/69843.html)(verified 20/01/2016)

Carter, T.R., 2010. Representing Multi-Model Climate Projection Uncertainties in Modelling Impact Risks and Adaptation Options: Recent Advances in Europe, in: Office. pp. 31-32.

CEDEX, 2011. Evaluación del impacto del cambio climático en los recursos hídricos en régimen natural [Evaluation of the Impact of Climate Change in Water Resources under Natural Regime]. CEDEX, Madrid, Spain. 2011

Chmielewski, F.-M., Rötzer, T., 2001. Response of tree phenology to climate change across Europe. Agric. For. Meteorol. 108, 101-112.

Council IO. 2014. Market Newsletter No 80. International Olive Council. , 1-5.

Cuevas, J., Pinillos, V., Polito, V.S., 2009. Effective pollination period for "Manzanillo" and "Picual" olive trees. J. Hortic. Sci. Biotechnol. 84, 370-374.

Davin, E.L., Seneviratne, S.I., Ciais, P., Olioso, A., Wang, T., 2014. Preferential cooling of hot extremes from cropland albedo management. Proc. Natl. Acad. Sci. U. S. A. 111, 9757-9761.

De Andrés, F., 1974. Estados tipo fenológicos del olivo. Comun. del Serv. Def. contra Plagas. Estud. y Exp. Madrid, Spain Minist. Agric. 33/74.

De Melo-Abreu, J.P., Barraco, D., Cordeiro, M., Tous, J., Rogado, B.M., Villalobos, F.J., 2004. Modelling olive flowering date using chilling for dormancy release and thermal time. Agric. For. Meteorol. 125, 117-127.

De Wit, C.T., Goudriaan, J., Van Laar, H.H., 1978. Simulation of Assimilation, Respiration and Transpiration of Crops. Pudoc, Wageningen, The Netherlands

Déqué, M., Rowell, D.P., Lüthi, D., Giorgi, F., Christensen, J.H., Rockel, B., Jacob, D., Kjellström, E., de Castro, M., van den Hurk, B., 2007. An intercomparison of regional climate simulations for Europe: assessing uncertainties in model projections. Clim. Change 81, 53-70. 
Dosio, A., Paruolo, P., 2011. Bias correction of the ENSEMBLES high-resolution climate change projections for use by impact models: Evaluation on the present climate. J. Geophys. Res. 116, D16106.

Dosio, A., Paruolo, P., Rojas, R., 2012. Bias correction of the ENSEMBLES high resolution climate change projections for use by impact models : analysis of the climate changes signal. J. Geophys. Res.117, D17110.

Doughty, C.E., Field, C.B., McMillan, A.M.S., 2011. Can crop albedo be increased through the modification of leaf trichomes, and could this cool regional climate? Clim. Change 104, 379-387.

El Yaacoubi, A., Malagi, G., Oukabli, A., Hafidi, M., Legave, J.-M., 2014. Global warming impact on floral phenology of fruit trees species in Mediterranean region. Sci. Hortic. (Amsterdam). 180, 243-253.

Eitzinger, J., Thaler, S., Schmid, E., Strauss, F., Ferrise, R., Moriondo, M., 2013. Sensitivities of crop models to extreme weather conditions during flowering period demonstrated for maize and winter wheat in Austria. J. Agric. Sci. 151, 813-835.

FAOSTAT, 2016. Statistical Databases. Agriculture Data Collection (Primary Crops). FAO Food and Agriculture Organization of the United Nations, Rome (http://faostat.fao.org/).

Fernández-Escobar, R., Gomez-Valledor, G., Rallo, L., 1983. Influence of pistil extract and temperature on in vitro pollen germination and pollen tube growth of olive cultivars. J. Hortic. Sci. 58, 219-227.

Fornaciari, M., Pieroni, L., Ciuchi, P., Romano, B., 1998. A regression model for the start of the pollen season in Olea europaea. Agric. Econ. 37, 110-113.

Fornaciari, M., Galan, C., Mediavilla, A., Dominguez, E., Romano, B., 2000. Aeropalynological and phenological study in two different Mediterranean olive areas: Cordoba (Spain) and Perugia (Italy). Plant Biosyst. 134, 199-204.

Gabaldón-Leal, C., Lorite, I., Mínguez, M., Lizaso, J., Dosio, A., Sanchez, E., Ruiz-Ramos, M., 2015. Strategies for adapting maize to climate change and extreme temperatures in Andalusia, Spain. Clim. Res. 65, 159-173.

Galán, C., García-Mozo, H., Vázquez, L., Ruiz, L., Díaz de la Guardia, C., Trigo, M.M., 2005. Heat requirement for the onset of the Olea europaea L. pollen season in several sites in Andalusia and the effect of the expected future climate change. Int. J. Biometeorol. 49, 184-188.

García-López, J., Lorite, I.J., García-Ruiz, R., Domínguez, J., 2014. Evaluation of three simulation approaches for assessing yield of rainfed sunflower in a 
Mediterranean environment for climate change impact modelling. Clim. Change $124,147-162$.

Garcia-Mozo, H., Galan, C., Gomez-Casero, M.T., Dominguez, E., 2000. A comparative study of different temperature accumulation methods for predicting the start of the Quercus pollen season in Cordoba (South West Spain). Grana 39, 194199.

Giannakopoulos, C., Le Sager, P., Bindi, M., Moriondo, M., Kostopoulou, E., Goodess, C.M., 2009. Climatic changes and associated impacts in the Mediterranean resulting from a $2{ }^{\circ} \mathrm{C}$ global warming. Glob. Planet. Change 68, 209-224.

Giorgi, F., Lionello, P., 2008. Climate change projections for the Mediterranean region. Glob. Planet. Change 63, 90-104.

Guereña, A., Ruiz-Ramos, M., Díaz-Ambrona, C.H., Conde, J.R., Mínguez, M.I., 2001. Assessment of Climate Change and Agriculture in Spain Using Climate Models. Agron. J. 93, 237-249.

Hartmann, H.T., Porlingis, I., 1957. Effect of different amounts of winter chilling in fruitfulness of several olive varieties. Bot. Gaz. 102-104.

Hawkins, E., Sutton, R., 2009. The potential to narrow uncertainty in regional climate predictions. Bull. Am. Meteorol. Soc. 90, 1095-1107.

Herrera, S., Gutiérrez, J.M., Ancell, R., Pons, M.R., Frías, M.D., Fernández, J., 2012. Development and analysis of a 50-year high-resolution daily gridded precipitation dataset over Spain (Spain02). Int. J. Climatol. 32, 74-85.

IPCC, 2014: Climate Change 2014: Synthesis Report. Contribution of Working Groups I, II and III to the Fifth Assessment Report of the Intergovernmental Panel on Climate Change [Core Writing Team, R.K. Pachauri and L.A. Meyer (eds.)]. IPCC, Geneva, Switzerland, $151 \mathrm{pp}$.

Koubouris, G.C., Metzidakis, I.T., Vasilakakis, M.D., 2009. Impact of temperature on olive (Olea europaea L.) pollen performance in relation to relative humidity and genotype. Environ. Exp. Bot. 67, 209-214.

Lieth, H., 1974. Phenology and Seasonality Modeling, vol.8. Springer-Verlag, BerlinHeidelberg/New York.

Menzel, A., 2000. Trends in phenological phases in Europe between 1951 and 1996. Int. J. Biometeorol. 44, 76-81.

Nakićenović, N., J. Alcamo, G. Davis, B. de Vries, and Z. Fenhann, Joergen; Gaffin, Stuart; Gregory, Kenneth; Grubler, Arnulf; Jung, Tae Yong; Kram, Tom; La Rovere, Emilio Lebre; Michaelis, Laurie; Mori, Shunsuke; Morita, Tsuneyuki; 
Pepper, William; Pitcher, Hugh M.; Price, Lynn; Riahi, Keywan; Roehrl, Alexander. 2000. Special Report on Emissions Scenarios (SRES). Cambridge Univ. Press. Cambridge.

Olesen, J.E., Carter, T.R., Díaz-Ambrona, C.H., Fronzek, S., Heidmann, T., Hickler, T., Holt, T., Mínguez, M.I., Morales, P., Palutikof, J.P., Quemada, M., Ruiz-Ramos, M., Rubaek, G.H., Sau, F., Smith, B., Sykes, M.T., 2007. Uncertainties in projected impacts of climate change on European agriculture and terrestrial ecosystems based on scenarios from regional climate models. Clim. Change 81, 123-143.

Orlandi, F., Fornaciari, M., Romano, B., 2002. The use of phenological data to calculate chilling units in Olea europaea L. in relation to the onset of reproduction. Int. J. Biometeorol. 46, 2-8.

Orlandi, F., Garcia-Mozo, H., Vazquez Ezquerra, L., Romano, B., Dominguez, E., Galan, C., Fornaciari, M., 2004. Phenological olive chilling requirements in Umbria (Italy) and Andalusia (Spain). Plant Biosyst. 138, 111-116.

Orlandi, F., Vazquez, L.M., Ruga, L., Bonofiglio, T., Fornaciari, M., Garcia-Mozo, H., Dominguez-Vilches, E., Romano, B., Galan, C., 2005a. Bioclimatic requirements for olive flowering in two Mediterranean regions located at the same lalitude (Andalusia, Spain and Sicily, Italy). Ann. Agric. Environ. Med. 12, 47-52.

Orlandi, F., Romano, B., Fornaciari, M., 2005b. Effective pollination period estimation in olive (Olea europaea L.): a pollen monitoring application. Sci. Hortic. (Amsterdam). 105, 313-318.

Orlandi, F., Lanari, D., Romano, B., Fornaciari, M., 2006. New model to predict the timing of olive (Olea europaea) flowering: a case study in central Italy. New Zeal. J. Crop Hortic. Sci. 34, 93-99.

Orlandi, F., Sgromo, C., Bonofiglio, T., Ruga, L., Romano, B., Fornaciari, M., 2010a. Spring Influences on Olive Flowering and Threshold Temperatures Related to Reproductive Structure Formation. Hortscience 45, 1052-1057.

Orlandi, F., Sgromo, C., Bonofiglio, T., Ruga, L., Romano, B., Fornaciari, M., 2010b. Yield modelling in a Mediterranean species utilizing cause-effect relationships between temperature forcing and biological processes. Sci. Hortic. (Amsterdam). 123, 412-417.

Orlandi, F., Garcia-Mozo, H., Galán, C., Romano, B., Díaz de la Guardia, C., Ruiz, L., Trigo, M. del M., Dominguez-Vilches, E., Fornaciari, M., 2010c. Olive flowering trends in a large Mediterranean area (Italy and Spain). Int. J. Biometeorol. 54, 151-163. 
Orlandi, F., Avolio, E., Bonofiglio, T., Federico, S., Romano, B., Fornaciari, M., 2013. Potential shifts in olive flowering according to climate variations in Southern Italy. Meteorol. Appl. 20, 497-503.

Osborne, C.P., Chuine, I., Viner, D., Woodward, F.I., 2000. Olive phenology as a sensitive indicator of future climatic warming in the Mediterranean. Plant, Cell Environ. 23, 701-710.

Oteros, J., García-Mozo, H., Vázquez, L., Mestre, a., Domínguez-Vilches, E., Galán, C., 2013. Modelling olive phenological response to weather and topography. Agric. Ecosyst. Environ. 179, 62-68.

Pérez López, D., Ruiz Ramos, M., Sánchez Sánchez, E., Centeno Muñoz, A., Prieto Egido, I., and López de la Franca, N. 2012. Influence of climate change on the flowering of temperate fruit trees. EGU General Assembly, Vienna, Austria

Ponti, L., Gutierrez, A.P., Ruti, P.M., Dell'aquila, A., 2014. Fine-scale ecological and economic assessment of climate change on olive in the Mediterranean Basin reveals winners and losers. Proc. Natl. Acad. Sci. U. S. A. 111, 5598-5603.

RAA (Red Andaluza de Aerobiología), 2015. http://www.ugr.es/ aerobio/. (verified 26/10/2015)

Rallo, L., Barranco, D., de la Rosa, R., León, L., 2008. “Chiquitita” Olive. Hortscience 43, 529-531.

Rapoport, H.F., Hammami, S.B.M., Martins, P., Pérez-Priego, O., Orgaz, F., 2012. Influence of water deficits at different times during olive tree inflorescence and flower development. Environ. Exp. Bot. 77, 227-233.

Richardson, E., Seeley, S., Walker, D., 1974. A model for estimating the completion of rest for Red haven and Elbert peach tree. HortScience 9, 331-332.

Rodríguez Díaz, J.A., Weatherhead, E.K., Knox, J.W., Camacho, E., 2007. Climate change impacts on irrigation water requirements in the Guadalquivir river basin in Spain. Reg. Environ. Chang. 7, 149-159.

Ruiz-Ramos, M., Mínguez, M.I., 2010. Evaluating uncertainty in climate change impacts on crop productivity in the Iberian Peninsula. Clim. Res. 44, 69-82.

Ruiz-Ramos, M., Sánchez, E., Galllardo, C., Mínguez, M.I., 2011. Impacts of projected maximum temperature extremes for $\mathrm{C} 21$ by an ensemble of regional climate models on cereal cropping systems in the Iberian Peninsula. Nat. Hazards Earth Syst. Sci. 11, 3275-3291.

Ruiz-Ramos, M., Rodríguez, A., Dosio, A., Goodess, C.M., Harpham, C., Mínguez, M.I., Sánchez, E., 2015. Comparing correction methods of RCM outputs for 
improving crop impact projections in the Iberian Peninsula for 21st century. Clim. Change 134, 283-297.

Sadras, V., Calderini, D., 2009. Crop physiology: applications for genetic improvement and agronomy. Acad. Press.

Schwartz, M.D., 1999. Advancing to full bloom: planning phenological research for the 21st century. Int. J. Biometeorol. 42, 113-118.

Tanasijevic, L., Todorovic, M., Pereira, L.S., Pizzigalli, C., Lionello, P., 2014. Impacts of climate change on olive crop evapotranspiration and irrigation requirements in the Mediterranean region. Agric. Water Manag. 144, 54-68.

Tebaldi, C., Hayhoe, K., Arblaster, J.M., Meehl, G.A., 2006. Going to the Extremes. An intercomparison of model-simulated historical and future changes in extreme events. Clim. Change 79, 185-211.

Teixeira, E.I., Fischer, G., van Velthuizen, H., Walter, C., Ewert, F., 2013. Global hotspots of heat stress on agricultural crops due to climate change. Agric. For. Meteorol. 170, 206-215.

Trnka, M., Rötter, R.P., Ruiz-Ramos, M., Kersebaum, K.C., Olesen, J.E., Žalud, Z., Semenov, M.A., 2014. Adverse weather conditions for European wheat production will become more frequent with climate change. Nat. Clim. Chang. 4, 637-643.

Van Vliet, A.J.H., Overeem, A., De Groot, R.S., Jacobs, A.F.G., Spieksma, F.T.M., 2002. The influence of temperature and climate change on the timing of pollen. Int. J. Climatol. 22, 1757-1767.

Vicente-Serrano, S.M., Trigo, R.M., López-Moreno, J.I., Liberato, M.L.R., LorenzoLacruz, J., Beguería, S., Morán-Tejeda, E., El Kenawy, A., 2011. Extreme winter precipitation in the Iberian Peninsula in 2010: Anomalies, driving mechanisms and future projections. Clim. Res. 46, 51-65.

Viola, F., Caracciolo, D., Pumo, D., Noto, L.V., 2013. Olive yield and future climate forcings. Procedia Environ. Sci. 19, 132-138.

Vuletin Selak, G., Cuevas, J., Goreta Ban, S., Pinillos, V., Dumicic, G., Perica, S., 2014. The effect of temperature on the duration of the effective pollination period in "Oblica" olive (Olea europaea) cultivar. Ann. Appl. Biol. 164, 85-94. 


\section{ANNEX}

Appendix. Supplementary material related to the Chapter 3 "Impact of changes in temperature and extreme events caused by climate change on olive flowering at southern Spain"

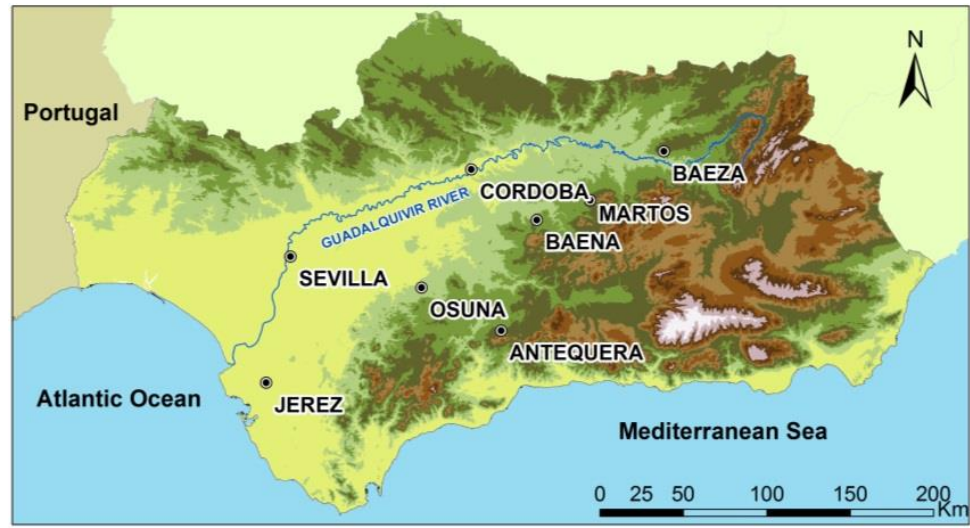

Figure A.1. Topographic map of Andalusia region
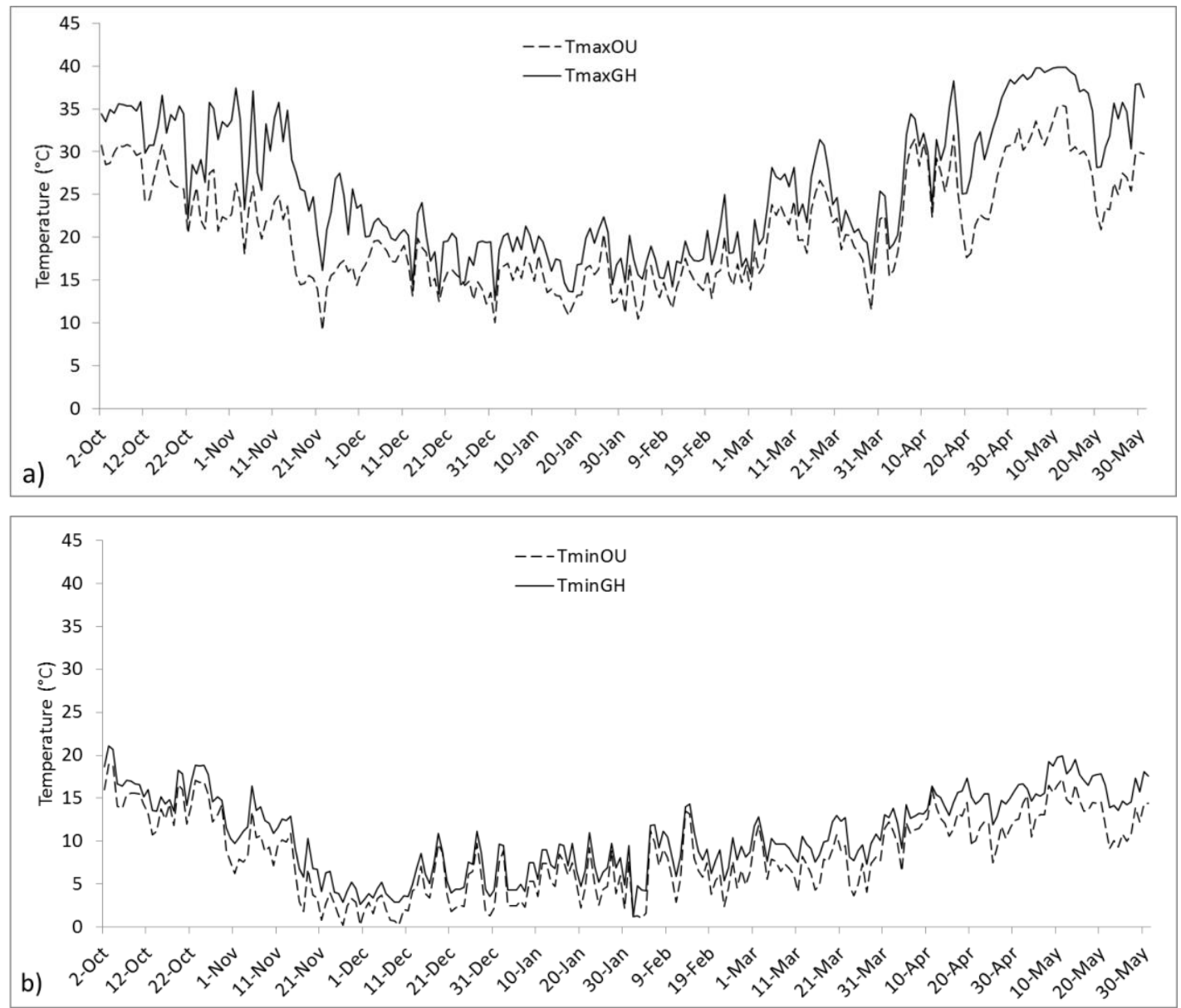

Figure A.2. a) Daily maximum ( $T \max$ ) and b) daily minimum ( $T \min$ ) temperatures inside greenhouse ( $\mathrm{GH}$; in continuous line) and outdoors (OU; in dotted line) 

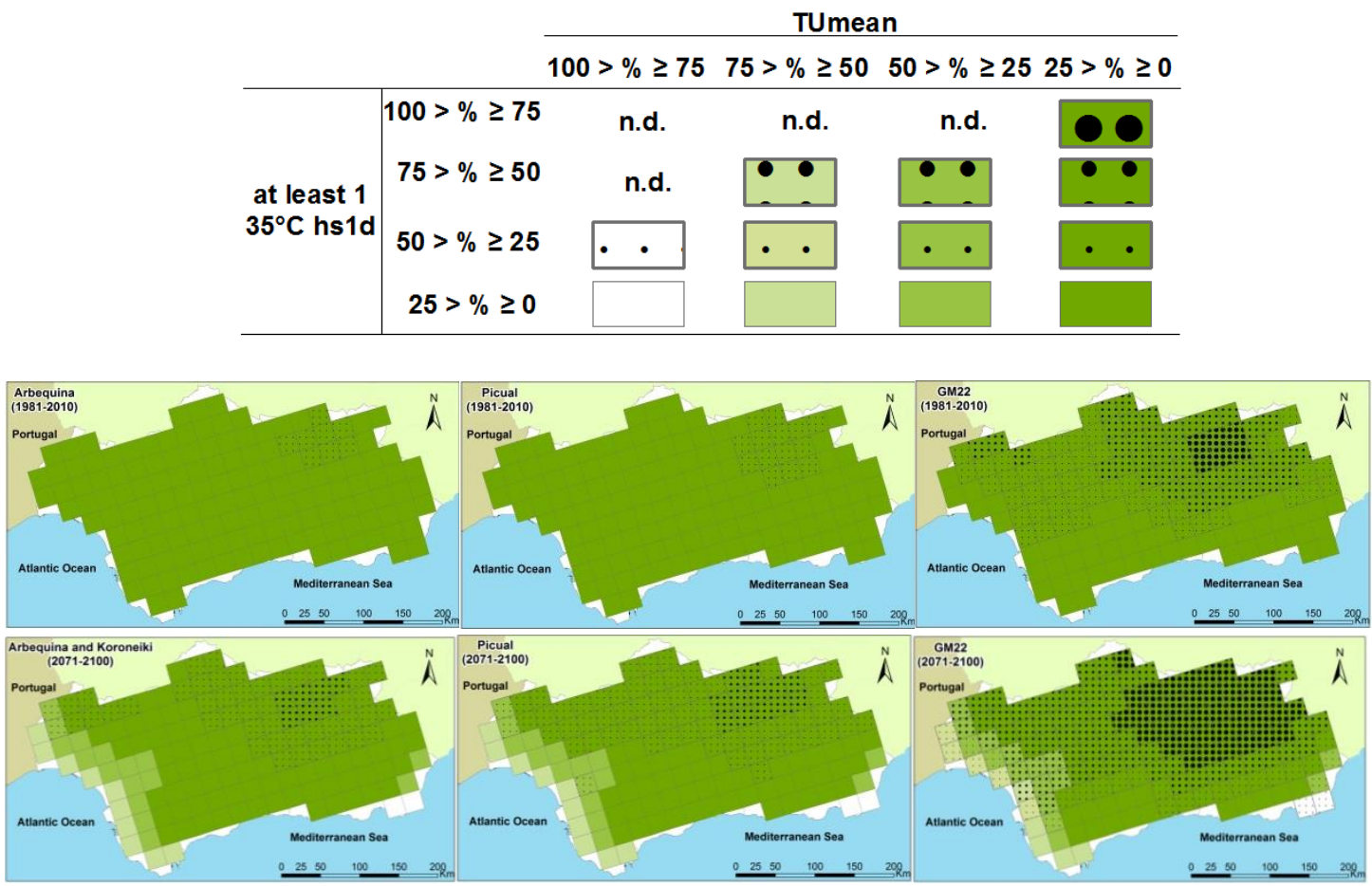

Figure A.3. Maps of threat for olive flowering overlapping the lack of chilling and the occurrence of extreme events during flowering period for Arbequina, Picual, and GM22, considering TU=467 $U$ and at least one event of 1-day with Tmax above $35^{\circ} \mathrm{C}$, for the baseline (1981-2010) and far future (20712100) periods. Colors represent the percentage of years with at least one event of Tmax, (dark color-lower number, light color--higher number), lines represent the percentage of years that the chilling requirements were not achieved (no lines-lower number, dense lines-higher number).

Table A.1. Comparison of advance in flowering days estimated with the Method 4 using the climate data from the outodoors (OU) and greenhouse (GH) conditions and for the baseline (1981-2010), near future (2021-2050) and far future (2071-2100) periods of ENS-Spain02 ensemble of climate. DOY: day of year.

Flowering dates (DOY)

Days in advance

\begin{tabular}{ccc|cc|cc}
\cline { 2 - 6 } & $\begin{array}{c}\text { With OU } \\
\text { data }\end{array}$ & $\begin{array}{c}\text { With B data } \\
\text { from } \\
\text { ENS- } \\
\text { Spain02 }\end{array}$ & $\begin{array}{c}\text { Observed } \\
(\text { GH) }\end{array}$ & $\begin{array}{c}\text { ENS- } \\
\text { Spain02 } \\
\text { (FF) }\end{array}$ & $\begin{array}{c}\text { Difference } \\
\text { (GH-OU) }\end{array}$ & $\begin{array}{c}\text { Difference } \\
\text { (FF-B) from } \\
\text { ENS- } \\
\text { Spain02 }\end{array}$ \\
\hline Arbequina & 123 & 132 & 111 & 119 & 12 & 13 \\
Arbosana & 126 & 136 & 114 & 122 & 12 & 14 \\
Chiquitita & 127 & 137 & 115 & 124 & 12 & 13 \\
Frantoio & 126 & 136 & 114 & 122 & 12 & 14 \\
FV18 & 130 & 141 & 118 & 127 & 12 & 14 \\
GM22 & 149 & 159 & 131 & 143 & 18 & 16 \\
GM25 & 149 & 159 & 131 & 143 & 18 & 16 \\
Hojiblanca & 126 & 136 & 114 & 122 & 12 & 14 \\
Koroneiki & 123 & 132 & 111 & 119 & 12 & 13 \\
Picual & 125 & 135 & 114 & 122 & 11 & 13 \\
\hline
\end{tabular}


Table A.2 a) Percentage of years where the chilling requirements (TU) were not reached, and b) the coefficient of variation (CV (\%)) of the end of endormancy (EDO) dates projected with the ENS-Spain02 ensemble and Method 4 for the minimum ( $\left.\mathrm{TU}_{\min }(302 \mathrm{U})\right)$, mean $\left(\mathrm{TU}_{\text {mean }}(467 \mathrm{U})\right)$ and maximum $\left(\mathrm{TU}_{\max }\right.$ (722 U)) chilling requirements, for the baseline (B, 1981-2010), near future (NF, 2021-2050) and far future $(\mathrm{FF}, \mathbf{2 0 7 1 - 2 1 0 0 )}$ periods at eight selected locations

\section{\%Years TU not reached/period}

\begin{tabular}{ccccccccccc} 
a) & \multicolumn{3}{c}{ TUmin } & \multicolumn{3}{c}{ TUmean } & \multicolumn{3}{c}{ TUmax } \\
\hline Location & $\mathrm{B}$ & $\mathrm{NF}$ & $\mathrm{FF}$ & $\mathrm{B}$ & $\mathrm{NF}$ & $\mathrm{FF}$ & $\mathrm{B}$ & $\mathrm{NF}$ & $\mathrm{FF}$ \\
\hline Jerez & 0 & 1.7 & 26 & 0 & 10.6 & 56.5 & 7.5 & 42.2 & 87.1 \\
Seville & 0 & 0.3 & 10.9 & 0 & 1.9 & 32.9 & 1.1 & 18.3 & 75.1 \\
Osuna & 0 & 0 & 1.2 & 0 & 0.3 & 4.9 & 0 & 0.8 & 33 \\
Antequera & 0 & 0 & 0 & 0 & 0 & 0.9 & 0 & 0 & 6.1 \\
Cordoba & 0 & 0 & 0.3 & 0 & 0 & 2.2 & 0 & 0.3 & 22.5 \\
Baena & 0 & 0 & 0 & 0 & 0 & 0 & 0 & 0 & 1.5 \\
Martos & 0 & 0 & 0 & 0 & 0 & 0 & 0 & 0 & 0.3 \\
Baeza & 0 & 0 & 0 & 0 & 0 & 0 & 0 & 0 & 0 \\
\hline & & & & & & $\mathrm{CV}_{\text {EDO }}(\%)$ & & \\
\hline b) & & $\mathrm{TUmin}$ & & & $\mathrm{TUmean}$ & & $\mathrm{TUmax}$ & \\
Location & $\mathrm{B}$ & $\mathrm{NF}$ & $\mathrm{FF}$ & $\mathrm{B}$ & $\mathrm{NF}$ & $\mathrm{FF}$ & $\mathrm{B}$ & $\mathrm{NF}$ & $\mathrm{FF}$ \\
\hline Jerez & 0.6 & 1.5 & 1.8 & 0.7 & 1.6 & 2.1 & 0.9 & 1.9 & 3.1 \\
Seville & 0.4 & 1.4 & 1.8 & 0.5 & 1.4 & 1.9 & 0.5 & 1.7 & 1.9 \\
Osuna & 0.3 & 1 & 1.6 & 0.4 & 1.1 & 1.9 & 0.4 & 1.3 & 2.1 \\
Antequera & 0.2 & 0.9 & 1.3 & 0.3 & 0.9 & 1.5 & 0.3 & 1.1 & 2.1 \\
Cordoba & 0.3 & 0.9 & 1.6 & 0.3 & 1 & 1.6 & 0.4 & 1.2 & 1.7 \\
Baena & 0.3 & 0.7 & 1.1 & 0.3 & 0.8 & 1.2 & 0.4 & 0.8 & 1.5 \\
Martos & 0.3 & 0.8 & 1.1 & 0.3 & 0.8 & 1.2 & 0.4 & 0.8 & 1.5 \\
Baeza & 0.3 & 0.9 & 1.2 & 0.3 & 0.9 & 1.3 & 0.4 & 0.9 & 1.7 \\
\hline & & & & & & & & &
\end{tabular}

